\title{
Experimental investigations on nuclear aerosols in a severe accident
}

\section{Universidad Politécnica de Valencia}

Department of Nuclear and Chemical Engineering

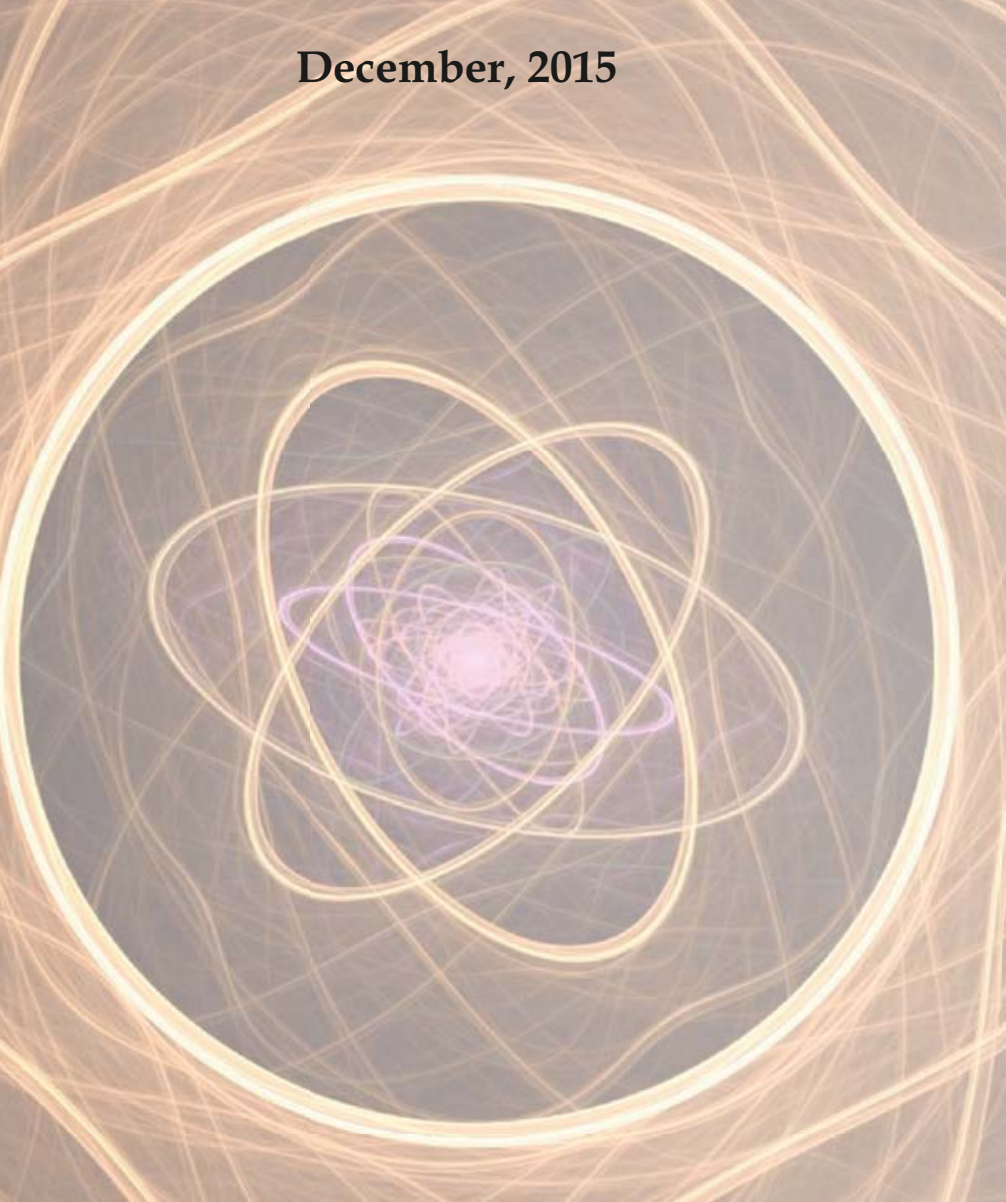

Ph.D Thesis

Presented by:

Rosario Delgado Tardáguila

UNIVERSITAT

PQLITECAICA DE VALENCIA

Supervised by:

Luis E. Herranz

José Luis Muñoz-Cobo 



\section{Experimental investigations on nuclear aerosols in a severe accident}

Thesis submitted by

Rosario Delgado Tardáguila

To obtain the degree of Doctor of Philosophy at the Polytechnic University of Valencia Valencia (Spain), 2015. 

For all those who helped me to believe and fight for the right to be right 


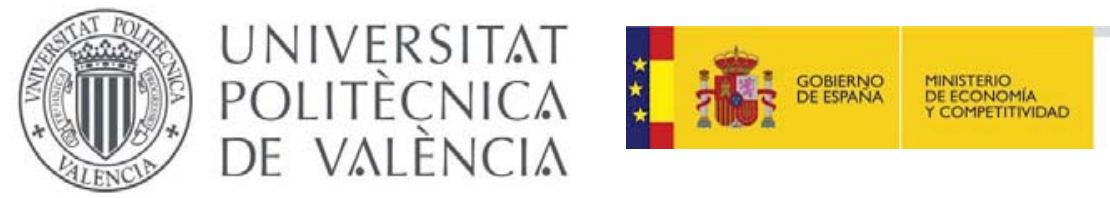

This PhD thesis has been developed within the frame of the ARTIST2 and PASSAM international projects in the Nuclear Safety Research Unit at CIEMAT (Madrid) under the supervision of Dr. Luis E. Herranz and Dr. José Luis Muñoz-Cobo.

The author is indebted to CIEMAT for allowing the use of its installations, in particular the Laboratory of analysis of Safety Systems. No less important the author acknowledges the Spanish Nuclear Safety Council (CSN) and the European Commission for the financial support.

This PhD thesis is presented in the Department of Nuclear and Chemical Engineering of the Polytechnic University of Valencia. 



\section{Acknowledgements}

This section is written in my mother tongue since it is the only way that I know to express my gratitude. Please, switch on the radio and play "Things the Grandchildren should know", by Eels. Por favor, encended la radio y que suene "Things the Grandchildren should know", de Eels.

Volver a España en plena crisis para dedicarte a la ciencia necesita cierta dosis de pasión y mucha locura. Los que me conocen saben bien que ambas me sobran. Pero iqué haríamos sin lo absurdo y lo fugaz de la vida! que decía Frida Kalho.

Es por fin el momento de vomitar y sacar de las entrañas la infinidad de emociones e incontables agradecimientos que brotan a raíz de este proyecto. $Y$ es que más allá de lo tangible del manuscrito, la tesis es un conjunto de circunstancias que conduce a un éxtasis de sensaciones. Produce un estado de altibajos encontrados entre exaltante alegría y frustración. Es un sabor de boca agridulce que mientras convives con ella no termina de desaparecer; la melodía con la que te acuestas, sueñas y tienes pesadillas. La tesis es el amigo de infancia que no elegiste y estás obligado instintivamente a querer. Es un estado de ánimo complicado pero a cambio te invita a satisfacer la maravillosa sensación de superación y saciar el instinto más básico con la veracidad del cariño de quienes gratuitamente te acompañan.

Mis primeros agradecimientos son a CIEMAT y su séquito de profesionales, particularmente a la Unidad de Seguridad Nuclear y a los que a pie de planta me han ayudado a conseguir todos y cada uno de los ladrillos de este edificio: Pedro, Alfonso y Miguel. Especialmente agradezco a mis directores: Luis Enrique Herranz, mentor de este trabajo, su esfuerzo y a José Luis MuñozCobo, su apoyo. A Marga Vila por su paciencia desde la UPV. To the ARTIST and PASSAM partners, especially to PSI. A CSIC y el magnífico equipo de ultrasonidos: a Manuel, Enrique y Juan, de donde he encontrado sin pedir ni buscar, un apoyo técnico tan profesional y amable que el propio trabajo ha resultado un ejercicio de autoayuda y ánimo en la recta final. Con especial cariño le agradezco el día a día a mi compañero Rafa, que sabe sacar del café la dosis de aroma exacta para hacer la vida más fácil. Y a Patrick Ramboud, "my scientific inventor", who taught me the "well doing mode".

En la más profunda amistad biológica le agradezco a mis fresas y particularmente a Ana y Elena el ánimo en los momentos en que los derroteros de la vida nos han hecho crecer juntas en la distancia. También a los que me acogisteis en lugares olvidados que ya nunca olvidaré porque los llevo tatuados: Inma, Isa, Julio, Pablo y a la inconmensurable nobleza de Chuvi. A Elisa, Antonio, Virgi, Rubén, Pedro, Stefan, al picopalismo... gracias! A Noemi, sigues aquí. A Marta porque la precisión de sus palabras son bocanadas de aire y a Ágata, por su tremenda ayuda. A tío Pauli, él lo sabe todo, también por qué. Y a los que también en la distancia su honestidad me ha obligado a creer para crear. To my lovely friend and friendly love Honzi, the purest person I have ever met. My gratitude for being everything that a person needs. Por su afán de conseguir esta victoria a través del más estricto seguimiento científico, empeño, apoyo, ánimo y cariño. To him, because there is something beyond.

A la elegancia, sensibilidad, emoción, nostalgia, dureza y veracidad de los que han llenado los huecos de silencio vacío, mis músicos y poetas: Nick Cave, Patti Smith, Lou Reed, Bob Dylan, David Bowie, Jeff Buckley. A Mark Oliver Everett, a "los Beat", Milan Kundera, Antonio López del Moral y el finito pero difícil de reproducir etcétera de tesoros poéticos, líricos y literarios.

Enlazando agradecimientos llego finalmente a quienes me han dado todo. Y digo bien ¡TODO! Pero en este momento las lágrimas me atragantan y enmudezco, pues desconozco la manera de sintetizar en un párrafo el agradecimiento por tanta luz, por tantos suspiros, por sus ganas, pasión y fortaleza. Esto es por ellos, por mis papás, Jacinto y Tere, por la incondicionalidad del amor y apoyo más verdadero. Porque me han enseñado sencilla y completamente a ser. También por mis hermanos que han recibido la misma dosis de esta exquisita flor de vida, Jaime Isidro, Ricardo y Domingo, jos adoro!. Y por su amor infinito, a mis personas favoritas en el mundo, Martín y Héctor, porque quieren sin querer y se hace irresistible ser feliz a su lado. 



\begin{abstract}
In case of a severe accident in a NPP fission products are released from the degraded fuel and may reach the environment if their confinement is lost and/or bypassed. Given the high radiotoxic nature of nuclear aerosols for environment and population, their unrestricted release should be absolutely avoided.

One particular situation is the core meltdown sequence with steam generator tube rupture (SGTR). The containment bypass turns this sequence into an indispensable scenario to model when assessing PWR risk. As a result, a significant database on the aerosol behavior in the secondary side of the steam generator (SG) has been developed within the international projects EU-SGTR, ARTIST and ARTIST-2. The role played by the break stage is particularly significant since it might be responsible for a good fraction of the total mass retained and for the shift of the particle size distribution towards smaller diameters. This awoke the interest in the effect of variables such as the particle nature, the breach type (size and shape) and the tubes vibration on the particle retention within the breach stage of a dry steam generator. Those aspects have been experimentally investigated in the first part of this thesis.
\end{abstract}

Two experimental campaigns, CAAT2 and SET, were conducted in order to explore the potential influence of the particle nature on their retention. Moreover, the effect of the breach size and shape has been investigated in the CAAT2 campaign while the SET experiments were devoted to the tube vibration characterization and the effect of the vibration on the particle retention. The tests conducted highlighted several key insights: the strong effect of particle nature in the secondary side capability to scrub the particle-laden gas; the confirmation of the high retention efficiency when using compact particles and the significant one when using agglomerates; the similarities between guillotine and fish-mouth breaches in terms of efficiency, but their noticeable different deposition patterns; and the secondary effect of the breach size. Finally, the tube vibration is not as significant as the particle nature effect on the net deposition.

The second part of the thesis is focused on the fraction of particles susceptible of leaving the containment in case of a severe accident regardless of the SGTR sequence. Accidents like Fukushima highlighted the importance of relying on efficient mitigation systems capable of reducing any release to the environment as much as possible. Although many reactors worldwide had installed filtered containment venting systems (FCVS) the interest in FCVS and even other mitigation systems has become of outstanding importance in nuclear safety. This is the frame of the PASSAM project in which an experimental sound database is being built to explore potential enhancement of existing source term mitigation devices and demonstrate the ability of innovative systems to achieve even larger source term attenuation. As a matter of fact, particle agglomeration processes via the propagation of acoustic vibrations through a gas could be applied for a better decontamination. High-intensity acoustic fields applied to an aerosol induce interaction effects among suspended particles, giving rise to successive collisions and agglomerations, resulting in larger particles that can be more easily removed or precipitated.

The mitigative system acoustic agglomerator was built-up and tested in the AAA experimental campaign. The tests were conducted under a constant ultrasonic field with aerosols of different nature and size with different gas mass flow rates. The results pointed out two main insights: the small acoustic-agglomeration effect and the key effect of the gas mass flow rate and the aggregation state of the former particles in the agglomeration process. This research is the first approximation on the application of the ultrasonic chamber as an innovative system for the source term mitigation. However, a broader experimental database is needed for proper assessment of this technology.

In summary, this thesis is based on two experimental initiatives, one investigating aerosol retention and the parameters that influence it (in particular, the particle nature, breach type and tube vibration) in the secondary side of a dried-out SG and the other on acoustic enhancement of aerosol agglomeration. The results of the vibrational and acoustic-agglomeration aspects of this work comprise particularly novel contributions to the nuclear-safety field. 



\section{$\underline{\text { Resumen }}$}

Durante un accidente severo en una central nuclear los productos de fisión liberados como consecuencia de la degradación del combustible podrían llegar a la atmósfera si se pierde la hermeticidad de la contención o si encuentran vías alternativas (bypass) para salir. Dada la radio-toxicidad del término fuente, las centrales nucleares deben contar con medios y medidas técnicas de seguridad para contener estos productos.

En un reactor PWR, un caso particular de secuencia accidental donde los productos de fisión tienen acceso directo a la atmósfera, es aquella en el que además de la fusión de núcleo existe rotura de tubos del generador de vapor (secuencia SGTR). En este caso, es de vital importancia la evaluación del riesgo del suceso, objetivo de los proyectos internacionales EU-SGTR, ARTIST y ARTIST-2. Particularmente significativa es la "etapa de rotura" (break stage) del generador de vapor (SG), que es responsable de la retención de una fracción importante de partículas y de la evolución de su distribución a tamaños más pequeños. Estos motivos despertaron el interés hacia la propia retención de las partículas sobre los tubos y el efecto de variables como la naturaleza de la partícula, el tipo de rotura y la vibración de tubos sobre la retención en la etapa de rotura en condiciones secas; aspectos en los que se centra la primera parte de esta tesis.

Con el objetivo de estudiar las cuestiones señaladas se han llevado a cabo dos campañas experimentales, CAAT2 y SET, con materiales enmarcados en el posible espectro de los aerosoles nucleares. La primera de ellas se centró en explorar la influencia potencial de la naturaleza de la partícula y el efecto del tipo de rotura de los tubos (forma y tamaño) sobre la retención de aerosoles. La segunda concierne la caracterización de la vibración de los tubos y el estudio de su efecto en la eficiencia de retención de partículas. Las pruebas realizadas resaltan varias ideas clave: el fuerte efecto de la naturaleza de la partícula sobre la retención en el lado secundario del SG; la alta eficiencia de retención cuando las partículas son compactas y la significativa retención cuando están aglomeradas; las pequeñas diferencias en eficiencia neta entre distintos tipos de rotura (guillotina vs. boca de pez) que resultan notables sobre los patrones de deposición, y el efecto secundario del tamaño de la rotura. Finalmente los resultados revelaron que frente a la naturaleza de la partícula, la vibración de tubos juega un papel secundario en la eficiencia de la retención.

La segunda parte de este trabajo se centra en la fracción de partículas que es susceptible de alcanzar la contención en caso de accidente severo. Accidentes como el de Fukushima ponen de manifiesto la necesidad de tecnologías capaces de evitar las indeseadas consecuencias de la emisión de material radiactivo al medio ambiente. Esta es la dirección de investigación del proyecto PASSAM ( $7^{\circ}$ Programa Marco de EURATOM) que está construyendo una base de datos experimental para el desarrollo de sistemas innovadores y la mejora de los sistemas de venteo filtrado de la contención que ya existen. Entre estos sistemas se encuentran las cámaras de ultrasonidos donde las ondas acústicas facilitan la aglomeración y el crecimiento de partículas, resultando sistemas potenciales para su mitigación.

La campaña experimental AAA ha constituido una primera aproximación para la aplicación de las cámaras de ultrasonidos como sistemas innovadores para la mitigación del término fuente en la contención. El sistema de mitigación de aglomeración acústica (MSAA) se construyó y ha sido probado durante los experimentos AAA. Los resultados obtenidos ponen de manifiesto el leve efecto del campo acústico sobre el crecimiento de las partículas. Además, tanto el flujo másico de gas portador como la naturaleza de la partícula son claves en el proceso de aglomeración.

En resumen, esta tesis está basada en dos iniciativas experimentales, por un lado la investigación de la retención de aerosoles y la influencia sobre ella de distintas variables (concretamente la naturaleza de la partícula, el tipo de rotura y la vibración de tubos) en el lado secundario de un generador de vapor seco; y por otro en el potenciamiento de la aglomeración de aerosoles a través de campos acústicos. Los resultados expuestos en este trabajo suponen contribuciones particularmente innovadoras. 



\section{Resum}

En cas d'accident sever d'una central nuclear els productes de fissió resultants del combustible degradat podrien assolir l'atmosfera si es perd la hermeticitat de la contenció o si troben un camí alternatiu que l'evitin. Donada la naturalesa radio-tòxica dels aerosols nuclears ha d'evitarse per tots els mitjans que surtin a l'exterior.

En un reactor PWR, un cas particular d'accident és en el qual a més de la fusió de nucli existeix trencament de tubs del generador de vapor. En aquest cas, l'alliberament de material radioactiu cap al medi ambient fa que l'escenari sigui indispensable de modelar en l'avaluació del risc d'aquest reactor. Aquesta és la raó dels projectes internacionals EU-SGTR, ARTIST i ARTIST-2, gràcies als quals s'ha construït una extensa base de dades sobre el comportament dels aerosols en el circuit secundari del generador de vapor (Steam Generator, SG). Particularment significativa és l'etapa de trencament, que és responsable de la retenció d'una fracció important de partícules i de modificar la seva distribució cap a les mides més petites. Aquests motius van despertar l'interès vers l'efecte de variables com la naturalesa de la partícula, el tipus de trencament i la vibració de tubs sobre la retenció de partícules sobre els tubs en condicions seques a l'etapa de trencament del SG. Aquests són els aspectes en els quals es centra la primera part d'aquesta tesi.

Dues campanyes experimentals, CAAT2 i SET, s'han dut a terme amb diferents materials, tots ells emmarcats dins del possible rang dels aerosols nuclears. La primera d'elles es va centrar a explorar la influència potencial de la naturalesa de la partícula i l'efecte del tipus de trencament (forma i grandària) sobre la retenció d'aerosols en els tubs. La segona va seguir per la caracterització en termes de vibració dels tubs i el seu efecte en l'eficiència de retenció de partícules. Les proves realitzades ressalten diverses idees clau: el fort efecte de la naturalesa de la partícula sobre la retenció en el costat secundari del SG; l'alta eficiència de retenció quan les partícules són compactes i la també significativa retenció quan són aglomerats; les petites diferències en eficiència entre diferents tipus de trencament (guillotina vs. boca de peix), però notables sobre els patrons de deposició, i l'efecte secundari de la grandària de trencament. Finalment van revelar que enfront de la naturalesa de la partícula, la vibració de tubs juga un paper secundari en l'eficiència de retenció del feix de tubs.

La segona part d'aquesta tesi es centra en la fracció de partícules que en cas d'accident sever, amb o sense seqüència SGTR, és susceptible d'aconseguir la contenció. Accidents com Fukushima posen de manifest la necessitat de tecnologia capaç de cobrir les indesitjades conseqüències de l'emissió de material radioactiu al medi. Aquesta és la raó del projecte PASSAM (7é Programa Marc d'EURATOM) que està construint una base de dades experimental per al desenvolupament de sistemes innovadors i millorar els sistemes de venteig filtrat que ja existeixen de la contenció. Les ones d'ultrasons faciliten l'aglomeració de partícules i resulten sistemes potencials per a la seva mitigació.

S'ha realitzat una primera aproximació per a l'aplicació de les càmeres d'ultrasons com a sistemes innovadors per a la mitigació del terme font en la contenció. El sistema de mitigació d'aglomeració acústica (MSAA) es va construir i ha estat provat durant la campanya experimental AAA. Els experiments duts a terme en la planta PECA-MSAA del LASS. Els resultats obtinguts posen de manifest dues idees: el sistema MSAA és efectiu en la reducció de la massa de partícules i tant el flux màssic de gas portador com la naturalesa de la partícula són claus en l'eficiència de retenció del sistema.

En resum, aquesta tesi està basada en dues iniciatives experimentals, d'una banda la investigació de la retenció d'aerosols i la influència sobre ella de diferents variables ( concretament la naturalesa de la partícula, el tipus de trencament i la vibració de tubs ) en el costat secundari d'un generador de calor seca ; i per un altre en el potenciament de l'aglomeració d'aerosols a través de camps acústics. Els resultats exposats en aquest treball suposen contribucions particularment innovadores en el camp de la seguretat nuclear. 



\section{$\underline{\text { TABLE OF CONTENTS }}$}

CHAPTER 1 29

1. INTRODUCTION 29

1.1. NUCLEAR AEROSOlS 29

1.2. SEVERE ACCIDENT SGTR SEQUENCES 30

1.3. BACKGROUND ON AEROSOL RETENTION IN THE SG UNDER SGTR SEQUENCES $\mathbf{3 4}$

1.3.1. HISTORICAL VIEW AND RESEARCH FRAMEWORK 34

1.3.2. STATE OF THE ART ON AEROSOL RETENTION ACROSS A TUBE BUNDLE 35

1.3.2.1. The "dry bundle break-stage" research: From SGTR to ARTIST-II 36

1.4. BACKGROUND ON ACOUSTIC AEROSOl AgGLOMERATION SYSTEMS 41

1.4.1. HISTORICAL VIEW AND RESEARCH FRAMEWORK 41

1.4.2. STATE OF THE ART ON ACOUSTIC AGGLOMERATION SYSTEMS 42

CHAPTER 2

2. INVESTIGATION SETTING OUT: MOTIVATION, OBJECTIVES AND SCOPE

2.1. MOTIVATION 45

2.2. ОВJECTIVES 46

$\begin{array}{ll}\text { 2.3. SCOPE } & 47\end{array}$

2.3.1. THESIS APPROACH 48

CHAPTER $3 \quad 51$

3. EXPERIMENTAL FACILITY

3.1. INTRODUCTION 51

3.2. THE PECA FACILITY DESCRIPTION

3.2.1. GAS SUPPLY SYSTEM

3.2.2. FLUID BED GENERATOR AND BED MATERIAL 54

3.2.3. INJECTION LINE 56

3.2.4. PECA VESSEL 57

3.2.5. EXHAUST LINE 59

3.2.6. FACILITY UPDATES 59

3.2.7. INSTRUMENTATION AND SAMPLING

3.2.7.1. Instrumentation and control of the thermal-hydraulic variables 62

3.2.7.2. Instrumentation for aerosol characterization 64

$\begin{array}{lll}\text { 3.2.7.2.1. } & \text { Real time devices } & 64\end{array}$

$\begin{array}{ll}\text { 3.2.7.2.2. Gravitational devices } & 65\end{array}$

3.2.7.3. Sampling $\quad 67$

\begin{tabular}{lr} 
CHAPTER 4 & 69 \\
\hline
\end{tabular}

4. SteAm Generator Aerosol Retention TESTS $\quad 69$

CIEMAT AEROSOl ARTIST TESTS \# 2

4.1. INTRODUCTION

4.2. CAAT2 EXPERIMENTAL CONFIGURATION

4.3. EXPERIMENTAL MATRIX

$\begin{array}{ll}\text { 4.3.1. TARGET VARIABLES } & 73\end{array}$

$\begin{array}{ll}\text { 4.3.1.1. Particle nature } & 73\end{array}$

\begin{tabular}{ll} 
4.3.1.2. & Gas mass flow rate \\
\hline
\end{tabular}

$\begin{array}{ll}\text { 4.3.1.3. The breach type } & 75\end{array}$

4.4. MEASUREMENT PROCEDURE 
4.5. RETENTION EFFICIENCY AND MAJOR VARIABLES

4.5.1. INLET AND OUTLET MASS

4.5.2. RETAINED MASS 77

$\begin{array}{ll}\text { 4.6. METHODOLOGY OF ANALYSIS } & 78\end{array}$

4.7. RESULTS AND DISCUSSION

4.7.1. MAJOR INSIGHTS

4.7.2. INFLUENCE OF MATRIX VARIABLES 84

4.7.2.1. Effect of the particle nature 84

4.7.2.2. Effect of the breach shape 86

4.7.2.3. Effect of the breach size 88

4.8. ANALYTICAL INTERPRETATION $\quad 89$

SEPARATE EFFECT TESTS $\quad 93$

4.9. INTRODUCTION 93

4.10. SET EXPERIMENTAL CONFIGURATION

4.10.1. INSTRUMENTATION FOR VIBRATION CHARACTERIZATION 96

4.10.1.1. Piezoelectric accelerometers 96

4.10.1.2. ICP® Accelerometers 96

4.10.2. INSTRUMENTATION FOR AEROSOL CHARACTERIZATION AND SAMPLING 98

4.11. EXPERIMENTAL MATRIX $\quad 99$

4.11.1. TARGET VARIABLES 100

$\begin{array}{ll}\text { 4.11.1.1. Particle nature } & 100\end{array}$

4.11.1.2. Breach shape and size 100

4.11.1.3. Tube arrangement: fixed vs. normal tubes 100

4.11.1.4. Gas mass flow rate 102

4.12. MEASUREMENT PROCEDURE 102

4.12.1. ASSESSMENT TESTS 102

4.12.2. ANALYSIS TESTS 103

4.13. MAJOR VARIABLES

4.13.1. AMPLITUDE AND FREQUENCY 103

4.13.2. RETENTION EFFICIENCY 103

$\begin{array}{lr}\text { 4.14. METHODOLOGY OF ANALYSIS } & 103\end{array}$

4.15. RESULTS AND DISCUSSION 104

\begin{tabular}{lr} 
CHAPTER 5 & 111 \\
\hline
\end{tabular}

5. ACOUSTIC AEROSOl AgglOMERATION TESTS

5.1. INTRODUCTION 111

5.2. BACKGROUND ON ACOUSTIC AEROSOL AGGLOMERATION $\mathbf{1 1 2}$

5.2.1. BASIC MECHANISMS OF AEROSOL ACOUSTIC AGGLOMERATION 112

5.3. AAA EXPERIMENTAL CONFIGURATION $\mathbf{1 1 3}$

5.3.1. PECA-MSAA SET-UP 113

5.3.1.1. The RBG-1000 aerosol generator 116

5.3.1.2. The Mitigative System Acoustic Agglomerator (MSAA) 117

5.3.2. INSTRUMENTATION FOR AEROSOL CHARACTERIZATION AND SAMPLING 120

5.4. EXPERIMENTAL MATRIX

5.4.1. TARGET VARIABLES 122

5.4.1.1. The particle nature, size and proportion $\quad 122$

$\begin{array}{ll}\text { 5.4.1.2. The gas mass flow rate } & 124\end{array}$

5.5. MEASUREMENT PROCEDURE

$\begin{array}{ll}\text { 5.6. MAJOR VARIABLES } & \mathbf{1 2 8}\end{array}$

$\begin{array}{lr}\text { 5.6.1. PARTICLE SIZE DISTRIBUTION } & 128\end{array}$ 
5.6.2. ACOUSTIC GROWTH FACTOR 129

$\begin{array}{ll}\text { 5.7. RESULTS AND DISCUSSION } & \mathbf{1 3 0}\end{array}$

$\begin{array}{lr}\text { 5.7.1. MAJOR INSIGHTS } & 130\end{array}$

5.7.2. PARTICLE NATURE EFFECT 133

5.7.3. GAS MASS FLOW RATE EFFECT 136

\begin{tabular}{lr} 
CHAPTER 6 & 139 \\
\hline
\end{tabular}

6. CONCLUSIONS AND FUTURE WORK $\quad 139$

6.1. CONCLUSIONS AND FINAL REMARKS ON CAAT2 TESTS $\mathbf{1 4 0}$

6.2. CONCLUSIONS AND FINAL REMARKS ON SET TESTS 141

6.3. CONCLUSIONS AND FINAL REMARKS ON AAA TESTS 141

6.4. FUTURE WORK 142

7. NOMENCLATURE $\quad 145$

8. REFERENCES $\quad 149$

\begin{tabular}{lr} 
APPENDIXES & 157 \\
\hline
\end{tabular}

\begin{tabular}{lr} 
APPENDIX 1 & 159 \\
\hline
\end{tabular}

1. STATE OF THE ART ON AEROSOl ACOUSTIC AgGLOMERATION SYSTEMS: THE \begin{tabular}{lr} 
STEPPED PLATE TRANSDUCERS & 159 \\
\hline
\end{tabular}

\begin{tabular}{lr} 
APPENDIX 2 & 165 \\
\hline
\end{tabular}

2. UNCERTAINTY ANALYSIS $\quad 165$

2.1. RETENTION EFFICIENCY 165

2.2. PARTICLE CONCENTRATION 167

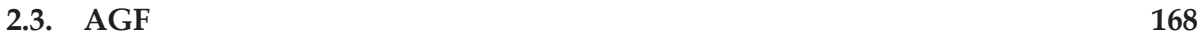

2.4. ACOUSTIC CHAMBER RETENTION $\mathbf{1 7 0}$

\begin{tabular}{lr} 
APPENDIX 3 & 173 \\
\hline
\end{tabular}

3. SET CAMPAIGN: A DYNAMIC ANALYSIS OF THE TUBES VIBRATION RESULTS $\quad \mathbf{1 7 3}$

$\begin{array}{ll}\text { 3.1. BACKGROUND ON TUBE VIBRATION } & \mathbf{1 7 3}\end{array}$

$\begin{array}{llr}\text { 3.1.1. FUNDAMENTALS OF THE VIBRATORY MOTION } & 174\end{array}$

3.1.2. THE PIEZOELECTRIC EFFECT 176

3.1.3. FLUID DYNAMICS ON THE TUBE BUNDLE 177

3.2. DYNAMIC ANALYSIS OF THE SET CAMPAIGN RESULTS $\quad 179$

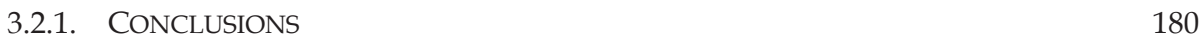

\begin{tabular}{ll} 
APPENDIX 4 & 181 \\
\hline
\end{tabular}

4. SEPARATE EFFECT TEST WITH EXPANDED POLYETHYLENE $\quad 181$

4.1. EXPERIMENTAL MATRIX

4.2. EXPANDED POLYETHYLENE

4.3. RESULTS

4.3.1. MAJOR INSIGHTS

4.3.1.1. Analysis tests 183

4.3.1.2. Assessment tests 184

4.4. CONCLUSIONS 186 
5. DESCRIPTION AND CHARACTERIZATION OF THE MITIGATIVE SYSTEM ACOUSTIC \begin{tabular}{ll} 
AGGLOMERATOR (MSAA) & 187 \\
\hline
\end{tabular}

$\begin{array}{lll}\text { 5.1. INTRODUCTION } & 187\end{array}$

5.2. STRUCTURE OF THE MSAA $\quad 188$

5.2.1. POWER STEPPED-PLATE TRANSDUCERS 189

5.2.1.1. The Impedance, Resonance and Q factor 190

5.2.2. ACOUSTIC FIELD MEASUREMENTS INSIDE THE MSAA 195

\begin{tabular}{lr} 
APPENDIX 6 & 199 \\
\hline
\end{tabular}

6. PRELIMINARY TESTS $\quad 199$

6.1. INTRODUCTION 199

6.2. AEROSOL GENERATION AND CHARACTERIZATION 199

6.3. DEVICES CORRELATION 204

6.4. INTEGRAL PRELIMINARY TESTS 205

\begin{tabular}{lr} 
APPENDIX 7 & 207 \\
\hline
\end{tabular}

7. PARTICLE SIZE DATA PROCESSING $\quad 207$

$\begin{array}{lr}\text { 7.1. INTRODUCTION } & 207\end{array}$

7.1.1. APS AND ELPI SIZE INTERVALS 208

$\begin{array}{ll}\text { 7.1.2. DATA PROCESSING } & 209\end{array}$

7.1.2.1. Number size distribution 209

$\begin{array}{ll}\text { 7.1.2.2. Mass size distribution } & 210\end{array}$

7.1.2.3. Number and mass concentration 210

7.1.3. MEAN DISTRIBUTIONS 210

\begin{tabular}{lr} 
APPENDIX 8 & 211 \\
\hline
\end{tabular}

8. $\quad$ AAA TESTS RESUltS $\quad 211$

$\begin{array}{ll}\text { 8.1. AAA1 } & 211\end{array}$

8.1.1. TEST STAGES AND PROTOCOL 212

8.1.2. SUMMARY OF THE TEST EVOLUTION 212

8.1.3. PARTICLE CONCENTRATION 213

8.1.4. PARTICLE SIZE 214

8.2. AAA2 216

8.2.1. TEST STAGES AND PROTOCOL 216

8.2.2. SUMMARY OF THE TEST EVOLUTION 217

8.2.3. PARTICLE CONCENTRATION 217

$\begin{array}{lr}\text { 8.2.4. PARTICLE SIZE } & 218\end{array}$

\begin{tabular}{ll} 
8.3. & AAA3 \\
\hline
\end{tabular}

$\begin{array}{lr}\text { 8.3.1. TEST STAGES AND PROTOCOL } & 219\end{array}$

8.3.2. SUMMARY OF THE TEST EVOLUTION 220

$\begin{array}{lr}\text { 8.3.3. PARTICLE CONCENTRATION } & 220\end{array}$

8.3.4. PARTICLE SIZE 221

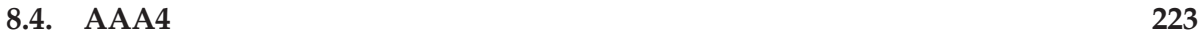

8.4.1. TEST STAGES AND PROTOCOL 223

8.4.2. SUMMARY OF THE TEST EVOLUTION 224

8.4.3. PARTICLE CONCENTRATION 224

8.4.4. PARTICLE SIZE 225

\begin{tabular}{ll} 
8.5. & AAA5 \\
\hline
\end{tabular}

$\begin{array}{ll}\text { 8.5.1. TEST STAGES AND PROTOCOL } & 227\end{array}$ 
8.5.2. SUMMARY OF THE TEST EVOLUTION

8.5.3. PARTICLE CONCENTRATION 228

8.5.4. PARTICLE SIZE 229

8.6. AAA6 231

8.6.1. TEST STAGES AND PROTOCOL 231

8.6.2. SUMMARY OF THE TEST EVOLUTION 232

8.6.3. PARTICLE CONCENTRATION 232

8.6.4. PARTICLE SIZE 233

8.7. AAA7 235

8.7.1. TEST STAGES AND PROTOCOL 235

8.7.2. SUMMARY OF THE TEST EVOLUTION 236

8.7.3. PARTICLE CONCENTRATION 236

$\begin{array}{ll}\text { 8.7.4. PARTICLE SIZE } & 237\end{array}$

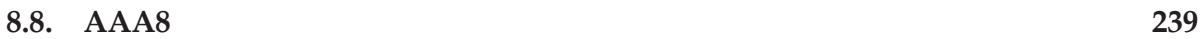

8.8.1. TEST STAGES AND PROTOCOL 239

8.8.2. SUMMARY OF THE TEST EVOLUTION 240

8.8.3. PARTICLE CONCENTRATION 240

8.8.4. PARTICLE SIZE 241

8.9. AAA9 243

8.9.1. TEST STAGES AND PROTOCOL 243

8.9.2. SUMMARY OF THE TEST EVOLUTION 244

8.9.3. PARTICLE CONCENTRATION 244

8.9.4. PARTICLE SIZE 245

$\begin{array}{ll}\text { 8.10. } & \text { AAA10 } \\ 247\end{array}$

$\begin{array}{ll}\text { 8.10.1. TEST STAGES AND PROTOCOL } & 247\end{array}$

8.10.2. SUMMARY OF THE TEST EVOLUTION 248

$\begin{array}{ll}\text { 8.10.3. PARTICLE CONCENTRATION } & 248\end{array}$

8.10.4. PARTICLE SIZE 249 



\section{LIST OF FIGURES}

Fig. 1 View of a PWR SG (www.panthersnuclearpower7.wikispaces.com, n.d.) ___ 32

Fig. 2 Scheme of the research program approach (Herranz et al., 2008)__ 36

Fig. 3 Mass retention efficiency as a function of the inlet. EU-SGTR tests (Herranz et al., 2006) 38

Fig. 4 Mass retention efficiency as a function of the Re numbers. EU-SGTR and CAAT tests _ 40

Fig. 5 Lay-out of the PECA-SGTR configuration for the CAAT2 and SET experimental campaigns _ 52

Fig. 6 The LASS facility with the PECA vessel at the bottom. Right: The tube bundle view _ 52

Fig. 7 Flow rate evolution

Fig. 8 Fluid Bed Generator

Fig. 9 Bed material for aerosol fluidization: Cu particles (left) and glass beads (right) __ 56

Fig. 10 Injection line entering into the PECA-vessel __ 56

Fig. 11 Control valves (pressure and gas mass flow rate) of the injection line __ 57

Fig. 12 Fish-mouth and guillotine breaches

Fig. 13 Fish-mouth breaches: 1D, 0.5D, 0.25D__ 58

Fig. 14 Radial turbines (up) and filtration system (right) _ 59

Fig. $15 \mathrm{SiO}_{2} / \mathrm{Cu}$ injection arrangement

Fig. $16 \mathrm{TiO}_{2}$ injection arrangement 61

Fig. 17 Control screens: compressor and gases/aerosols injection lines (left), vessel (right). _ 62

Fig. 18 APS: Aerodynamic Particle Sizer___ 64

Fig. 19 ELPI: low pressure impactor and its stages __ 65

Fig. 20 Mark III (left) and DLPI (right) impactors _ 66

Fig. 21 Membrane filter

Fig. 22 Left: U-ring: bevelled bi-cone and squared nut _ 68

Fig. 23 From left to right: $\mathrm{SEM}$ images of $\mathrm{SiO}_{2}, \mathrm{Cu}$ and $\mathrm{TiO}_{2}$ particles

Fig. 24 Fish-mouth breaches: 1D, 0.5D, 0.25D__ 75

Fig. 25 CAAT2 measurement procedure schedule _ 76

Fig. 26 Tube bundle: sampled tubes and regions

Fig. 27 Methodology for $\eta$ estimate

Fig. 28 Collection efficiency of CAAT2 tests _ 82

Fig. 29 Retention efficiency vs. non-dimensional flow rate ___ 83

Fig. 30 Retention efficiency vs. non-dimensional inlet concentration __ 83

Fig. 31 Retention efficiency vs. non-dimensional inlet particle diameter ___ 83

Fig. 32 Inlet to outlet particle mass size distribution of experiments ___ 85

Fig. 33 Inlet and outlet distributions of $\mathrm{TiO}_{2}$. CAAT2_1'

Fig. 34 Guillotine (top) and fish-mouth (down) deposition patterns __ 88

Fig. 35 Normalized efficiency vs. breach size $\left(\mathrm{SiO}_{2} \text { tests }\right)_{-} \quad 89$

Fig. 36 Empirical correlation of CAAT and CAAT2 data ___ 91

Fig. 37 View of the mini-bundle with piezo electric accelerometers (left) and full bundle (right) _ 95

Fig. 38 Sketch of the mini-bundle of tubes (left) and full bundle (right) __ 95

Fig. $39 \mathrm{ICP} 囚$ accelerometer

Fig. 40 Two views of the ICP ${ }^{\circledR}$ Accelerometers on the tubes surface $\_97$

Fig. 41 LMS SCADAS mobile with some connected accelerometers__

Fig. 42 ICP ${ }^{\circledR}$ System set-up ___ 98

Fig. 43 Tube inside the supporting plate in the "normal" arrangement__101

Fig. 44 Tubes inside the supporting plate in the fixed arrangement____ 101

Fig. 45 SEM of river sand used to fill the tubes in the fixed arrangement __ 101

Fig. 46 Schedule of the measurement procedure during the assessment tests __ 102

Fig. 47 SET campaign methodology__ 104

Fig. 48 Comparison of the amplitude (left) and characteristic frequency (right) of the tubes

under fixed and normal fish-mouth configuration 105 
Fig. 49 Comparison of the amplitude of tube vibration under guillotine (left) and fish-mouth (right) tube breach

Fig. 50 Collected efficiency of fixed vs. normal integral tests__ 107

Fig. 51 Retention efficiency of CAAT, CAAT2 (normal bundle) and SET (fixed bundle) __ 108

Fig. 52 Deposition pattern of fixed bundle (up) vs normal bundle (down). $\mathrm{SiO}_{2}$, fish-mouth configuration

Fig. 53 Lay-out of the PECA-MSAA facility __ 114

Fig. 54 Outside view of the MSAA within the PECA vessel __ 115

Fig. 55 Inside view of the MSAA within the PECA vessel __ 115

Fig. 56 RBG-1000 aerosol generator used for the AAA tests __ 116

Fig. 57 Sketch diagram of RBG system __ 117

Fig. 58 Mitigative System for Aerosol Acoustic Agglomeration sketch _ 118

Fig. 59 Stepped-plate power transducer for airborne applications at $21 \mathrm{kHz}$

Fig. $60 \mathrm{SEM}$ of $2.5 \mu \mathrm{m} \mathrm{SiO} 2$ particles

Fig. $61 \mathrm{SEM}$ of $0.3 \mu \mathrm{m}$ (left) and mixture of $0.3 \mu \mathrm{m}+1 \mu \mathrm{m} \mathrm{SiO}{ }_{2}$ particles (right) __ 123

Fig. $62 \mathrm{SEM}$ of $\mathrm{TiO}_{2}$ particles _ 123

Fig. 63 AAA measurement procedure schedule _ـ127

Fig. 64 Tri-modal measured distribution adjusted with four lognormal equations __ 129

Fig. 65 Acoustic growth factor of AAA tests __ 132

Fig. 66 AAA9 and AAA9' particle size distribution with (F1 and F1') and without (F2 and F2') ultrasonic field

Fig. 67 AAA10 and AAA10' particle size distribution with (F1 and F1') and without (F2 and

F2') ultrasonic field

Fig. 68 AAA3 and AAA3' concentration of particles with (F1 and F1') and without (F2 and

F2') ultrasonic field

Fig. 69 Acoustic retention factor of AAA tests 136

Fig. 70 Acoustic growth factor vs. gas mass flow rate___ 137

Fig. 71 Particle size distribution at different gas flow rates _ 138

Fig. 72 The normalized mass loading (with respect to the initial mass loading) as a function of time for various transducer power applied within the $5 \mathrm{~m}^{3}$ chamber under static condition (Magill et al., 1989)

Fig. 73 Scheme of the pilot plant scale ultrasonic installation at $20 \mathrm{kHz}$ for fine particle agglomeration with diesel exhausts under dynamic conditions __ 162

Fig. 74 Phase relationships among displacement, velocity and acceleration __ 174

Fig. 75 Atoms displacement by the application of a force __ 176

Fig. 76 Sketch of an accelerometer __ 177

Fig. 77 Vortex shedding (von Karman vortices)___ 178

Fig. 78 Structural tube vibration coupled with vortex shedding ___ 178

Fig. 79 Turbulent eddies coupled___ 178

Fig. 80 Tube displacement vs. flow velocity ("Flow-Induced Vibration of Shell and Tube Heat Exchangers," 2013) _ـ 179

Fig. 81 T4-y FFT spectra 180

Fig. 82 Tubes filled with EPE 182

Fig. 83 Sketch of the tubes tested and real position of the accelerometers ___ 183

Fig. 84 Collected efficiency in the Analysis Tests under _ 184

Fig. 85 Amplitude of the tubes under the excitation of $150 \mathrm{~kg} / \mathrm{h}$ flow rate ___ 185

Fig. 86 Frequency of vibration of the tubes at the flow rates tested __ 186

Fig. 87 MSAA (overall height $3444 \mathrm{~mm}$ ) __ 189

Fig. 88 a) Simple RLC equivalent electrical circuit of a piezoelectric transducer at the resonance; b) Conductance (G) and Susceptance (B) of a piezoelectric transducer at the resonance versus frequency

Fig. 89 Ultrasonic power transducer 193

Fig. 90 Scheme of the electronic equipment __ 194

Fig. 91 Impedance Analyzer and response _ 195 
Fig. 92 Calibration Chart of the 1/8" pressure microphone type 40DP, GRAS Sound and Vibration

Fig. 93 Ultrasound field patterns

Fig. 94 MSAA Acoustic measurements

Fig. 95 Sketch of the experimental set-up for acoustic field measurments in the semi-anechoic chamber

Fig. 96 Directivity pattern of a circular stepped-plate directional transducer of $21 \mathrm{kHz}$

Fig. 97 APS measurements with and without dilution. __ 200

Fig. 98 ELPI measurements with and without dilution _ 201

Fig. 99. APS saturation tests __ 202

Fig. 100 With a Particle size distributions with and without dilution __ 203

Fig. 101 ELPI vs APS __ 204

Fig. 102 Integral-preliminary test protocol __ 205

Fig. 103 AAA test protocol 206

Fig. 104 APS and ELPI common range __ 209

Fig. 105 Hydraulic variables evolution __ 213

Fig. 106 Hydraulic variables evolution __ 217

Fig. 107 Hydraulic variables evolution 2220

Fig. 108 Hydraulic variables evolution __ 224

Fig. 109 Hydraulic variables evolution 2228

Fig. 110 Hydraulic variables evolution

Fig. 111 Hydraulic variables evolution 236 



\section{LIST OF TABLES}

TABLE 1 EU-SGTR and CAAT test matrixes __ 37

TABLE 2 EU-SGTR results (Herranz et al., 2006)__ 38

TABLE 3 CAAT results _ 39

TABLE 4 Fish-mouth breaches features

TABLE 5 Instrumentation __ 63

TABLE 6 Flow monitoring _ 63

TABLE 7 Aerosol size characterization instrumentation and sampling ___ 67

TABLE 8 Estimation of characteristic parameters of depletion mechanisms (López del Prá, 2012) 72

TABLE 9 Variables and non-dimensional numbers characterizing SGTR scenarios ___ 73

TABLE 10 CAAT2 Experimental test matrix __ 73

TABLE 11 Aerosol main features __ 74

TABLE 12 CAAT2 boundary conditions and results___ 81

TABLE 13 Experimental test matrix __ 100

TABLE 14 Main components of directional circular stepped-plate transducers at $21 \mathrm{kHz} \_119$

TABLE 15 Anticipated boundary conditions for FCVs (L.E. Herranz et al., 2014) __ 121

TABLE 16 AAA experimental test matrix __ 122

TABLE 17 Aerosols main features__ 124

TABLE 18 Gas mass flow rate, velocity and residence time of particles within the MSAA _ 125

TABLE 19 AAA tests boundary conditions and results ___ 131

TABLE 20 Aerosol agglomeration research projects. Experimental conditions tested___ 163

TABLE 21. Experimental matrix of SET campaign performed with EPE ___ 182

TABLE 22 Expanded Polyethylene properties ___ 182

TABLE 23 Main characteristics of directional circular stepped-plate transducers at $21 \mathrm{kHz} \_194$

TABLE 24 APS bin sizes __ 208

TABLE 25 ELPI bin sizes 208

TABLE 26 Mixture of particles __ 211

TABLE 27 Mixture of particles _ 216

TABLE 28 Mixture of particles __ 219

TABLE 29 Mixture of particles __ 223

TABLE 30 Mixture of particles __ 227

TABLE 31 Mixture of particles __ 231

TABLE 32 Mixture of particles _ 235

TABLE 33 Mixture of particles _ 239

TABLE 34 Mixture of particles _ 243

TABLE 35 Mixture of particles __ 247 



\section{Chapter 1}

\section{Introduction}

In case of a severe accident in a Nuclear Power Plant (NPP) fission products are released from the degraded fuel and may reach the environment if their confinement is lost and/or bypassed. Given the high radio-toxic nature of fission products for environment and population, their unrestricted release should be avoided at all costs. This highlights the importance of relying on efficient mitigation systems capable of reducing as much as possible any accidental release. This overall statement becomes even stronger after the unfortunate accident of March 2011 at the Fukushima Daiichi NPP.

\subsection{Nuclear Aerosols}

Source Term is defined as the amount and composition of radioactive material that would be released from a nuclear power plant in case of an accident (Allelein et al., 2009). Most of it will escape in form of aerosols, very small solid particles or liquid droplets suspended in a gas phase, typically ranged in sizes. At high temperatures reached during nuclear reactor degradation, most radionuclides (particularly, those of high radiobiological impact, as I-131 and Cs-137) leave the reactor core in form of vapours (Pontillon and Ducros, 2010). Nevertheless, as soon as vapours reach colder regions along their pathway to the containment (last barrier before the environment), e.g. through the primary circuit, homogeneous and heterogeneous nucleation 
turns most of them into particulate matter (Kissane, 2008). As a consequence most of the fission products, except for noble gases and a fraction of iodine, already enter the primary side of the steam generator as particles (Haste et al., 2012).

The nature and behaviour of nuclear aerosols can potentially influence both the course and the consequences of reactor accidents. Nuclear aerosols can affect the performance of engineered safety systems (e. g. air cleaning systems) as well as the magnitude, dispersion and effects of the radioactive source term leaked to the atmosphere. As a result of the extreme conditions for nuclear aerosols in case of an accident, they exhibit very dynamic mostly physical, but also chemical behaviour and pose special analytical and experimental problems different from those associated with aerosols found under industrial and ambient conditions.

In-containment nuclear aerosols are characterized by particles sizes ranged from $0.1 \mu \mathrm{m}$ to 10 $\mu \mathrm{m}$ and concentrations going from 1 to $10 \mathrm{~g} / \mathrm{m}^{3}$ (Allelein et al., 2009). At these concentrations, the aerosol particles hardly affect the gas hydrodynamics, but the gas dynamics profoundly affect the behaviour of the suspended particles. The behaviour of the larger aerosol particles are described usually by continuum mechanics. The smallest particles have diameters less than the mean free path of gas phase molecules and the behaviour of these particles can often be described well by free molecular physics. The vast majority of aerosol particles arising in reactor accident analyses have behaviours in the very complicated regime intermediate between the continuum mechanics and free molecular limit. The number density of aerosol particles in a gas phase can be so large (more than $10^{13}$ counts $/ \mathrm{m}^{3}$ ) that is difficult to predict aerosol behaviour by calculating the dynamics of individual particles. Instead aerosols must be considered in a collective sense and the aerosol is taken to have some continuous distribution of particle sizes. There is no fundamental theoretical reason why particle size data should approximate the lognormal distribution, but it has been found to apply to most natural distributions of aerosols (Hinds, 1999). Thus, for a lognormal size distribution the probability density function can be expressed as:

$$
p d f\left(d_{p}\right)=\frac{1}{\sqrt{2 \pi} \ln \sigma} \exp \left[-\left(\frac{\ln d_{p} / \mu}{\sqrt{2 \ln \sigma}}\right)^{2}\right] d \ln d_{p}
$$

which gives the fraction of particles having diameters whose logarithms lie between lndp and $\operatorname{lndp}+\operatorname{dln} d p$.

\subsection{Severe Accident SGTR sequences}

Pressurized water reactors (PWR) rely on indirect cycles to generate electricity. The thermal energy generated in the nuclear reactor is transferred to a steam power cycle through steam generators (SGs). A variety of phenomena such stress corrosion, high-cycle fatigue or wastage, may degrade the tubes of the SG leading to the tube rupture, so-called SGTR (Steam Generator Tube Rupture). 
The SGTR scenario with reactor core melt (i.e. severe accident SGTR sequence) (NUREG-1570, 1998) has been described previously by López del Prá and Sánchez-Velasco (López del Prá, 2012; Sánchez Velasco, 2008). In summary the scenario is described as follows. The SGs of PWRs are large shell-and-tube heat exchangers that use the heat from the primary reactor coolant to produce steam in the secondary side to drive turbine generators. A typical western plant (Westinghouse, Framatome, Siemens designs) has from two to four SGs per plant, depending on plant capacity. Fig. 1 shows a cut-away view of a typical recirculating SG. The steam generator (SG) is a complex structure housing various components and around $4000 \mathrm{U}$-inverted tubes each of them welded to a thick plate with a hole for each tube end (called tube sheets) located near the bottom of the SG vessel. The reactor coolant enters the hemispherical bottom head through an inlet nozzle, flows through the U-tubes and exits the lower plenum through an outlet nozzle. The tubes are supported with plates at a number of fixed axial locations along the tube bundle. The region defined by two consecutive support plates is usually called "stage". Above the heat exchanger, there is an integral moisture separation equipment to dry the steam. Primary coolant enters the SG at around $315{ }^{\circ} \mathrm{C}$ to $330{ }^{\circ} \mathrm{C}$ on the hot leg side and leaves it at about $288{ }^{\circ} \mathrm{C}$ on the cold leg side. About $25 \%$ of the secondary coolant is converted into steam on each pass through the generator. The remains are recirculated. The SGs are generally designed to produce, at rated steam flow, saturated steam with less than $0.25 \%$ moisture by weight.

Since primary reactor coolant is working at a higher pressure than the secondary coolant, any leakage coming from defects in the tubes is from the primary to secondary-side, and rupture of the tubing may result in release of radioactivity to the environment outside the reactor containment through the pressure relief valves in the secondary system. The thin-walled SG tubes are therefore an important part of the reactor boundary. In order to act as an effective barrier, this tubing must be essentially free of cracks, perforations, and general deterioration. However, widespread degradation of the SG tubes has occurred at a number of plants. As a result, about one-half of the PWR nuclear power plants in the world have been removing SG tubes from service (plugging) or repairing (sleeving) them in any given year. Until 1996, the total number of SG tubes plugged per year rached about 10000. Also about 48000 tubes had been sleeved per year (USNRC, 1996). This means that a large fraction of PWR plants are operating with tubing defects near of beyond the safety limits at any given time. 


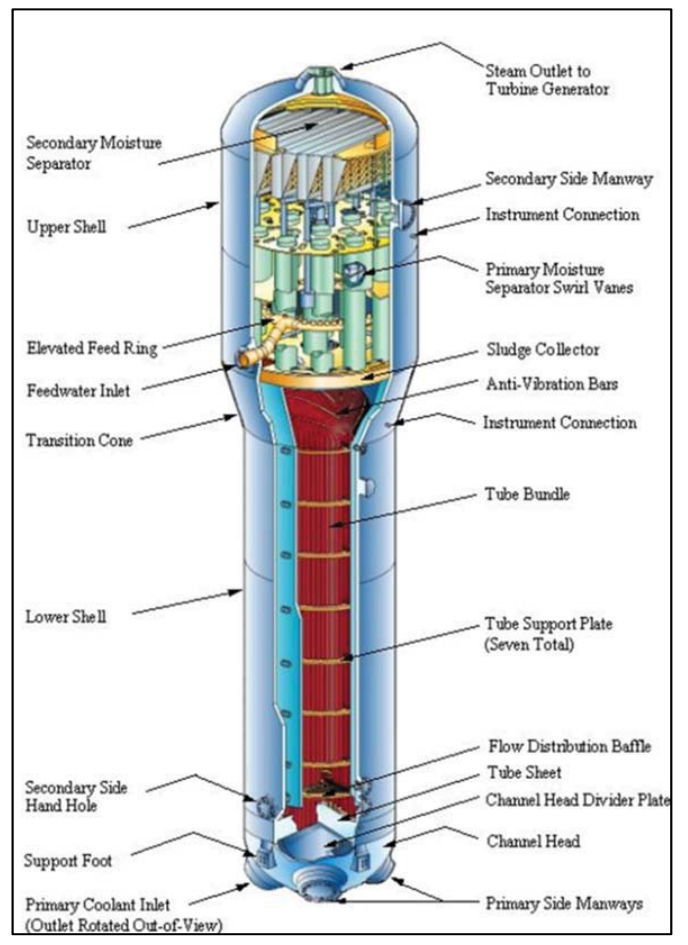

Fig. 1 View of a PWR SG (www.panthersnuclearpower7.wikispaces.com, n.d.)

Up to ten spontaneous steam generator tube ruptures (SGTR) have been reported in NUREG6365 (USNRC, 1996). A spontaneous tube rupture is a rupture of one or more SG tubes that is not caused by another event or an upset in normal expected operational parameters. These ruptures have been caused by a variety of tubing degradation mechanisms including stress corrosion of the surface of the tubing, high-cycle fatigue and wastage (uniform corrosion) (Hwang et al., 2008). Statistically, break locations have been distributed between bend region $(50 \%)$ and in the hot leg near the tube sheet $(50 \%)$. The ruptures resulted in leak rates ranging from $425 \mathrm{l} / \mathrm{min}$ to $2900 \mathrm{l} / \mathrm{min}$ (i.e. $0.007-0.048 \mathrm{~m}^{3} / \mathrm{s}$ ) and complex plant transients which had not always been easy for the operators to control. In some cases, it took a relatively long time to realize that a SGTR had occurred. Therefore, there was no immediate reaction or answer to start reducing power and isolate the defective SG (Sánchez Velasco, 2008). Also, at some plants, the reactor coolant system pressures were held above the defective SG secondary side pressures for relatively long periods of time and the defective SG were overfilled (USNRC, 1996). All in all, these events were always successfully countered as no other major malfunctions occurred at same time.

SGTR sequences are handled within design basis accidents (DBA) of western PWR. Plants are designed to cope with such accidents and no major consequences should be expected. However, 
certain nuclear power plant DBA, such as a sudden break in the steam line, may lead to rapid depressurization of the secondary coolant system. The pressure difference across the tubing walls generated during these accidents may result in simultaneous leakage or rupture of a number of SG tubes when an active degradation mechanism has severely damaged a large number of tubes generating an induced SGTR (USNRC, 1996). Simultaneous leakage or rupture of several tubes can lead to a plant transient which is even more difficult to control than a spontaneous tube rupture transient, and radioactivity levels released to the environment which may exceed site limits.

In addition, if during a SGTR event other malfunctions happen, the sequence may lead to severe accidents. If the safety relief valve of the failed SG was damaged due to water ingression and stayed stuck open it would result in a loss of coolant that, eventually, would lead to core degradation and meltdown. Under these conditions, fission products and aerosols released from the reactor would bypass the containment. These accident scenarios are very unlikely but, given the potential consequences of a direct path for fission products from the primary coolant system to the environment, they were estimated to be important risk contributors (USNRC, 1990). Actually, spontaneous tube rupture contribution to total core damage frequency varies from $10^{-8}$ to $10^{-5}$ per reactor year. However, a review of 20 U.S. PWR individual plant examinations has shown that the risk associated with SGTR at most PWR plants is above $10 \%$ and at many plants is as high as $75 \%$ to $99 \%$ of the total risk (USNRC, 1996). These numbers are based on the past history of spontaneous tube ruptures, but do not consider the possibility of induced tube ruptures (i.e. progression of other accidents to induced SGTR) in badly degraded SGs. Current power plants operate with detectable flaws in tubes, which are controlled during revisions by a criteria of limiting the flaw size. Under accident conditions, heat transfer from the reactor core to the primary circuit boundary weakens the structure and it might break at vulnerable locations, such as the hot leg nozzle, the surge line to the pressurizer or the SG tubes. As a reference for this case, NUREG-1150 (USNRC, 1990), which is an assessment for five NPP in the severe accident risks based on Probabilistic Risk Assessment (PRA), showed that all PWR plants analyzed could suffer induced SGTR.

The potential retention within the secondary side of a failed steam generator during a SGTR severe accident sequence was seen as one of the largest uncertainties in the analyses reported in NUREG-1150 (USNRC, 1990). An expert elicitation panel (USNRC, 1990) considered that little retention of radionuclides would occur both in the reactor coolant piping and the failed steam generator. The overall transmission factor from the reactor to the environment was estimated to be higher than $75 \%$ for all radionuclides considered, and the experts agreed to attribute such a small attenuation to the retention in the primary coolant piping. Consistently, and given present absence of a comprehensive database or specific model for the retention in the secondary side of the failed steam generator, Probabilistic Risk Assessments (PRA's) usually give no credit to any potential decontamination within the secondary side of a steam generator. However the complex geometry of the tube bank, support plates, separators and dryers provides a large surface area on which fission products may be trapped. Moreover, the presence of liquid water in the SG bundle (i.e. flooded bundle) may further augment the retention. Nevertheless, regulatory conservatism is based on the fact that aerosol interactions in the SG are too complex to quantify retention with good accuracy. 
Then, for SGTR quantifying decontamination factor $\left(D F=\frac{m_{\text {in }}}{m_{\text {out }}}\right.$; also given in terms of retention efficiency, $\eta=\frac{m_{\text {ret }}}{m_{i n}}$ ) of a dry SG and understanding the trapping process are of great practical importance. Theoretical and laboratory-scale experiments showed evidences of high potential for aerosol removal in dry SG due to inertial impaction and turbulent deposition on secondary tube bundle. Based on $10 \mu \mathrm{m}$ particles studies, industry analysis suggests very high decontamination factor for dry SG (DF $\approx 10000$, (Dehbi, 2007)) which is far away from the regulators view. Nevertheless this assertion is based in only one analysis.

In the hypothetical case of a reactor core melting, SGTR could result in a direct release of radioactive particles to the environment. However, given the large surface area available, radioactive aerosol could be partially retained in the secondary side of the steam generator. The extent of aerosol trapping is heavily dependent on the conditions in the secondary side during the accident. Under normal working conditions the secondary side is flooded with water to generate steam. Under accident conditions, however, the tube breach could be over the water level and particles would enter a "dry" secondary side carried by a high-velocity gas flow. This scenario is especially critical since no attenuation will occur due to the retention of particles by water (i.e. pool scrubbing). The particle laden gas, however, could still be filtered as it passes through the multiple structures within the secondary side. Under these conditions, it is expected that the tube surfaces in the region between two support plates where the tube breach is located (hereafter called "break stage"), play a key role in the retention process.

\subsection{Background on Aerosol retention in the SG under SGTR sequences}

\subsubsection{Historical view and research framework}

The potential radioactive release to the environment in case of meltdown sequences with steam generator tube rupture (section 1.2), turns this type of by-pass sequences into an indispensable scenario to model when assessing PWR risk. In order to build up a sound database on aerosol retention during this accidental sequence, ambitious research programs have been developed in the recent years. The first was the EU-SGTR project (2000-2002). It was followed by international collaboration projects ARTIST (Aerosol Trapping In a Steam Generator, 2003-2007), ARTIST-II (2008-2011) and the ARTIST extension. They all have been coordinated by the Paul Scherrer Institut (PSI) in Switzerland.

The projects were aimed to generate a comprehensive database on aerosol retention in a steam generator. To do so, several experimental campaigns have been developed in two experimental facilities: ARTIST (Guntay, 2004) located at PSI and PECA-SGTR (Sánchez Velasco, 2008) located at CIEMAT (in particular at the Laboratory for Analysis of Safety Systems (LASS)). The ARTIST facility is a scaled-down model of the FRAMATOME 33/19 type steam generator in operation at the Swiss power Plant Beznau 1136 MWth PWR (KKB). The PECA-SGTR facility is a mock-up of the break stage of a SG. The experimental data was used to verify and develop 
predictive models for aerosol retention in the steam generator under both dry and flooded secondary side conditions.

This thesis, trough the CIEMAT (Centro de Investigaciones Energéticas Medio Ambientales y Tecnológicas) and supported by the Spanish Nuclear Safety Council, is experimentally involved in the ARTIST-II project. The ARTIST-II project was divided in several phases. Each one was basically concentrated on the investigation of the aerosol retention on a different element or geometry of the SG. The present work is focused on aerosol retention in the break vicinity under "dry" conditions. It belongs to the Phase-II of the project.

\subsubsection{State of the Art on Aerosol Retention across a tube bundle}

Although there are some studies regarding particle deposition in the external surface of bundles, experimental data is still required. As it will be shown, only some insights have been done within the projects predating the ones concerning this thesis, i.e., EU-SGTR and ARTIST.

Most of the existing deposition correlations are referred to internal flows. There are some experimental studies on particle retention on single tubes surfaces (Douglas and Ilias, 1988; Ranz and Wong, 1952; Wessel and Righi, 1988; Wong and Johnstone, n.d.; Zhu et al., 2000) as well as on adhesion mechanisms of particles impinging on single tubes (Aylor and Ferrandino, 1985; Paw U, 1983; Wang and John, 1988).

The earlier experimentalists, Ranz et al (1952) and Wong et.al (1953) developed a database of more than 100 tests in which a tube was facing a particle laden gas at low Reynolds numbers (under 450) and Stokes number above 0.1. Their results showed that under the conditions studied, the collection efficiency increases with the Stokes number. Then, Douglas \& Ilias, (1988) developed a model to describe deposition of aerosol on an isolated cylindrical tube under turbulent cross flow conditions. The experiments consisted in exposing the tube to an aerosol stream. Afterwards, the aerosol deposited on the tube surface was collected. The retention efficiency was found to be roughly correlated with the Stokes number for Stokes number equal or smaller than 1.

There are few investigations dealing with the particle retention across a bundle of tubes. The retention efficiency in a bundle differs with respect to the retention efficiency in a single tube. It is due to the effect that the adjacent tubes might have on the deposition process (Konstandopoulos et al., 1993). In a bundle configuration, the flow field around each tube is modified by the surrounding. As a result, a non-uniform deposition pattern might appear across the tubes of the bundle.

The most recent investigation on aerosol retention within a tube bundle deal with the EU-SGTR and ARTISTs projects (Auvinen et al., 2005, p. 200; Herranz et al., 2008; Lind et al., 2012; Routamo et al., 2005; Sánchez-Velasco et al., 2010). 


\subsubsection{The "dry bundle break-stage" research: From SGTR to ARTIST-II}

Research activities on SGTR sequences were carried out at CIEMAT in the frame of the EUSGTR program to investigate the retention capability of the break stage of a SG. EU-SGTR project was the initial part of a long term program designed by CIEMAT to characterize the influence of flow and aerosol conditions in retention efficiency of the break stage of the SG secondary side during a SGTR sequence. The overall approach of the research program (not fully addressed in EU-SGTR project) was structured in three working lines (Fig. 2): test performance, three-dimensional aerodynamic simulations and model development.

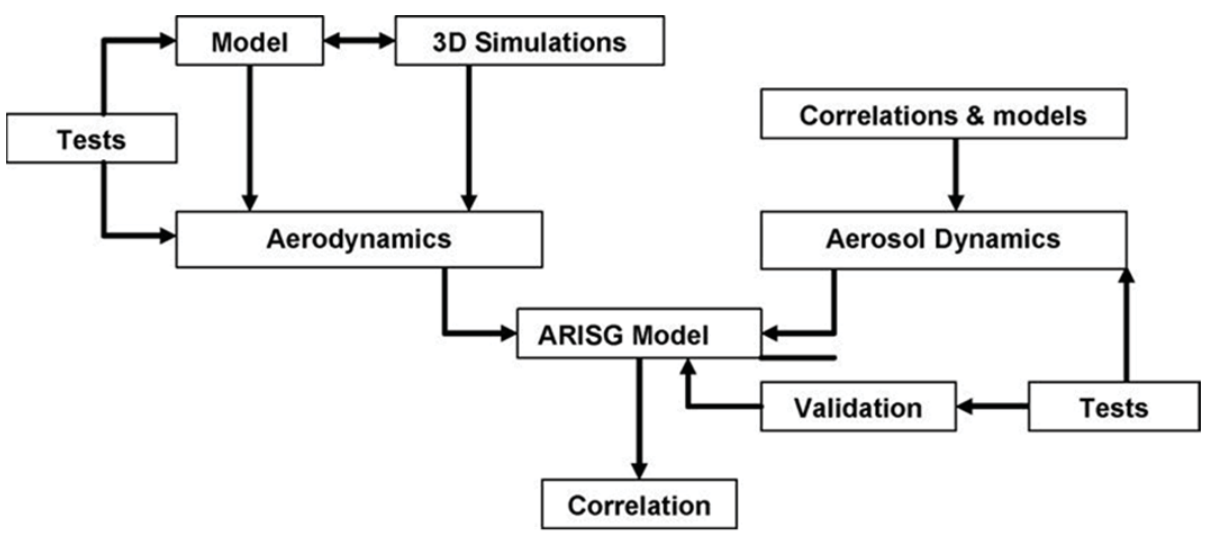

Fig. 2 Scheme of the research program approach (Herranz et al., 2008)

The experimental phase consisted of 12 tests performed at CIEMAT's PECA-SGTR facility (Herranz et al., 2006). The main objective of the experimental campaign was to assess the influence of the inlet gas mass flow rate and the break configuration on particle retention. To do so, the inlet mass flow rate was varied from $75 \mathrm{~kg} / \mathrm{h}$ to $250 \mathrm{~kg} / \mathrm{h}$ and two rupture types, "guillotine" and "fish mouth", were investigated at different locations and orientations (TABLE 1). The remaining boundary conditions were imposed according to previous analysis performed with MELCOR and SCDAP/RELAP codes (Bakker, 2001; Güntay et al., 2002). $\mathrm{TiO}_{2}$ particles were used as aerosol compound. The particle diameter at the inlet of the rig ranged approximately from 5 to $7 \mu \mathrm{m}$. 


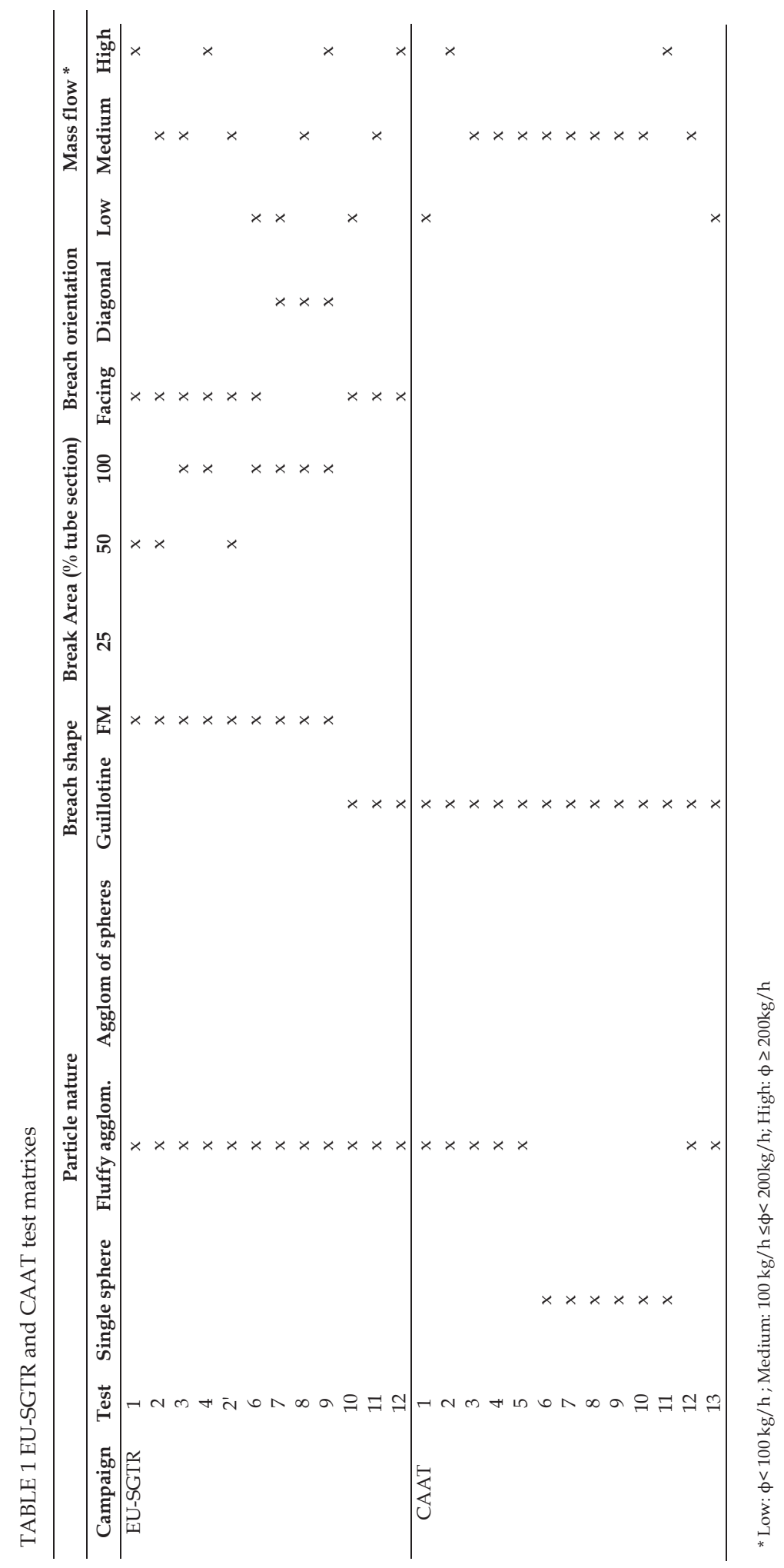


The main results obtained during the experiments showed that the mass of the retained aerosols was always below a value of $20 \%$ of the total injected mass (TABLE 2). However, it was found and correlated that when the gas mass flow rates were over $100 \mathrm{~kg} / \mathrm{h}$ the higher the inlet gas flow rate, the lower the mass fraction retained (Fig. 3). From the qualitative point of view, the deposits distribution on the tube surfaces was not uniform. The surface density decreased with radial distance from the breach (i.e., thicker deposits were observed at the closest tubes). The influence of the breach type, its orientation and location within the bundle had a secondary importance compared to the flow rate (this trend did not hold below $100 \mathrm{~kg} / \mathrm{h}$ ). Nevertheless, the mass distribution on the tubes surface was highly dependent on the breach type (Herranz et al., 2006).

TABLE 2 EU-SGTR results (Herranz et al., 2006)

\begin{tabular}{|c|c|c|c|c|c|c|c|c|c|c|c|c|}
\hline Test & 1 & 2 & 3 & 4 & 5 & 6 & 7 & 8 & 9 & 10 & 11 & 12 \\
\hline$\Phi(\mathrm{kg} / \mathrm{h})$ & 249.71 & 100.42 & 149.30 & 251.20 & 103.13 & 78.64 & 71.79 & 156.95 & 245.18 & 72.13 & 150.26 & 243.83 \\
\hline AMMD $(\mu \mathrm{m})$ & 7.42 & n. a. & 6.72 & 6.69 & n. a. & n. a. & 3.37 & 6.95 & 7.13 & 5.16 & 6.7 & 4.87 \\
\hline $\mathrm{m}_{\text {in }}(\mathrm{g})$ & 96.61 & 108.55 & 113.47 & 133.53 & 74.87 & 65.12 & 56.60 & 182.73 & 186.35 & 49.52 & 120.36 & 133.52 \\
\hline $\mathrm{m}_{\text {out }}(\mathrm{g})$ & 92.78 & 90.89 & 103.60 & 128.21 & 60.57 & 59.27 & 48.05 & 170.31 & 178.72 & 46.31 & 111.63 & 130.31 \\
\hline$\eta(\%)$ & 3.96 & 16.09 & 8.65 & 3.98 & 18.84 & 8.93 & 14.98 & 6.77 & 4.08 & 6.45 & 7.24 & 2.40 \\
\hline DF & 1.04 & 1.19 & 1.09 & 1.04 & 1.23 & 1.10 & 1.18 & 1.07 & 1.04 & 1.07 & 1.08 & 1.02 \\
\hline
\end{tabular}

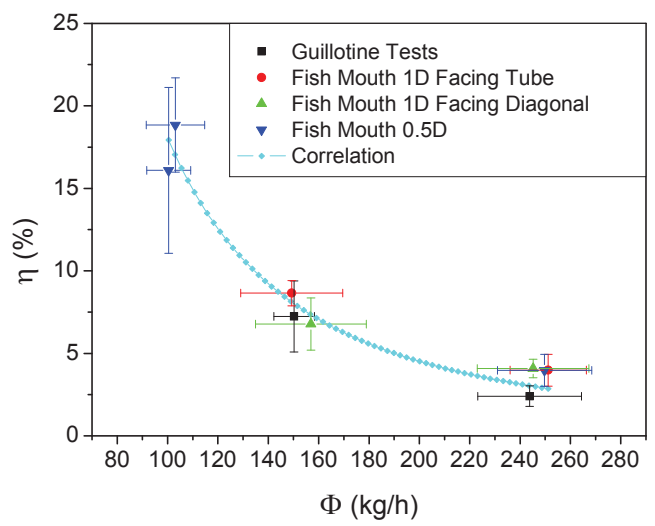

Fig. 3 Mass retention efficiency as a function of the inlet. EU-SGTR tests (Herranz et al., 2006)

The extension of the SGTR experiments was the Ciemat Aerosol Artist Tests (CAAT) campaign performed within the ARTIST project (Sánchez-Velasco et al., 2010). It consisted of 13 guillotinetests focused on the effect of the flow rate and of the particulate nature on the aerosol retention. To do so the experimental matrix was based on two main variables: the mass flow rate and the particle type (TABLE 1).

The former was varied from $75 \mathrm{~kg} / \mathrm{h}$ to $250 \mathrm{~kg} / \mathrm{h}$. For the latter a new type of particle was introduced, $\mathrm{SiO}_{2}$. It permitted setting the aggregation state (compact or fluffy) or the particle nature as variable. $\mathrm{SiO}_{2}$ particles are solid spheres while $\mathrm{TiO}_{2}$ are agglomerates of a large number of primary nano-particles. The size of particles was between 1 and $3 \mu \mathrm{m}$. The fact of 
using a new type of aerosol of $\mathrm{TiO}_{2}$ permitted amplifying the range of particles sizes of the database.

The main conclusions obtained from CAAT tests (TABLE 3) showed that particle nature strongly affects the retention capability of the bundle of tubes surrounding the breach. Under the same conditions, retention efficiency can range from low (5-25\%) to high (70-90\%) values if $\mathrm{TiO}_{2}$ or $\mathrm{SiO}_{2}$ are used respectively. Beyond the collection efficiency, particle nature also influences the distribution of deposit surface density throughout the tube bundle. In particular, major differences have been observed regarding profile and structure of deposits on the tubes facing the breach (Sanchez-Velasco et. al., 2010).

TABLE 3 CAAT results

\begin{tabular}{|c|c|c|c|c|c|c|c|c|c|c|c|c|c|}
\hline Test & 1 & 2 & 12 & 3 & 4 & 5 & 6 & 7 & 8 & 9 & 10 & 11 & 13 \\
\hline Particle nature & $\begin{array}{c}\mathrm{TiO}_{2} \\
\text { (Deg) }\end{array}$ & $\begin{array}{c}\mathrm{TiO}_{2} \\
\text { (Deg) }\end{array}$ & $\begin{array}{c}\mathrm{TiO}_{2} \\
(\mathrm{Deg})\end{array}$ & $\begin{array}{c}\mathrm{TiO}_{2} \\
(\mathrm{Nph})\end{array}$ & $\begin{array}{c}\mathrm{TiO}_{2} \\
(\mathrm{Nph})\end{array}$ & $\begin{array}{c}\mathrm{TiO}_{2} \\
(\mathrm{Nph})\end{array}$ & $\mathrm{SiO}_{2}$ & $\mathrm{SiO}_{2}$ & $\mathrm{SiO}_{2}$ & $\mathrm{SiO}_{2}$ & $\mathrm{SiO}_{2}$ & $\mathrm{SiO}_{2}$ & $\mathrm{SiO}_{2}$ \\
\hline$\Phi(\mathrm{kg} / \mathrm{h})$ & 93.4 & 225.0 & 145.0 & 99.7 & 169.0 & 125.0 & 105.8 & 148.4 & 183.7 & 133.9 & 167.1 & 237.0 & 81.4 \\
\hline$\Delta \mathrm{p}_{\text {breach }}$ (bar) & 0.2 & 1.4 & 0.5 & 0.1 & 1.2 & 0.2 & 0.6 & 0.2 & 0.5 & 0.1 & 0.5 & 0.8 & $<0.1$ \\
\hline $\mathrm{C}_{\text {in }}\left(\mathrm{mg} / \mathrm{Nm}^{3}\right)$ & n.a. & n.a. & n.a. & n.a. & 744.7 & 1506.2 & n.a. & 42.1 & 344.2 & 426.1 & 266.5 & 201.4 & 947.0 \\
\hline $\mathrm{C}_{\text {out }}\left(\mathrm{mg} / \mathrm{Nm}^{3}\right)$ & 304.9 & 85.8 & 178.0 & 1564.2 & 561.5 & 981.8 & 30.5 & 12.8 & 42.2 & 46.2 & 22.5 & 10.9 & 151.6 \\
\hline $\operatorname{AMMD}_{\text {In }}(\mu \mathrm{m})$ & 3 & 1.8 & 1.3 & 1.1 & $0.9-1.6^{\mathrm{II}}$ & 1.1 & 1.4 & 2.3 & 1.2 & 1.5 & 1.3 & 1.3 & 1.3 \\
\hline $\mathrm{GSD}_{\text {In }}$ & 2.9 & 2.9 & 2.8 & 4.8 & 4.8 & 3.8 & 3 & 3.1 & 3.3 & 4.2 & 6.1 & 4.8 & 2.8 \\
\hline $\mathrm{m}_{\text {ret }}$ (g) & 5.30 & 1.29 & 2.82 & 17.46 & 10.26 & 9.22 & 2.39 & 0.86 & 28.27 & 69.72 & 30.11 & 8.93 & 32.45 \\
\hline $\mathrm{m}_{\text {out }}(\mathrm{g})$ & 13.98 & 8.23 & 17.34 & 92.68 & 64.98 & 49.15 & 1.62 & 0.94 & 5.34 & 4.32 & 2.29 & 2.10 & 7.50 \\
\hline$\eta(\%)$ & 27.48 & 13.53 & 14.00 & 15.85 & 13.64 & 15.79 & 59.47 & 48.03 & 84.11 & 94.16 & 92.94 & 80.93 & 81.24 \\
\hline
\end{tabular}

The decreasing tendency of the retention efficiency with the gas mass flow rate found in SGTR was validated with the CAAT tests (Fig. 4). A correlation involving some of the anticipated phenomena was developed. It enlarges the number of parameters taken into account in the expression developed during SGTR (Sánchez-Velasco et al., 2010). 


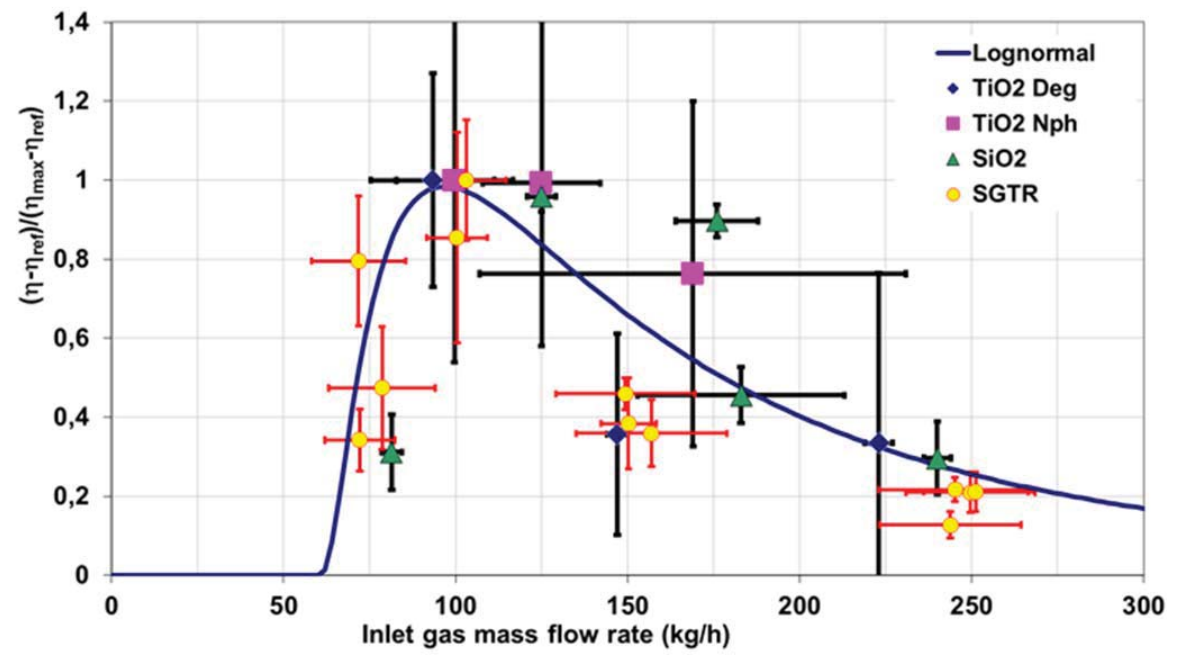

Fig. 4 Mass retention efficiency as a function of the Re numbers. EU-SGTR and CAAT tests

$$
\eta(\%)=\frac{a_{4}}{\sqrt{2 \pi} \cdot\left(\phi-a_{1}\right) \cdot a_{2}} \exp \left(-\frac{\left(\operatorname{Ln}\left(\frac{\phi-a_{1}}{a_{3}}\right)\right)}{2 a_{2}^{2}}\right)+\psi
$$

Where $\mathrm{a}_{1}, \mathrm{a}_{2}$, $\mathrm{a}_{3}$ are known as the location, scale and the shape parameters, respectively, and $\mathrm{a}_{4}$ is a multiplicative factor (Sánchez-Velasco et al., 2010). According to the expression found, once the gas mass flow rate becomes higher than around $100 \mathrm{~kg} / \mathrm{s}$, particle resuspension reduces the net particle on-tube deposition. Anyway, the quantitative effect of the gas mass flow rate was found to be of secondary significance as compared to the particle nature one.

To be able to apply the EU-SGTR and ARTIST experimental results to source term assessment, the ARI3SG model was developed to calculate the aerosol retention in the break vicinity under water-empty conditions (Herranz and Lopez, 2012; Lopez and Herranz, 2012). It is a semiempirical, Langragian model based on the filter-concept approach. It was built to compute retention efficiency according to dominant aerosol phenomena and gas fluid-dynamics underneath (López del Prá, 2012).

ARTIST2 is the natural continuation of the ARTIST project. This project seeks to complete the database and model development by applying lessons learnt in EU-SGTR and ARTIST. Once again, CIEMAT participated in the Phase II with the aim of exploring the effect of the variables still unknown and validating previous observations. 
Regarding a vertical steam generator arrangement, the PSI conducted a remarkable Phase IIcampaigns mainly within the ARTIST and ARTIST-2 projects. In total 14 tests were conducted in the ARTIST facility (Lind et al., 2011). These tests used guillotine and fish-mouth broken tubes, $\mathrm{TiO}_{2}, \mathrm{SiO}_{2}$ and DEHS particles and addressed aerosol retention under very high velocities (Lind et al., 2012). These experiments allowed comparing CIEMAT and PSI results to check the scale effect on the results (PSI bundle had about double number of tubes that CIEMAT's).

\subsection{Background on Acoustic Aerosol Agglomeration}

\section{Systems}

\subsubsection{Historical view and research framework}

Current NPPs are furnished with safeguards based on the Design Basis Accident (DBA) and some extensions to cope with accidents beyond the design bases. So, there are a number of mitigation systems within a NPP, both to accommodate the energy released and to deplete most of potential radioactive emissions to the environment. Nevertheless, after the stress tests that followed the Fukushima-1 accident, the interest in Filtered Containment Venting Systems and even other mitigation systems has become of outstanding importance in nuclear safety (OECD/NEA/CSNI, 2014).

With the objective of building up an experimental sound database to explore potential enhancement of existing source term mitigation devices and to demonstrate the ability of innovative systems to achieve even larger source term attenuation, the PASSAM (Passive and Active Systems on Severe Accident Source Term Mitigation) project (2013-2016 EU-7th Framework) has been arranged (Albiol et al., 2012). Heavily relying on experiments, its activities are focused on: degraded conditions of NPP operation, source term composition effects and long term behaviour. Hence, the PASSAM project might provide new data on the capability and reliability of a number of systems related to source term mitigation, including Filtered Containment Venting Systems (FCVS): aqueous ponds, sand filters, high pressure sprays, acoustic agglomerators, electrostatic precipitators, new trapping materials and combinations of different methods (Herranz et al., 2013). The acoustic agglomeration systems would induce particle agglomeration as result of the application of high intensity acoustic fields through a gas. It might be a pre-conditioning phase for the enhancement of the filtration efficiency of conventional filtration systems.

There are no previous studies on the application of the acoustic agglomerator (i.e. a chamber equipped with plate transducers able to generate a constant acoustic field) in the nuclear industry. CSIC and CIEMAT collaborated to integrate a specially designed acoustic chamber within the PECA vessel in LASS at CIEMAT, called PECA-MSAA (Mitigative System Acoustic Agglomerator) facility. The present work is focused in the study the application of this system under scenarios postulated within a severe accident. 


\subsubsection{State of the Art on Acoustic Agglomeration systems}

High efficiency removal of fine aerosols (i.e. particle diameter under $2.5 \mu \mathrm{m}$ ) from different kind of emissions is an issue difficult to solve by conventional separation technology. Particle agglomeration processes via the application of sound waves through air might have an important role to play in cutting down the concentration of solid and liquid particles from exhaust gases. High-intensity acoustic fields applied to an aerosol may, in fact, induce interaction effects among suspended particles, giving rise to successive collisions and agglomerations resulting in larger particles that can be more removed or precipitated. This change in the particle size distribution helps the precipitation of the particles and improves the collection efficiency of conventional filter systems (cyclone filters, sedimentation chambers, granular beds, electrostatic precipitators, wet scrubbers, bag houses, etc.) (L. E. Herranz et al., 2014).

During the beginning of the $20^{\text {th }}$ century, the acoustic agglomeration (Mednikov, 1965) process started to be experimentally investigated (Patterson and Cawood, 1931). It has been studied extensively over many years to understand its basic mechanisms. Several researchers as Brandt, Mednikov, Rozenberg or Timoshenko (Brandt et al., 1936; Mednikov, 1965, Rozenberg, 1973; Timoshenko et al., 1976) among others have greatly contributed to this objective. A variety of mechanisms have been suggested to be involved in the process. At present, it is generally accepted that orthokinetic and hydrodynamic interactions are the predominant mechanisms, while other effects, such as streaming and turbulence, may also play an important role in promoting particles interactions.

An orthokinetic interaction occurs between two or more suspended particles of different sizes when they are located within the displacement amplitude due to the sound field. The particles vibrate with different amplitudes and phases that results in a differential motion that greatly increases the probability of collision and, therefore, of agglomeration.

The second key mechanism influencing the acoustic agglomeration of particles in suspensions is the action of the hydrodynamic forces on the particles (Hoffmann and Koopmann, 1996; Shaw and Tu, 1979; Temkin, 1994). Intense acoustic fields generate hydrodynamic forces that induce interactions between particles separated at distances much larger than their respective acoustic displacements. Such interactions can be mainly due either to viscous asymmetries in the flow field around the particles (i.e. Acoustic Wake Effect, AWE) and/or to nonlinear effects between particle scattering waves and the incident acoustic field (Radiation Pressure Effect).

Practical applications of the agglomeration process have been synthetized within the State-OfThe-Art Report Technical Bases for Experimentation on Source Term Mitigation Systems (Herranz et al., 2013). In summary, development of the acoustic agglomeration systems started in the late 40's, with the powerful air-jet sound generators (sirens).The Ultrasonic Corporation discussed the design of full-scale acoustic agglomerators using the sirens driven by compressed air. During the World War II, attempts were made in the USA to disperse fog on airport runways by using acoustic sirens. 
In countries such as the Soviet Union and Japan experimental and theoretical studies continued through the 50's and 60's. An excellent report covering the theoretical, experimental and applied work developed up to the early 60's was published in the Soviet Union (Mednikov, 1965). The interest for the agglomeration technology revived in the USA and Canada from the 70 's to the beginning of the new century when stringent air pollution legislation for particle removal was enacted (Hoffmann, 1997; Hoffmann and Koopmann, 1996; Scott, 1975; Shaw and $\mathrm{Tu}, 1979$; Song et al., 1994).

In Europe, since the early 70's to the beginning of the XXI century, two main groups, GallegoJuárez and his co-workers at the Spanish National Research Council (CSIC) in Spain (GallegoJuárez et al., 1999, 1979; González et al., 2002, 2001; Riera et al., 2005; Riera-Franco de Sarabia et al., 2003; Riera-Franco de Sarabia and Gallego-Juárez, 1986) and Magill and his co-workers at the Institute for Transuranium Elements (ITU) in Germany (Magill et al., 1989), conducted experimental and theoretical studies of acoustic agglomeration. Their joint studies (1989-1993) were conducted under static and dynamic conditions with micron and submicron aerosols (Magill et al., 1992). They developed an innovative system by applying a new type of airborne high-efficient and high-directional power piezoelectric transducer as a sound source. It was the stepped plate transducer (appendix 1). The structure essentially consists of a vibrating circular plate with a stepped profile driven at its center by a piezoelectrically activated vibrator. 



\section{Chapter 2}

\section{Investigation setting out: motivation,}

\section{objectives and scope}

This thesis is a contribution to the technical understanding of the possible source term mitigation in two postulated severe accident scenarios. Thus, this research has been divided into two parts, each one dedicated to one scenario. The first part, devoted to aerosol retention in the SG under dry conditions, is framed within the severe accident SGTR sequence. The second one is enclosed in the filtered containment venting and investigates the behavior of the aerosols under the effect of an ultrasonic field.

\subsection{Motivation}

The EU-SGTR and ARTIST projects have demonstrated that even in the absence of water in the secondary side of a failed steam generator, a radioactivity release would be mitigated on its way through the steam generator during a severe accident SGTR sequence. The complex structure and large surface area of the break stage secondary side of a failed steam generator makes it feasible to remove a fraction of gas-borne particles from the carrier gas on their pathway to the environment. In particular, they showed that the break stage is highly relevant for an aerosol retention of large particles $\left(\mathrm{d}_{\mathrm{p}} \geq 1 \mu \mathrm{m}\right)$. On one side, gas flowing at high velocity would be capable of making a fraction of particles to deposit onto the tubes near the breach. On 
the other, particles exiting this stage would show key properties such as size, substantially different from those of incoming particles. Both facts would remarkably affect the source term, and consequently deposition in upper stages and components.

The specific experimental campaigns mentioned above (EU-SGTR and CAAT) addressed effects of variables that directly influence the aerosol retention, as the gas mass flow rate and particle nature. However, the need of enlarging the data base as well as the un-fulfilled characterization of the particle nature and the breach characteristics (i.e., size and shape) influence on the aerosol retention, promoted the launch of this research. The present investigation get insights into the actual retention/decontamination capability of the dry SG during severe accident SGTR sequences by performing experimental parameter studies in a mock-up of the break stage of the SG using aerosol particles with sizes close to the prototypical ones (i.e. around $1 \mu \mathrm{m}$ ) (Allelein et al., 2009; Kissane, 2008).

An important interest on the venting systems arose from the unfortunate Fukushima accident. Even though it is still very early to draw final lessons from it, some insights into nuclear safety have been gained. Indeed, among the main issues presently being seriously considered as potential plant updates are the enhancement of radioactive trapping and filtered containment venting.

The containment venting has been an accident management strategy in nuclear power plants in countries such as France or Sweden. It consists of venting the containment to the atmosphere through specific pipes, so that a fatal structural damage is prevented. Despite the benefit of keeping containment integrity, the venting entails release of radioactive material to the environment. In order to minimize this radioactive load the contaminated gas is filtered through systems based on diverse technologies that basically are classified as dry or wet venting and the a combination of both.

The agglomeration of particles by acoustic fields would have the potential of enhancing mitigation in the two scenarios described above. On one hand, if acoustic systems are installed in the containment, submicron particles would result in micronic ones that would be much faster depleted by sedimentation (settling velocity is proportional to aerodynamic diameter squared). On the other, if they are implemented in the venting line to a wet/dry containment filter, they would largely improve the performance of the filtration devices by enlarging particles, since efficiency of those systems show a minimum in the range of 0.1 to $0.3 \mu \mathrm{m}$ (Albiol et al., 2012). Therefore, since the efficiency of the acoustic systems has been demonstrated in a variety of conditions, the challenge would be to extend the already proven working domain to those conditions characterizing the scenarios above and to optimize its operation accordingly.

\subsection{Objectives}

This work is an experimental research on nuclear aerosols in case of a severe accident centered on the aerosol retention in the two above postulated scenarios. The general objective is to build up a sound experimental database on the aerosols behavior under different boundary conditions. One of the scenarios is focused on the aerosol retention in the break stage of the secondary side of a steam generator during severe accident SGTR sequences. It would help understanding the physics behind the depletion process to assist its modelling. The other scenario is focused on the particle growth by an ultrasonic agglomeration system. Such a 
system could be an innovative technology to be implemented for the enhancement of the particulate source term mitigation during the filtered containment venting process in a severe accident.

Regarding the severe accident SGTR sequence research, the EU-SGTR and ARTIST projects showed that, under dry conditions, a tube breach would result in an aerosol flow stream emerging from the primary circuit into the secondary one. The particles carried by the gas would deposit on the tubes near the breach by different depletion mechanisms. These mechanisms are extremely dependent on the flow rate across the breach and the particle nature. The ARTIST project also showed that tube dependent variables could influence the aerosol retention. Regarding the SG, a key variable that could play a role in the aerosol depletion is tube vibration. Thus, the specific objectives for this thesis are:

- To assess the effect of breach characteristics, i.e. size and shape, on aerosol retention and aerosol size distributions (i.e. incoming and outgoing of the break stage).

- To set the effect of the particle nature on the aerosol retention.

- To investigate the effect of the tube vibration on the retention of aerosols.

No previous studies have been developed on the growth of prototype severe accident nuclear aerosols with ultrasonic traducers. The precise objectives of the investigation of the acoustic aerosol agglomeration systems for this thesis are:

- To assess the effect of the ultrasonic acoustic field on the particle growth

- To set the effect the particle nature and gas mass flow rate on the growth of aerosols.

The tests required to set-up, develop and integrate the ultrasonic agglomeration chamber within the PECA vessel of the LASS facility and find out the best operational conditions of the system.

\subsection{Scope}

The first stage of this thesis is an aerosol retention study during the SGTR severe accident sequence under dry conditions, which is the most unfavorable scenario from the safety point of view. Within the general boundary conditions of the SGTR sequence, the scope of the experimental campaigns developed (CAAT2 and SET) achieve the following items:

- The most common break types in a SG (Guntay et al., 2000): fish-mouth and guillotine prototypic breaches; three sizes of fish-mouth breaches: $1 \mathrm{D}, 0.5 \mathrm{D}$ and $0.25 \mathrm{D}$ (i.e. cross section areas corresponding to $1,0.50$ and 0.25 the transverse cutting of the tube)

- Three particle types different in nature: $\mathrm{TiO}_{2}$ fractal like agglomerates, solid and dense spheres of $\mathrm{SiO}_{2}$ and agglomerates of a few rough spheres of $\mathrm{Cu}$ with sizes close to the one expected during a severe accident (Arreghini et al., 2000). It is worth to point out that the nature of the actual particles in case of a severe accident is still not well settled. To overcome this drawback, the chosen particles have a nature (physical features) that would enclose the behaviour of those aerosols in case of severe accident, no matter their 
composition.

- A gas mass flow rate ranged in the lower bound of the sequence flow rate conditions, i.e. inlet gas mass flow rate through the breach up to $200 \mathrm{~kg} / \mathrm{h}$.

- A scaled down bundle $\left(0.33 \times 0.33 \mathrm{~m}^{2}\right)$ comprising 121 straight tubes with an outer diameter of $19.08 \mathrm{~mm}$. The scaling ratio with respect the real $1136 \mathrm{MWth}$ PWR SG (Swiss power Plant Beznau), for the number of tubes and free flow area is approximately 1:45.

The second part of the thesis investigates the aerosol growth and retention by the ultrasound acoustic system. It has been taken the conditions foreseen the FCVS operation as a reference. It is worth noting that the conditions are not unique since the FCVS performance requirements are different depending on the country approach (OECD/NEA/CSNI, 2014). The scope of this part is centered on:

- Two particles type different in nature: $\mathrm{SiO}_{2}$ and $\mathrm{TiO}_{2}$, with 3 particles diameters of $\mathrm{SiO}_{2}$ $(0.3 \mu \mathrm{m}, 1 \mu \mathrm{m}$ and $2.5 \mu \mathrm{m})$ and mixture of several proportions of the particles.

- An aerosol concentrations of approximately $5 \cdot 10^{-3} \mathrm{~kg} / \mathrm{m}^{3}$.

- Three gas mass flow rates: $12 \mathrm{~kg} / \mathrm{h}, 50 \mathrm{~kg} / \mathrm{h}$ and $100 \mathrm{~kg} / \mathrm{h}$. They are ranged in the lowest bound of the anticipated FCVS boundary conditions due to the facility limitations.

- A linear array of two stepped-plate high-intensity piezoelectric transducers working at $21 \mathrm{kHz}$ placed within the $1 \mathrm{~m}$ high acoustic chamber with $0.5 \times 0.45 \mathrm{~m}^{2}$ cross section.

\subsubsection{Thesis approach}

This thesis is structured in 6 chapters as follows: "Introduction", "Investigation setting out: motivation, objectives and scope", "Experimental facility", the "Ciemat Aerosol Artist Tests" where the CAAT2 and SET experimental campaigns took place, the "AAA Tests" and the last one dedicated to the "Conclusions and future work". Chapters 1, 2,3 and 6 are common to the experimental phases, which are the main body of this research. It is worth to mention that the PECA facility has been used in all the experimental campaigns. The facility was built for the generation and characterization of aerosols which is the common fact of all the experimental tests performed. However, each campaign needed its particular design and arrangement. The particularities associated for each type of test are presented in the chapter of the corresponding experimental campaign.

To accommodate the anticipated objectives, this thesis has been divided into three experimental campaigns:

- Experimental campaign I: Devoted to the CAAT2 (Ciemat Aerosol ARTIST \# 2 tests). Integral tests were aimed to study and validate effects of the three key variables on the aerosol retention within the break stage tube bundle: particle nature, breach shape and size and gas mass flow rate. The precise objectives of each one are: 
$\checkmark$ Particle nature: To derive a correlation based on non-dimensional numbers dependent on particle properties.

$\checkmark$ Breach shape: To establish a quantitative (net retention) and qualitative (deposition pattern) related to the breach shape.

$\checkmark$ Breach size: Based on a well-defined breach shape (fish-mouth prototype break) of different sizes, to find out a dependence of this variable with the collection efficiency.

$\checkmark$ Flow rate: To validate the results and correlation developed in the previous campaigns.

The CAAT2 campaign required an adaptation of the PECA-SGTR set-up.

- Experimental campaign II: Devoted to the SET (Separate Effect Tests). The key parameter of this campaign is the tube vibration. The precise objectives of this campaign are:

$\checkmark$ To determine a dependence of the aerosol retention within the bundle due to the tube vibration.

$\checkmark$ To determine and characterize a vibration pattern of the tubes under "normal" and "fixed" conditions.

To do so, a system which attenuates the vibration of the tubes has been designed and manufactured.

All these tests have the common objective of extending the database generated by CIEMAT in the EU-SGTR and ARTIST projects to support the SA modelling developments.

- Experimental campaign III: Devoted to the AAA (Aerosol Acoustic Agglomeration Tests). An ultrasonic acoustic chamber has been especially designed for this campaign. This investigation is focused on the analysis of the MSAA system. The tests are aimed to its assessment as a mitigative system. Thus, the objectives of the experimental campaign are:

$\checkmark$ To define and determine experimental factors enclosing the particle growth and efficiency of the acoustic system.

$\checkmark \quad$ To evaluate the effect of the particle nature and gas mass flow rate variables on the efficiency of the acoustic system.

To do so, it was necessary to set up, develop and integrate the ultrasonic chamber (MSAA) in the PECA facility.

The MSAA was specially designed for the development of this set of experiments. A new set of devices and instrumentation from the aerosol generator to the ultrasonic characterization system was required. 



\section{Chapter 3}

\section{Experimental facility}

\subsection{Introduction}

The Laboratory for Analysis of Safety Systems (LASS) was built up in the late 80's within the so called LACE-España consortium. It was mainly designed around the PECA facility, a multipurpose facility that has been mostly used for aerosol studies. Since then, it has been involved in a good number of projects like LACE-España, where pool scrubbing experiments were carried out; GECI, where passive decontamination capability of the SBWR reactor was tested; and ARTIST's and the ongoing PASSAM project.

\subsection{The PECA facility description}

The present section introduces the PECA facility. The three experimental campaigns performed within this work, CAAT2, SET and AAA, have been developed experimentally here. Each experimental campaign was preceded by the facility setting up. As a result two configurations were specially designed for this purpose: the PECA-SGTR (for the CAAT2 and SET experiments) and the PECA-MSAA configuration (for the AAA tests). This section introduces the PECA under the configuration for the CAAT2 tests. 
The PECA facility is a medium-scale experimental plant designed for the characterization of aerosol behaviour studies under different hypothetical accident conditions. Fig. 5 shows a sketch of the facility in the configuration under which CAAT2 tests have been performed and Fig. 6 shows a partial view of LASS with the PECA vessel at the back.

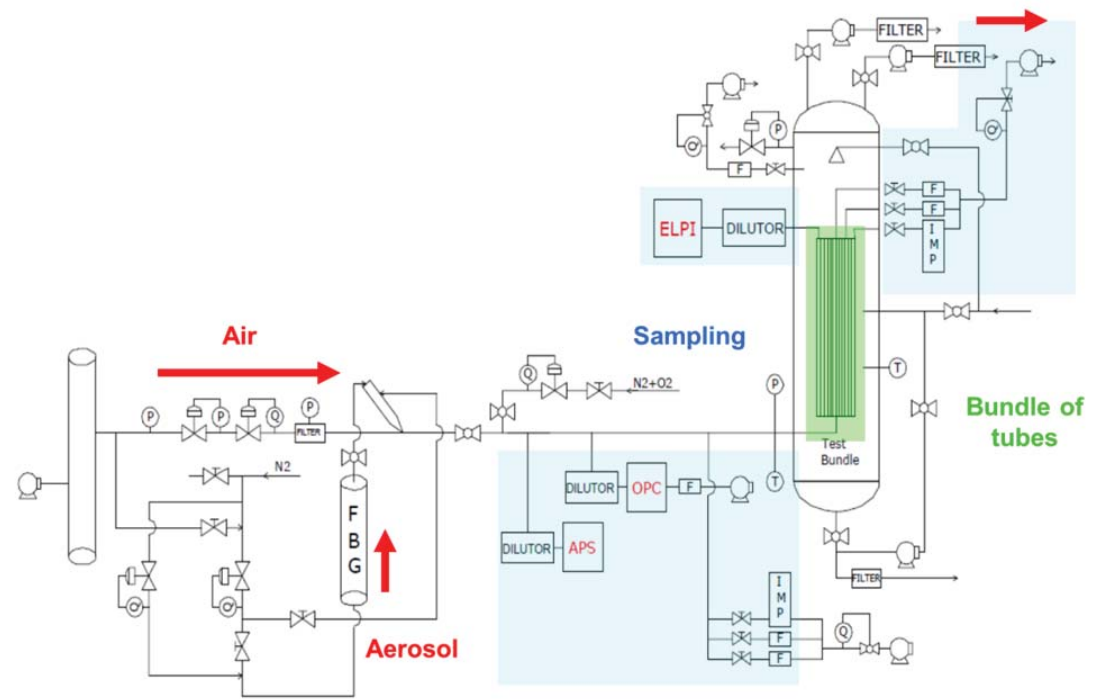

Fig. 5 Lay-out of the PECA-SGTR configuration for the CAAT2 and SET experimental campaigns

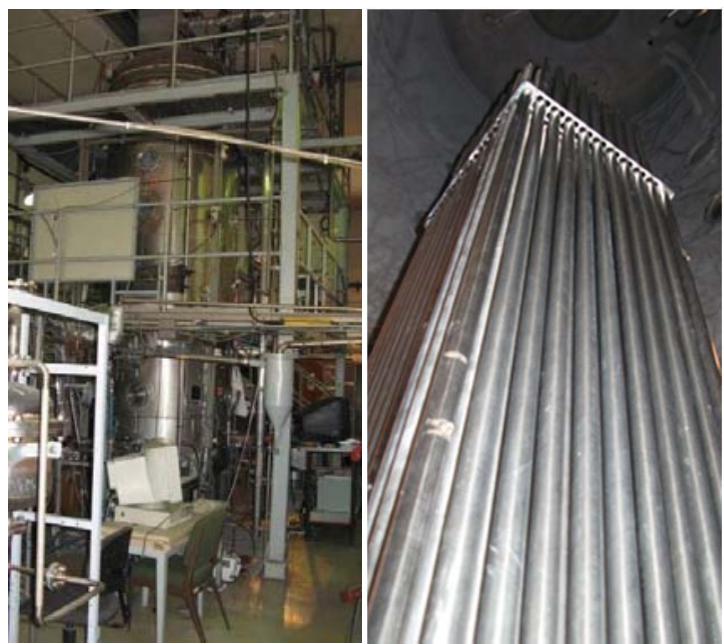

Fig. 6 The LASS facility with the PECA vessel at the bottom. Right: The tube bundle view 
The facility has been adapted to fit within the experimental requirements of the ARTIST-II project. The main updates were:

- A secondary side mock-up bundle in the vessel

- Aerosol devices (i.e. aerosol generators, particle sizers and counters, aerosol diluters) and instrumentation (flowmeters, manometers, pumps).

- Configuration of the piping net.

The PECA facility is made of several components: of a gas supply system, an aerosol generation device, an injection line, a vessel where the tube bundle is located, an exhaust line and a measurement system (i.e. sampling and instrumentation). Details of all of them are given in the text below.

\subsubsection{Gas supply system}

The gas supply system is composed of two sections, one for feeding the aerosol generator and the other for supplying air to the injection line. The former includes a cluster of eight gas bottles and the corresponding instrumentation for pressure and flow rate regulation. The gas used for particle generation is $\mathrm{N}_{2}$. The gas storage permits the injection up to $25 \mathrm{~kg} / \mathrm{h} \mathrm{N}$ seed flow at high pressure. The latter is basically an air station with an $18.5 \mathrm{~kW}$ compressor that maintains an air supply tank at pressure of 6 bar, a filtration system that keeps the air clean, and the associated measuring and controlling instrumentations. This system is able to provide up to 250 $\mathrm{kg} / \mathrm{h}$ of air with continuous pulses that, in average, are the set flow rate. The flow evolution is sinusoidal and stable even though it has been experimentally observed that the higher the flow rate, the larger the fluctuations around the mean value set (Fig. 7). Under $100 \mathrm{~kg} / \mathrm{h}$ the fluctuations are below those from the figure $(\leq \pm 5 \mathrm{~kg} / \mathrm{h}$ ). The results of the tests (either in the retention efficiency or particle growth) have not been affected by flow variations.

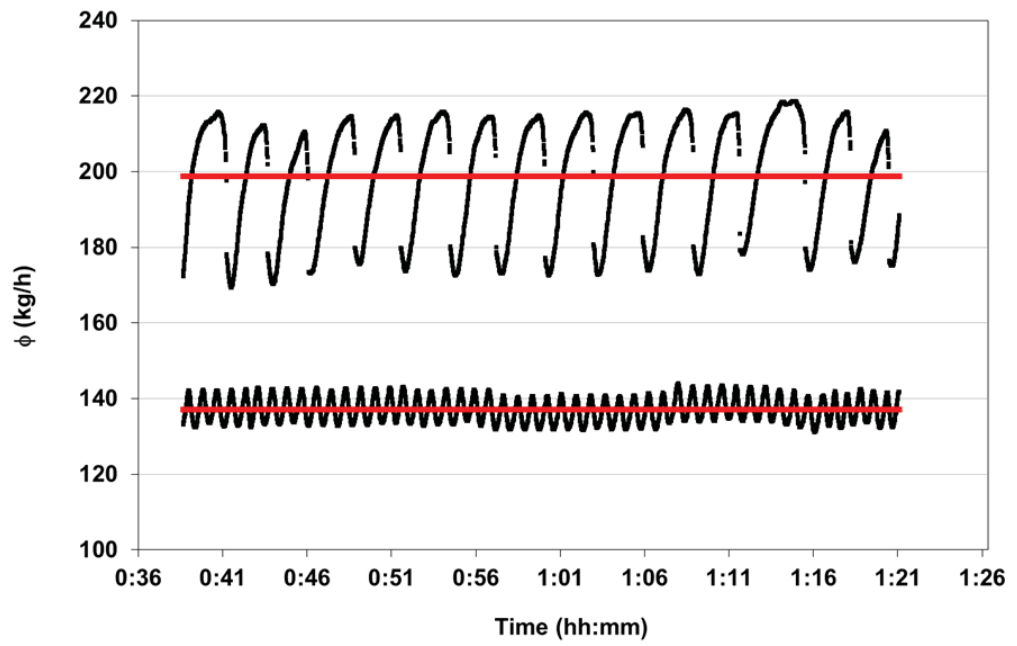

Fig. 7 Flow rate evolution 


\subsubsection{Fluid bed generator and bed material}

The aerosols generated in the CAAT2 and SET experimental campaigns were produced by a system based on the fluidized bed technology, so-called Fluidized Bed Generator (FBG). This technology enables production of relatively high aerosol concentration in a steady way.

Fig. 11 shows the details of the generator (FBG) of the LASS facility. In summary it consists of a straight cylinder of about $1 \mathrm{~m}$ high and $20 \mathrm{~cm}$ in diameter whose bottom is covered with beads (made of glass for $\mathrm{SiO}_{2}$ and $\mathrm{TiO}_{2}$ and of $\mathrm{Cu}$ for $\mathrm{Cu}$ fluidization) mixed with the powder to fluidize. The bottom plate of the FBG is a metal grid that can hold the bed particles in, but let nitrogen flow upward. When the gas passes through the diffusers, it enhances the flow distribution and homogenize the aerosol concentration inside the cylinder. To reduce electrical charging of the powder, the bed column is made of stainless steel and grounded by metal parts (Lind et al., 2010b). The top of the FBG is made of valves that control the pressure inside the vessel and the exit of the aerosols. The outlet of the FBG has been connected to a Venturi nozzle where the particles-laden nitrogen is mixed with an extra-air flow and particles speed up. As a consequence agglomerates like $\mathrm{TiO}_{2}$ are prone to get fragmented into smaller particles before joining the main gas stream. 


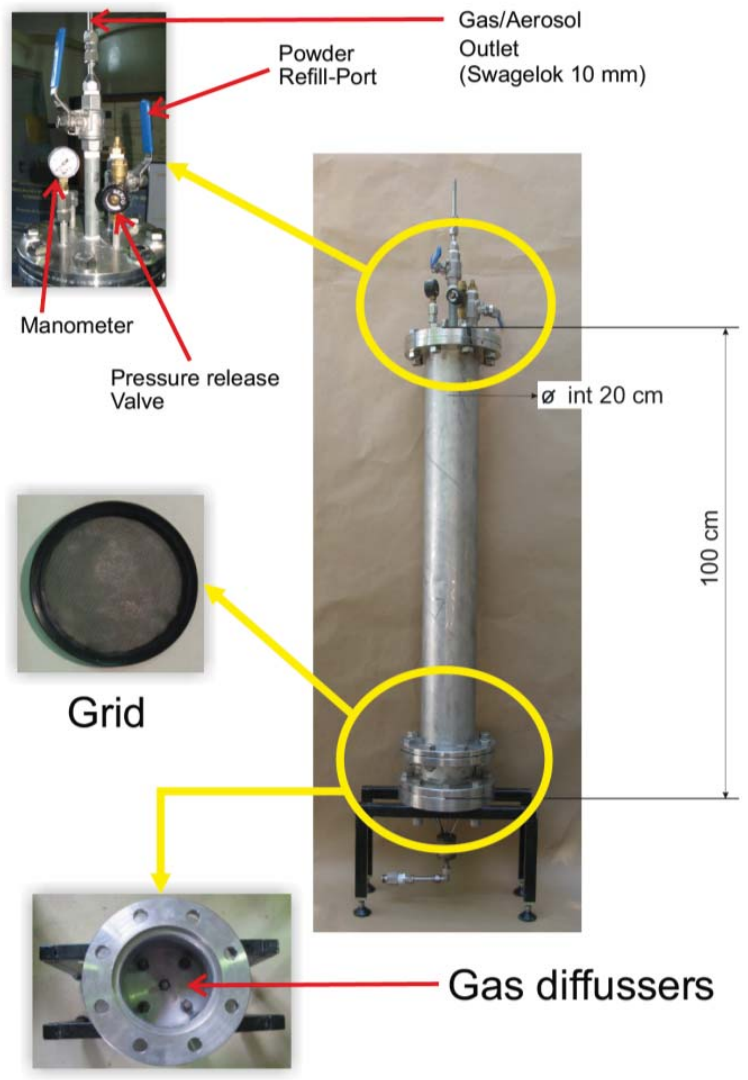

Fig. 8 Fluid Bed Generator

Fluidization of fine particles, particularly those fallen within the Group C of the Geldart classification (Geldart, 1973) is difficult. This group is characterized by particle sizes under $30 \mu \mathrm{m}$ and in any way, cohesive. This is the case of the $\mathrm{SiO}_{2}, \mathrm{TiO}_{2}$ and $\mathrm{Cu}$ particles. In order to improve the fluidization, besides of using stainless steel FBG, different types of particles have been used as bed material.

The bed material for $\mathrm{SiO}_{2}$ and $\mathrm{TiO}_{2}$ fluidization is composed of glass beads. They are spherical particles of silica of two sizes, i.e. $1 \mathrm{~mm}$ and $2 \mathrm{~mm}$ in diameter. Both sizes are mixed in proportions of approximately $1: 1$. In the case of $\mathrm{Cu}$, the particles of around $50 \mu \mathrm{m}$ in size were used (Fig. 9). The bed material is mixed with the aerosols in small quantities to enhance the fluidization process 

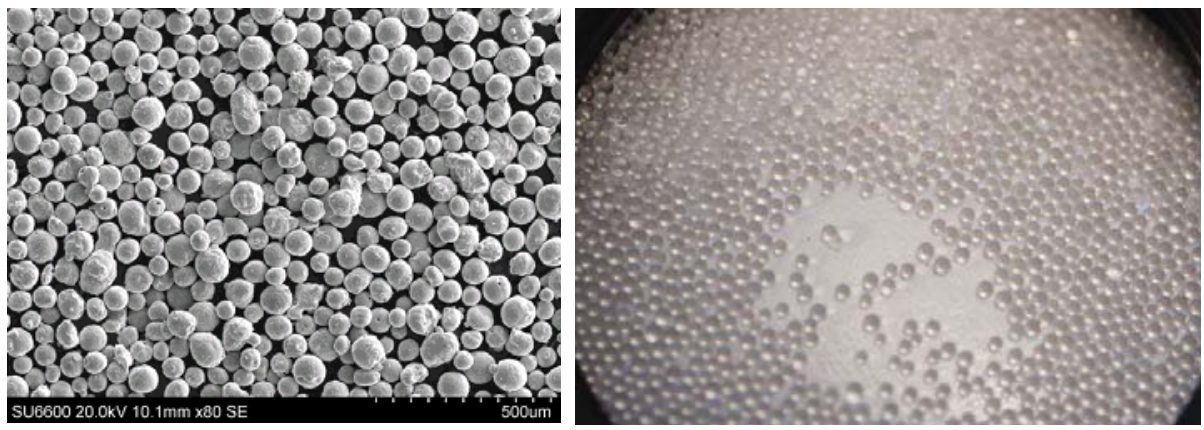

Fig. 9 Bed material for aerosol fluidization: Cu particles (left) and glass beads (right)

The key parameter of the FBG is the fluidization velocity. It should provide the best fluidization feasible for the highest concentration without dragging any glass bead out of the FBG. The optimum velocity has been found experimentally to be around $0.2 \mathrm{~m} / \mathrm{s}$, while the air stream injected to the Venturi nozzle increased the $\mathrm{TiO}_{2}$ speed to at least $0.6 \mathrm{~m} / \mathrm{s}$. To avoid plugging and channelling (Wang et al., 1998) the velocity has been increased in steps of approximately $0.05 \mathrm{~m} / \mathrm{s}$. Each step has been kept for at least one minute to let the bed expand.

\subsubsection{Injection line}

The particles generated with the FBG are injected into the main gas stream. The injection line is the pipe that drives the aerosol stream to the vessel (Fig. 10). Several control valves regulate and control the pressure and mass flow rate in the line (Fig. 11). Isokinetic samples coming out from the injection line permit to characterize the size distribution and concentration at the inlet of the vessel by different aerosol instrumentation.

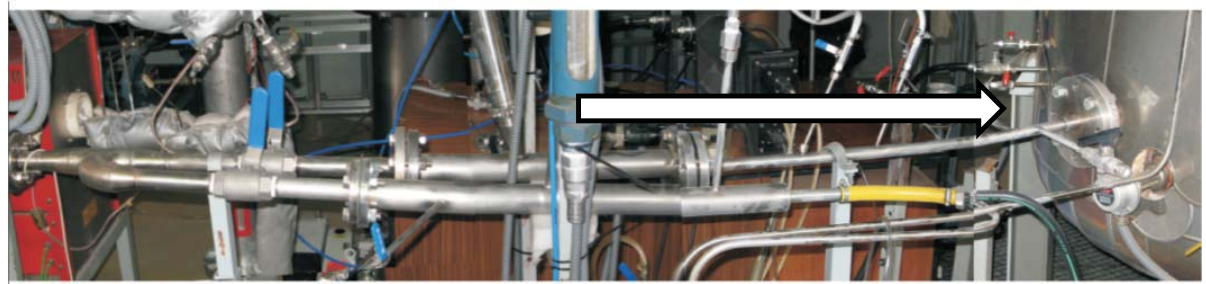

Fig. 10 Injection line entering into the PECA-vessel 


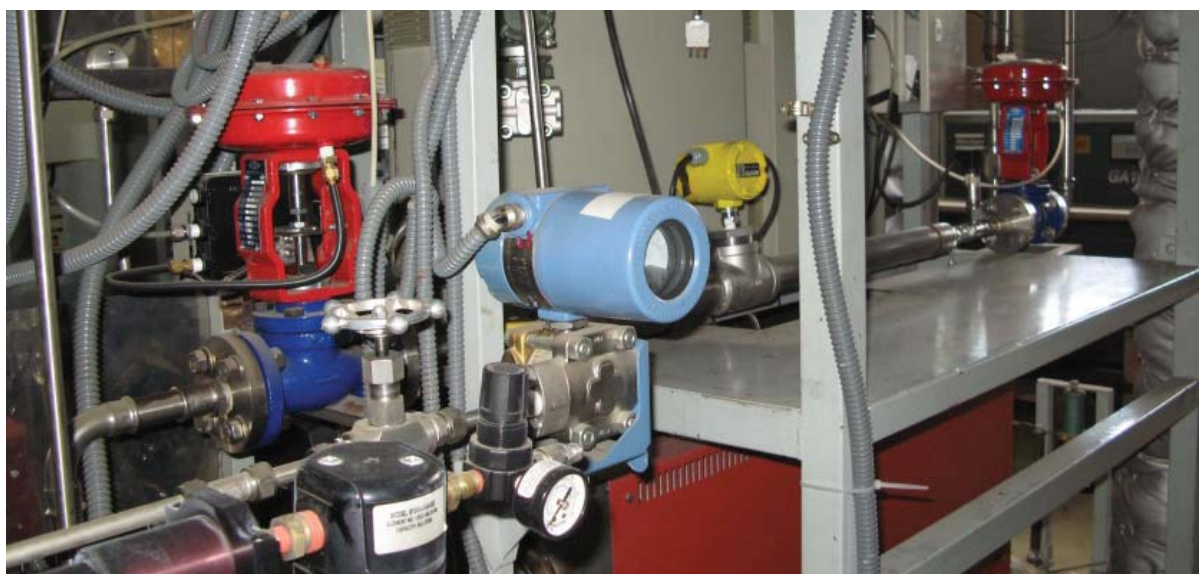

Fig. 11 Control valves (pressure and gas mass flow rate) of the injection line

\subsubsection{PECA vessel}

The vessel is a vertical cylinder with upper and lower hemispherical ends, $5 \mathrm{~m}$ in height and $1.50 \mathrm{~m}$ in diameter. It was designed under ASME VIII DIV-1 code requirements, and is capable to withstand pressure up to 3.5 bar and temperature up to $140{ }^{\circ} \mathrm{C}$ in normal operating conditions. It is made of stainless steel of $8.0 \mathrm{~mm}$ in thickness. The total volume is $8.4 \mathrm{~m}^{3}$ and its weight is 2.5 tons. The vessel is equipped with 26 glass windows which allow visual observation and also image acquisition of the phenomena occurring inside during a test.

The SG bundle is a scaled down mock-up of the tube bundle of a vertical steam generator. Specifically supplied by PSI (Paul Scherrer Institut), the structure is a squared arrangement hosting inside a total of 117 tubes plus four supporting rods placed at the corners. At the bottom of the structure there is a squared-shape plate $(330 \times 330 \mathrm{~mm})$ with a set of holes holding the tubes. The tubes are $1.5 \mathrm{~m}$ long, $16.07 \mathrm{~mm}$ and $19.05 \mathrm{~mm}$ in inner and outer diameter respectively, with a pitch to diameter ratio in the bundle of $\mathrm{p} / \mathrm{D}=1.4$. The bundle allows two possible locations of the broken tube, one placed just at the center of the structure and the other in the third row from the bundle edge mid-plane (i.e. T1 of the Fig. 26). The limited size of the full bundle was supported by CFD analyses (López del Prá et al., 2007) which strengthened confidence in the jet momentum dissipation in about 5 tube rows when the gas inlet mass flow rate was less than $250 \mathrm{~kg} / \mathrm{h}$. The whole structure is housed in a methacrylate frame and ends up with an upper plate simulating the separation between the break stage and the rest of the SG. The flow is injected into the broken tube through the base. Since the end of the tube is closed, the flow is forced to exit through the breach and to expand across the bundle. It is worth to point out that under real conditions a fraction of gas flows downstream the breach since the broken tube is not blockage. Nevertheless, as it is presented in section 4.3 the aerodynamic scenario has been designed to be as close as possible to the real SGTR one. 
The high-pressure and temperature that the tubes of the SG have to withstand during normal working conditions, lead to its degradation and sometimes to rupture. The most common shapes of tube breaches in the SGTR events are guillotine and fish-mouth (Fig. 12). The rupture size depends on how advanced the degradation process is.

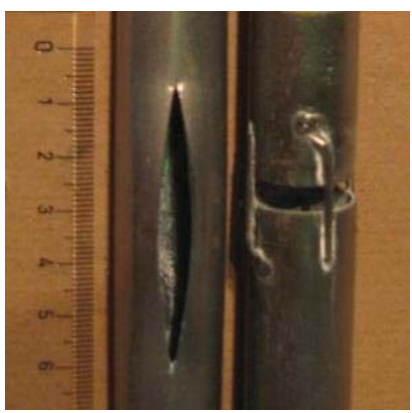

Fig. 12 Fish-mouth and guillotine breaches

The integral tests of the CAAT2 campaign were performed with the fish-mouth broken tube. Fig. 13 shows the three breaches tested: 1D, 0.5D and 0.25D, i.e., cross-sectional area equivalent to a $1,0.5$ or 0.25 a guillotine break (i.e., transversal section) in a postulated tube of $1 \mathrm{D}$, being D the tube diameter. Results have been compared with those from CAAT, performed under guillotine breach.

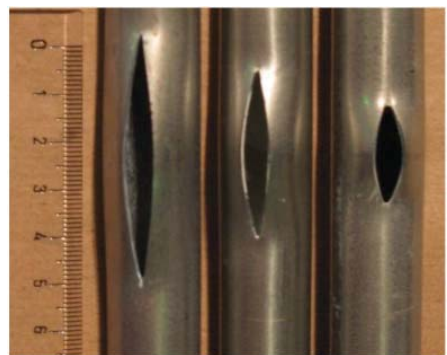

Fig. 13 Fish-mouth breaches: 1D, 0.5D, 0.25D

Normally, the breaches have been distinguished by their characteristic lengths (i.e., squared root of the cross-sectional area). Their size features are summarized in TABLE 4.

TABLE 4 Fish-mouth breaches features

\begin{tabular}{ll}
\hline Breach size & L $_{\text {breach }}(\mathrm{m})$ \\
\hline $1 \mathrm{D}$ & $1.69 \cdot 10^{-2}$ \\
$0.5 \mathrm{D}$ & $1.19 \cdot 10^{-2}$ \\
$0.25 \mathrm{D}$ & $0.84 \cdot 10^{-2}$ \\
\hline
\end{tabular}


Due to the fact that the jet leaving from a fish-mouth breach is confined to a small angle, loss of momentum is slower than for guillotine breaches. This fact recommends fish-mouth breaches to be located at a periphery position, so that gas jet can lose its initial momentum through the bundle.

\subsubsection{Exhaust line}

The exhausting line is a loop system with two radial turbine blowers with installed power of $4.4 \mathrm{~kW}$ implemented with bag filters that capture the particles remaining airborne beyond the bundle mock-up. The aerosol stream outgoing the vessel is exhausted with the turbines. The particles keep retained in the filters while the clean air is released to the free atmosphere.

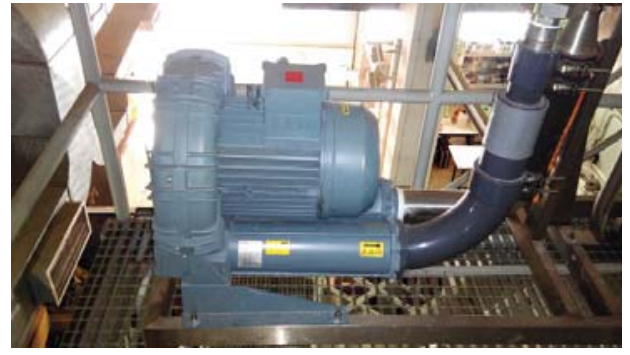

Fig. 14 Radial turbines (up) and filtration system (right)

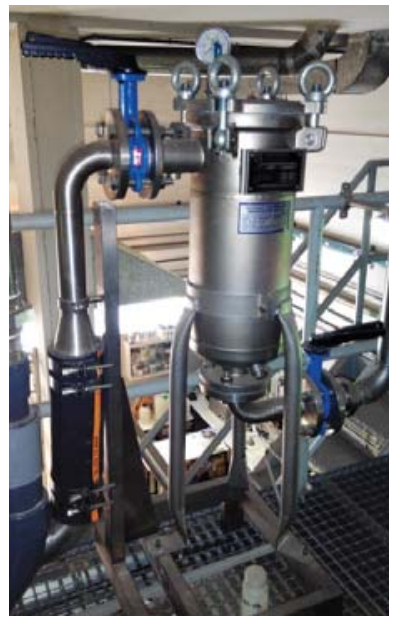

\subsubsection{Facility Updates}

The updates of the PECA facility are focused on the injection line. The new configuration is made up of a piping network with ball and electronic valves that allow introducing the particles whatever their nature, i.e., if they need to be de-agglomerated or not. The arrangement has been modified in such a way that a unique piping system drives the aerosols to the injection line. The mode of particles ejection varies depending on its nature. Three types of aerosols have been tested: agglomerates formed from primary $\mathrm{TiO}_{2}$ nano-particles; and spherical, single- or fewparticle aggregates of $\mathrm{SiO}_{2}$ and of $\mathrm{Cu}$.

$\mathrm{TiO}_{2}$ coalesce in big agglomerates after its fluidization. To reduce their size they are speeded up by increasing the carrier gas flow ejected with a Venturi nozzle. For high velocities (over 100 $\mathrm{m} / \mathrm{s}$ ) it has been demonstrated that the average particle size at the outlet of the tube was significantly smaller than at the inlet due to particle de-agglomeration (Ammar et al., 2012; Ihalainen et al., 2014; Lind et al., 2010a). To do so, a fraction of the main air gas stream is bypassed from the exit of the compressor to the Venturi nozzle. 
The piping net drives the streams along different paths by opening/closing ball valves. Different ways have been designed to let the particles enter into the main line. For $\mathrm{TiO}_{2}$, the $\mathrm{N}_{2}$ is introduced trough a 0-100 lpm electronic valve, while that for $\mathrm{SiO}_{2}$ and $\mathrm{Cu}$ particles, a bigger valve ranging between $0 \mathrm{lpm}$ and $700 \mathrm{lpm}$ is used. It is worth to note that to $\mathrm{TiO}_{2}$ particles the extra air gas flow for de-agglomeration is used. In any case, the pressure drop between the injection point and the main line has to be positive. In other words, the aerosol flow needs to overpass the pressure loss at the main line.

This system covers the following necessities:

- Injection of $\mathrm{SiO}_{2} / \mathrm{Cu}$ : The particles enter the main stream trough the Venturi nozzle pulled by $\mathrm{N}_{2}$. Acceleration of $\mathrm{SiO}_{2}$ and $\mathrm{Cu}$ is not required.

- Injection of $\mathrm{TiO}_{2}: \mathrm{TiO}_{2}$ needs to be accelerated. As a matter of fact the main stream is bypassed up to the entrance of the Venturi nozzle and mixed with particles pulled by $\mathrm{N}_{2}$.

Fig. 15 and Fig. 16 show both configurations with details of all ball valves and electronic valves that allow automation of the injection process. In blue, the way of the air is shown; while the red line corresponds to the $\mathrm{N}_{2}$ stream. Black means that the valves are closed and finally, purple, shows the carrier gas which is the mixture of air and $\mathrm{N}_{2}$, when the particles are introduced into the bundle. 


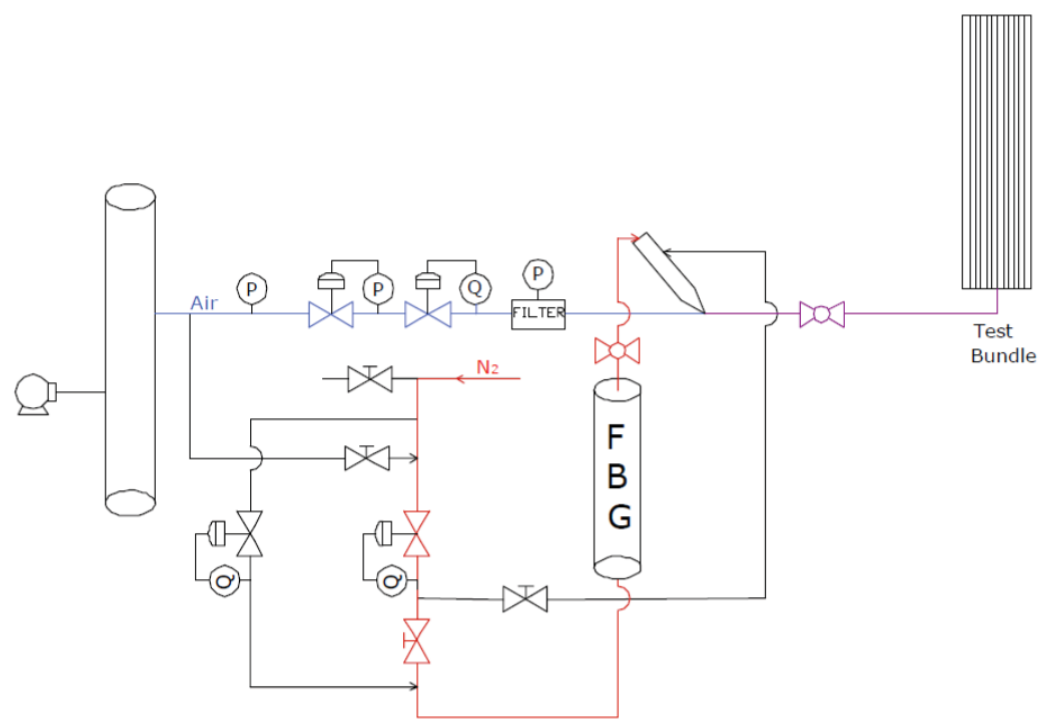

Fig. $15 \mathrm{SiO}_{2} / \mathrm{Cu}$ injection arrangement

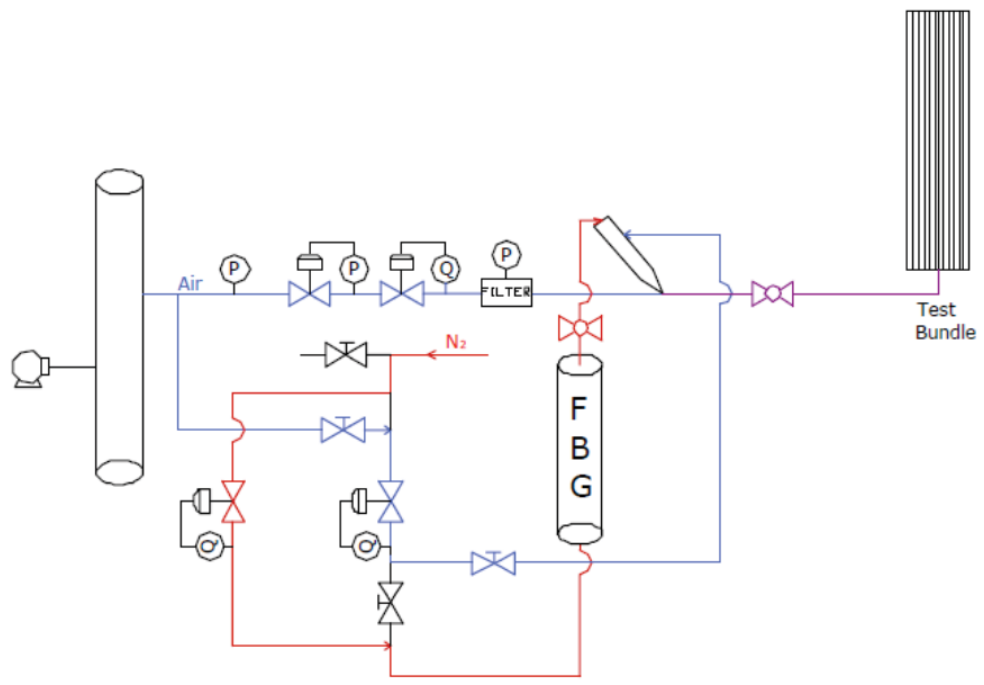

Fig. $16 \mathrm{TiO}_{2}$ injection arrangement 
In summary, the main technological changes performed in the facility include:

- The bypass of the air stream

- Addition of valves

- Substitution of the rubber tubes for stainless steel pipes

As a consequence, the following results have been achieved:

- Reduction of particle retention along the pipes

- Flexibility in terms of the type of particle injected

- Reduction of the possibility of overpressure along the injection line due to the better control of the flow rate

- Simplification of the stream lines

\subsubsection{Instrumentation and sampling}

\subsubsection{Instrumentation and control of the thermal-hydraulic variables}

The PECA uses several types of instruments and sensors for the measurement and control of the thermal-hydraulic variables. The air is controlled through pressure and flow rate valves to achieve the desired conditions. Similarly, another flow rate valve controls the flow of the $\mathrm{N}_{2}$ stream fluidizing the particles. Pressure and temperature sensors measure the final inlet tube conditions upstream the breach as well as the conditions in the vessel. Two blowers relieve the pressure to ensure atmospheric conditions at the vessel. It is worth to note that the tests have been performed under room temperature conditions. Finally, the variables were controlled and logged every $700 \mathrm{~ms}$ through the Program Loger Controller (PLC) which incorporates an SCADAS system for the acquisition and storage of the variables. Fig. 17 shows two of the interfaces to control the plant.

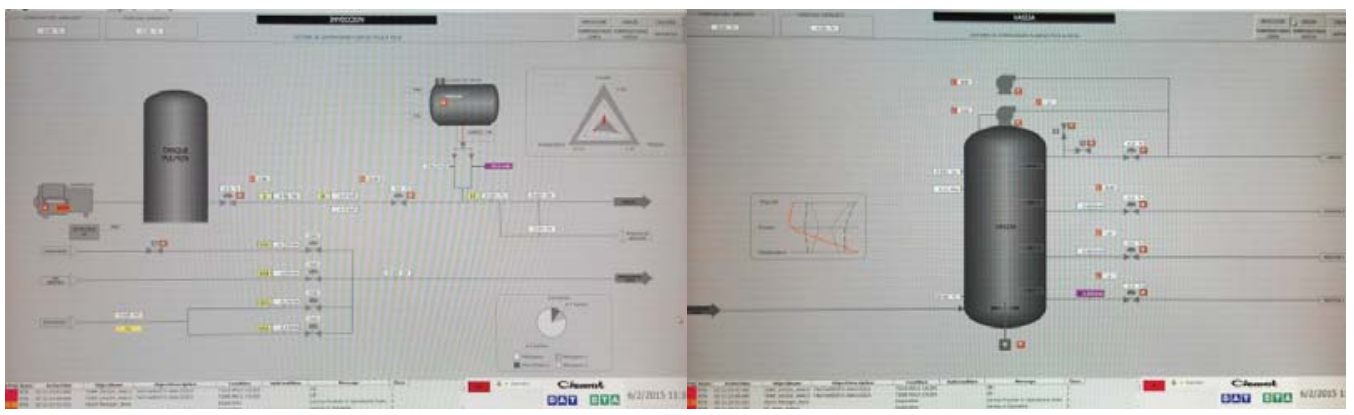

Fig. 17 Control screens: compressor and gases/aerosols injection lines (left), vessel (right). 
TABLE 5 and TABLE 6 summarize the sensors and systems used for the control of the hydraulic variables.

TABLE 5 Instrumentation

\begin{tabular}{|c|c|c|c|c|}
\hline System & Method & $\mathrm{N}^{\mathbf{0}}$ & Range & Accuracy \\
\hline \multirow[b]{2}{*}{$\begin{array}{l}\text { Pressure in PECA vessel and } \\
\text { pipes }\end{array}$} & $\begin{array}{l}\text { Pressure difference } \\
\text { sensors }\end{array}$ & 6 & $\begin{array}{l}(-0.1)-0.2 \text { bar } \\
(-0.5)-0.5 \text { bar, } \\
0-5 \text { bar, } 0-7 \text { bar, } \\
0-10 \text { bar }\end{array}$ & $<1 \%$ \\
\hline & $\begin{array}{l}\text { Bourdon } \\
\text { manometers }\end{array}$ & 10 & $\begin{array}{l}(-1)-3 \text { bar, } \\
0-1 \text { bar, } \\
0-2.5 \text { bar, } \\
0-4 \text { bar, } \\
0-7 \text { bar, } 0-10 \text { bar }\end{array}$ & $1 \%$ \\
\hline \multirow{2}{*}{$\begin{array}{l}\text { Temperature vessel } \\
\text { atmosphere fluid, walls }\end{array}$} & Thermocouples & 16 & $0-180^{\circ} \mathrm{C}$ & $0.3^{\circ} \mathrm{C}$ \\
\hline & PT-100 & 48 & $0-100{ }^{\circ} \mathrm{C}$ & $0.2^{\circ} \mathrm{C}$ \\
\hline Air supply system loop & $\begin{array}{l}\text { Air compressor } \\
18.5 \mathrm{~kW}\end{array}$ & 1 & $\begin{array}{l}0-240 \mathrm{~kg} / \mathrm{h} \\
<4 \mathrm{bar}\end{array}$ & $\begin{array}{l}5 \% \\
<1 \%\end{array}$ \\
\hline $\begin{array}{l}\text { Synthetic gas supply system } \\
\text { loops }\end{array}$ & $\mathrm{N}_{2}, \mathrm{O}_{2}, \mathrm{H}_{2}, \mathrm{~N}_{2}+\mathrm{O}_{2}$ & $\begin{array}{l}10 \text { bottles } \\
\text { rack }\end{array}$ & $\begin{array}{l}<3 \mathrm{bar} \\
0-750 \mathrm{Nl} / \mathrm{min}\end{array}$ & $\begin{array}{l}<1 \% \\
<1 \%\end{array}$ \\
\hline $\begin{array}{l}\text { Exhaust depressurization } \\
\text { loop }\end{array}$ & $\begin{array}{l}\text { Radial turbine } \\
\text { blower }\end{array}$ & 2 & $4.4 \mathrm{~kW}$ & $<1 \%$ \\
\hline
\end{tabular}

TABLE 6 Flow monitoring

\begin{tabular}{llll}
\hline System & $\mathbf{N}^{\mathbf{0}}$ & Range & Accuracy \\
\hline Hot film sensors & 3 & $0-30 \mathrm{Nl} / \mathrm{min}$ & $<1 \%$ \\
Thermal resistive sensors & 5 & $2 \times 0-50 \mathrm{Nl} / \mathrm{min} 0-100 \mathrm{Nl} / \mathrm{min}$ & $<1 \%$ \\
& & $0-250 \mathrm{Nl} / \mathrm{min}, 0-750 \mathrm{Nl} / \mathrm{min}$ & \\
Rotameters & 7 & $0-4.18 \mathrm{l} / \mathrm{h}, 0-15 \mathrm{~m} 3 / \mathrm{h}, 0-280 \mathrm{~kg} / \mathrm{h}$ & $2 \%$ \\
\hline Orifice pressure difference sensor & 1 & $0-250 \mathrm{~kg} / \mathrm{h}$ & $5 \%$ \\
Pressure difference & 2 & $0-350 \mathrm{~cm}^{3} / \mathrm{s}, 0-3250 \mathrm{~cm}^{3} / \mathrm{s}$ & $3 \%$ \\
\hline
\end{tabular}


Characterization of incoming and outgoing particles is performed by real time devices (i.e., APS ${ }^{\circledR}$ and ELPI ${ }^{\circledR}$ ) and integral gravimetric systems (i.e. cascade impactors, membrane filters) in terms of particle concentration and particle size distribution. The number size distribution is characterized thanks to the APS and the ELPI, while the size distribution in terms of mass is characterized with the cascade impactors. Filters are used for particle concentration measurements. At least, one device for each measurement is located upstream the broken tube and one at the bundle exit.

\subsubsection{Instrumentation for aerosol characterization}

The instrumentation aims to characterize particle size distribution and their concentration in aerosol. Such characterization provides key information: the mass depleted on the bundle of tubes and on structures (i.e., overall retention efficiency) and a shift of the particles size distribution to smaller diameters. This can be done on real-time through devices that operate during nearly the entire test (ELPI and APS) and by other systems that work over time spans much shorter than test duration (impactors and membrane filters). All of them required collecting isokinetic samples from the main inlet and outlet lines.

\subsection{Real time devices}

- Aerodynamic Particle Sizer (APS)

The APS TSI 3321 is a time-of-flight spectrometer that measures flight time of the particles in an accelerating air flow through a nozzle. From a calibration curve (Aerosol Instrument Manager, 2002) time of flight is converted into aerodynamic diameter. In the instrument, the particles are confined to the centerline of an accelerating flow by sheath air. Then they pass through two parallel laser beams scattering light. Side scattered light is collected onto photo-detector, which converts the light pulses to electrical pulses. The velocity can be calculated for each individual particle by electronically timing between the peaks of the pulses (typically about 0.8-4.1 $\mu$ s). Velocity information is stored in a 1024 time-of-flight bits. Using a calibration curve based on latex particles, the APS converts each time-of-flight measurement to aerodynamic particle diameter. As a result the APS provides on-line aerosol aerodynamic count distribution (Fig. 18).
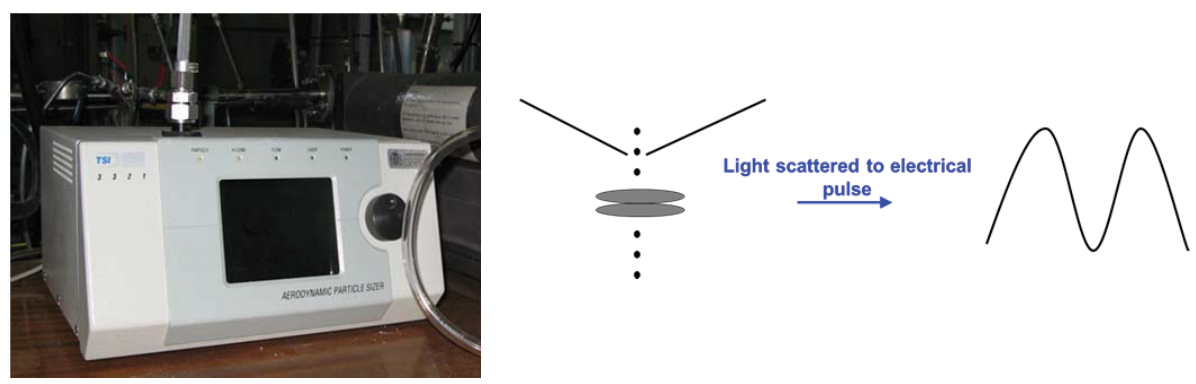

Fig. 18 APS: Aerodynamic Particle Sizer 
- Electrical Low Pressure Impactor (ELPI)

ELPI is a particle sizer based on 3 elements: a charger, a low pressure cascade impactor and a charge detector. Fig. 19 shows a scheme of the structure and parts of the ELPI. During a measurement, particles are charged when passing through a high voltage electrical field in a Corona charger. Then, the aerosol flow passes through the jet nozzles of the successive 13 stages of the low pressure impactor. Particles larger than the cutoff size of the plate are collected and make an electrical current to be detected by the charger detectors connected to each impactor stage. A correlation curve converts charge into number of particles for each stage. As a result ELPI provides the real-time aerosol aerodynamic count distribution ("ELPI user manual," 2008).
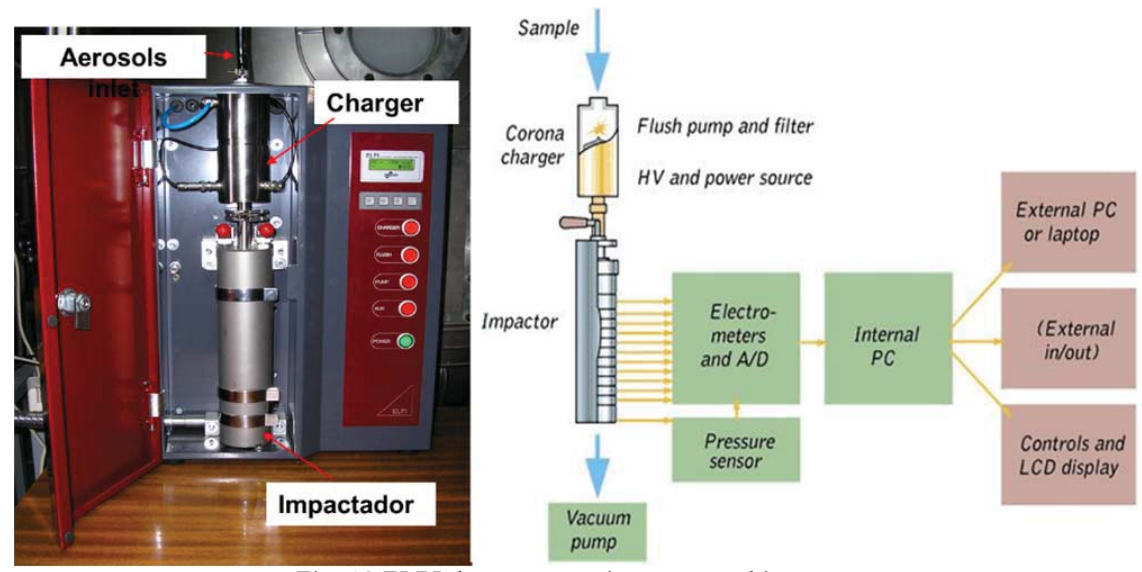

Fig. 19 ELPI: low pressure impactor and its stages

\subsection{Gravitational devices}

- Mass cascade impactors and membrane filters

Mass cascade impactors use inertial impaction to differentiate particles by size when they pass at high flow velocity through the nozzles of their successive stages. By pre-weighed and postweighed of the stages, the collected mass of aerosols is determined and so, the aerodynamic mass size distribution of the aerosol is obtained. Two mass cascade impactors have been used: MARK III which classifies particles into 8 stages, from $0.69 \mu \mathrm{m}$ to $15.7 \mu \mathrm{m}$; and DLPI (Dekati Low Pressure Impactor) with 13 stages that go from $0.028 \mu \mathrm{m}$ to $9.88 \mu \mathrm{m}$ (Fig. 20). DLPI and ELPI use the same type of impactor and both classify the particles in the same bin of sizes. 

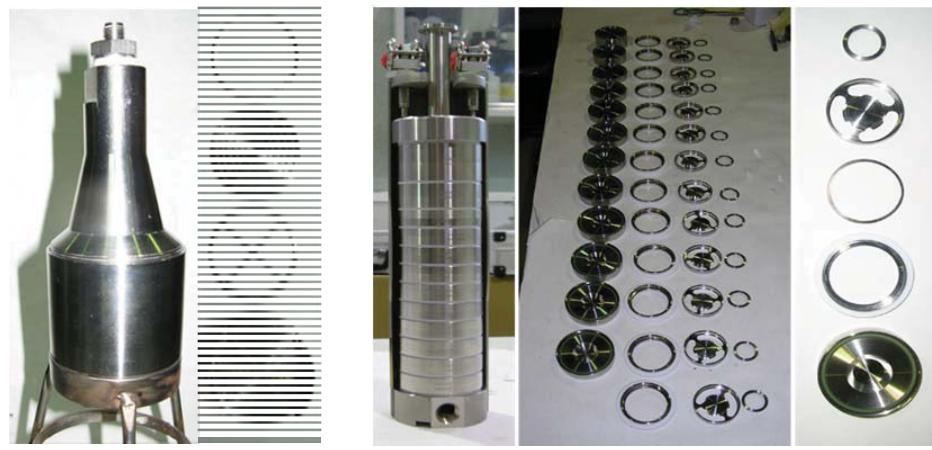

Fig. 20 Mark III (left) and DLPI (right) impactors

Membrane filters (Fig. 21) sample the aerosol stream by using a vacuum pump during a period of time $t_{\mathrm{si}}(\mathrm{s})$ at a controlled flow rate $\Phi_{\mathrm{s}}\left(\mathrm{Nm}^{3} / \mathrm{s}\right)$. The mass of particles are retained by the filter, that is weighed: $\mathrm{m}_{\mathrm{i}}(\mathrm{g})$. Particles concentration is estimated by the following equation:

$$
C\left(g / \mathrm{Nm}^{3}\right)=\frac{m_{i}(g)}{t_{s i}(s) \cdot \varphi_{s}\left(\mathrm{Nm}^{3} / s\right)}
$$

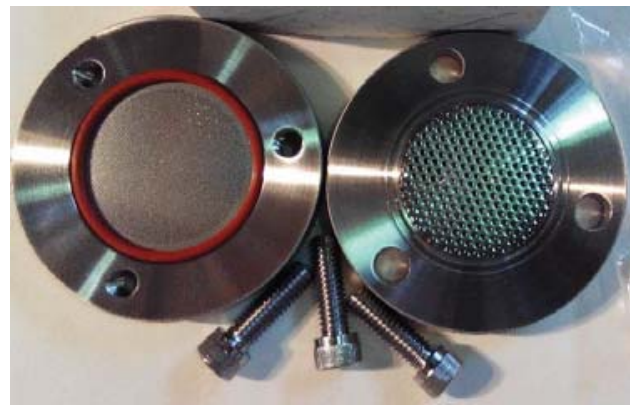

Fig. 21 Membrane filter

TABLE 7 synthetize the aerosol size characterization of each instrument. 
TABLE 7 Aerosol size characterization instrumentation and sampling

\begin{tabular}{|c|c|c|c|c|}
\hline Variable & Device & $\mathbf{N}^{0}$ & Range & \\
\hline \multirow{2}{*}{$\begin{array}{l}\text { Concentration } \\
\text { and particle } \\
\text { (counts) size } \\
\text { distribution }\end{array}$} & Aerodynamic Particle Sizer (APS) & 1 & $\begin{array}{l}\mathrm{dp} 0.5-20 \mu \mathrm{m} \\
5 \mathrm{lpm}\end{array}$ & $\begin{array}{l}<10^{4} \\
\text { counts } / \mathrm{cm}^{3} \\
<1.5 \text { bar }\end{array}$ \\
\hline & $\begin{array}{l}\text { Electrical low pressure impactor } \\
\text { (ELPI) }\end{array}$ & 1 & $\begin{array}{l}\mathrm{dp} 0.03-10 \mu \mathrm{m} \\
10 \mathrm{lpm}\end{array}$ & $\begin{array}{l}2.7 \mathrm{E} 4-3.8 \mathrm{E} 7 \\
\text { counts } / \mathrm{cm}^{3} \\
<60^{\circ} \mathrm{C}\end{array}$ \\
\hline $\begin{array}{l}\text { Particle (mass) } \\
\text { size distribution }\end{array}$ & Low pressure cascade impactor & 3 & $\begin{array}{l}\text { dp 0.41-12 } \mu \mathrm{m} \\
0.1-0.75 \mathrm{acfm} \\
\mathrm{dp} 0.25-15 \mu \mathrm{m} \\
0.035-0.35 \mathrm{acfm} \\
\mathrm{dp} 0.028-9.88 \mu \mathrm{m} \\
10 \mathrm{lpm}\end{array}$ & $<5 \mathrm{~g} / \mathrm{m}^{3}$ \\
\hline Concentration & Absolute mass filters & 8 & $<501 / \mathrm{min}$ & \\
\hline Aerosol Dilution & $\begin{array}{l}\text { APS diluter } \\
\text { High temperature jet diluters }\end{array}$ & $\begin{array}{l}1 \\
3\end{array}$ & $\begin{array}{l}\text { Dilution ratio 100: } \\
\text { Dilution ratio 1:8 }\end{array}$ & 20:1 \\
\hline
\end{tabular}

\subsubsection{Sampling}

The layout of the instruments in the PECA-SGTR is shown in Fig. 5. The aerosols are characterized at the entrance of the line in the vessel, via iso-kinetic probes:

- One isokinetic sample feeds the APS dilutor and the diluted stream is sampled by the APS. The dilution ratio of particles concentration goes up to 100:1. The dilutor makes the pressure drop up to the working value of the APS, i.e. between 0 and 0.5 bar. APS measurements allow the real-time determination of the aerosol particle count distribution.

- The other isokinetic sample is divided into three streams: two for the membrane filters and one for the DLPI impactor. The inlet concentration and aerosol mass size distribution are estimated out of them, respectively. Two vacuum pumps, one for the filters and the other one for the DLPI are used to suck the aerosol sample from the injection line.

At the exit of the bundle the outgoing aerosols are characterized via four atmospheric samples:

- One sampling is connected in series to an ejector diluter (dilution ratio 8:1) and to the ELPI. The latter allows the real-time characterization of the aerosol particle count distribution.

- One sample is connected to the Mark III cascade impactor that permits the aerosol mass size distribution characterization.

- The last two samples are connected to membrane filters that permit the measuring of the outgoing aerosol concentration. 
Two vacuum pumps, one for the filters and the impactor and another one for the ELPI are used to subtract the aerosols. The ELPI one is specially designed for it and let pass a constant flow rate of $10 \mathrm{lpm}$.

The aerosols deposits on tube surfaces are collected and weighed to characterize the deposition pattern of the bundle of tubes. Mass collection is conducted by double sweeping of tubes surface, the first one with U rings (Fig. 22) and the second one with wet paper. Finally, U rings and wet paper which were previously weighted are weighed again to calculate the mass by difference of the results.

The U-rings have been specially designed for the tests. They are made of a brass nut with cubic shape, with a beveled stainless steel bi-cone inside (Fig. 22). The bi-cone is only in contact with the tube surface and the inlet part of the nut and particles fall within this gap when the tube is being swept. In this way any contamination of the sample collected is avoided.
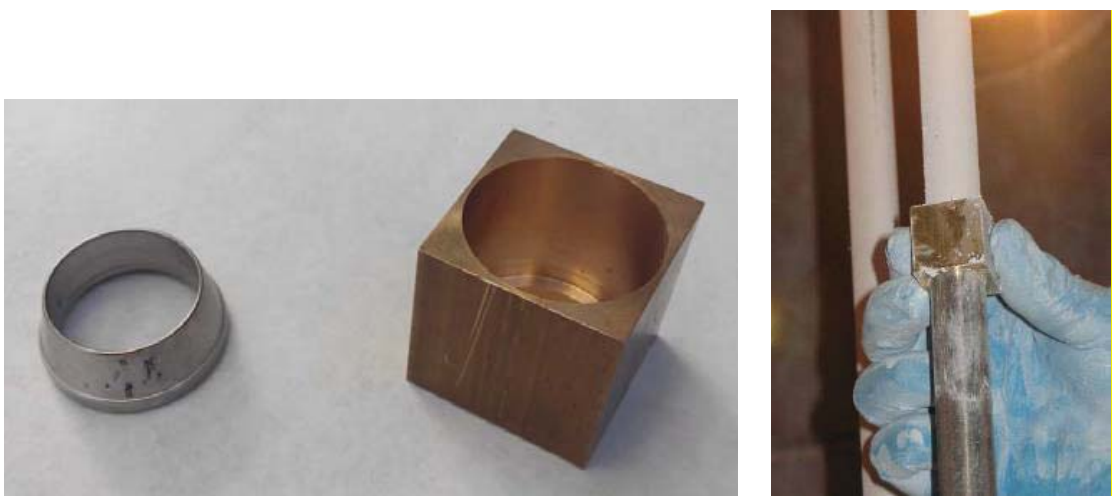

Fig. 22 Left: U-ring: bevelled bi-cone and squared nut

Right: Collection of particles along a tube 


\section{Chapter 4}

\section{Steam Generator Aerosol Retention Tests}

This chapter presents the studies of an experimental investigation aimed to assess and characterize the aerosol retention that might occur right at the vicinity of the tube breach when the particle-laden gas flows through the dry secondary side of a steam generator during SGTR severe accident sequences.

It is divided in two sub-chapters, each one dedicated to an experimental campaign: The CIEMAT Aerosol ARTIST Tests \# 2 (CAAT2) and the Separate Effect Tests (SET). Both have been completed in a down-scaled tube bundle of a real steam generator. It has been demonstrated that particles are significantly retained in the region around the breach, even in the total absence of water. From the nuclear safety point of view, the particles size $\left(d_{p} \geq 1 \mu \mathrm{m}\right)$ are considered large. Thus, the retention results of the CAAT2 and SET campaigns show the large particle mitigation. The tests explored the anticipated conditions in the scenario: gas jet injection, micron particles of different nature (dense spheres vs. aggregates), tube breach types (guillotine vs. fish-mouth) and the absence of the tube vibration. The main variable affecting retention is the particle nature. The collection efficiency reached $75-95 \%$ in the case of dense spheres. The influence of natural aerosol mechanisms like inertial impaction, turbulent deposition, resuspension and fragmentation are discussed in the chapter. 



\section{Ciemat Aerosol ARTIST Tests \# 2}

\subsection{Introduction}

This section is dedicated to the CAAT2 experimental campaign. The tests are focused on gaining insights into the influence of the particle nature and the breach shape and size of the broken tube, in the aerosol collection of the tube bundle.

The particles carried by the jet are discharged through the breach of the broken tube into the tubes bundle. The jet expands across the bundle that simulates the break stage of a "dry" steam generator.

The scope of the first stage of the thesis in summary is:

- Three types of particles different in nature $\mathrm{SiO}_{2}, \mathrm{TiO}_{2}$ and $\mathrm{Cu}$;

- Fish-mouth breaches of three sizes: 0.25D, 0.5D and 1D;

- Gas mass flow rate of the jet discharged, ranged from $100 \mathrm{~kg} / \mathrm{h}$ to $200 \mathrm{~kg} / \mathrm{h}$.

Whenever available, a comparison with CAAT and PSI experiments performed under similar conditions are presented. 


\subsection{CAAT2 experimental configuration}

The experimental configuration of the PECA facility for CAAT2 experiments has been presented above. It can be found in section 3.2.

\subsection{Experimental Matrix}

The design of the experimental matrix was based on the analysis of the expected boundary conditions during the rupture of a tube in a SG and the facility capability.

The magnitude of gas velocities and other SGTR features was determined by simulating SGTR severe accident sequences with nuclear safety codes (Bakker, 2001; Güntay et al., 2002). According to the simulations, thermal and steam concentration gradients were not anticipated to play any significant role in the aerosol deposition in the break stage. Moreover, most of the aerosol were big enough $\left(d_{p}>0.1 \mu \mathrm{m}\right)$ as for Brownian diffusion to be negligible. The potential depletion mechanisms are inertial impaction, turbulent deposition, settling and interception. López del Prá (López del Prá, 2012) made an assessment based on the characteristic parameters of each mechanisms that could play role under the anticipated SGTR conditions (i.e. gas velocities ranged between $10 \mathrm{~m} / \mathrm{s}$ and $400 \mathrm{~m} / \mathrm{s}$ and particle diameters between $1 \mu \mathrm{m}$ and $10 \mu \mathrm{m}$ ) (TABLE 8). The parameters are non-dimensional numbers generally defined as the ratio of forces causing particle removal and gas resistance forces opposing to the particle motion (Ranz and Wong, 1952). The product of the turbulent Schmidt number and the square root of the Reynolds number $\left(\mathrm{S}_{\mathrm{tbt}} \cdot \mathrm{Re}^{0.5}\right)$ characterize turbulent deposition mechanism (Douglas and Ilias, 1988).

TABLE 8 Estimation of characteristic parameters of depletion mechanisms (López del Prá, 2012)

\begin{tabular}{lll}
\hline Depletion mechanism & Characteristic parameter & Estimate \\
\hline Inertial impaction & $\mathrm{Stk}$ & $>10^{-2}$ \\
Turbulent deposition & $\mathrm{SC}_{\mathrm{tbt}} \cdot \mathrm{Re}^{0.5}$ & $>10^{-2}$ \\
Settling & $\mathrm{V}_{\mathrm{TS}} / \mathrm{V}_{\mathrm{g}}$ & $\sim 10^{-6}$ \\
Interception & $\mathrm{d}_{\mathrm{p}} / \mathrm{d}_{\text {tube }}$ & $\sim 10^{-4}$ \\
\hline
\end{tabular}

According to Ranz and Wong (1952) under characteristic parameter values below $10^{-2}$ a mechanism does not play a role. Then, particle inertia and turbulent deposition are the dominant mechanisms of the particles retention in the secondary side of the steam generator. Thanks to this, it was appropriate to focus the attention on achieving aerodynamic scenarios as close as possible to the SGTR one and to use the air as the carrier gas.

TABLE 9 compares some experimental aerodynamic-related variables (i.e. particle diameter $\left(\mathrm{d}_{\mathrm{p}}\right)$, breach size $(\mathrm{D})$ and theoretical velocity of the gas through the breach $\left(\mathrm{V}_{\text {theo }}\right)$ and nondimensional numbers (i.e. gas Reynolds number through the breach $\left(\operatorname{Re}_{\mathrm{D}}\right)$, the particle Stokes 
number (Stk) and, in order to avoid the particle diameter dependence, the dimentionals ratio of the square Reynolds particle number to the Stokes number) to those of the SGTR sequence. As can be realized, most of the PECA aerodynamic variables are within the range of values anticipated in the SGTR code predictions (Herranz et al., 2006).

TABLE 9 Variables and non-dimensional numbers characterizing SGTR scenarios

\begin{tabular}{lllllll}
\hline & $\mathrm{d}_{\mathrm{p}}(\mu \mathrm{m})$ & $\mathrm{D}(\mathrm{m})$ & $\mathrm{V}_{\text {theo }}(\mathrm{m} / \mathrm{s})$ & $\mathrm{Re}_{\mathrm{D}}$ & $\mathrm{Stk}$ & $\mathrm{Re}^{2} \mathrm{p} / \mathrm{Stk}$ \\
\hline SGTR & $1-10$ & $10^{-2}$ & $10-400$ & $10^{4}-10^{6}$ & $10^{-2}-10$ & $10^{2}-10^{3}$ \\
CAAT2 & $1-10$ & $10^{-2}$ & $10-300$ & $10^{4}-10^{5}$ & $10^{-2}-10$ & $10^{2}-10^{3}$ \\
\hline
\end{tabular}

In order to meet the objectives set, the main variables of the experimental matrix (TABLE 10) were the particle nature and the break cross section of the fish-mouth breach; additionally, the effect of the mass flow rate was also tested. The majority of tests are $100 \%$ break area since it is equal to the tube cross section. It will allow the analysis of the breach size effect by the comparison between the guillotine and fish-mouth results. A total of 11 tests ( 3 of them targeted at repeatability) have been conducted.

TABLE 10 CAAT2 Experimental test matrix

\begin{tabular}{|c|c|c|c|c|c|c|}
\hline \multirow{2}{*}{ Test } & \multirow{2}{*}{ Particle nature } & \multicolumn{2}{|c|}{ Flow rate $(\mathrm{kg} / \mathrm{h})$} & \multicolumn{3}{|c|}{ Break Area (\% tube section) } \\
\hline & & 150 & 200 & 25 & 50 & 100 \\
\hline 1 & \multirow{3}{*}{$\mathrm{TiO}_{2}$} & $x$ & & & & $x$ \\
\hline $1^{\prime} b$ & & $x$ & & & & $x$ \\
\hline 2 & & & $x$ & & & $x$ \\
\hline 3 & \multirow{5}{*}{$\mathrm{SiO}_{2}$} & $x$ & & & $x$ & \\
\hline 4 & & $x$ & & $x$ & & \\
\hline $4^{\prime} \mathrm{b}$ & & $x$ & & $x$ & & \\
\hline 5 & & $\mathrm{x}$ & & & & $x$ \\
\hline 6 & & & $x$ & & & $x$ \\
\hline 7 & \multirow{3}{*}{$\mathrm{Cu}$} & $x$ & & & & $\mathrm{x}$ \\
\hline $7^{\prime} \mathrm{b}$ & & $x$ & & & & $x$ \\
\hline 8 & & & $x$ & & & $\mathrm{x}$ \\
\hline
\end{tabular}

\subsubsection{Target variables}

\subsubsection{Particle nature}

Three types of particles were tested: $\mathrm{TiO}_{2}, \mathrm{SiO}_{2}$ and $\mathrm{Cu}$. The main reason for this choice was to use particles with an extremely different aggregation state $\left(\mathrm{TiO}_{2}\right.$ vs. $\left.\mathrm{SiO}_{2}\right)$, and to include a new particle type with aggregation properties in between those extremes $(\mathrm{Cu})$. Thus, measurements would allow studying aerosol retention of large fluffy aggregates (i.e., $\mathrm{TiO}_{2}$ ) and single particles $\left(\mathrm{SiO}_{2}\right)$, of a similar size and shape (the $\mathrm{Cu}$ particles observations would provide insights to bridge the gap). The existing information regarding actual particles in case of a severe accident 
is certainly scarce (Kissane, 2008) and not conclusive, so that by addressing this broad range of primary particles aggregation, it was pursued to encompass the potential scrubbing of severe accident particles.

A SEM (Scanning Electron Microscopy) characterization of the three types of particles (Fig. 23) shows the first evidences of the different aggregation state of the three types of particles chosen. The three images are in the same scale.

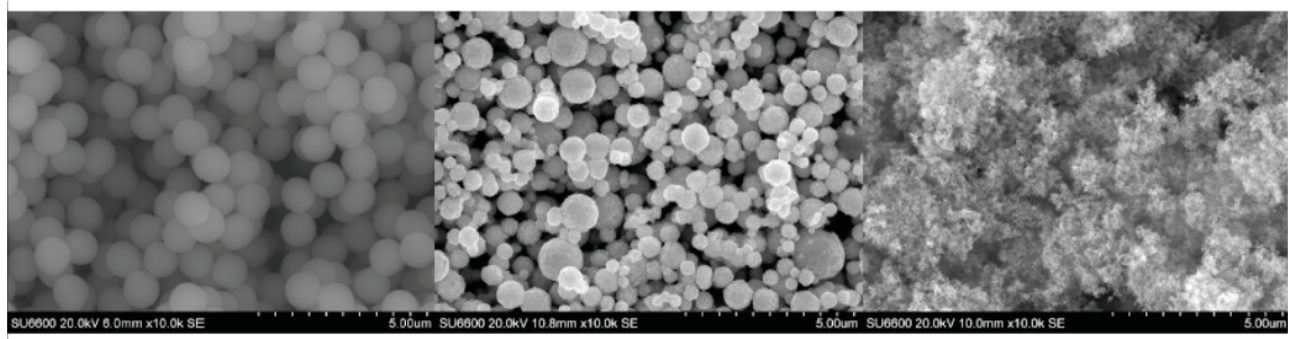

Fig. 23 From left to right: SEM images of $\mathrm{SiO}_{2}, \mathrm{Cu}$ and $\mathrm{TiO}_{2}$ particles

The $\mathrm{TiO}_{2}$ particles consisted of a large number of primary particles that resulted in aerosols with a broad interval of AMMD (Aerodynamic Mass Median Diameter) throughout the experiments $(1.4-3.8 \mu \mathrm{m})$. Given their agglomerate nature, their density is uncertain, although it is known to be far from the nominal one. López and Herranz (Lopez and Herranz, 2012) assumed that primary $\mathrm{TiO}_{2}$ particles were solid spheres randomly packed and approximated a density interval for $\mathrm{TiO}_{2}$ agglomerates in between $395.5 \mathrm{~kg} / \mathrm{m}^{3}$ and $2528 \mathrm{~kg} / \mathrm{m}^{3}$; nonetheless, their study pointed that $\mathrm{TiO}_{2}$ density should be near the lower bound, as also proposed by Leskinen (Leskinen et al., 2010). The $\mathrm{SiO}_{2}$ particles, much closer to a mono-disperse size distribution than $\mathrm{TiO}_{2}$, showed AMMDs ranging between 1.6 and $2.5 \mu \mathrm{m}$; as they were individual particles their density is supposed to be near the nominal one. The $\mathrm{Cu}$ aggregates consisted of few primary particles that resulted in larger AMMDs $(3.9-5.7 \mu \mathrm{m})$. Unlike $\mathrm{TiO}_{2}$ particles, given the small number of individual primary particles $(\approx 1 \mu \mathrm{m})$ and their trend to form globular clusters, their density was approximated according to Torquato (Torquato et al., 2000) to be around $64 \%$ of the nominal one (i.e., $5722 \mathrm{~kg} / \mathrm{m}^{3}$ ). TABLE 11 summarizes the $\mathrm{SiO}_{2}, \mathrm{Cu}$ and $\mathrm{TiO}_{2}$ main features.

TABLE 11 Aerosol main features

\begin{tabular}{llll}
\hline Aerosol type & $\mathrm{SiO}_{2}$ & $\mathbf{C u}$ & $\mathrm{TiO}_{2}$ \\
\cline { 2 - 4 } Average primary particle diameter $(\boldsymbol{\mu m})$ & 1.020 & 1 & 0.0218 \\
Nominal density $\left(\mathbf{k g} / \mathbf{m}^{3}\right)$ & $\sim 2000$ & $\sim 8940$ & $\sim 3950$ \\
Aerosol density $\left(\mathbf{k g} / \mathbf{m}^{3}\right)$ & $\sim 2000$ & $\leq \sim 5722$ & $395-2528$ \\
Specific surface area $\left(\mathbf{m}^{2} / \mathbf{g}\right)$ & n.a. & $0.5-1.0$ & $\sim 50$ \\
\hline
\end{tabular}

${ }^{*}$ Note that GSD does not appear since it has not been provided by the aerosol producer. 


\subsubsection{Gas mass flow rate}

The flow rates, $150 \mathrm{~kg} / \mathrm{h}$ and $200 \mathrm{~kg} / \mathrm{h}$, were found to be at the low extreme of the anticipated range during a meltdown SGTR sequence at the time span at which fission products enter the secondary side of the SG (Guntay et al., 2000).

\subsubsection{The breach type}

The SGTR events show that fish-mouth and guillotine break are common types of tube ruptures (Guntay et al., 2000). Three different sizes of fish-mouth breach have been tested: $48 \mathrm{~mm}, 34 \mathrm{~mm}$ and $20 \mathrm{~mm}$ high in order to explore the effect of the tube breach shape and size. Their crosssection areas correspond to $1,0.5$ or 0.25 times the guillotine break used in the CAAT experiments (Sánchez-Velasco et al., 2010). By comparing CAAT2 and CAAT results, the effect of breach shape on the in-bundle retention will be discussed. Fig. 24 shows the three breaches tested.

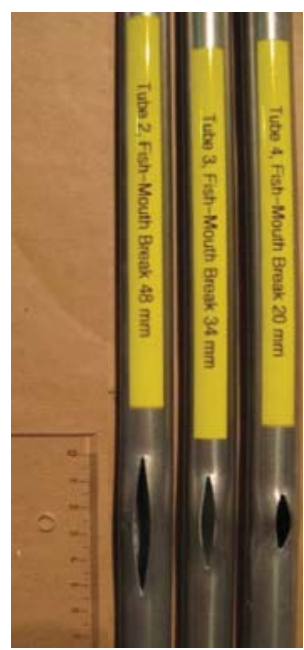

Fig. 24 Fish-mouth breaches: 1D, 0.5D, 0.25D

\subsection{Measurement Procedure}

Room temperature and atmospheric pressure were kept in the bundle of tubes during the tests. Once the desired hydraulic conditions in terms of the gas mass flow rate were reached and kept steady, the aerosol injection started. The total duration of a test was about 2 hours. The test duration is limited by the consecutive integral devices measuring and the time required by them to get a comprehensive mass into the membrane filters and cascade impactors (either the mass ones, DLPI and MARK III, and the electrical one, ELPI) without their saturation. This time allowed a comprehensive set of measurements both at the inlet (or primary side) and at the 
outlet (or secondary side) of the facility. During the entire test, real time devices (APS and ELPI) were measuring the aerosol concentration and size distribution. Fig. 25 shows the aerosol measurement plan during a test. Once membrane filters and mass cascade impactors measurements were finished, the aerosol injection was shut down and the test was considered ended. Twenty four hours after each test, the bundle shroud was removed. Then the mass retained over the tubes was collected and weighed.

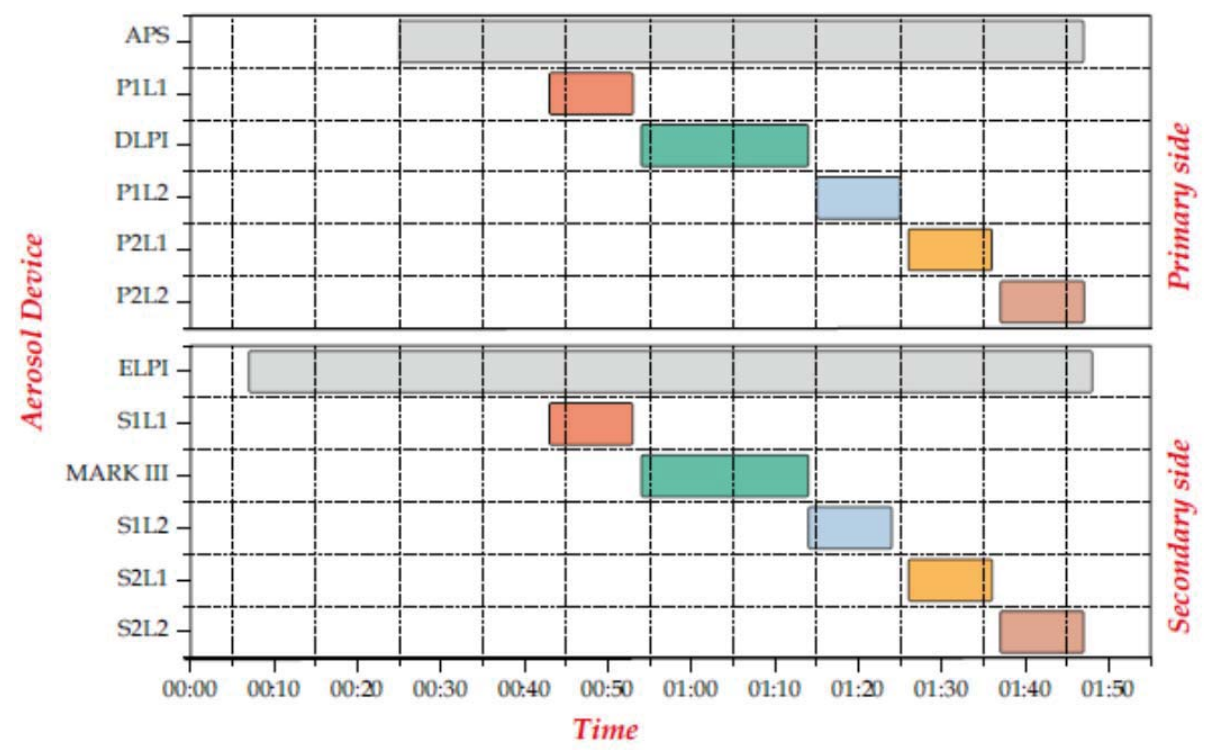

Fig. 25 CAAT2 measurement procedure schedule

\subsection{Retention efficiency and major variables}

Retention efficiency $(\eta)$ is a magnitude derived from measurements that is defined as the fraction of retained mass $\left(\mathrm{m}_{\text {ret }}\right)$ with respect to the total inlet mass $\left(\mathrm{m}_{\mathrm{in}}\right)$ :

$$
\eta=\frac{m_{\text {ret }}}{m_{\text {in }}}
$$

In these experiments, $m_{i n}$ is the mass of particles entering the bundle and $m_{\text {ret }}$ is the mass retained within the bundle of tubes. $\mathrm{m}_{\text {ret }}$ is a magnitude estimated directly from the mass deposited on the tubes surface, but it can be also derived from the entering and leaving mass, i.e. by the mass balance: $\mathrm{m}_{\mathrm{ret}}=\mathrm{m}_{\mathrm{in}}-\mathrm{m}_{\text {out }}$. It leads to an equivalent equation: 


$$
\eta=1-\frac{m_{\text {out }}}{m_{\text {in }}}
$$

where $m_{\text {out }}$ is the particle mass leaving the facility.

\subsubsection{Inlet and outlet mass}

The mass entering $\left(\mathrm{m}_{\text {in }}\right)$ and leaving $\left(\mathrm{m}_{\text {out }}\right)$ the facility were quantified by filters and impactors. A sample of aerosols $\left(\mathrm{m}_{\mathrm{i}}\right)$ is taken by using a vacuum pump during the sampling time $\left(\mathrm{t}_{\mathrm{si}}\right)$ at a given flow rate $\left(\Phi_{\mathrm{s}}\right)$. Note that adding up all the individual contributions covers nearly $75 \%$ of the test time. The extrapolation of the measured mass to the entire test can be calculated by:

$$
m_{\text {in/out }}=\frac{\sum_{i=1}^{n} m_{i}}{\sum_{i=1}^{n} \phi_{s_{i}} \cdot t_{s_{i}}} \cdot \phi_{\text {test }} \cdot t_{\text {test }}
$$

\subsubsection{Retained mass}

The aerosols deposits on tube surfaces are collected and weighed to characterize the desposition pattern of the bundle of tubes (see section 3.2.7.3). To quantify the total mass retained in the bundle, the mass deposited on 30 tubes out of 121 was collected. Extrapolation to the whole bundle might be considered reliable based on symmetry conditions (Herranz et al., 2006; Sánchez-Velasco et al., 2010), CFD simulations (López del Prá et al., 2010) and previous experience. The estimated net retention might be independent from any variable besides the symmetry. Hence, two alternative equations have been used (Eq 7 and Eq 8). Their difference comes from the extrapolation of the mass depossited in the tubes that do not belong to the regions denoted as R1, R2 and R3 in Fig. 26.

Fig. 26 shows the template of the sampling regions where $\mathrm{T} 1$ is the broken tube.

$$
\begin{aligned}
& \mathrm{m}_{\mathrm{ret} 1}=\mathrm{m}_{\mathrm{T} 1}+\mathrm{m}_{\mathrm{R} 1}+\mathrm{m}_{\mathrm{R} 2} \cdot 2+\mathrm{m}_{\mathrm{R} 3} \cdot 2+\left[\mathrm{m}_{\mathrm{T} 14}+\mathrm{m}_{\mathrm{T} 21}\right]+\left[\mathrm{m}_{\mathrm{T} 19}+\mathrm{m}_{\mathrm{T} 20}\right]+<\mathrm{m}>\cdot 91 \\
& <\mathrm{m}>=\left(\mathrm{m}_{\mathrm{T} 22}+\mathrm{m}_{\mathrm{T} 23}+\mathrm{m}_{\mathrm{T} 24}+\mathrm{m}_{\mathrm{T} 25}+\mathrm{m}_{\mathrm{T} 26}+\mathrm{m}_{\mathrm{T} 27}+\mathrm{m}_{\mathrm{T} 28}+\mathrm{m}_{\mathrm{T} 29}+\mathrm{m}_{\mathrm{T} 30}\right) / 9 \\
& \mathrm{~m}_{\mathrm{ret} 2}=\mathrm{m}_{\mathrm{T} 1}+\mathrm{m}_{\mathrm{R} 1}+\mathrm{m}_{\mathrm{R} 2} \cdot 2+\mathrm{m}_{\mathrm{R} 3} \cdot 2+\left[\mathrm{m}_{\mathrm{T} 14}+\mathrm{m}_{\mathrm{T} 21}\right]+\left[\mathrm{m}_{\mathrm{T} 19}+\mathrm{m}_{\mathrm{T} 20}\right]+<\mathrm{m}_{1}>\cdot 51+<\mathrm{m}_{2}>\cdot 40 \\
& <\mathrm{m}_{1}>=\left(\mathrm{m}_{\mathrm{T} 22}+\mathrm{m}_{\mathrm{T} 24}+\mathrm{m}_{\mathrm{T} 25}+\mathrm{m}_{\mathrm{T} 27}+\mathrm{m}_{\mathrm{T} 29}\right) / 5 \\
& <\mathrm{m}_{2}>=\left(\mathrm{m}_{\mathrm{T} 23}+\mathrm{m}_{\mathrm{T} 26}+\mathrm{m}_{\mathrm{T} 28}+\mathrm{m}_{\mathrm{T} 30}\right) / 4
\end{aligned}
$$




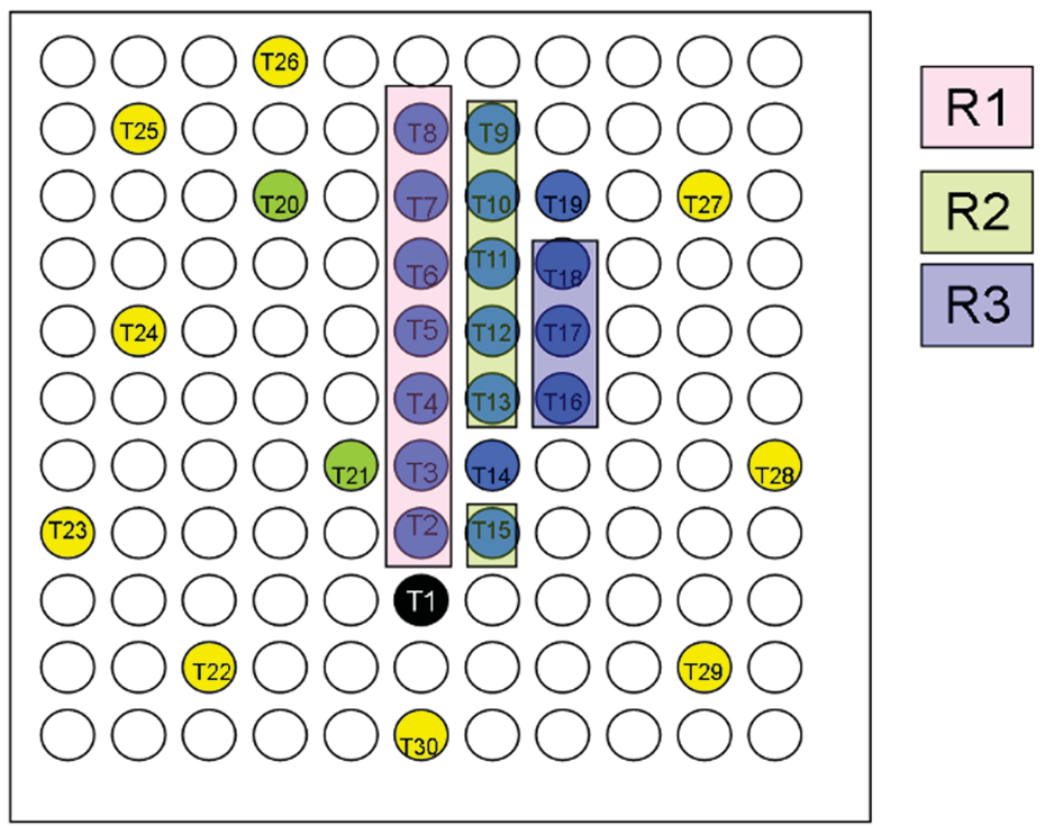

Fig. 26 Tube bundle: sampled tubes and regions

\subsection{Methodology of analysis}

The main variable to be determined experimentally is the aerosol collection efficiency $(\eta)$ :

$$
\eta=\frac{m_{\text {ret }}}{m_{\text {in }}}=1-\frac{m_{\text {out }}}{m_{\text {in }}}
$$

It can be derived from two mass ratios: the retained mass to input mass ratio and the outgoing mass to input mass ratio (that is the complementary function of $\eta$ ). These magnitudes allow setting a number of different ways to derive $\eta$. A set of consistency criteria has been proposed as a way of discriminating reliable and non-reliable data:

- Technical criteria: $\mathrm{m}_{\mathrm{i}}>0.1 \mathrm{mg}$

The mass collected by each instrument has to be over $0.1 \mathrm{mg}$ (precision of the analytical scale used for weighing the samples).

- Coherence criteria: $m_{\text {in }} \geq m_{\text {ret }}$

Whenever $m_{\text {in }}$ does not comply with the coherence condition, it is assumed that $m_{\text {in }}$ is affected by large uncertainties and it is approximated by closing the particle mass balance: $\mathrm{m}_{\text {in }}=\mathrm{m}_{\text {out }}+$ $\mathrm{m}_{\text {ret. }}$ 
- Qualitative assessment:

a. $\Delta \mathrm{m}_{\mathrm{i}}$

Scattering of individual mass measurements with respect to the average mass, i.e.:

$\bar{m}=\frac{1}{n} \sum_{i=1}^{n} m_{i}$

should never be large. Arbitrarily, it has been set a deviation under $50 \%$, i.e.

Deviation $=\frac{1}{n} \cdot \sum_{i=1}^{n} \frac{\left|m_{i}-\bar{m}\right|}{\bar{m}} \cdot 100<50 \%$

If this criterion is not met, the inlet mass is calculated as $m_{\text {in }}=m_{\text {out }}+m_{\text {ret }}$

b. $\Delta \mathrm{m}_{\text {in }}$

To avoid $m_{\text {in }}$ overestimation, scattering of individual inlet mass measurements $\left(\mathrm{m}_{\mathrm{i}}\right)$ with respect to the maximum mass introduced $\left(\mathrm{m}^{\left.\text {max }_{\mathrm{i}}\right)}\right.$ should never be large. Arbitrarily it has been arranged that

$\left|\frac{m_{i}^{\max }-m_{i}}{m_{i}^{\max }}\right| \cdot 100<50 \%$

If this criterion is not met, then $\mathrm{m}_{\mathrm{in}}=\mathrm{m}_{\text {out }}+\mathrm{m}_{\text {ret }}$.

c. $\Delta \mathrm{m}_{\mathrm{ret}}$

$\mathrm{m}_{\text {ret }}$ has been estimated by equations (5) and (6). $\mathrm{m}_{\text {ret }}$ is reliable when the relative deviation between both results is under $20 \%$.

Relative deviation $=\left|\frac{m_{r e t}^{\max }-m_{r e t}^{\min }}{m_{r e t}^{\min }}\right| \cdot 100<20 \%$

This analysis resulted in an ad hoc methodology (Fig. 27) that, depending upon measurements uncertainties, identifies the most suitable equation to assess the retention efficiency, $\eta$. 


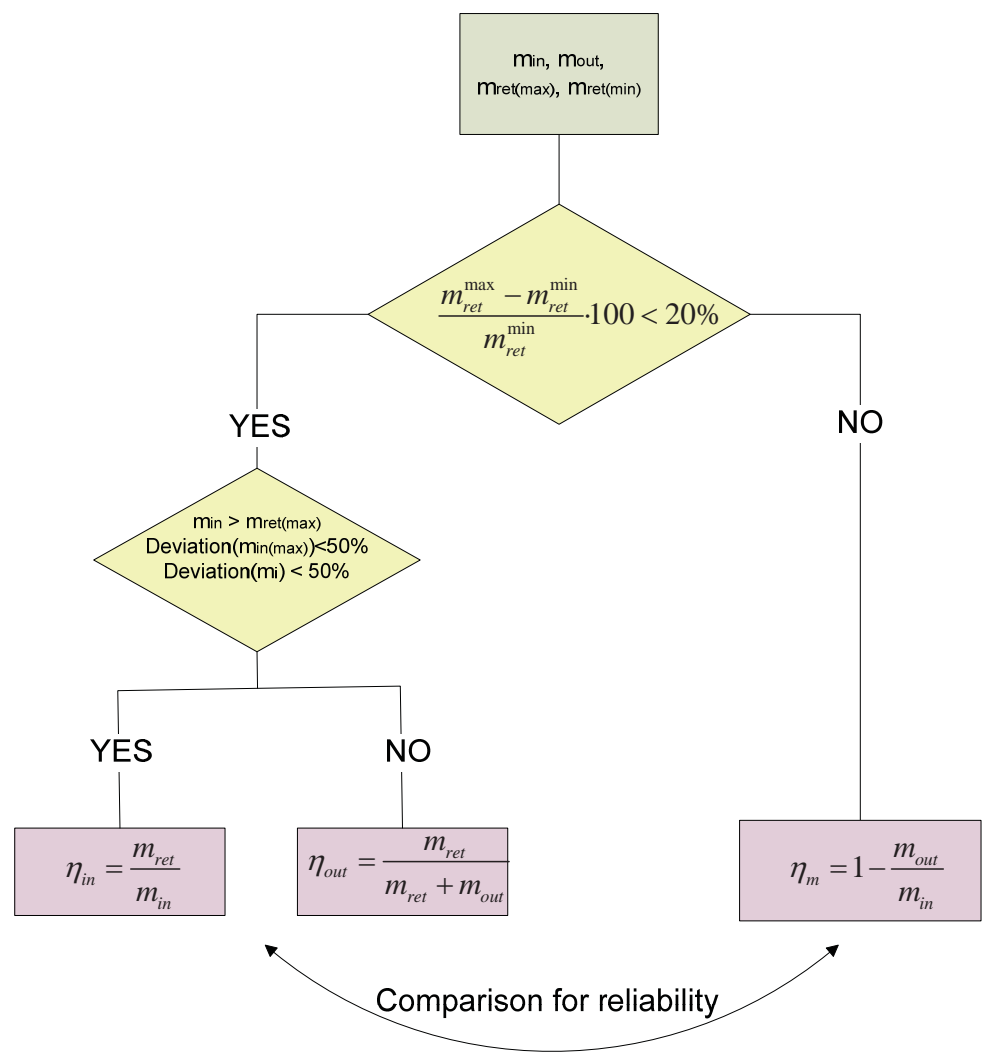

Fig. 27 Methodology for nestimate

In short, if $m_{\text {ret }}$ and $m_{\text {in }}$ measurements are reliable, $\eta$ is calculated based on these two variables; if, however, $\mathrm{m}_{\text {ret }}$ is reliable but $\mathrm{m}_{\mathrm{in}}$ is highly uncertain, then $\mathrm{m}_{\mathrm{in}}$ is approximated as $\mathrm{m}_{\mathrm{in}}=$ $\mathrm{m}_{\text {ret }}+\mathrm{m}_{\text {out }}$.

\subsection{Results and discussion}

\subsubsection{Major insights}

The CAAT2 results (Herranz and Tardáguila, 2014; Tardáguila and Herranz, 2013) have been summarized in TABLE 12. They show the main data obtained in terms of aerosol concentration and size distribution entering and leaving the facility as well as the mass retained. Last columns synthetize the main result, the retention efficiency and its associated uncertainty. The uncertainty analysis is presented in appendix 2 where the uncertainty estimation of the variables is estimated. 


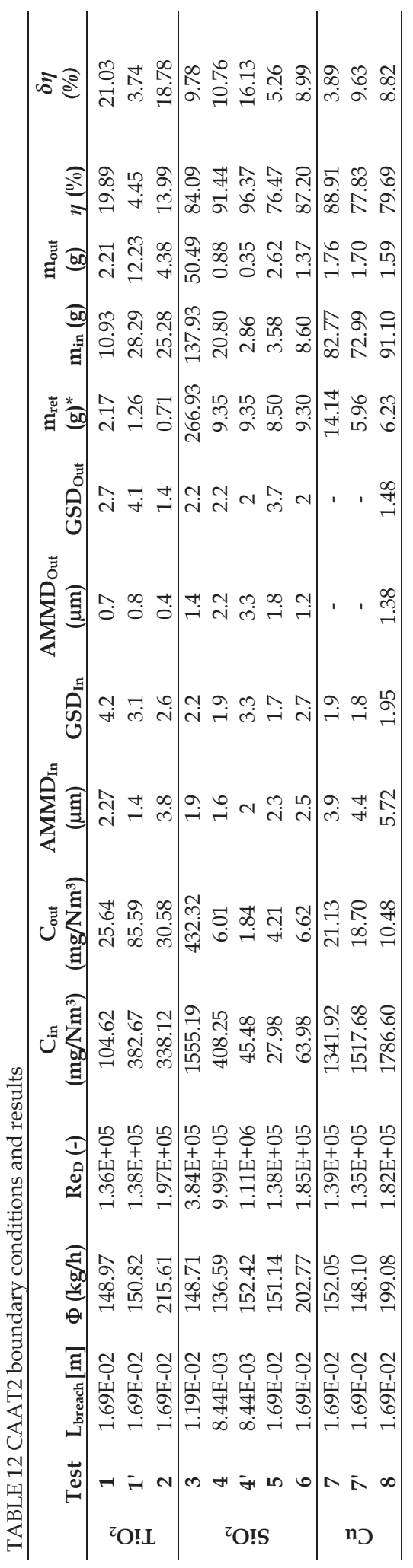


As noted in TABLE 12, the efficiency of tubes retaining particles is lower or higher depending mainly on the type of particles used. Fig. 28 synthesizes the retention of the CAAT2 tests. Two major observations can be made: on one hand, retention efficiency is never zero; on the other, retention efficiency fits into two major bands, one corresponding to very high values (75-95\%) and the other corresponding to low values $(<20 \%)$. These results are consistent with those reported by Sánchez-Velasco (Sánchez-Velasco et al., 2010), who already observed this clustering of retention efficiency in two very different levels for guillotine breaches under similar test conditions.

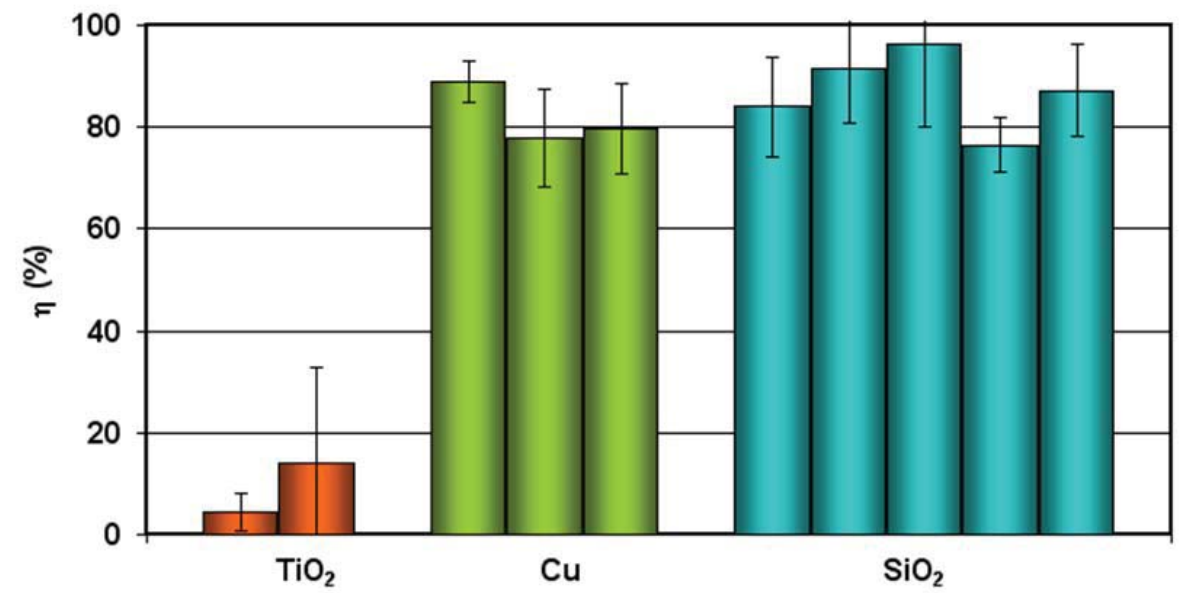

Fig. 28 Collection efficiency of CAAT2 tests

Consistency of the net retention results (Fig. 28) goes further than the previous experimental CAAT campaign conducted in the same facility. PSI built-up an ad-hoc facility to study aerosol retention at the break stage (Guntay et al., 2000). As in the case of the CAAT2 mockup bundle, it was scaled down from a FRAMATOME 33/19 type SG and it kept both tube diameter and pitch as in the original steam generator. However, dimensions were larger (270 tubes vs. 121 tubes in the PECA-SGTR facility) and design conditions enabled it to reach pressures up to 4.5 bar and gas flow rates up to $600 \mathrm{~kg} / \mathrm{h}$. The experimental data from the PSI-breach stage experiments (Lind et al., 2012) are plotted in Fig. 29-Fig. 31 together with the CAAT and CAAT2 tests. As observed, a sound consistency between both databases is noted with respect to the effect of some physical variables (presented as non-dimensional values in the graphs) on the net retention efficiency, despite the fact that the experimental campaigns addressed different conditions as the breach type (G: guillotine or FM: fishmouth) and others in different mock-ups.

Fig. 29-Fig. 31 highlight that the influences of variables such the gas flow rate, inlet concentration and particle size on the aerosol retention efficiency are negligible compared to that of the particle nature. This is even further supported when data uncertainties are considered, which make most data in the same efficiency band (either upper or lower) indistinguishable. 


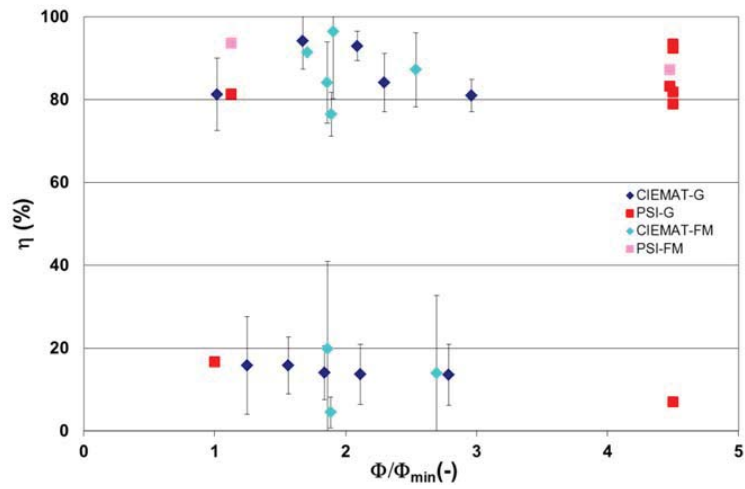

Fig. 29 Retention efficiency vs. non-dimensional flow rate

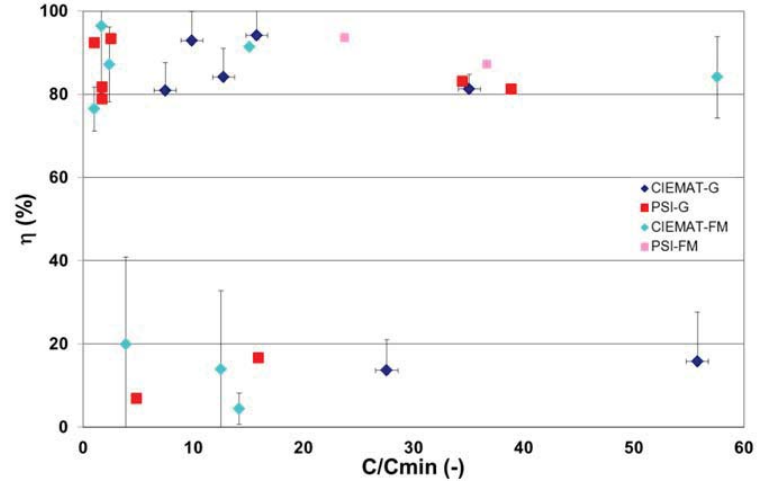

Fig. 30 Retention efficiency vs. non-dimensional inlet concentration

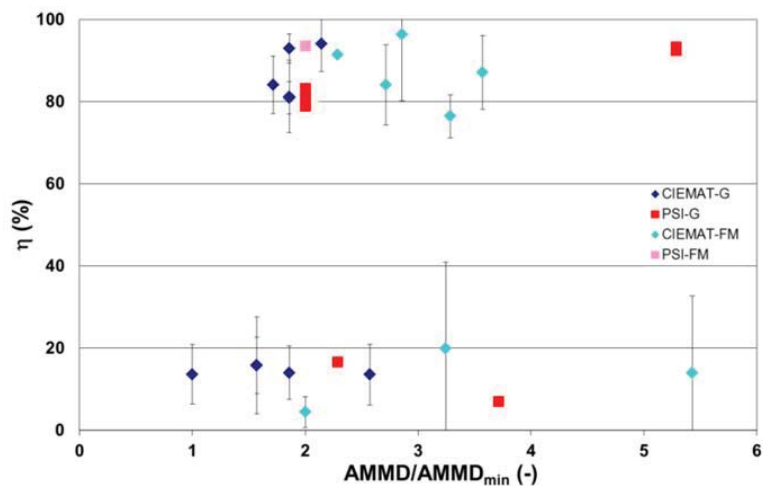

Fig. 31 Retention efficiency vs. non-dimensional inlet particle diameter 


\subsubsection{Influence of matrix variables}

\subsubsection{Effect of the particle nature}

In addition to the above mentioned generic statements, Fig. 28 clearly indicates a strong link between particle nature and retention efficiency. Those aerosols that consist of a single or fewaggregate particles $\left(\mathrm{SiO}_{2}\right.$ and $\mathrm{Cu}$, respectively) are trapped very efficiently within the tube bundle $(75-95 \%)$, regardless any other test conditions. On the contrary, those aerosols in which particles are formed by hundreds of primary particles $\left(\mathrm{TiO}_{2}\right)$ are more likely to go through the bundle without being retained. As discussed above, the aggregation state affects key properties of aerosol particles, like density, which final value is dependent on the number and packing of primary particles.

Either as agglomerates or as individual particles, the aerosols are discharged into the bundle at high velocities (in the order of $100 \mathrm{~m} / \mathrm{s}$ ). Some particles would be prone to get deposited by impaction when they impinge against the facing tube. It has been seen that this is the most efficient tube when using $\mathrm{TiO}_{2}$, as it traps at least 3 times the average mass retained by any other tube of the bundle.

Several factors regarding the particle nature may play a key role on the retention. On one hand, fluffy aggregates $\left(\mathrm{TiO}_{2}\right)$ would be prone to undergo fragmentation, either by the tangential relative velocity between cluster and gas or by collision with tubes (Ammar et al., 2012; Lind et al., 2010b). Whatever the actual mechanism was, the result would be that micron-range particles would disintegrate into submicron particles, which would be much harder to be removed from the gas flow by inertial and/or turbulent mechanisms; this would be further fostered by their loose packing of the primary particles that resulted in very low values of density. On the other hand, the single particles and few-particle aggregates $\left(\mathrm{SiO}_{2}\right.$ and $\left.\mathrm{Cu}\right)$ are much denser spheres that, even if they broke up, they would never fall in the submicron size range.

In Fig. 32 the inlet-to-outlet ratio of the particle population as a function of their aerodynamic diameter is shown for $\mathrm{TiO}_{2}$ and $\mathrm{SiO}_{2}$ (CAAT2-1 and CAAT2-5 tests). In the case of $\mathrm{SiO}_{2}$ a large decrease of the particles bigger than $2 \mu \mathrm{m}$ is produced within the bundle, whereas those of smaller diameters are hardly affected. These observations indicate that the particle retention within the bundle must have been mostly governed by inertial mechanisms. Unlike $\mathrm{SiO}_{2}$, the $\mathrm{TiO}_{2}$ particles show a totally different profile. The ratio is around approximately of unity for all the particle sizes, except for those smaller than $1 \mu \mathrm{m}$, at which ratio is substantially less than 1.0. This means that $\mathrm{TiO}_{2}$ is less affected by retention than $\mathrm{SiO}_{2}$ and that it underwent some fragmentation from the big particles to the small ones. 


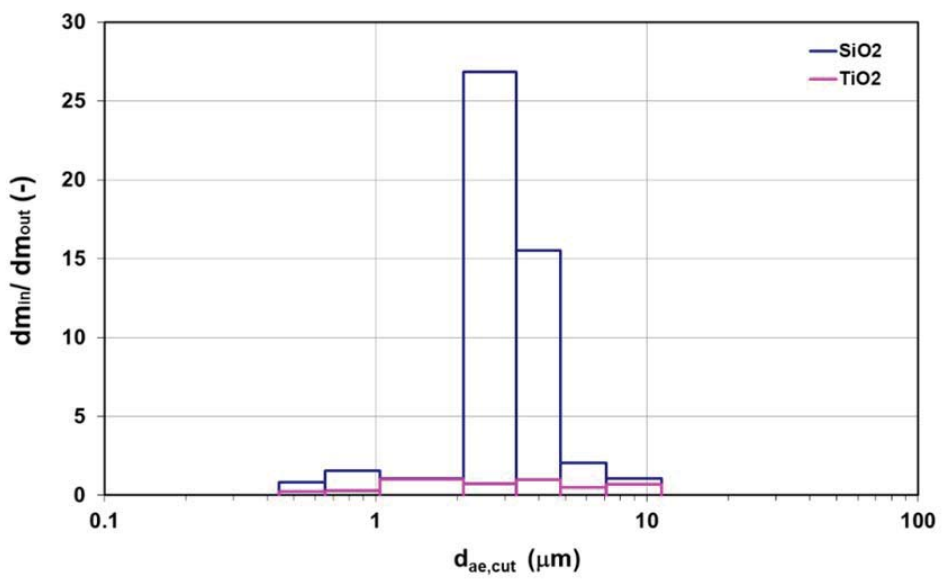

Fig. 32 Inlet to outlet particle mass size distribution of experiments CAAT2-1 $\left(\mathrm{TiO}_{2}\right)$ and CAAT2-5 $\left(\mathrm{SiO}_{2}\right)$

Comparison of inlet and outlet size distributions of $\mathrm{TiO}_{2}$ (Fig. 33) show that for the particle sizes

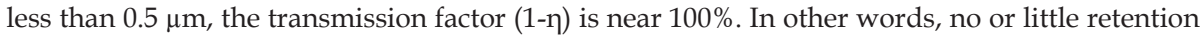
should be expected for the small particles resulting from the aggregates break-up, which according to the studies conducted by Ammar (Ammar et al., 2012) and Thalainen (Ihalainen et al., 2014) would be in the range of few hundreds of nanometers.

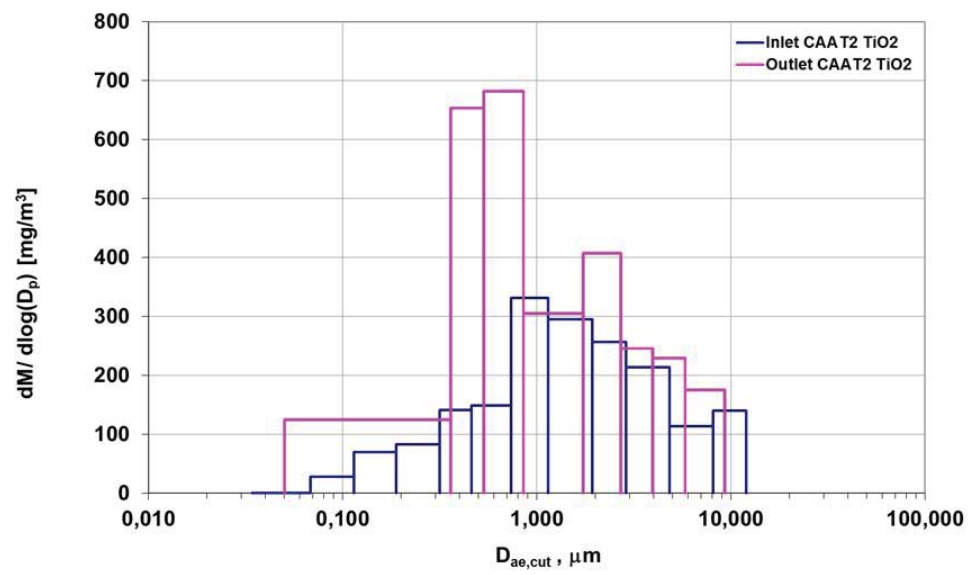

Fig. 33 Inlet and outlet distributions of $\mathrm{TiO}_{2}$. CAAT2_1' 


\subsubsection{Effect of the breach shape}

The influence of the breach shape has been investigated through the comparison of the CAAT2 experiments with those from the previous CAAT campaign (guillotine breach) conducted under similar conditions (i.e., breach cross-section area, mass flow rate, type of particles). As noted above (Fig. 29- Fig. 31), in the CAAT tests the $\mathrm{SiO}_{2}$ particles were also retained with an efficiency ranging from about $75 \%$ to $95 \%$, whereas a much lower deposition was observed for the $\mathrm{TiO}_{2}$ particles $(<30 \%)$. In fact, the relative deviation of the CAAT2 tests with respect to the average retention efficiency was less than $12 \%$, except for the test with lowest retention efficiency; namely, CAAT2 data fit within the CAAT data cloud. Therefore, in terms of the net collection efficiency breach shape causes no major effect under the conditions explored, regardless particle nature.

This observation, although empirically supported, is rather due to the different topology induced by the breach shape on the gas flow distribution within the bundle: the guillotine jet spans $360^{\circ}$ whereas the fish-mouth jet is confined to a much smaller angle. One of the consequences of a much narrower angle is the higher velocity reached by the gas at the breach outlet at a specific mass flow rate. This fact together with the less surface contacting the gas jet along the main motion direction, makes momentum dissipation take longer (i.e., a deeper jet penetration) in the fish-mouth configuration than in the guillotine break. In other words, tubes may behave as efficient particle traps at longer distances from the broken tube in a fish-mouth configuration, but the tube surface area exposed to the gas jet at high velocities is likely to be greater for guillotine breaches. It is however that the tube in front of the fish-mouth breach act as a gas jet "splitter" producing two nearly symmetric jets that head to $\pm 15-25^{\circ}$ directions from the breach. This may explain the enhancement of the efficiency of the tubes trapping particles in the diagonal direction, as discussed below.

The jet behaviour discussed above involves the fact that the guillotine and fish-mouth deposition patterns are different. Fig. 34 shows the deposition profiles of two $\mathrm{SiO}_{2}$ tests conducted at the same gas mass flow rate. The guillotine breach test shows a progressive decrease in the mass deposited as a function of the distance from the broken tube (downhill), whereas the fish mouth profile reaches a maximum deposition at a certain distance and from there on it decays continuously (up-down hill). It is noteworthy that individual tube mass load is never over $2 \%$ of the total retained mass.

A potential explanation of the different profiles observed is the tube surface area exposed to the jet. As said above, fish-mouth jets split into two streams at $15^{\circ}-25^{\circ}$ from the tube facing the breach, this would mean that, after getting split, the next hit of gas stream on a tube surface would take at least two rows distance. In other words, the higher local deposition occurs as a result of the largest tube surface contact exposed to a gas stream with still enough momentum. Even though this is considered the most likely rationale of the observations, another potential contributor may be the resuspension effect in the high gas velocity region within the bundle. As jet gets deeper, resuspension influence decreases until reaching a deposition maximum; from that location on, a deposition evolves as it does in the guillotine configuration. The 
resuspension effect would be less noticeable in the guillotine configuration because of the lower gas velocities achieved.

These differences between the gas jets caused by breach shape may affect the deposition differently according to particle nature. For instance, the highly agglomerated condition of the $\mathrm{TiO}_{2}$ particles which break up even upstream the breach in the turbulent flow (Ammar et al., 2012) and the higher velocities that would be reached with a fish-mouth breach, would make the $\mathrm{TiO}_{2}$ particles be more prone to fragmentation and, hence, harder to be retained. On the other hand, in the guillotine breach configuration, the amount of surfaces facing the jet coming from the breach is significantly greater, which would make $\mathrm{TiO}_{2}$ more susceptible to undergo fragmentation by impaction. This complex discussion regarding particle nature effect depending on breach shape is also affected by the potential of particles to undergo bouncing. Apparently, $\mathrm{TiO}_{2}$ aggregates are less prone to bounce than $\mathrm{SiO}_{2}$ particles since the $\mathrm{TiO}_{2}$ hillshaped deposits formed in front of the breach were not observed for $\mathrm{SiO}_{2}$ (Sánchez-Velasco et al., 2010). Highly agglomerated particles can accommodate impaction energy by deforming (quasi-plastic behavior) so that their probability to collide in an inelastic mode with tubes is higher than for dense particles $\left(\mathrm{SiO}_{2}\right)$, which structure does not allow deformation to a comparable extent to that of the "fluffy" particles. That is, particle nature might also affect the way the kinetic energy is dissipated through the bundle until getting stuck, resulting in different deposition patterns as observed. Hence, any discussion on this area is uncertain and, anyway, net mass retention results do not show any major difference in $\mathrm{TiO}_{2}$ deposits caused by breach shape.

Therefore, the observed similar net retention of particles regardless breach shape should be a consequence of aerosol deposition farther the region around the breach. That is, no matter how particles deposit in the breach nearby, the tube surface still available in the bundle is so huge that particles remaining in the gas flow get deposited to approximately the same extent in their pathway to the next SG stage. 

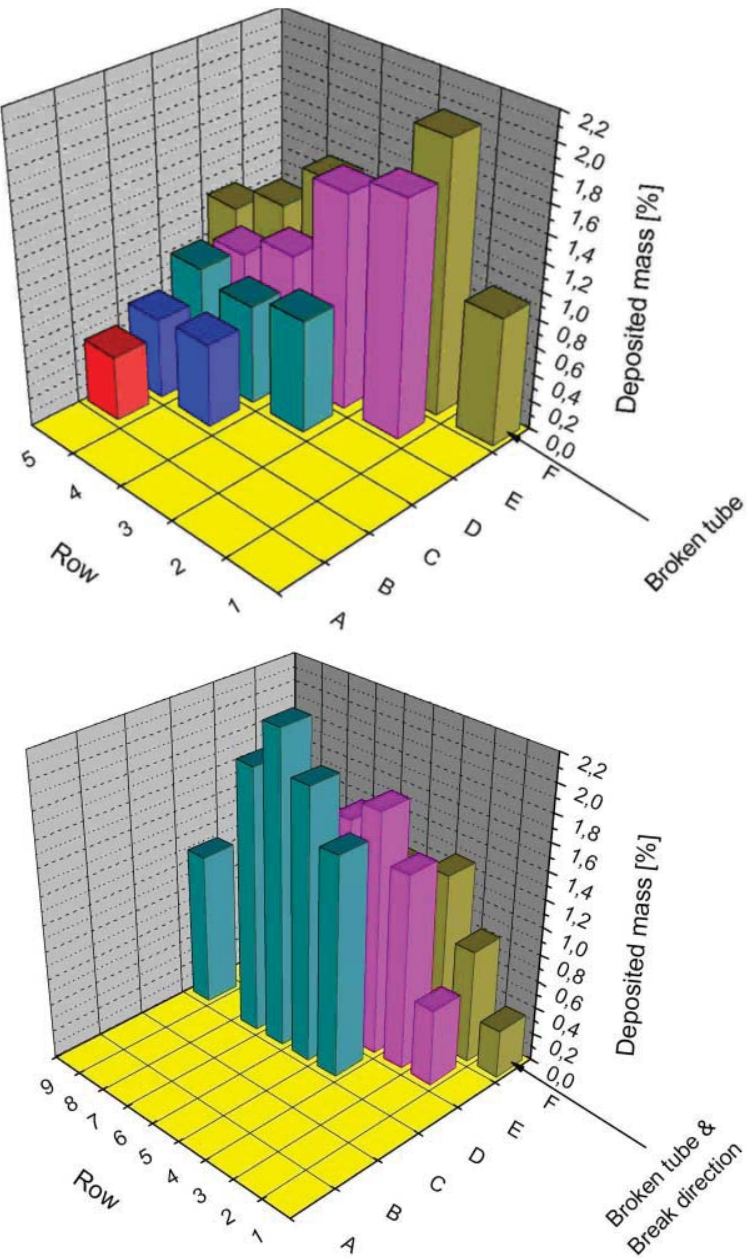

Fig. 34 Guillotine (top) and fish-mouth (down) deposition patterns

\subsubsection{Effect of the breach size}

The influence of the breach size on the retention is analyzed through the CAAT2 $\mathrm{SiO}_{2}$ tests. Fig. 35 shows the normalized efficiency with respect to the lowest value of the retention efficiency among the tests as a function of the breach size $\left(\mathrm{L}_{\text {breach }}=\left(\mathrm{A}_{\text {breach }}\right)^{0.5}\right)$. 


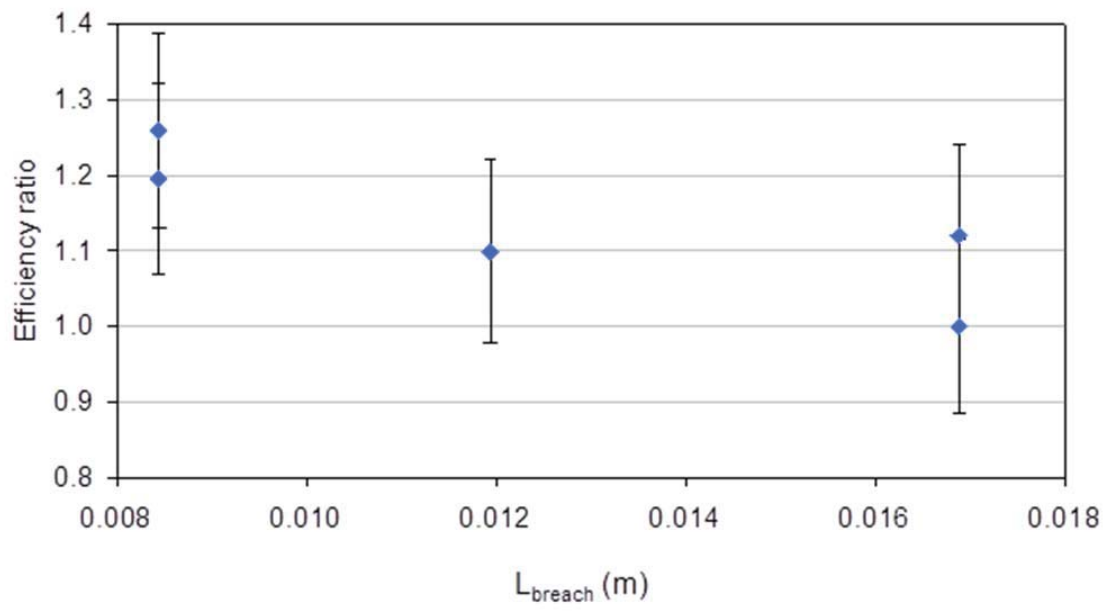

Fig. 35 Normalized efficiency vs. breach size $\left(\mathrm{SiO}_{2}\right.$ tests)

Even though the data points are few and a solid correlation cannot be derived, a gentle trend can be noted: the larger the break the lower the aerosol retention. By increasing the breach size in about a factor of 2.0, the efficiency is reduced around $20-25 \%$. This observation indicates that for a fixed gas mass flow rate, the higher the velocity at the breach outlet, the higher the retention, as it was found by Sánchez-Velasco (Sánchez-Velasco et al., 2010). However, measurements uncertainty makes these two data points overlap over approximately the same efficiency range. Finally, as for data quality, given the proximity between the retention efficiencies of the two tests with the smaller $\mathrm{L}_{\text {breach }}\left(4\right.$ and $\left.4^{\prime}\right)$, reproducibility looks satisfactory.

The on-tube aerosol mass found is eventually the result of the balance between removal mechanisms and "deposition inhibiting" phenomena, like resuspension and/or bouncing. Under the same inlet gas mass flow rate, in-bundle gas Reynolds number would be inversely proportional to the breach size (Re a $\left.\mathrm{L}_{b r e a c h}{ }^{-1}\right)$. A Reynolds number decrease would mean less chance for particles to get deposited either by turbulent mechanisms or by inertial impaction (Stk a $\operatorname{Re}_{\mathrm{p}}$ ). Therefore, the anticipated response of deposition mechanisms to the breach size change, could explain the observed trend.

\subsection{Analytical interpretation}

Through sections above and in previous studies (Sánchez-Velasco et al., 2010), effects of variables such as breach shape or gas mass flow rate on the retention efficiency have been investigated. Nonetheless, they have been shown to be so mild that they practically vanish when data uncertainties are taken into account. In addition, the outstanding influence of 
particle nature (i.e., aggregation state) on aerosol retention efficiency makes any other potential effect explored insignificant in quantitative terms. Therefore, it seems that particle properties, like size and density, should be heavily involved when correlating the data presented above (both CAAT2 and CAAT tests included).

In addition, the discussion of the trends concerning net deposition has highlighted that the particle removal mechanisms such as inertial impaction and turbulent deposition are highly likely to play a major role in the studied scenario. This insight turns Stokes and particle Reynolds numbers into sound candidates to be considered in any empirical correlation to be derived. The former accounts for particle inertia and the latter does for turbulence influence. Additionally, both involve kinetic characteristics of the scenario ( $\left.\mathrm{u}_{\mathrm{gas}}\right)$ and particle properties $\left(d_{p}, \rho_{\mathrm{p}}\right)$ :

$$
\begin{aligned}
& S t k=C_{c} \cdot \frac{\rho_{p} \cdot d_{p}^{2}}{18 \cdot \mu_{g a s}} \cdot \frac{u_{g a s}}{D} \\
& \operatorname{Re}_{p}=\frac{\rho_{\text {gas }} \cdot u_{\text {gas }} \cdot d_{p}}{\mu_{\text {gas }}}
\end{aligned}
$$

This rationale becomes reinforced when the ratio of these two non-dimensional numbers is assumed to be the correlation independent variable $\left(\mathrm{Stk} / \mathrm{Re}_{\mathrm{p}}\right)$. On one hand, this ratio is dependent on those particle properties emphasized to be crucial in the discussion above:

$$
\frac{S t k s}{\operatorname{Re}_{p}}=C_{c} \cdot \frac{\rho_{p} \cdot d_{p}}{\rho_{g} \cdot D}
$$

On the other, conceptually speaking, it looks consistent with the fact that a $100 \%$ efficiency has not been reached, even at the higher velocities explored by PSI (Lind et al., 2012). The existence of a threshold may be understood as a balance between deposition mechanism and deposit removal mechanisms (i.e. resuspension). Such a tradeoff is also captured by the nondimensional numbers ratio, since high velocities would increase both Stk and Rep.

By plotting the experimental data of the efficiency as a function of the $S t k / R e_{p}$ ratio (Fig. 36), a sigmoidal type correlation of the form

$$
\eta=83.97538+\frac{14.18368-83.97538}{1+1.294^{10^{25}}\left(\frac{S t k}{\operatorname{Re}_{p}}\right)^{8.22621}}
$$

which correlation coefficient, $\mathrm{R}^{2}$, is 0.982 . It is worth mentioning that the highest and lowest efficiency data have been screened out to derive this correlation. 


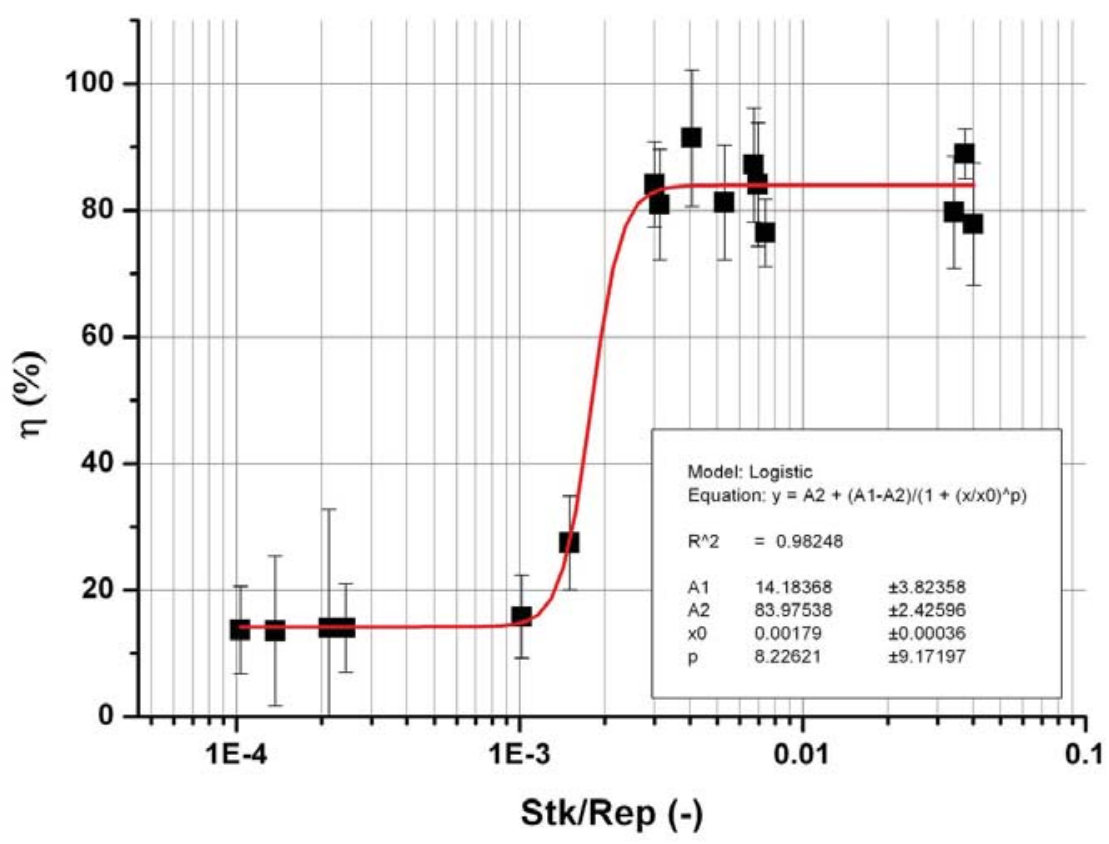

Fig. 36 Empirical correlation of CAAT and CAAT2 data

This correlation is seen as accurate enough given that the average error of the efficiency data shown in Fig. 29 - Fig. 31, are around 9.5\% in the upper efficiency band (i.e., Stk/ $\operatorname{Re}_{\mathrm{p}} \geq 2 \cdot 10^{-3}$ ) and much higher $(\sim 76.5 \%)$ in the lower one (i.e., $\left.\mathrm{Stk} / \operatorname{Re}_{\mathrm{p}} \leq 1 \cdot 10^{-3}\right)$. That is, no trend should be sought further than asymptotic efficiencies around $14.1 \%$ and $83.3 \%$ for the lower and upper efficiency bands, respectively. In addition, the particle density is one of the most influencing variables in the correlation, but it is also largely uncertain for the aggregates $\left(\mathrm{TiO}_{2}\right.$ and $\left.\mathrm{Cu}\right)$ whose values are just estimates. Therefore, the significance of the correlation derived is more qualitative than quantitative; this is even further stressed by the fact that there is just a single data point in the transition region (i.e., $10^{-3}<\mathrm{Stk} / \operatorname{Re}_{\mathrm{p}}<2 \cdot 10^{-3}$ ). 



\section{Separate Effect Tests}

\subsection{Introduction}

Along the ARTISTs experiments the deposition mechanisms of particles on the tubes surface were studied. The deposition patterns observed in previous CAAT2 campaign (Tardáguila and Herranz, 2013) and the modelling results (López del Prá et al., 2010) have helped to understand the gas flow interaction with the tubes (Herranz and Velasco, 2013; Khushnood et al., 2004; Sánchez-Velasco et al., 2010). The flow-induced vibration manifests the possible interaction of the tubes vibration mechanisms with the particles deposition ones. This interaction, which is a gap in knowledge, could interfere in the net radioactivity retained in the secondary side of the SG. To cover this gap, the SET experimental campaign has been launched. This second part of the chapter is aimed at studying the effect of tube vibration on the aerosol retention.

The scope of the SET campaign in summary is:

- Two tube arrangements, fixed and normal;

- Two types of particles different in nature $\mathrm{SiO}_{2}$ and $\mathrm{TiO}_{2}$;

- Two breach shapes, fish-mouth and guillotine of the same size (1D);

- Gas mass flow rate of the jet discharged, ranged from $50 \mathrm{~kg} / \mathrm{h}$ to $220 \mathrm{~kg} / \mathrm{h}$.

The SET campaign was divided into two stages of different nature: 4 assessment tests and 4 analysis tests. The assessment tests were focused on the vibration characterization of normal 
and vibration-attenuated tubes (or fixed tubes). Once the vibration attenuation was confirmed, the analysis tests consisted of integral tests under vibration-attenuated conditions. The comparison of the retention efficiency between normal integral tests and fixed-integral tests, has allowed fixing the effect of the vibration attenuation on the aerosol retention.

This study does not intend to be a comprehensive work on the tubes vibration characterization. However, thanks to the assessment test the dynamic behavior of the tubes can be studied. Although it is out of the aim of the SET campaign they have been analyzed too. A background on tubes vibration and the results and discussion of the dynamic behavior of the tubes can be found in appendix 3 .

\subsection{SET experimental configuration}

The SET program has been conducted, as the CAAT2 experiments, at the PECA-SGTR facility, located at the Laboratory for Analysis of Safety Systems (LASS). The facility (Fig. 5) has a very similar experimental configuration of previous CAAT2: an injection line through which the particle carrier gas is injected, an aerosol generator, a bundle of tubes (placed inside of the PECA vessel), the measurement instrumentation to characterize the vibration of tubes and the particles entering and leaving the facility, and the control (PLC) and data acquisition systems (SCADAS) to control and acquire the thermahydraulic variables. Particles have been generated with the FBG. (For a detailed description of the systems see section 3.2).

The bundle of tubes is a scaled-down assembly simulating the break stage of the secondary side of the steam generator. A mini-bundle consisting of an array of $5 \times 4$ tubes has been used in the assessment tests, while a full bundle, i.e. square array of $11 \times 11$ tubes, has been used in the analysis campaign (Fig. 37 and Fig. 38). In any case, the dimensions of the tubes and the support plate are representative of those used in a stage of real SG of a nuclear power plant (Auvinen et al., 2005) as described in section 3.2.4. 

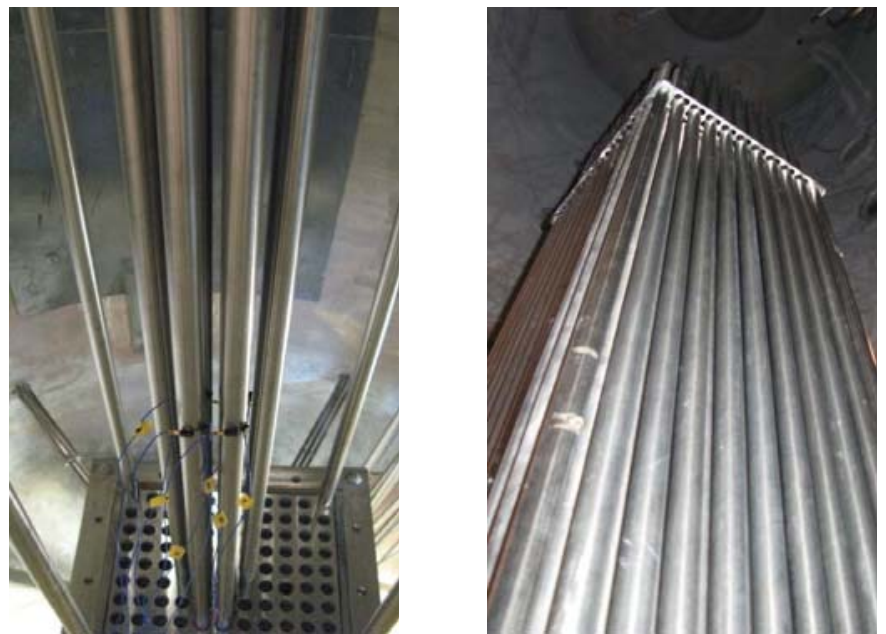

Fig. 37 View of the mini-bundle with piezo electric accelerometers (left) and full bundle (right)

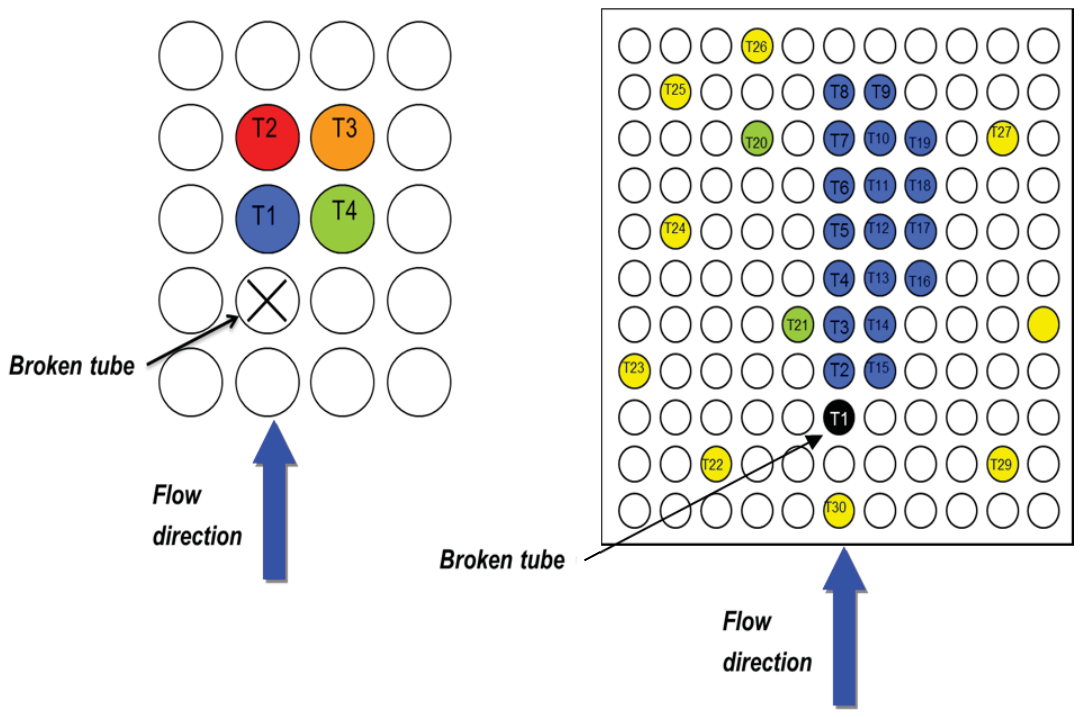

Fig. 38 Sketch of the mini-bundle of tubes (left) and full bundle (right) 


\subsubsection{Instrumentation for vibration characterization}

The first stage of the SET campaign comprises the assessment tests. They consisted of a set of tests aimed to characterize the vibration of the tubes under normal-vibrating (normal tubes) and non-vibrating (fixed tubes) conditions. The instrumentation used for this purpose is a set of accelerometers and the corresponding acquisition system.

\subsubsection{Piezoelectric accelerometers}

Most modern vibration measurements are performed by measuring the acceleration. If velocity or displacement data are required, the acceleration data can be integrated (velocity) or double integrated (displacement). Some accelerometer signal conditioners have built-in integrators for that purpose. Despite the different electromechanical transduction mechanisms of the accelerometers, all of them use a variation of the spring mass system, and are classified as seismic transducers.

An accelerometer has to be fixed on a surface whose vibration mode needs to be determined. In this study the accelerometers have been placed on the tube surface. The tube to tube distance is the key variable to decide the accelerometer type for these tests. It is so small that the choice is restricted to the piezoelectric transducer type.

The accelerometers use the piezoelectric effect for vibration measurements. A summary of the principle applied by this type of transducers is given in appendix 3 .

\subsubsection{2. $\quad \mathrm{ICP} ®$ Accelerometers}

ICP, as described earlier, is PCB's registered trademark that stands for "Integrated Circuit Piezoelectric". It identifies PCB sensors that incorporate built-in, signal-conditioning electronics. The built-in electronics convert the high-impedance charge signal that is generated by the piezoelectric sensing element into a usable low-impedance voltage signal that can be readily transmitted, over ordinary two-wire or coaxial cables, to any voltage readout or recording device. The low-impedance signal can be transmitted over long cable distances, from the accelerometer placed on the tubes within the vessel until outside from the vessel where the LMS is; and used in dirty environments as the vessel atmosphere, loaded of particles. The simplicity of use, high accuracy, broad frequency range and the tiny size (under $1 \mathrm{~cm}$ long and $0.5 \mathrm{~cm}$ thickness) of ICP accelerometers made them the suitable type for being used in the SET campaign (Fig. 39). Two ICP® accelerometers placed in each tube allowed their vibration mode to be characterized. The accelerometers were glued at the middle point between the plates that hold the tubes (Fig. 40). 


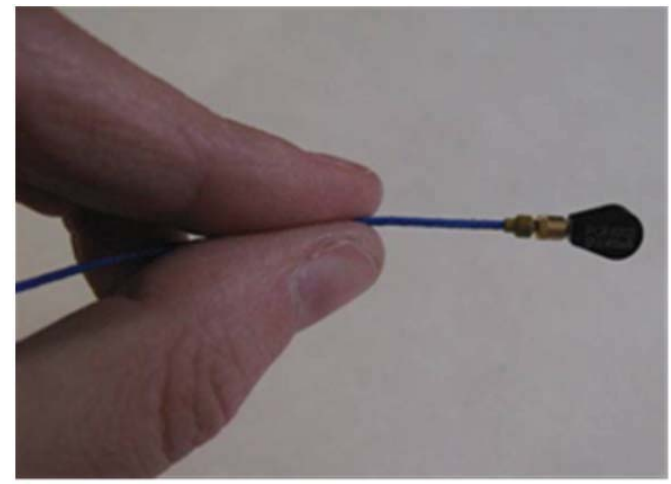

Fig. 39 ICP® accelerometer
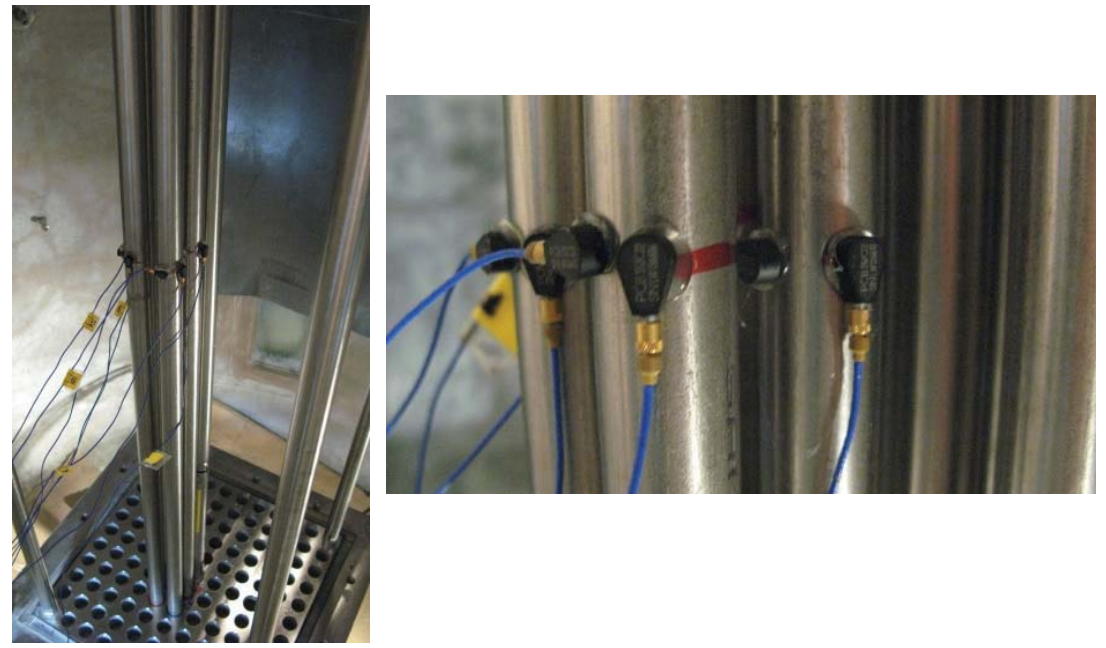

Fig. 40 Two views of the ICP ${ }^{\circledR}$ Accelerometers on the tubes surface

The electronics within ICP accelerometers require excitation power from a constant-current regulated, DC voltage source. This power source has been obtained from the LMS SCADAS mobile (Fig. 41). It is a vibration data collector signal conditioning. In addition to providing the required excitation, it incorporates additional signal conditioning, such as gain, filtering, buffering, and overload indication. 


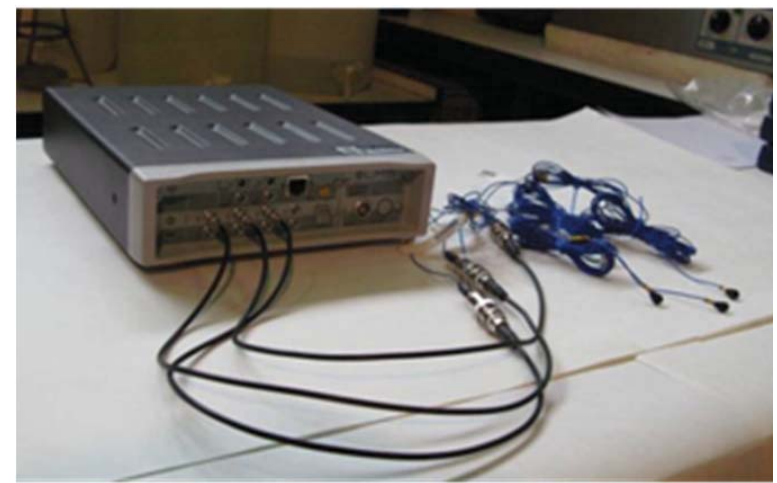

Fig. 41 LMS SCADAS mobile with some connected accelerometers

The sketch of a system set-up for ICP accelerometers with an LMS SCADAS signal conditioning and data acquisition system are shown in Fig. 42.

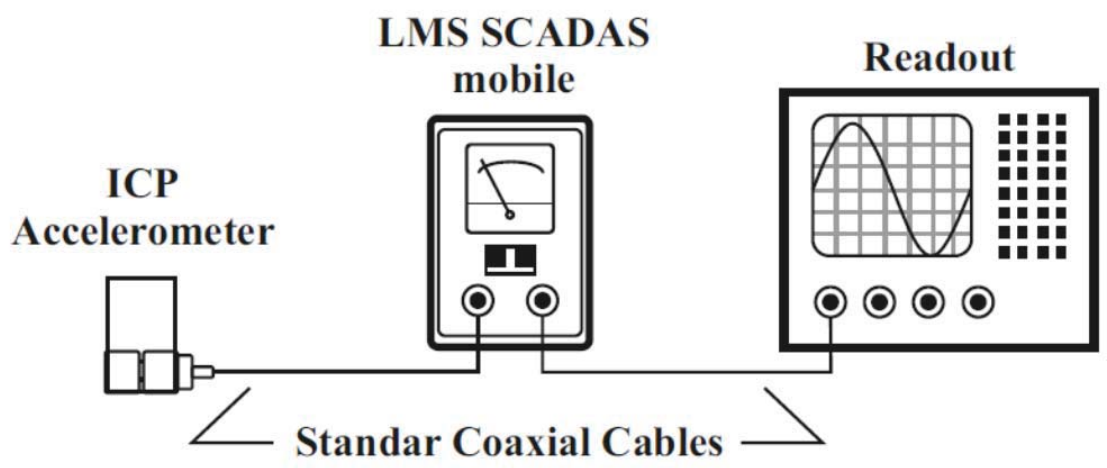

Fig. $42 \mathrm{ICP}{ }^{\circledR}$ System set-up

\subsubsection{Instrumentation for aerosol characterization and sampling}

The second stage of the SET campaign is the analysis tests, integral tests aimed to determine the tube vibration effect on the aerosol retention. The tests are focused on the particles characterization and retention efficiency measurements, in which the tubes have been fixed. 
Characterization of incoming and outgoing aerosols provides major insights into the scenario: the mass depleted on the bundle of tubes and structures leads to the overall retention efficiency determination; and the shift of particle size to smaller diameters to determine the retention as a function of diameter. This has been done in real-time through the devices that operate during nearly the entire test (ELPI and APS) and by other systems (impactors and membrane filters) that work over much shorter time spans (all together, though, they extend to nearly the entire test duration). All of them required withdrawing isokinetic samples from the main inlet and outlet lines. APS determines the aerodynamic number size distribution of particles entering the facility, whereas this same variable is measured by the ELPI at the bundle outlet. Mass cascade impactors determine the aerodynamic mass size distribution of the aerosols. Two of them have been used, one at the inlet (DLPI, Dekati Low Pressure Impactor, with 13 stages that cover a particle size range from $0.03 \mu \mathrm{m}$ to $10 \mu \mathrm{m}$ ) and the other at the outlet (MARK III, which classifies particles into 8 stages, from $0.69 \mu \mathrm{m}$ to $15.7 \mu \mathrm{m})$. It is worth mentioning that DLPI and ELPI use the same type of impactor and both classify particles in the same size bins.

Membrane filters sample the aerosol stream by using a vacuum pump during a period of time, at a controlled flow rate. The mass of particles are retained by the filter that is weighed.

Details of each device can be found in previous section 3.2.7 Instrumentation and sampling, within the CAAT2 experimental campaign.

\subsection{Experimental matrix}

The test matrix has been based on the analysis of experimental conditions (Bakker, 2001; Güntay et al., 2002) and previous CAAT's campaigns (Sánchez-Velasco et al., 2010). The attention is focused on achieving aerodynamic scenarios as close as possible to the SGTR. Previous integral CAAT's tests have shown that the main variable affecting the particle retention is the particle nature. Then, this is again the key variable of the SET tests in which two types of particles with a different aggregation state have been used: $\mathrm{SiO}_{2}$ and $\mathrm{TiO}_{2}$. The gas mass flow rate ranged between $50-250 \mathrm{~kg} / \mathrm{h}$ and two breach types (fish-mouth and guillotine) of the same size, 1D (i.e. cross-section areas correspond to the tube transversal section), have been used. The final experimental matrix is shown in TABLE 13. 
TABLE 13 Experimental test matrix

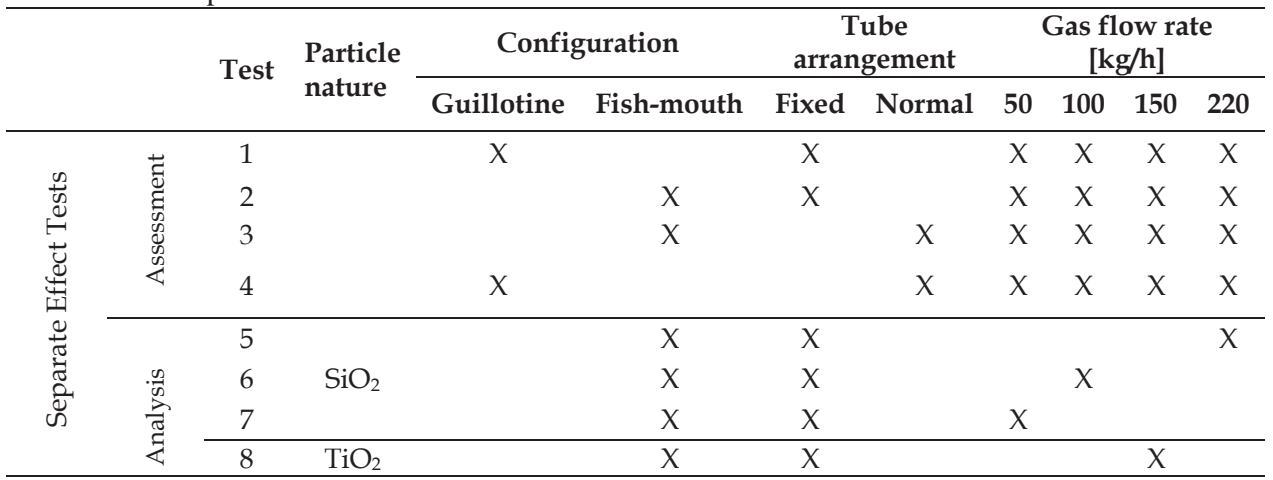

\subsubsection{Target variables}

\subsubsection{Particle nature}

Two types of particles were tested in the analysis tests: $\mathrm{TiO}_{2}$ and $\mathrm{SiO}_{2}$. The main aerosol features, average primary diameter, nominal density, estimated aerosol density and specific surface area, of both types of particles are summarized in TABLE 11. Moreover, details of them have been previously discussed and can be found in section 4.3.1.1.

\subsubsection{Breach shape and size}

Since the vibration driving mechanism is the gas jet momentum, two types of tube breaches have been used (besides two different flow rates, from $50 \mathrm{~kg} / \mathrm{h}$ to $250 \mathrm{~kg} / \mathrm{h}$ ): guillotine and fishmouth, the most common types of tube ruptures in SGTR events. Both breaches have the same size, 1D (Fig. 10), whose area corresponds to the cross section of the tube. The main reason for using this size is that they have the same section and comparison of the effect of both configurations can be done. By comparing the vibration mode of tubes when the gas leaves through the breaches, under the range of gas mass flow rate, the effect of the gas jet momentum on the tube vibration will be discussed.

\subsubsection{Tube arrangement: fixed vs. normal tubes}

The aim of the SET campaign is to determine the effect of the tube vibration on the aerosol retention. To do so, the tubes have to be characterized in terms of vibratory mode under normal and fixed arrangements. Normal arrangement refers to the one described in section 3.2.4, in which two support plates with holes stand the tubes. As observed in Fig. 43, a tiny gap exists between the tubes and the holes of the plate. This gap was eliminated by fixing the tubes. To do so, the tube surface in contact with the plate was enrolled with tape. Then, the four contact points of the supporting plate were thermally glued to the tube (Fig. 44). In this way, the tubes 
shaking were eliminated. Moreover, to increase the tubes weight and its resistance to be moved, they were filled with $1 \mathrm{~mm}$ in diameter river sand (Fig. 45). Most of the volume of the tube was filled with the sand. As a consequence, the tube mass was increased in average in a factor of 1.77 .

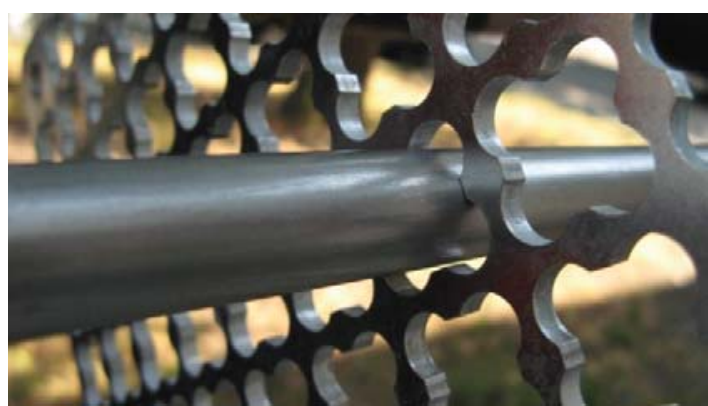

Fig. 43 Tube inside the supporting plate in the "normal" arrangement

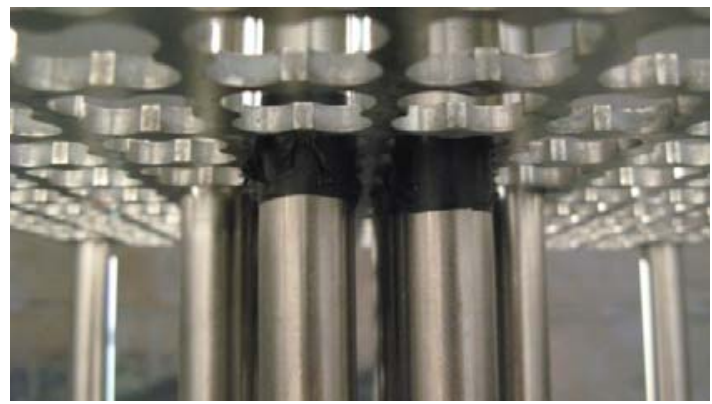

Fig. 44 Tubes inside the supporting plate in the fixed arrangement

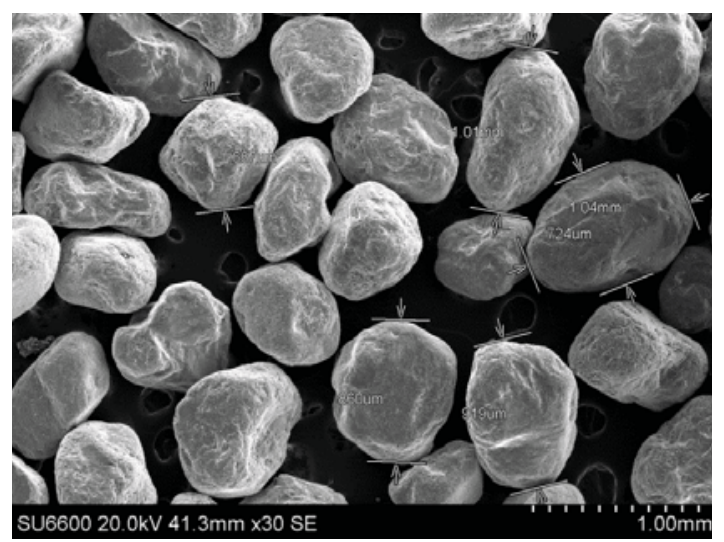

Fig. 45 SEM of river sand used to fill the tubes in the fixed arrangement 
Fixing the tube correctly is a key to achieve the goal of the experiments. By the way described above, the results showed a drastic drop of the amplitude of the vibration. It is assumed that is an efficient mode of fix arrangement. However, other ways were tested before, whose results did not satisfy the vibration attenuation required. The results of that experimental campaign are presented in appendix 4.

\subsubsection{Gas mass flow rate}

The flow rates set (from $50 \mathrm{~kg} / \mathrm{h}$ to $220 \mathrm{~kg} / \mathrm{h}$ ) were found to be in the range anticipated during a meltdown SGTR sequence at the time span at which fission products enter the secondary side of the SG (Guntay et al., 2000). The scope is to characterize the tube vibration in the full range of gas mass flow rate covered in the facility.

\subsection{Measurement procedure}

\subsubsection{Assessment tests}

Room temperature and atmospheric conditions were maintained during the SET experiments. The assessment tests were rather simpler than the analysis ones since they do not inject aerosols in the bundle. The vibration of the tubes was characterized with 8 accelerometers. Two accelerometers attached on each of the tubes allow determining the frequency and amplitude in two directions, parallel and perpendicular to the jet stream. The accelerometers were placed at the middle of a tube between the end plates, (Fig. 40). The tests started when the desired mass flow rate was stabilized. Then the vibration was measured during 10 minutes. This time allowed acquiring an extensive data to characterize the vibration mode of the tubes. Fig. 46 shows an assessment of the test measurement plan during a test.

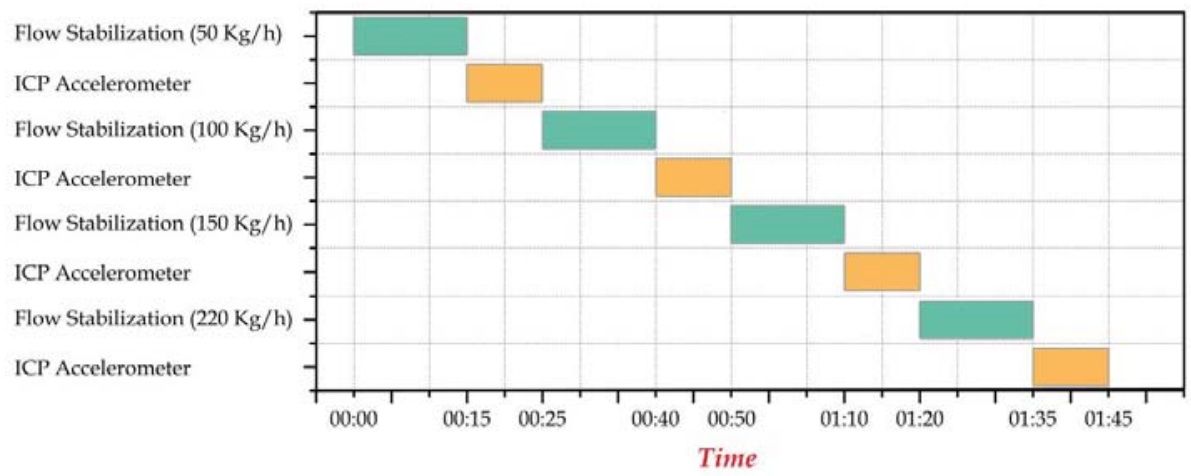

Fig. 46 Schedule of the measurement procedure during the assessment tests 


\subsubsection{Analysis tests}

As mentioned above, the analysis tests were integral tests in which the tubes were fixed. Hence, these experiments were performed by following the procedure of the CAAT2 tests. It is detailed in section 4.4 .

\subsection{Major variables}

\subsubsection{Amplitude and frequency}

As mentioned before, the tubes vibrate describing a non-constant motion but alternately greater and less than some average values. It is well known that the extent of the oscillation determinates the magnitude of the vibration or amplitude and the repetition rate of the cycles of oscillation determines the frequency of vibration.

The accelerometer signal was acquired in the time-domain, from where the amplitude is obtained. To determine the frequency content it has been shifted to the frequency-domain by applying the FFT. From the power spectrum of each tube the characteristic frequency was obtained.

\subsubsection{Retention efficiency}

The retention efficiency is calculated as derived in the section 4.5.

\subsection{Methodology of analysis}

The SET program, as introduced before, was carried out in two phases: the assessment tests and the integral tests. With the precise objective of attenuating the vibration, in the first phase the tubes were fixed. Each fixed tube was characterized from the point of view of the vibration in terms of amplitude and frequency. A method used for fixing the tubes was considered efficient when it obeys that $2 / 3$ tubes $A_{\mathrm{NT}}>2 \mathrm{~A}_{\mathrm{FT}}$, i.e. in at least $67 \%$ of the cases the amplitude by fixing the tube is reduced by more than $50 \%$.

The analysis test campaign was performed with tubes efficiently fixed. It consisted of 4 integral tests in which the retention efficiency of the fixed bundle was determined. The results were compared with previous CAAT and CAAT2 tests performed under similar conditions but with the normal bundle.

In summary, the performance of the SET campaign was done under the methodology shown in Fig. 47. 


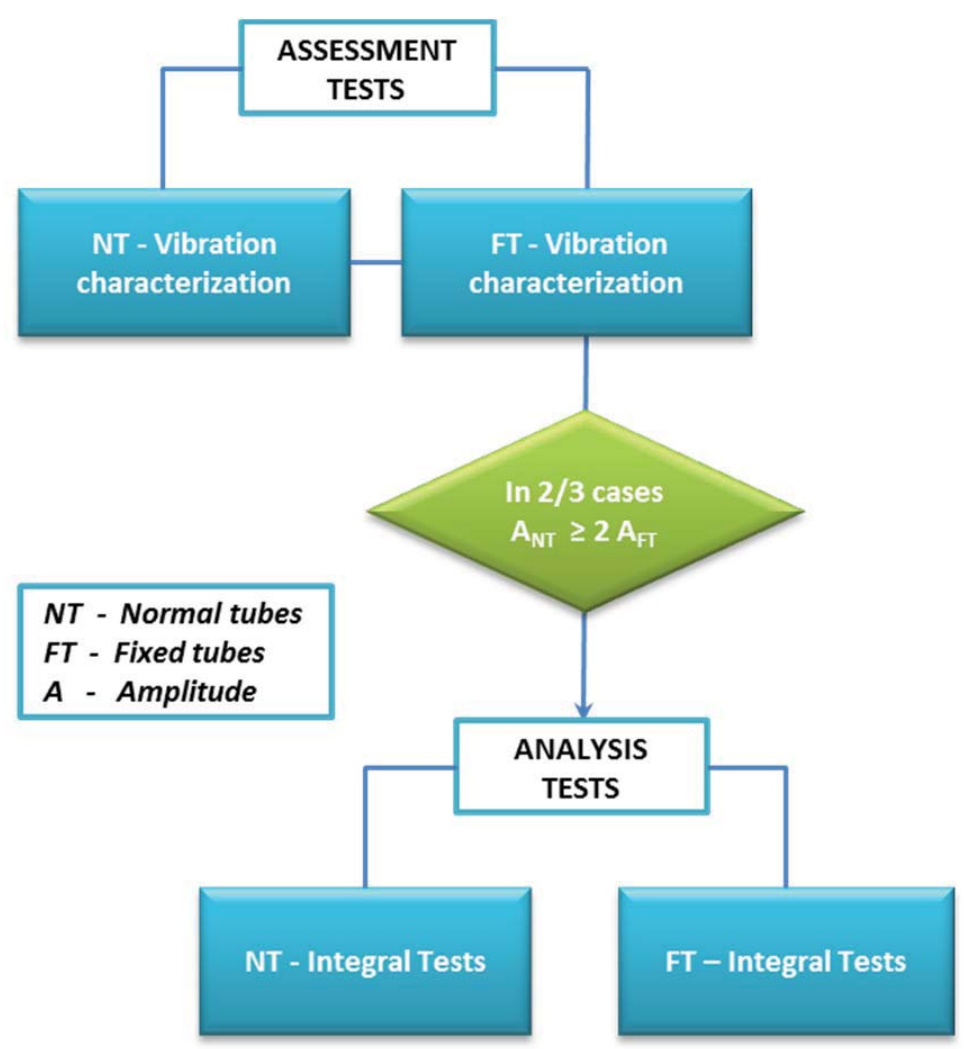

Fig. 47 SET campaign methodology

\subsection{Results and discussion}

The vibration of the tubes has been characterized in terms of their amplitude and characteristic frequency, given in units of acceleration $(\mathrm{g})$ and Hertz $(\mathrm{Hz})$ respectively. Fig. 48 shows the characteristic frequency and amplitude at flows around 100, 150 and $220 \mathrm{~kg} / \mathrm{h}$ for the fishmouth configuration (SET 2 and SET 3). The amplitude corresponds to the RMS (root mean square) value of the temporal series of the acceleration acquired while the signal is stable. The characteristic frequency of the vibration has been determined by developing the FFT analysis of the signal. A comparison of the guillotine (SET 1 and SET 4) and fish-mouth (SET 2 and SET 3) leaving jet induced vibration (amplitude) is shown in Fig. 49. The guillotine vibration was expected smaller than the fish-mouth. Nevertheless, it has been characterized in order to compare both vibration modes. 
In Fig. 48 and Fig. 49 columns are denoted by Tix and Tiy. i refers to the tube in which the measurement is taking place according to Fig. 38 tubes numbers. X-direction refers to the accelerometer placed in the tube $\mathrm{Ti}$ in the same direction than the flow leaving the breach whereas y-direction refers to the axial direction of the tube. Moreover, it is worth to highlight that any single column missed means that the amplitude is under a threshold, i.e. $0.1 \mathrm{~g}$. Results at $50 \mathrm{~kg} / \mathrm{h}$ are not shown because the vibration in every single tube has been attenuated below this level.
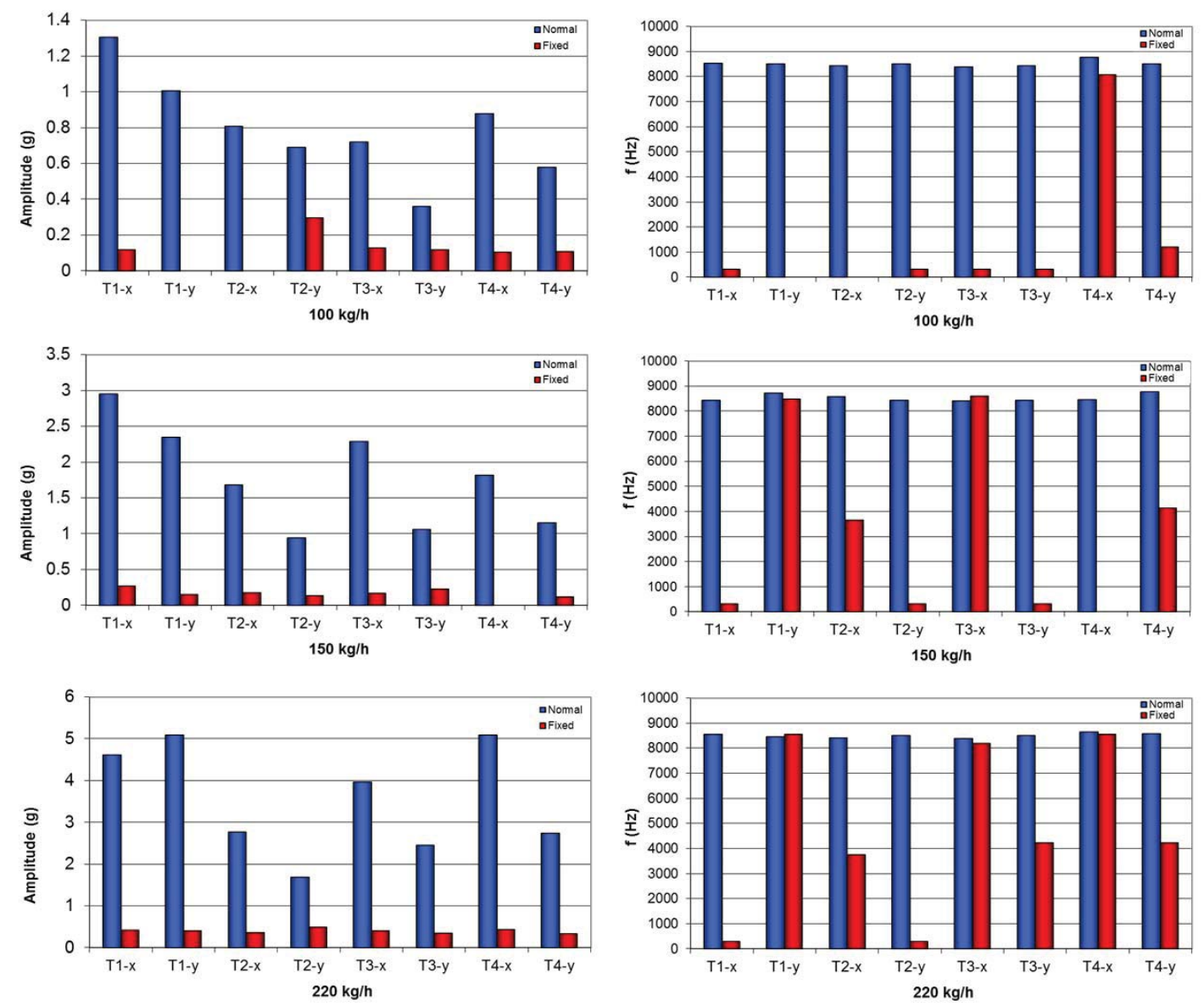

Fig. 48 Comparison of the amplitude (left) and characteristic frequency (right) of the tubes under fixed and normal fish-mouth configuration

Guillotine

Fish-mouth 

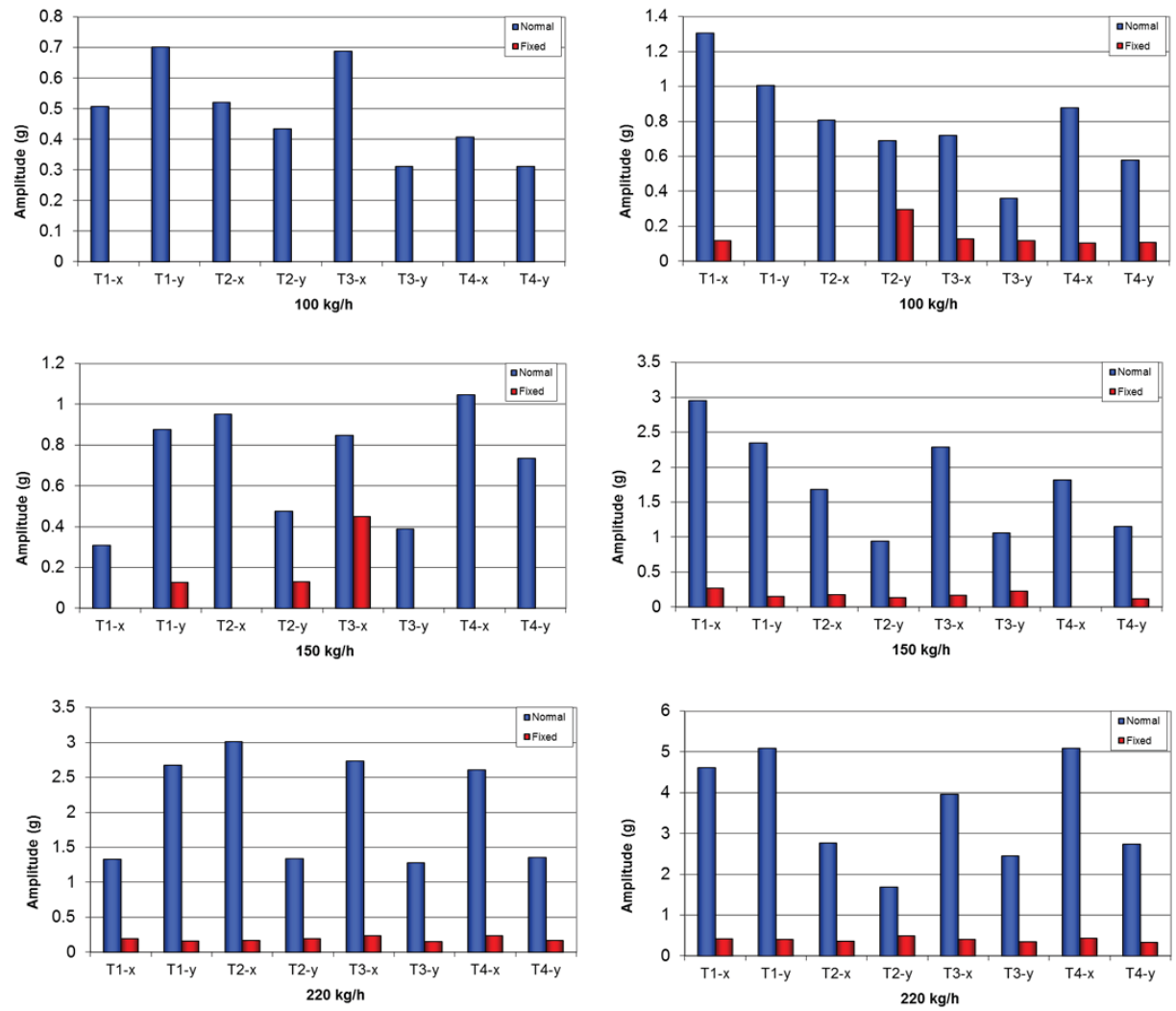

Fig. 49 Comparison of the amplitude of tube vibration under guillotine (left) and fish-mouth (right) tube breach

Results in Fig. 48 and Fig. 49 present a sound evidence of the attenuation of vibrations. Under the normal configuration (as-fabricated tubes, blue column) it can be observed that the higher the jet momentum the higher the amplitude. When tubes are fixed (red column) the amplitude drops from $50 \%$ to almost zero. It is worth to point out that, as expected, the tubes vibrations are stronger in the x-direction, parallel to the jet, except in most of the cases, for the T1. T1 stands for the first tube in front of the breach and the jet impinges directly against it. Then, the flow may ascend along the tube surface producing higher amplitudes in y-direction. The measured frequencies are also affected when the jet inertia is increased; however, the frequencies become more similar to the normal or free-vibration situation as the mass flow rate gets higher. 
Fig. 49 shows the important role that the breach shape plays, since for the same section, the gas leaving a guillotine breach spreads into $360^{\circ}$ while the fish-mouth breach lets the gas confine into a $15^{\circ}-25^{\circ}$ angle. Consequently the jet of the fish-mouth keeps higher momentum that results in higher amplitude of vibration of the tubes around the breach. In any case, when the tubes are fixed, the flow induced vibration effect is lost. The amplitude drops under $0.5 \mathrm{~g}$ and the vibration is considered attenuated.

Fig. 50 - Fig. 51 show the results obtained in the analysis campaign. Fixed-integral tests have been compared with previous tests performed under similar conditions within the CAAT (Sánchez-Velasco et al., 2010) and CAAT2 campaigns with normal tubes (Tardáguila and Herranz, 2013). To study the effect of the tube attenuation on the retention, the breach shape for which the jet induces the strongest vibration on the tubes has been chosen. The fish mouth breach presents the most conservative scenario since the jet is confined into a narrow breach so it keeps a stronger jet momentum and as a result, the vibration produced into the tubes is larger.

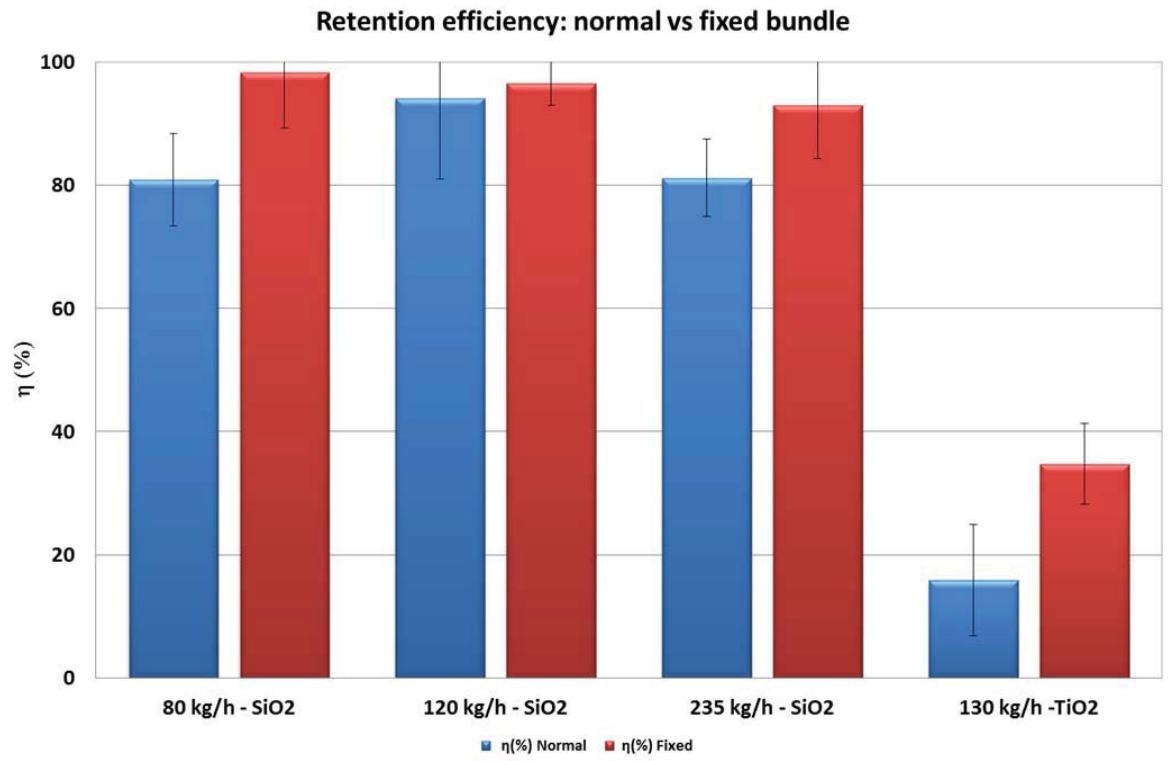

Fig. 50 Collected efficiency of fixed vs. normal integral tests 


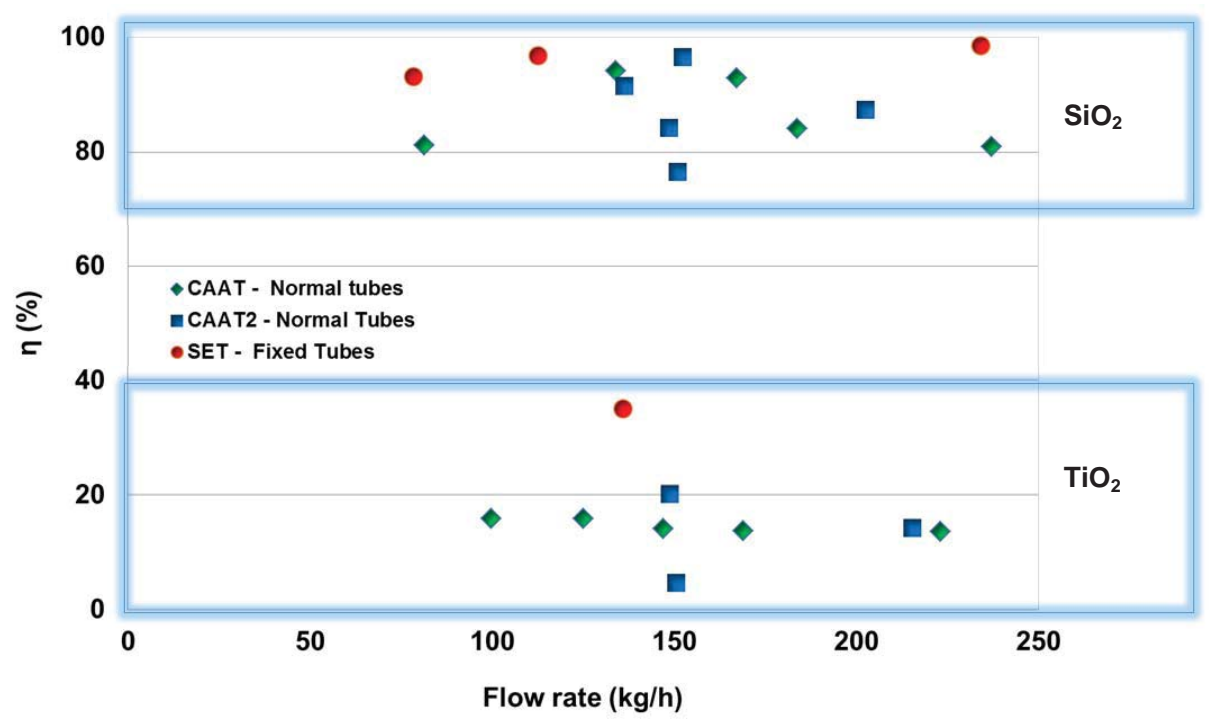

Fig. 51 Retention efficiency of CAAT, CAAT2 (normal bundle) and SET (fixed bundle)

Fig. 50 is a comparison of the net retention of the fixed and normal bundle under similar conditions. It indicates that vibration does not affect significantly the net retention in the bundle. The $\mathrm{SiO}_{2}$ data in both tubes arrangements indicate a slight tendency towards increasing retention in the absence of vibration; however, differences found are within the experimental uncertainty so that such trend cannot be strictly set. This result may be also extended to the $\mathrm{TiO}_{2}$ data, where increasing trend is more noticeable. Nevertheless one test does not allow extending a trend and the result might be confirmed. When the comparison is extrapolated to any set condition within the CAAT's campaigns, it is observed that under the normal tube vibration, $\mathrm{SiO}_{2}$ retention is over $70 \%$, whereas $\mathrm{TiO}_{2}$ shows much lower values (Fig. 51). Therefore, one may conclude that whatever the influence of the vibration is, it is a second order when compared to the particle nature.

However, when the mass distribution on the bundle of tubes is analyzed (Fig. 52) a noticeable difference in the deposition pattern across the bundle is observed. The absence of vibration results in a rather uniform deposition all over the surfaces, whereas a visible non-uniform profile was obtained in the presence of vibration. This observation may be the result of the resuspension enhancement caused by vibration. The particles deposited on those tubes submitted to the highest vibration level resuspend and are dragged deeper in the bundle until they collide again with another tube. The absence of vibration may thus hinder resuspension to a large extent, so that a rather more uniform deposition pattern is observed. Whatever the actual reason for the retention pattern difference is, the fact is that the integral mass retained hardly changes, probably because the total tube surface available for deposition is so large that 
differences in the nearby area of the breach become meaningless. In the case of $\mathrm{TiO}_{2}$ agglomerates, the uniformity of deposits distribution in the absence of vibration is also observed.
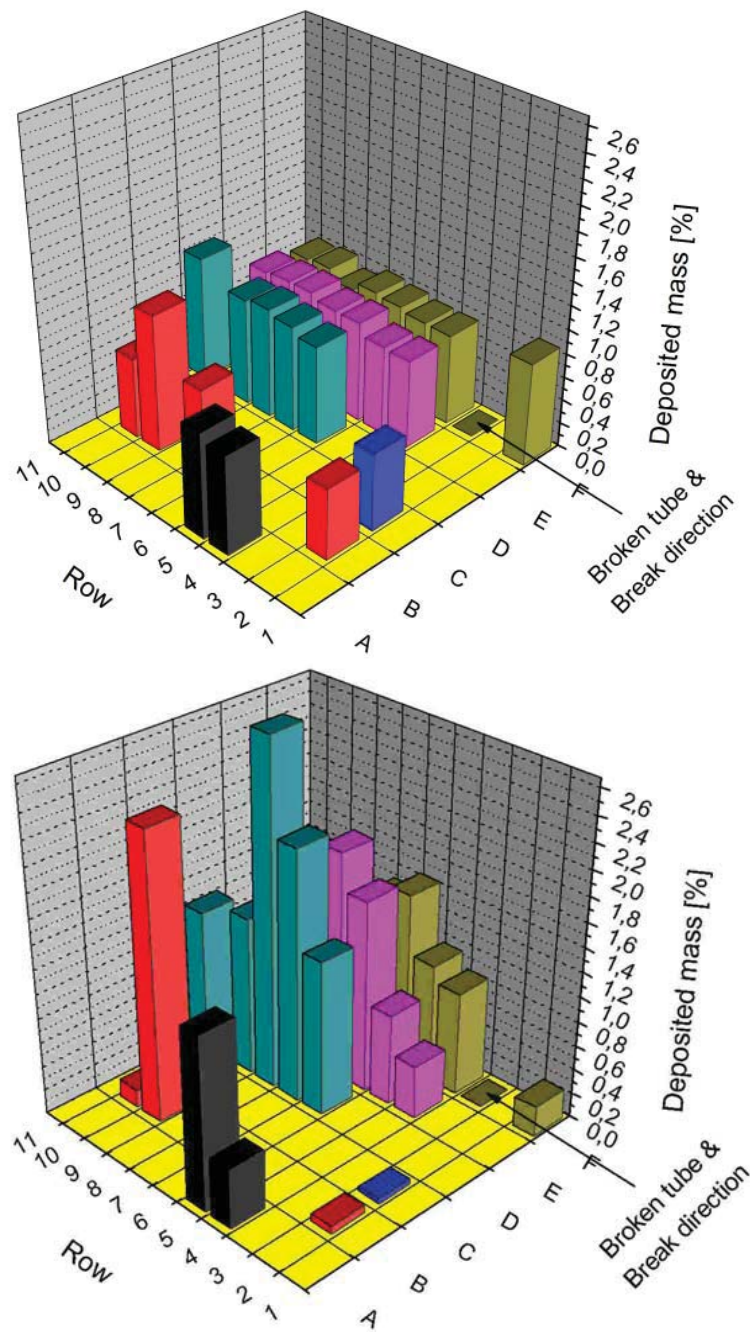

Fig. 52 Deposition pattern of fixed bundle (up) vs normal bundle (down). $\mathrm{SiO}_{2}$, fish-mouth configuration 



\section{Chapter 5}

\section{Acoustic Aerosol Agglomeration Tests}

\subsection{Introduction}

This section is dedicated to the Acoustic Aerosol Agglomeration (AAA) experimental campaign. The tests are focused on getting insights into acoustic agglomeration of aerosols for the source term mitigation. The experimental campaign has been developed to investigate the performance of an acoustic agglomerator system at lab-scale under conditions as close as possible to those prevailing under containment venting. To achieve this generic objective, the following specific objectives have been reached: i) to determine the aerosol growth in the MSAA (Mitigative System Acoustic Agglomerator) set-up and ii) to explore the main variables affecting previous factors. To do so, it has been necessary to set-up, develop and integrate an acoustic agglomeration system, the MSAA, in the PECA facility; as well as to find out the best operational conditions of the acoustic agglomerator system.

The particles carried by the gas are discharged into the acoustic chamber in which the ultrasound field is applied, they pass along and leave the system through a chimney. As a summary of the scope of the thesis, regarding this experimental campaign, two types of particles different in nature, $\mathrm{SiO}_{2}$ and $\mathrm{TiO}_{2}$; with 3 particles diameters of $\mathrm{SiO}_{2}(0.3 \mu \mathrm{m}, 1 \mu \mathrm{m}$ and $2.5 \mu \mathrm{m})$ and three gas mass flow rates $(12 \mathrm{~kg} / \mathrm{h}, 50 \mathrm{~kg} / \mathrm{h}$ and $100 \mathrm{~kg} / \mathrm{h})$ of the jet discharged into the chamber, have been used. 


\subsection{Background on acoustic aerosol agglomeration}

The acoustic agglomeration of microparticles is a process generated in aerosols via intense acoustic fields and is governed by complex mechanisms of interaction which usually appear in a combined fashion. The primary mechanism is associated with the relative motion between suspended particles of different sizes which promote particle collisions (orthokinetic effect) (Riera et al., 2005). However, particles of the same size may also agglomerate due to the action of hydrodynamic forces resulting from viscous asymmetries generated in the flow field around the particles (acoustic wake effect) and/or to nonlinear interactions between the particle scattering waves and the incident field (mutual radiation pressure effect) (Power ultrasonics, 2014; Riera et al., 2005).

The process of acoustic agglomeration depends on several acoustic parameters such as intensity, frequency, and field distribution which are related to the aerosol characteristics such as size distribution, density and concentration of particles and density and viscosity of the gas.

In order to obtain an efficient agglomeration process, powerful and directional acoustic generator capable of producing fields above $140 \mathrm{~dB}$ are required. The acoustic field should be homogeneously distributed in the treatment volume and emitted at a frequency suitable to the size range of the particles to agglomerate. To cluster particles in the micronic - submicronic range (i.e. under $1-2 \mu \mathrm{m}$ ), the most effective frequencies are around $20 \mathrm{kHz}$ or more. For particles between 5 and $20 \mu \mathrm{m}$ appropriate frequencies lay in the 1 to $4 \mathrm{kHz}$ range (Power ultrasonics, 2014).

CSIC has been developing an innovative family of plate transducers since the 70's to be used in industrial applications (Power ultrasonics, 2014). This technology is the only one effective on scales larger than the laboratory one. They have been able to precipitate significant aerosol volumes with mean particle size of $0.6 \mu \mathrm{m}$ and mass concentrations of $1 \mathrm{~g} / \mathrm{m}^{3}$ in a few minutes by applying an acoustic power of about $45 \mathrm{~W} / \mathrm{m}^{3}$. The size of the agglomerated particles obtained was higher than one centimeter in its largest dimension, which means a growing factor higher than $10^{4}$ (Magill et al., 1988). However, there are only a few applications in the nuclear industry and no previous experimental studies oriented towards assessing the effect of the acoustic agglomeration system within the nuclear safety have been published.

\subsubsection{Basic mechanisms of aerosol acoustic agglomeration}

The acoustic agglomeration is a process in which acoustic forces cause particles to interact and eventually to cluster. At present, it has been generally accepted that the complex mechanisms of this process involve orthokinetic and hydrodynamic as predominant interactions, while other effects, such as radiation force, acoustic streaming and turbulence, can play an important role in promoting these interactions. 
The orthokinetic interaction occurs between two or more suspended particles of different sizes when they are located within a distance approximately equal to the displacement amplitude of the sound field and their relative motion is substantially parallel to the direction of vibration (Power ultrasonics, 2014). Due to the different fluid and inertial forces, the particles vibrate with different amplitudes and phases and such different motion increases the probability of collision and, therefore of agglomeration.

Hydrodynamic mechanisms are those which produce particle interactions through the surrounding fluid due to hydrodynamic forces and the asymmetry of the flow field around each particle (Power ultrasonics, 2014). In particular, these forces govern particle interactions in monodisperse suspensions, where the orthokinetic mechanism vanishes because the particles are similarly entrained by the acoustic field, without probability of direct collision. Among the several effects induced by hydrodynamic forces the Acoustic Wake Effect (AWE) plays a significant role. The AWE is based on the asymmetry of the flow field around a moving particle at moderate Reynolds numbers (Oseen regime). To describe this mechanism an agglomeration volume is defined around each particle as a volume where another particle can be captured (Mednikov, 1965). If two closely spaced particles fall within the agglomeration volume and they are oscillating, the leading particle will disturb the fluid and generate a wake behind itself. In the first semi-cycle the second or trailing particle might travel within the wake. The wake leads to a pressure reduction behind the leading particle so that the trailing particle moves faster. The same effect occurs in the second semi-cycle, but roles of leading and trialing particles are switched. As a result, particles on the acoustic axis converge during a number of cycles and eventually collide (Riera-Franco de Sarabia et al., 2000).

\subsection{AAA experimental configuration}

The AAA program has been conducted at the specially designed PECA-MSAA facility, located at the LASS. The facility is a medium scale plant designed for the characterization of aerosols behavior under different hypothetical severe accident conditions. The plant has been adapted to work under severe accident conditions according to the PASSAM project. The particularity of the PECA-MSAA configuration is that an acoustic agglomerator chamber, specially designed for this set-up and the anticipated conditions, has been implemented within the PECA vessel. The MSAA is aimed to make particles agglomerate and grow, which should result in an easier filtration. The aerosols carried by the gas have been studied by particle characterization before and after passing along the chamber.

The PECA-MSAA simulates a "pre-treating" phase which, if particles grow, could be implemented before the FCVS to increase the aerosol retention within the containment.

\subsubsection{PECA-MSAA set-up}

The AAA experimental campaign has been conducted at the PECA-MSAA facility (Fig. 53). The set-up consists of a gas supply system that allows the gases to carry particles; an injection line through which the particle carrier gas is led to the injection point, the aerosol generator; the 
acoustic chamber (that is part of the MSAA system) located in the $8 \mathrm{~m}^{3}$ steel vessel; the measurement instrumentation on one hand to characterize the acoustic field generated and on the other, the instrumentation for characterization of the particles entering and leaving the facility, and the control (PLC) and data acquisition systems (SCADAS) to control and acquire the thermal-hydraulic variables. Particles are generated with the powder generator system developed by Palas, the RBG system.

In order to reach the aerosol concentration required in the AAA experimental campaign (section 5.4) the aerosol generator has been changed with respect to previous CAAT2 and SET experiments. Details of the RBG generator and the MSAA are given later on. For a detailed description of other systems see section 3.2.7.

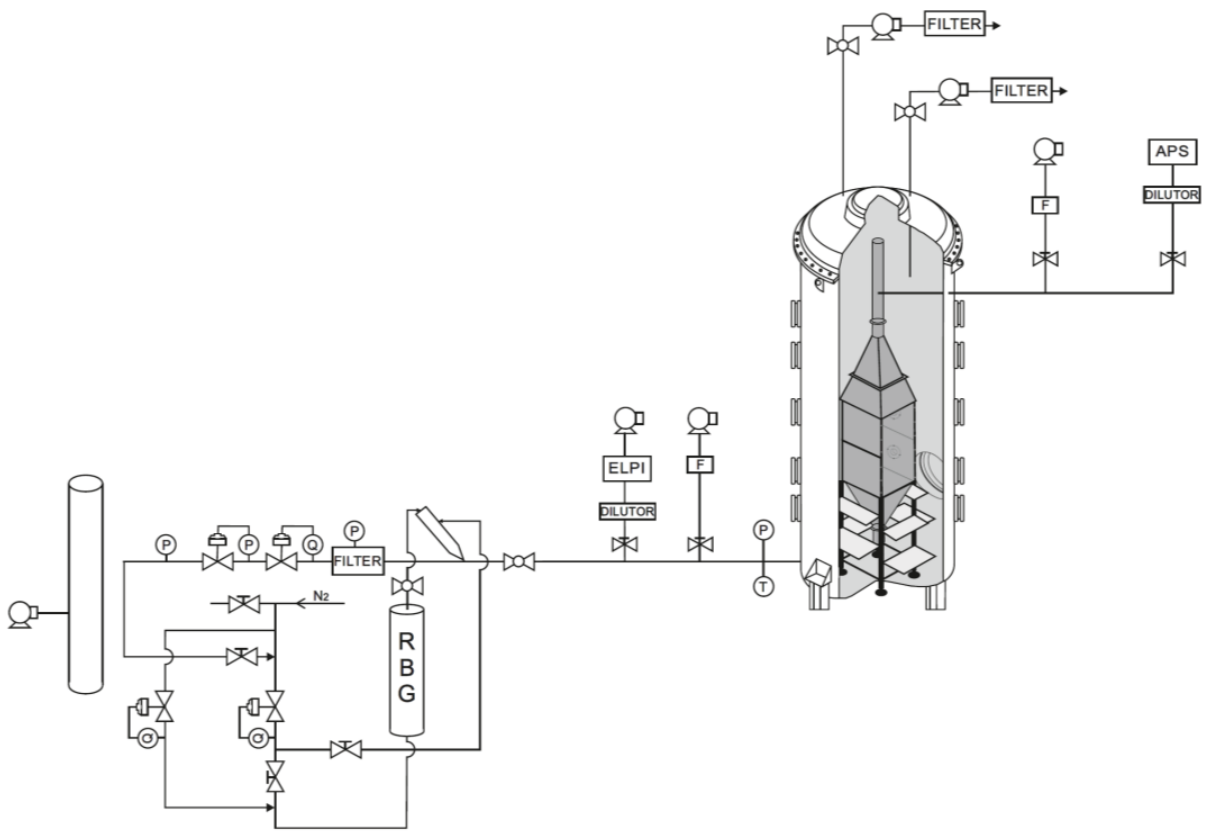

Fig. 53 Lay-out of the PECA-MSAA facility

The gas supply system consists of two sections, one to carry particles from the aerosol generator with $\mathrm{N}_{2}$, and the other which feeds air into the injection line. The latter is made of an $18.5 \mathrm{~kW}$ compressor that keeps an air tank at 6 bar and a filtration system that maintains the air pumped into the injection line clean. The top system capacity can supply an average flow rate up to 250 $\mathrm{kg} / \mathrm{h}$. 
The aerosol has been produced with the RBG-1000 aerosol generator. The outlet of aerosol generator has been connected to a Venturi nozzle where the particle-laden nitrogen joins the main gas stream that is injected into the acoustic agglomerator chamber.

The acoustic chamber has been developed to carry out dynamic tests within the PECA vessel. Fig. 54 and Fig. 55 show the outside and inside view of the MSAA-PECA vessel.

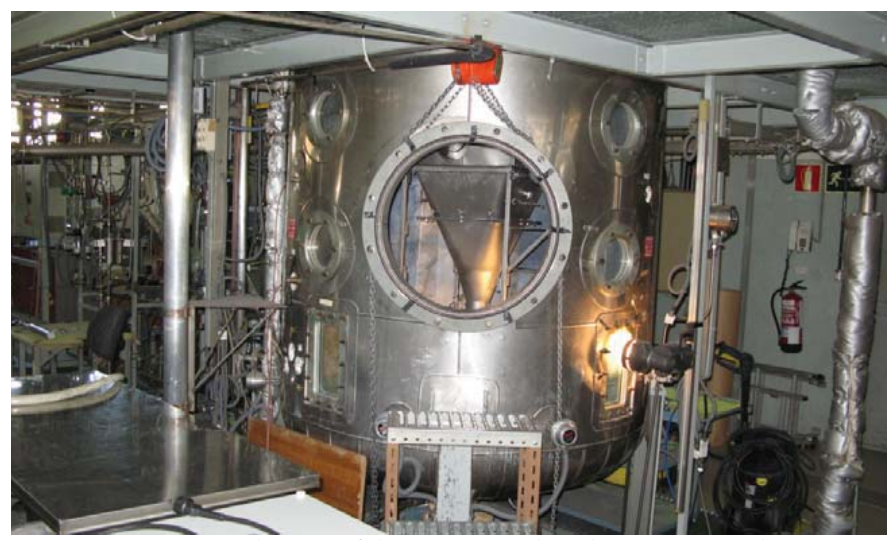

Fig. 54 Outside view of the MSAA within the PECA vessel

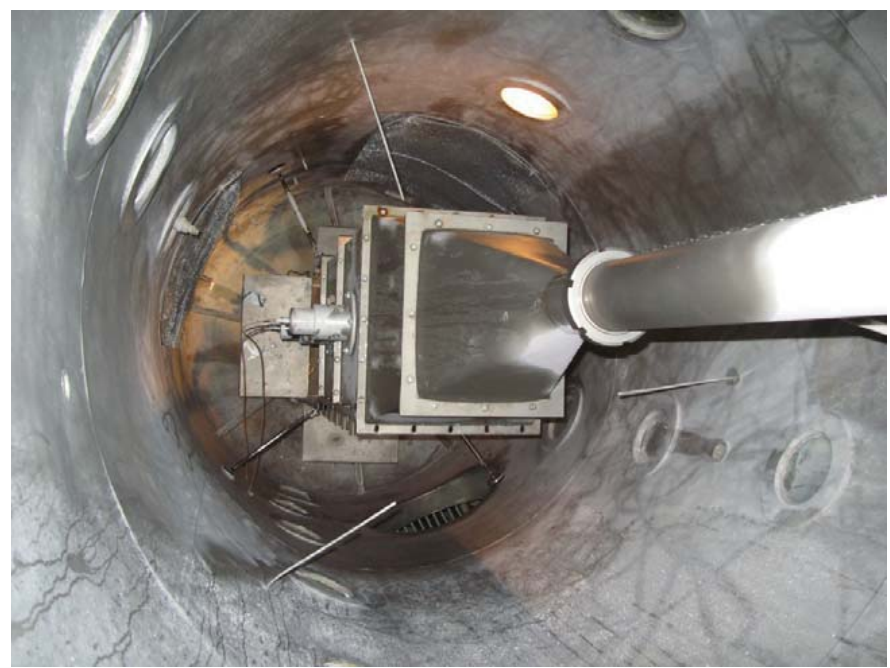

Fig. 55 Inside view of the MSAA within the PECA vessel

The aerosols leaving the acoustic chamber follow the exhaust line through bag filters to capture the airborne particles exiting the chamber. 


\subsubsection{The RBG-1000 aerosol generator}

The aerosols of the AAA experiments have been generated with the system called RBG-1000 device developed by Palas (Fig. 56). The powder to be dispersed is filled into the cylindrical solid reservoir and compressed with a tamper. The filled solid material reservoir is inserted into the dispersing head of the RGB, and the powder, which has thus been uniformly compressed across the filling level, is conveyed onto a rotating brush at a precisely controlled feed rate. An adjustable volume flow streams over the tightly woven precision brush at a very high speed and tears the particles out of the brush.

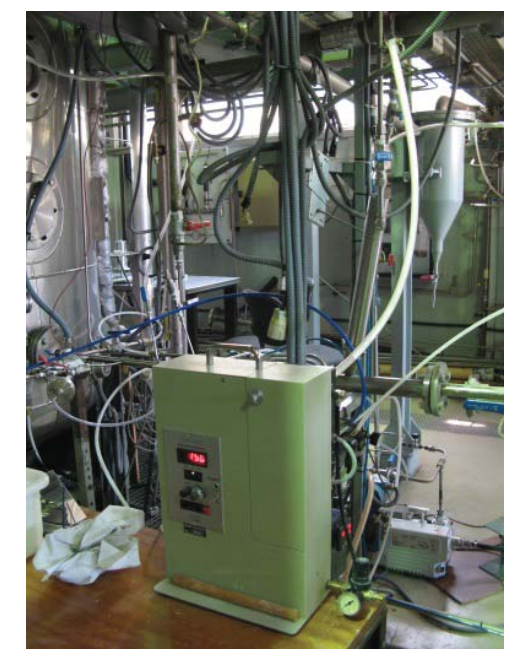

Fig. 56 RBG-1000 aerosol generator used for the AAA tests

The dispersing head assembly comprises a dispersing head, dispersing cover, precision brush, and solid material reservoir (Fig. 57). 


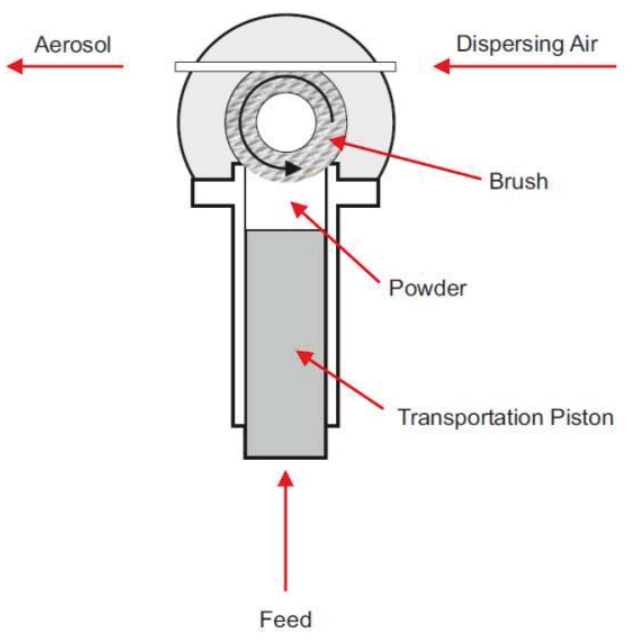

Fig. 57 Sketch diagram of RBG system

Dosing is performed via a precisely controlled rate of the feed piston. The mass flows can be determined based on the cross section of the solid material reservoir.

\subsubsection{The Mitigative System Acoustic Agglomerator (MSAA)}

The MSAA consists of a carbon steel acoustic agglomeration chamber to operate in vertical position within the PECA vessel. It was developed by CSIC and it is $1.0 \mathrm{~m}$ high with a rectangular cross-section of $0.5 \times 0.45 \mathrm{~m}^{2}$. A linear array of two power stepped-plate highintensity piezoelectric transducers at $21 \mathrm{kHz}$ are arranged along the elongated side of the agglomeration chamber to achieve a homogeneous distribution of the sound field as well as sufficient residence time of the aerosol in the chamber, between 10-80s. The transducers have their circular radiating faces installed on the vertical face of the chamber. The system includes several aerosol particle sampling points placed along the chamber. A high-intensity ultrasonic standing-wave field perpendicular to the gas flow has been established within the acoustic agglomeration chamber. During the AAA experiments the transducers operate with an applied input power of $300 \mathrm{~W}$ per transducer, i.e., they generate a mean sound pressure level (SPL) of about $155 \mathrm{~dB}$ inside the chamber. According to literature (Mednikov, 1965) a SPL higher than $140 \mathrm{~dB}$ is required to generate an acoustic agglomeration process.

Fig. 58 shows a sketch and a real picture of the acoustic chamber. Details of the entrance of the flow and the $1 \mathrm{~m}$ long and $10 \mathrm{~cm}$ in diameter chimney are given, as well as the sampling points for particle characterization and the position of the ultrasonic transducers. 


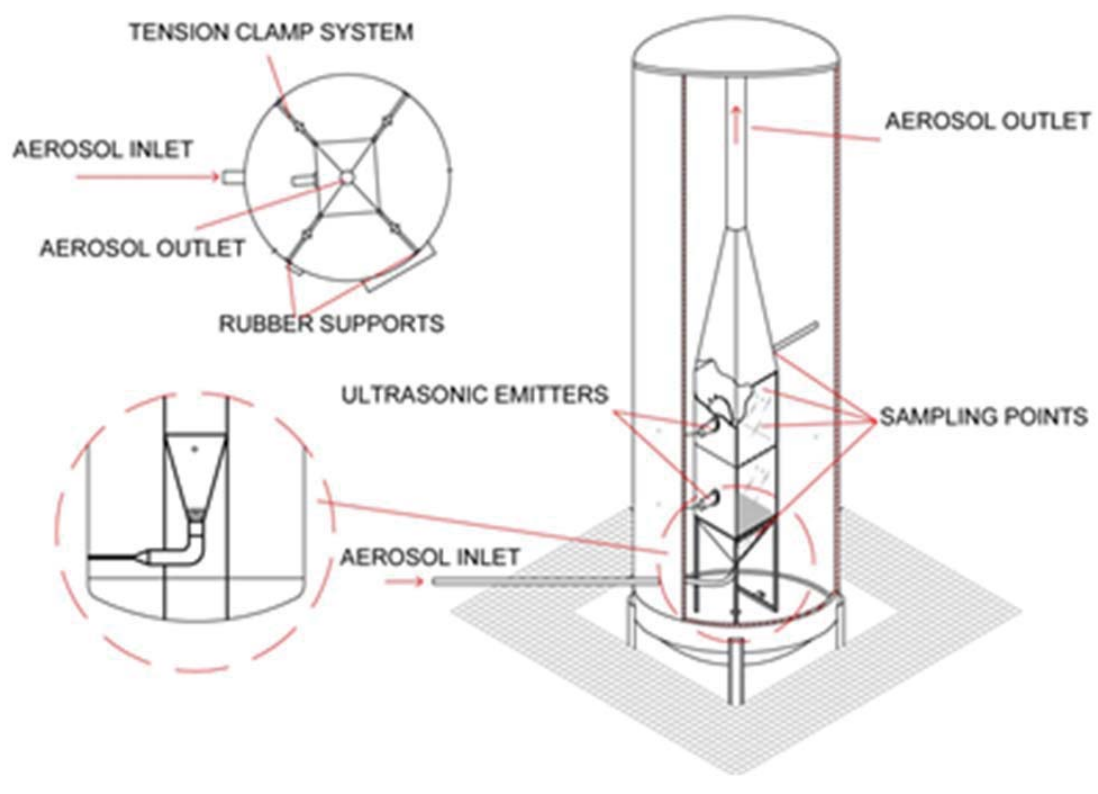

Fig. 58 Mitigative System for Aerosol Acoustic Agglomeration sketch

The design and development of the transducer-chamber system has been carried out by the application of theoretical and numerical methods in connection with a program of experiments in scale models (J A Gallego-Juárez et al., 2014).

\section{- Power stepped-plate transducers}

The ultrasonic power generator for the AAA experiments has been developed by CSIC. It is based on the stepped-plate piezoelectric transducer (Fig. 59). It consists of an extensive circular vibrating plate of stepped profile driven at its center by a piezoelectrically activated vibrator. The vibrator has two components, a piezoelectric element of transduction in a sandwich configuration and a mechanical transformer (also known as solid horn) which acts as a vibration amplifier. The sandwich transducer is a half-wave resonant length-expander structure. It consists of paired discs of piezoelectric ceramics sandwiched between two metal blocks. The extensional vibration, generated by the transducer element and amplified by the horn, drives the radiating plate which vibrates flexurally in one of its modes. The horn is designed to resonate at the same frequency as the sandwich transducer. The vibration amplitude at the radiating surface of the circular plate depends on the geometry of the horn. In this case it is stepped and it is made of titanium alloy. The assembly formed by the piezoelectric 
sandwich and the stepped horn constitutes the ultrasonic vibrator that drives the circular vibrating plate. TABLE 14 summarizes the components of the ultrasonic transducer

TABLE 14 Main components of directional circular stepped-plate transducers at $21 \mathrm{kHz}$

\begin{tabular}{ll}
\hline Piezoelectric Sandwich & Features \\
\hline $\begin{array}{l}\text { Half-wave resonant length-expander structure } \\
4 \text { Electro ceramic disks }\end{array}$ & Morgan \\
2 metal block cylinders & Stainless-steel, titanium alloy \\
1 bolt mechanical pre-stressing & \\
Mechanical Amplifier (Horn) & \\
\hline Half-wave resonant length-expander structure & Titanium alloy \\
Stepped-plate Radiator & Geometry: Circular $(48 \mathrm{~cm}$ diameter) \\
\hline Front Face Profile stepped & Titanium Alloy (Ti6V4Al) \\
Resonant Vibrating Mode: Seven nodal circles & 7 NC \\
\hline
\end{tabular}

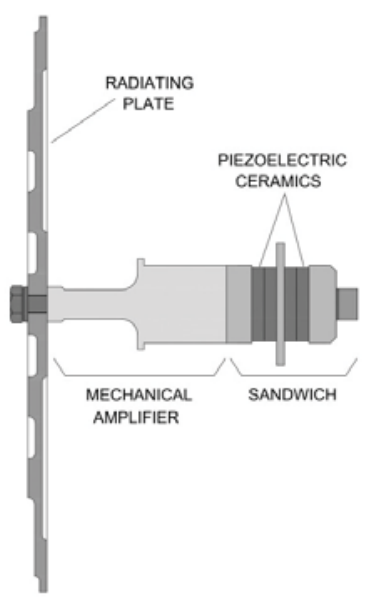

a) Sketch of the airborne ultrasonic power transducer

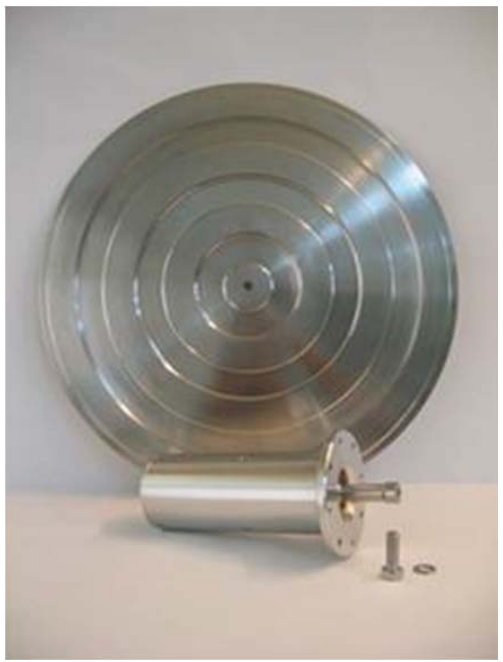

b) View of the circular radiating plate, the ultrasonic vibrator and the bolt mechanical pre-stressing

Fig. 59 Stepped-plate power transducer for airborne applications at $21 \mathrm{kHz}$

The profile of the plate permits the control of the vibration amplitude and the radiation pattern. 
It means that the direction of the radiation can be controlled and aligned for larger acoustic intensity levels. A flat plate radiator presents in general a poor directivity pattern due to phase cancellation. Nevertheless, the surface elements on the two sides of the nodal line (that vibrate in counter-phase) can be alternatively shifted half a wavelength of the sound along the acoustic axis. As a result, the radiation is in phase across the whole beam and directivity pattern can be done.

An electronic system has been designed to operate the transducer. Moreover, a test campaign was conducted for experimental validation of the stepped-plate transducers. It was carried out by measuring the acoustic field under free field conditions and inside the acoustic agglomeration chamber. A full description of the systems composing the MSAA as well as the results of the validation campaign has been included in appendix 5 .

\subsubsection{Instrumentation for aerosol characterization and sampling}

The instrumentation and devices used for the aerosol characterization are those used in CAAT2 and SET campaigns: real-time devices (ELPI at the inlet and APS at the outlet) and by gravitational devices (membrane filters). Details of all them (principles and characteristics) are given in section 3.2.7. Nevertheless, based on the nature of the experiments and the results expectation (particles growth) their distribution is rather different. The layout of the instruments in the PECA-MSAA is shown in Fig. 53.

The aerosols are characterized at the entrance of the line in the vessel:

- One sampling tap is connected in series to two ejector diluters (dilution ratio 8:1 each one) and to the ELPI. The latter allows the real-time characterization of the aerosol particle count distribution.

- Another sampling is connected to membrane filters that permit the measuring of the outgoing aerosol concentration.

At the exit of the bundle the outgoing aerosols are characterized via a sample tap divided in two streams to be used alternatively, one for the APS sampling and the other for the membrane filter sampling.

- One sampling feeds the APS dilutor and the diluted stream is sampled by the APS. The dilution ratio is 100:1.

- The other sample is connected to membrane filters that permit the measuring of the outgoing aerosol concentration

Membrane filters sample the aerosol stream as described in section 3.2.7. 


\subsection{Experimental matrix}

The design of the AAA experimental matrix has been based on the expected boundary conditions during the FCVS operation (TABLE 15) (L. E. Herranz et al., 2014).

TABLE 15 Anticipated boundary conditions for FCVs (L.E. Herranz et al., 2014)

\begin{tabular}{ll}
\hline Parameter & Value \\
\hline Temperature $\left({ }^{\circ} \mathrm{C}\right)$ & $100-300$ \\
Absolute Pressure $(\mathrm{bar})$ & $1-10$ \\
Gas mass flow rate $(\mathrm{kg} / \mathrm{s})$ & $1.0-30.0$ \\
Gas composition (molar fraction) & $\mathrm{Air}-0-25 \%$ \\
& $\mathrm{H}_{2} \mathrm{O}_{\mathrm{v}}-40-100 \%$ \\
& $\mathrm{H}_{2}-0-2 \%$ \\
& $\mathrm{CO}_{2}-0-40 \%$ \\
& $\mathrm{CO}^{-0}-20 \%$ \\
& $<10-4$ \\
Aerosol concentration $\left(\mathrm{kg} / \mathrm{m}^{3}\right)$ & $0.1-10$ \\
Particle diameter $(\mu \mathrm{m})$ & $500-1000 \mathrm{~kW}$ \\
Decay heat &
\end{tabular}

It is worth to mention that the variables in the table will change as the accident unfolds. This is the meaning of the tables, an attempt to cover all potential conditions at different venting times. An example is the particle size. The AMMD is foreseen to reach values around 3-5 $\mu \mathrm{m}$ in containment but, after a while, deposition mechanisms, mainly settling, will shift the particle size distribution towards smaller diameters (Allelein et al., 2009). Nonetheless, particle production through Molten Corium Concrete Interactions (MCCI) if the reactor vessel fails might also alter the size distribution. Anyway, the most challenging condition is expected to happen at around $0.1 \mu \mathrm{m}$, and that value is included.

The main variables of the experimental matrix (TABLE 16) are the aerosol mixture and the gas mass flow rate. The particle used was in most of the cases of the same aerosol $\left(\mathrm{SiO}_{2}\right)$. The aerosol mixture has been made of different size proportions and according to TABLE 14, within the range of the nuclear aerosols diameter prone to reach the containment. The gas mass flow has allowed controlling the particle concentration and the residence time of the particles within the acoustic chamber. Targeted at repeatability, every experiment has been repeated (denoted by prime or '). Consequently the final matrix is comprised of 20 experiments (TABLE 16). 
TABLE 16 AAA experimental test matrix

\begin{tabular}{|c|c|c|c|c|c|c|c|}
\hline \multirow{3}{*}{ Test } & \multicolumn{4}{|c|}{$\begin{array}{c}\text { Particle } \\
\text { Nature / Size / Proportion ( } \% \text { mass) }\end{array}$} & \multirow{2}{*}{\multicolumn{3}{|c|}{$\dot{m}(\mathrm{~kg} / \mathrm{h})$}} \\
\hline & \multicolumn{3}{|c|}{$\mathrm{SiO}_{2}$} & \multirow{2}{*}{$\begin{array}{c}\mathrm{TiO}_{2} \\
0.01-0.05 \mu \mathrm{m}\end{array}$} & & & \\
\hline & $0.3 \mu \mathrm{m}$ & $1 \mu \mathrm{m}$ & $2.5 \mu \mathrm{m}$ & & 12 & 50 & 100 \\
\hline $1-1^{\prime}$ & & $100 \%$ & & & $x$ & & \\
\hline $2-2^{\prime}$ & & $100 \%$ & & & & & $x$ \\
\hline $3-3^{\prime}$ & $50 \%$ & $50 \%$ & & & $x$ & & \\
\hline $4-4^{\prime}$ & $75 \%$ & $25 \%$ & & & $x$ & & \\
\hline $5-5^{\prime}$ & $75 \%$ & $25 \%$ & & & & $x$ & \\
\hline $6-6^{\prime}$ & $75 \%$ & $25 \%$ & & & & & $\mathrm{x}$ \\
\hline $7-7^{\prime}$ & $90 \%$ & $10 \%$ & & & $x$ & & \\
\hline $8-8^{\prime}$ & & $75 \%$ & $25 \%$ & & $x$ & & \\
\hline 9-9' & $50 \%$ & $30 \%$ & $20 \%$ & & $x$ & & \\
\hline $10-10^{\prime}$ & $50 \%$ & $30 \%$ & & $20 \%$ & $\mathrm{x}$ & & \\
\hline
\end{tabular}

\subsubsection{Target variables}

\subsubsection{The particle nature, size and proportion}

As it has been introduced in section 4.3.1.1, the particle nature refers to the particle aggregation state. The key particles used during the AAA tests are $\mathrm{SiO}_{2}$ with three different sizes: $0.3 \mu \mathrm{m}, 1$

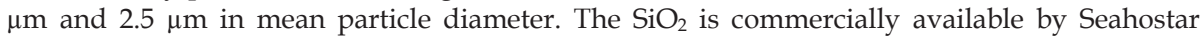
("Nippon Shokubai - Seahostar," 2015) in a range of sizes within the nuclear aerosols ones. The three sizes have been chosen to be around $1 \mu \mathrm{m}$, the most explored size. They are compact and spherical particles (Fig. 60-Fig. 62). The main reason to use these particles is that they are monodisperse and their features such as density or particle diameter are well known. It means that the uncertainty associated to their characterization before and after the agglomeration process might be narrower compared to fluffy agglomerates as $\mathrm{TiO}_{2}$. Nevertheless, clusters of $\mathrm{TiO}_{2}$ have been used too to explore any effect of the nature in the acoustic agglomeration process. According to the SEM study, the $\mathrm{TiO}_{2}$ primary particles have been found to be around $0.05 \mu \mathrm{m}$ (Fig. 62). They are agglomerated naturally and as can be observed in Fig. 62 reach clusters sizes of about $5 \mu \mathrm{m}$ in diameter.

The particles were mixed in proportions prone to agglomerate, i.e. with higher mass fraction of the smaller sizes: from the $50 \%$ of small and $50 \%$ of larger particles, to the $90 \%$ and $10 \%$ respectively. Moreover, monodispersed tests with $100 \%$ of one particle size and polydispersed tests of three particles mixture cover an extent range of proportions. The mixture is done by weighting the mass of each type of aerosol in a small reservoir. Then, they are mixed by agitation of the reservoir used. The mixture is used for recharging the particle generator during the stages of the experiment. 
A comparison of the inlet and outlet aerosols measurements and characterization would allow studying aerosol agglomeration between spherical particles and with fluffy poly-dispersed clusters.
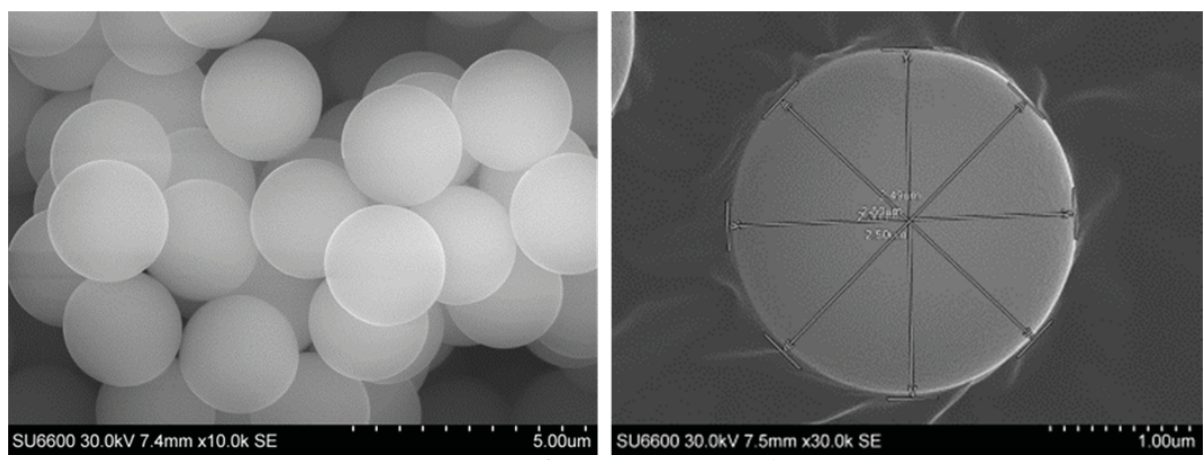

Fig. $60 \mathrm{SEM}$ of $2.5 \mu \mathrm{m} \mathrm{SiO} 2$ particles

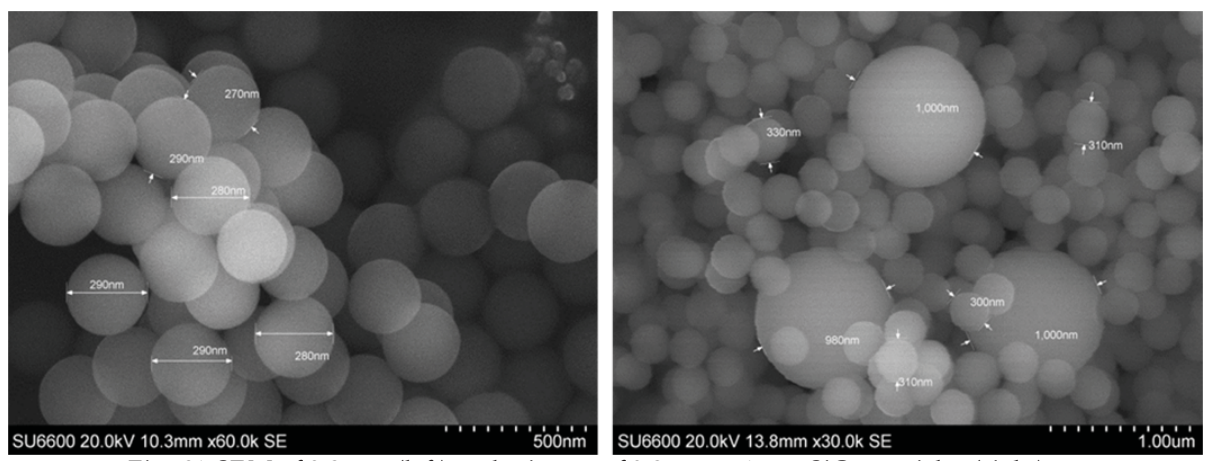

Fig. 61 SEM of $0.3 \mu \mathrm{m}$ (left) and mixture of $0.3 \mu \mathrm{m}+1 \mu \mathrm{m} \mathrm{SiO}{ }_{2}$ particles (right)
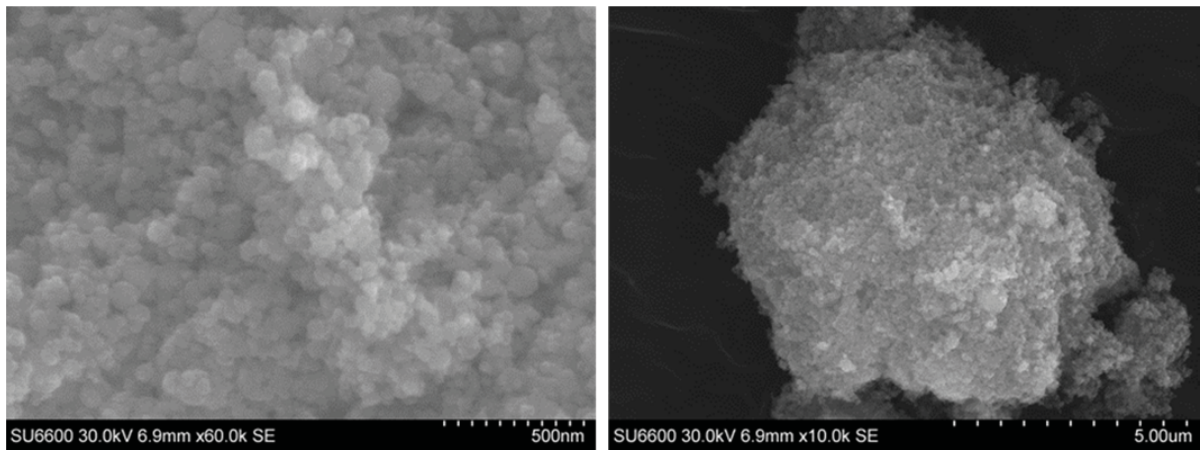

Fig. $62 \mathrm{SEM}$ of $\mathrm{TiO}_{2}$ particles 
As it has been observed in Fig. 60 and Fig. $61, \mathrm{SiO}_{2}$ are spherical, dense and very close to a mono-disperse size distribution. As they are individual particles, their density is supposed to be near the nominal one, i.e. $2000 \mathrm{~kg} / \mathrm{m}^{3}$.

The $\mathrm{TiO}_{2}$ particles consisted of large number of primary nano particles that resulted in aerosols with a broad interval of sizes. Then, their density is uncertain, although it is known to be far from the nominal one. The $\mathrm{TiO}_{2}$ particles are different from CAAT2 and SET, but their same composition led to estimate its density based on López and Herranz (Lopez and Herranz, 2012) who assumed that primary $\mathrm{TiO}_{2}$ particles were solid spheres randomly packed with a density between $395.5 \mathrm{~kg} / \mathrm{m}^{3}$ and $2528 \mathrm{~kg} / \mathrm{m}^{3}$.

The main aerosol features, average primary diameter, nominal density, estimated aerosol density and specific surface area of $\mathrm{SiO}_{2}$ and $\mathrm{TiO}_{2}$ particles are summarized in TABLE 17.

TABLE 17 Aerosols main features

\begin{tabular}{lll}
\hline Aerosol type & \multicolumn{1}{c}{$\mathrm{SiO}_{2}$} & $\mathrm{TiO}_{2}$ \\
\cline { 2 - 3 } Average primary particle diameter $(\boldsymbol{\mu m})$ & $0.28 / 1.02 / 2.50$ & 0.05 \\
Nominal density $\left(\mathbf{k g} / \mathbf{m}^{3}\right)$ & $\sim 2000$ & $\sim 3950$ \\
Aerosol density $\left(\mathbf{k g} / \mathbf{m}^{3}\right)$ & $\sim 2000$ & $395-2528$ \\
Specific surface area $\left(\mathbf{m}^{2} / \mathrm{g}\right)$ & n.a. & $\sim 50$ \\
\hline
\end{tabular}

\subsubsection{The gas mass flow rate}

The gas mass flow rate is directly related with the concentration of particles and the time of residence inside the chamber. The lower the gas mass flow rate the lower the gas velocity and larger the time that particles reside within the chamber. Moreover, the lower the gas mass flow rate the bigger the particle concentration. According to literature (Power ultrasonics, 2014) the particle concentration is limited by $10^{5}$ counts $/ \mathrm{cm}^{3}$ and the time of residence by 5 seconds.

The minimum concentration was experimentally determined in the preliminary test campaign (appendix 6). It was set that the minimum measureable particle concentration was obtained for gas mass flow rates of $100 \mathrm{~kg} / \mathrm{h}$. The gas mass flow rate was finally set to be $12 \mathrm{~kg} / \mathrm{h}, 50 \mathrm{~kg} / \mathrm{h}$ and $100 \mathrm{~kg} / \mathrm{h}$.

TABLE 18 shows the gas velocities and time of residence of the particles for the mass flows set. It was estimated for air $\left(\rho_{\text {air }}=1.2 \mathrm{~kg} / \mathrm{m}^{3}\right)$ passing across the chamber with a cross area of 0.2349 $\mathrm{m}^{2}$ and $1 \mathrm{~m}$ high. 
TABLE 18 Gas mass flow rate, velocity and residence time of particles within the MSAA

\begin{tabular}{ccc}
\hline$\dot{\mathbf{m}} \mathbf{( k g / h )}$ & $\mathbf{v}_{\mathbf{g}} \mathbf{( m / s )}$ & $\mathbf{\tau}(\mathbf{s})$ \\
\hline 12 & 0.012 & 80 \\
50 & 0.049 & 20 \\
100 & 0.099 & 10 \\
\hline
\end{tabular}

\subsection{Measurement procedure}

The AAA tests have been performed under room temperature and atmospheric pressure. The aerosol generator has a capacity for no longer than 45 minutes. Thus, the test was split in phases that take no more than this time while the generator is refilled between the phases. The total duration of a test was about 2 hours.

Fig. 63 shows the measurement procedure that can be summarized as given below:

1. Stabilization phase :

a. Thermal-hydraulic stabilization

b. Particle injection and stabilization

2. Reference phase (RP): The particles are characterized without ultrasonic field (-US) before (inlet) and after the chamber (outlet) with the real time devices (ELPI and APS) and the membrane filters.

3. Flushing phase (FP): The particle injection is stopped and the gas mass flow rate is increased to $200 \mathrm{~kg} / \mathrm{h}$ in order to drag the particles that could be trapped within the chamber. The particles are characterized at the outlet by the APS.

\section{RECHARGING THE PARTICLE GENERATOR}

4. Stabilization phase:

a. Thermal-hydraulic stabilization

b. Particle injection and stabilization under the ultrasonic field.

5. Acoustic phase (AP): The particles are characterized with the ultrasonic field (+US) before (inlet) and after the chamber (outlet), with real time devices (ELPI and APS) and membrane filters.

6. Flushing phase (FP): The injection of particles and the ultrasonic field is stopped. The gas mass flow rate is increased to drag the dust deposited within the chamber and is characterized with the APS at the exit. 
As mentioned above (section 5.2), the acoustic field promotes particle to collide and grow. The acoustic chamber acts by trapping the fraction of particles that are not able to follow the stream lines and do not reach the chimney of the facility. Thus, they are not characterized during the reference or acoustic phases. Nevertheless, the analysis of the particle growth should take them into account. To solve this problem the flush phase was introduced. High gas mass flow carries particle up to the chimney that are characterized at the outlet.

Each test has been repeated for reproducibility reasons. In the repetition, stage 5 has been elongated with a set of measurement with alternation of the ultrasonic field. 

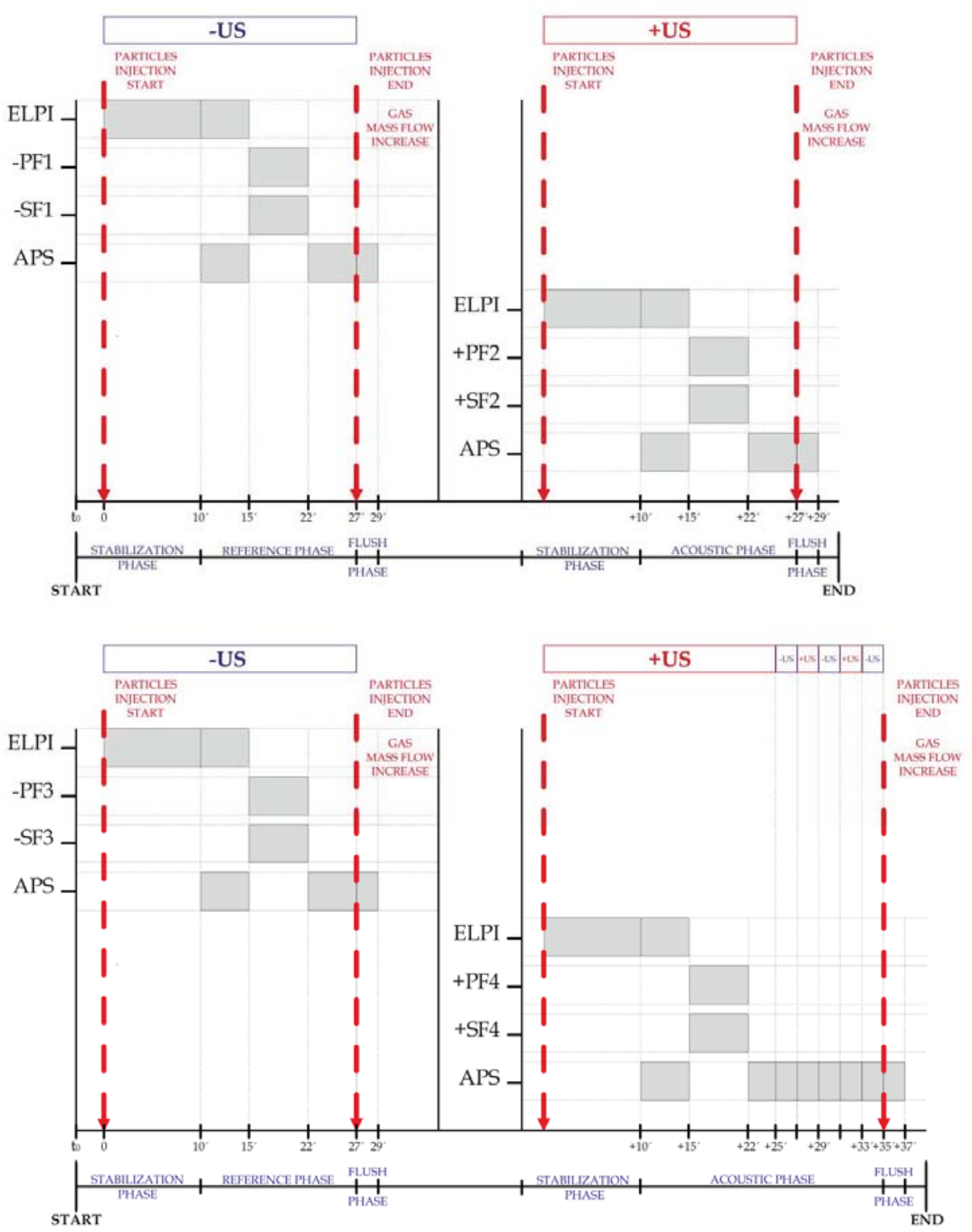

Fig. 63 AAA measurement procedure schedule 


\subsection{Major variables}

\subsubsection{Particle size distribution}

The aerosol size distribution has been determined at the inlet and outlet of the chamber with ELPI and APS, respectively. The measurements of both devices have been correlated (appendix 6).

The analysis of the ultrasonic field effect on the particle growth requires the determination of the aerosol diameter and the particle concentration of the outgoing stream. The APS software makes its own conversion in order to calculate parameters as the particle size or concentration (Aerosol Instrument Manager, 2002). However, the particle size distribution (in terms of AMMD and GSD) and the mass particle concentration have been calculated separately from the raw data (Appendix 7). Then, they have been verified with the software results.

The APS determines the number of particles per bin channel. The total number concentration is calculated by adding the counts at each bin $(\mathrm{N})$ and then, it is transformed into mass $(\mathrm{M})$ :

$$
\begin{gathered}
N=\sum n_{b i n} \\
M=\sum M_{b i n}=\frac{\pi}{6} \sum N_{b i n} d_{p}^{3} \rho
\end{gathered}
$$

By dividing $\mathrm{N}$ or $\mathrm{M}$ by the bin size the number or mass size distribution is obtained. Note that the APS is a real time device sampling the aerosol every second. The mean distribution of each phase has been calculated by averaging the distribution during 3 minutes.

The characterization of monodisperse aerosols by the AMMD and GSD from the lognormal distribution is straightforward (Hinds, 1999). However, the mixture of particles generates polydispersed distributions. Its characterization (i.e. AMMD and GSD) has been estimated by assuming that the poly-dispersed distribution is made of several monodispersed ones. Then, it can be calculated by a sum of lognormal distributions that are adjusted by the least squares method:

$$
f=\sum \text { A lognormal }(\overline{d p}, \sigma)=\sum \frac{1}{d p \cdot \sigma \sqrt{2 \pi}} e^{-\frac{(\ln d p-\overline{d p})^{2}}{2 \sigma^{2}}}
$$

Normally, the amount of lognormal equations is the number of types of particles used in the 
experiment or peaks identified in the distribution. Nevertheless, a larger number of distributions are used if the adjustment is improved. In any case, each particle size distribution is characterized by the lognormal distribution centered or averaged on the peak. As a result, one AMMD and GSD value is obtained for each peak (i.e. particle size).

As example, in Fig. 64 the measured and fitted distributions of a tri-modal (thee dominant particle sizes) experiment has been represented.

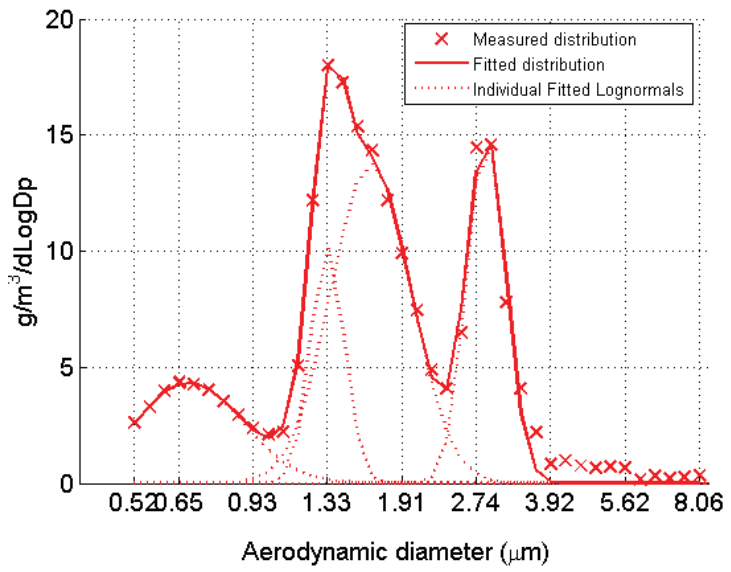

Fig. 64 Tri-modal measured distribution adjusted with four lognormal equations

(AAA 9, acoustic phase)

\subsubsection{Acoustic Growth Factor}

The acoustic growth factor (AGF) is a dimensionless magnitude that quantifies how much the particles grow due to the acoustic field effect. It is defined as:

$$
A G F=X_{A P} \cdot \triangle A M M D_{\text {out } A P}+X_{F P} \cdot \triangle A M M D_{\text {out } F P}
$$

Where,

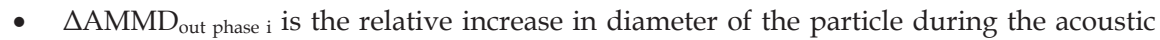
phase, $\mathrm{AP}$, or flush phase, $\mathrm{FP}$ ). It is given by: 


$$
\triangle A M M D_{\text {Phase } i}=\frac{\sum_{\text {Peak } 1}^{\text {Peakn }}\left(A M M D_{\text {out at phase }}-A M M D_{\text {out } R P}\right)}{A M M D_{\text {out } R P}}
$$

- $X_{i \text { phase }}$ is the mass fraction of particles outgoing the facility during the $i$ phase. It has been calculated with the real time data acquired by APS.

\subsection{Results and discussion}

\subsubsection{Major insights}

TABLE 19 shows the major results of the AAA experiments. It summarizes the boundary conditions of each test: the gas mass flow rate and the time of residence, as well as the particle nature, size and proportion of the mixture used in each test. Moreover, the main data obtained in terms of aerosol mass and size distribution entering and leaving the facility is presented. The last columns show the growth of particles produced in the chamber in terms of the AGF factor and its corresponding uncertainty limits. The uncertainty analysis can be found in appendix 2 . 


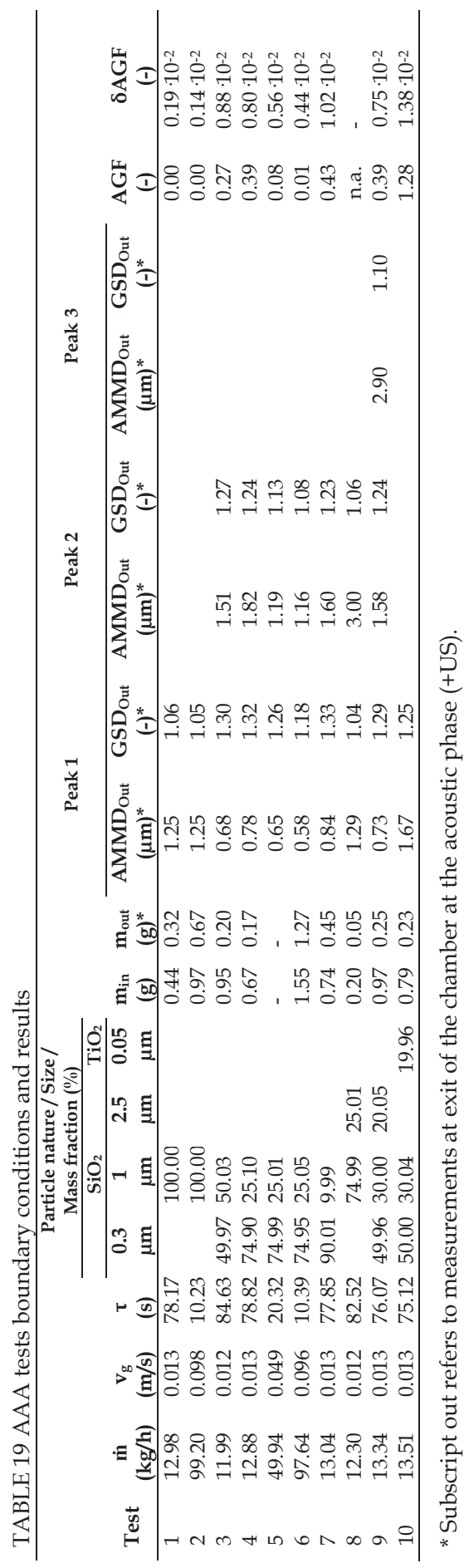


As introduced above (section 5.4), the tests were repeated aimed to data validation. Thus, each AAA experiment has its corresponding $\mathrm{AAA}^{\prime}$. The overall acquired data is the result of the average of both AAA and AAA'. Details of all of them can be found in Appendix 8.

It can be noticed that no value of the AGF parameter of test 8 is presented in TABLE 19. The AGF estimation led to a negative value with no physical sense. Hence, it has been disregarded in the overall experimental discussion. In addition, the particle size measurements of aerosols entering into the acoustic chamber (AMMD in) are neither given. The data have been disregarded due to the differences of the ELPI measurements with respect the theoretical values. The particle size distribution obtained were shift more than 1 micron with respect the theoretical particle size which was measured by the APS and validated by a SEM analysis (section 5.4.1.1). Since the results at the outlet of the chamber (without US) shows that no agglomeration was produced, it has been assumed that no agglomerates were generated from the generation system and no agglomeration occurred before the acoustic test section.

Fig. 65 presents the AGF of the AAA tests. As noted, the particles become larger in any case under the ultrasonic field. The A10 experiment, performed with $\mathrm{TiO}_{2}$ aerosols, shows the difference with respect to any other test. Its AGF is more than $60 \%$ larger than any experiment of $\mathrm{SiO}_{2}$. When only the $\mathrm{SiO}_{2}$ experiments are considered and independently from the particle mixture, the effect of the gas flow rate is noted. For low gas flow rates $(12 \mathrm{~kg} / \mathrm{h})$ the particles grow under the ultrasonic field in a factor between 0.25 and 0.45 . It drops to values as low as 0.09 when the gas mass flow rate is increased to $50 \mathrm{~kg} / \mathrm{h}$ and finally, in case of large gas flows $(100 \mathrm{~kg} / \mathrm{h})$, the effect of the chamber in the particle growth is dissipated.

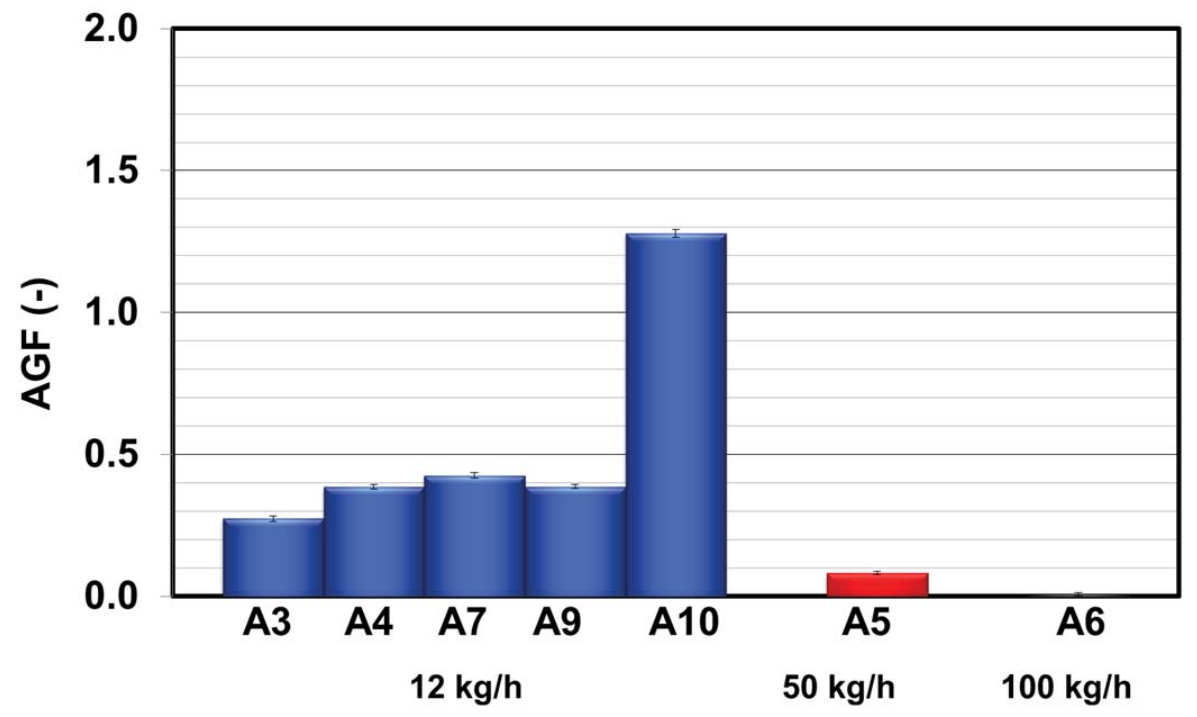

Fig. 65 Acoustic growth factor of AAA tests 


\subsubsection{Particle nature effect}

The main difference between tests from 1 to 9 , and 10 is the mixture of particles used. While $\mathrm{TiO}_{2}$ were used in test 10 , the rest of tests have been carried out with a mixture $100 \%$ of $\mathrm{SiO}_{2}$. Besides previous general insights, the large AGF factor of the $\mathrm{TiO}_{2}$ test, compared to any other, indicates a link between the particle nature and the ultrasonic field.

In each test of TABLE 19 it can be observed that the number of peaks of the final distribution (+US) corresponds with the number of particles used in the mixture of the experiment. It may mean that particles hardly agglomerate except the smallest ones of $0.3 \mu \mathrm{m}$. Fig. 66 shows the outlet aerosol distribution of test number 9, in which the three $\mathrm{SiO}_{2}$ sizes were mixed, without ultrasounds (F1 and F1') and with ultrasounds (F2 and F2'). The analysis of the AMMD out under the ultrasonic field shows a small size shift with respect to the reference particle diameter (without US) and a wider distribution. In other words, the smallest $\mathrm{SiO}_{2}$ particles $(0.3 \mu \mathrm{m})$ seem to be affected by the ultrasound field and collide either with others like them or/and bigger ones (i.e. of $1 \mu \mathrm{m}$ and $2.5 \mu \mathrm{m}$ ). The lack of larger peaks (at least double) than $1 \mu \mathrm{m}$ and $2 \mu \mathrm{m}$ demonstrates the absence of outgoing agglomerates that would result from the coalescence among particles of such sizes. It may be the consequence of the constant mean pressure level $(155 \mathrm{~dB})$ of the transducers produced inside the chamber too. The generated acoustic forces act stronger on smaller particles sizes than in bigger ones, i.e., the smaller the particle size the larger their vibration for a constant sound field.

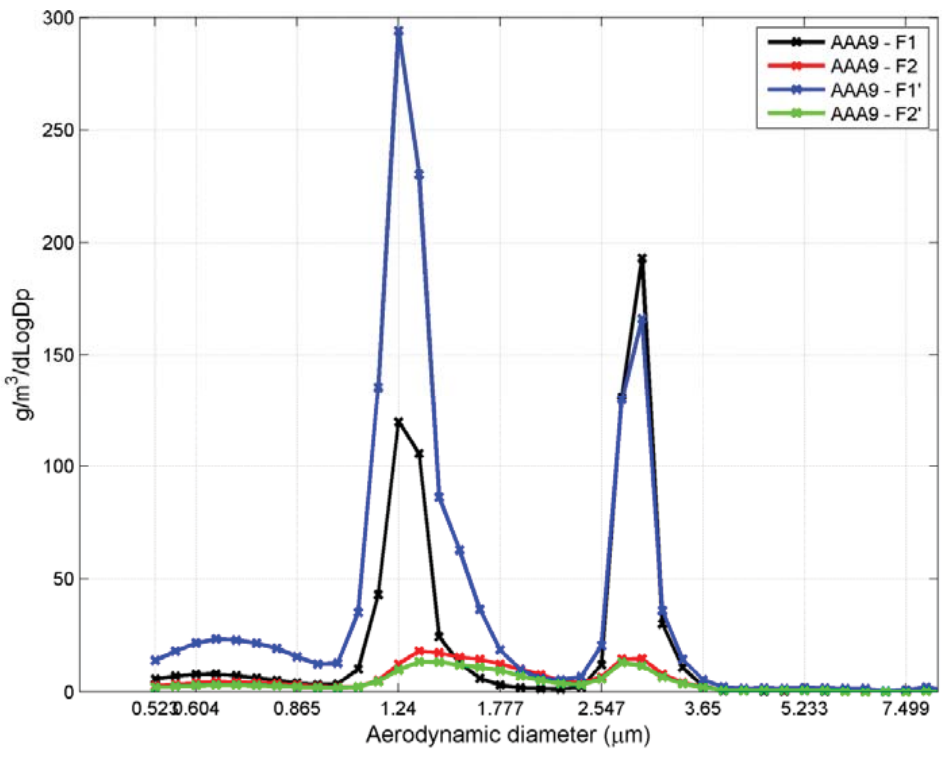

Fig. 66 AAA9 and AAA9' particle size distribution with (F1 and F1') and without (F2 and F2') ultrasonic field 
Test 10 is an exception of the previous statement (Fig. 67). There are three particles type involved in the mixture but, when the ultrasonic field is applied, the outlet particles are monodistributed. As observed in Fig. 67, the outlet distribution is wide and the mean size is larger than $1 \mu \mathrm{m}$, the size of the biggest former particles. It would mean that the aerosols made of many $\mathrm{TiO}_{2}$ nanoparticles without a defined shape are prone to interact with any other particles of different or same nature. As a result, the former aerosols collide, grow and become in bigger but wooly particles, able to leave the chamber.

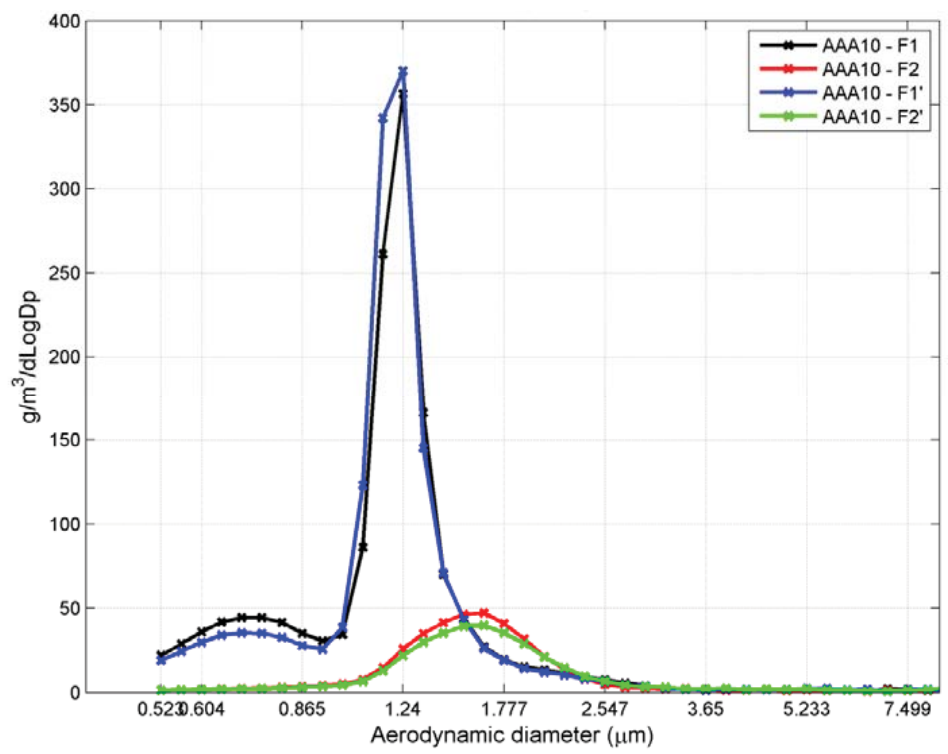

Fig. 67 AAA10 and AAA10' particle size distribution with (F1 and F1') and without (F2 and F2') ultrasonic field

As it was said above, the AGF is calculated based on the relative difference of the particle growth. It is worth to highlight that in this case the $\mathrm{TiO}_{2}$ particles and the small $\mathrm{SiO}_{2}$ ones $(0.3$

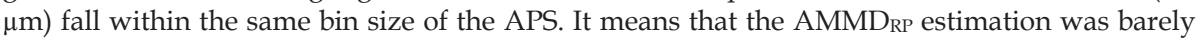
balanced. As a result, the AGF is probably underestimated. In any case as mentioned in section 5.4.1.1, the own nature (agglomerate) of the $\mathrm{TiO}_{2}$ produces aerosols with a wide distribution (GSD > 3). Under the acoustic field, these particles vibrate with different amplitudes and phases. The differential motion increases the probability of collision and therefore of agglomeration. Even though only one test does not allow extend this statement, the experiment was repeated and very similar results were obtained. As a matter of fact, the comparison of the equivalent tests $\left(X\right.$ and $\left.X^{\prime}\right)$ have been done for every single experiment. Fig. 67 shows the same AMMD and GSD in the repetition while the difference in the concentration is under $5 \%$. The data consistency validates thus the results and the measurement procedure. 
Besides the small particle grow rate, it was found that a particles mass depletion is produced when the ultrasound field is applied regardless the particle nature. The area under the curve of the size distribution shows the normalized mass accumulated during the measurement. The comparison of the areas without US (F1 and F1') and with US (F2 and F2') in Fig. 66 and Fig. 67 shows a reduction of the mass by a factor of approximately 4 . These results are validated with the mass measurements.

Fig. 68 shows a concentration of the particles entering and leaving the facility during the reference phase (F1 and $\left.F 1^{\prime}\right)$ and acoustic phase (F2 and F2') of test 3 . The inlet mass was constant during the tests (blue columns, Fig. 68), but a drastic drop of the outgoing particle concentration is produced during the acoustic phase. They are an integral measurement that contemplates the overall accumulated particles during the measuring time (7 minutes). In fact, the difference between the inlet and outlet corresponds to the mass of particles retained in the acoustic chamber during each period.

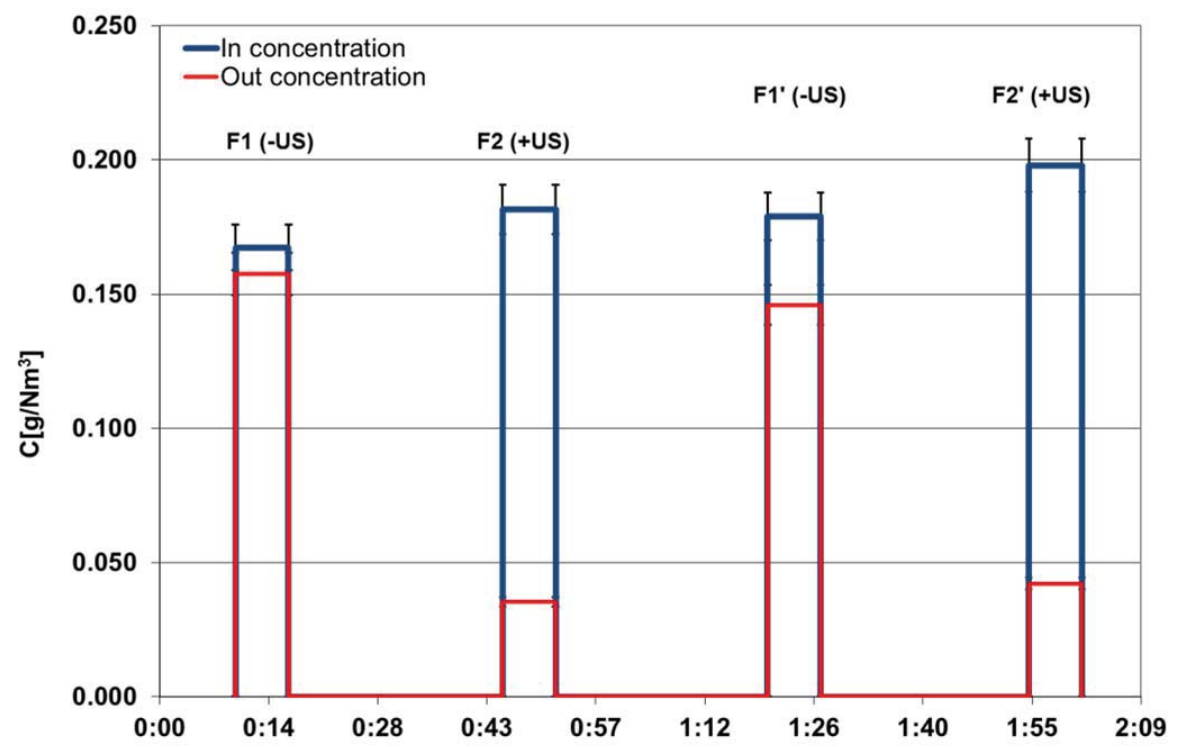

Fig. 68 AAA3 and AAA3' concentration of particles with (F1 and F1') and without (F2 and F2') ultrasonic field 
Although the retention of particles due to the ultrasonic field is a parallel effect derived from the growth particle observations, it has been quantified too. To do so, the ratio of the retention efficiency of the acoustic chamber with ultrasonic field to the retention efficiency without ultrasonic field has been calculated: $\frac{\eta_{+U S}}{\eta_{-U S}}$, where $\eta$ is defined in accordance to eq. (4).

Fig. 69 synthesizes the acoustic retention of the AAA tests. As noted, the acoustic chamber is efficient as a "particle trapper" in a factor ranged from 1.02 to over 1000. Two main observations can be made: on one hand, the efficiency becomes negligible with the monodispersed particles (tests A1 and A2). Medium efficiencies (until acoustic retention equal to 10) are found for mixtures of $\mathrm{SiO}_{2}$, and if credit is given to the only $\mathrm{TiO}_{2}$ test, the larger the particles poly-dispersion the larger the retention. On the other hand, the gas mass flow rate has an effect on the retention. The low gas mass flow rates (i.e. $12 \mathrm{~kg} / \mathrm{h}$ ) show medium acoustic retention, however, no effect of the ultrasound field is observed for the high gas flows (100 $\mathrm{kg} / \mathrm{h}$ ) when uncertainty bars are considered (tests A2 and A6).

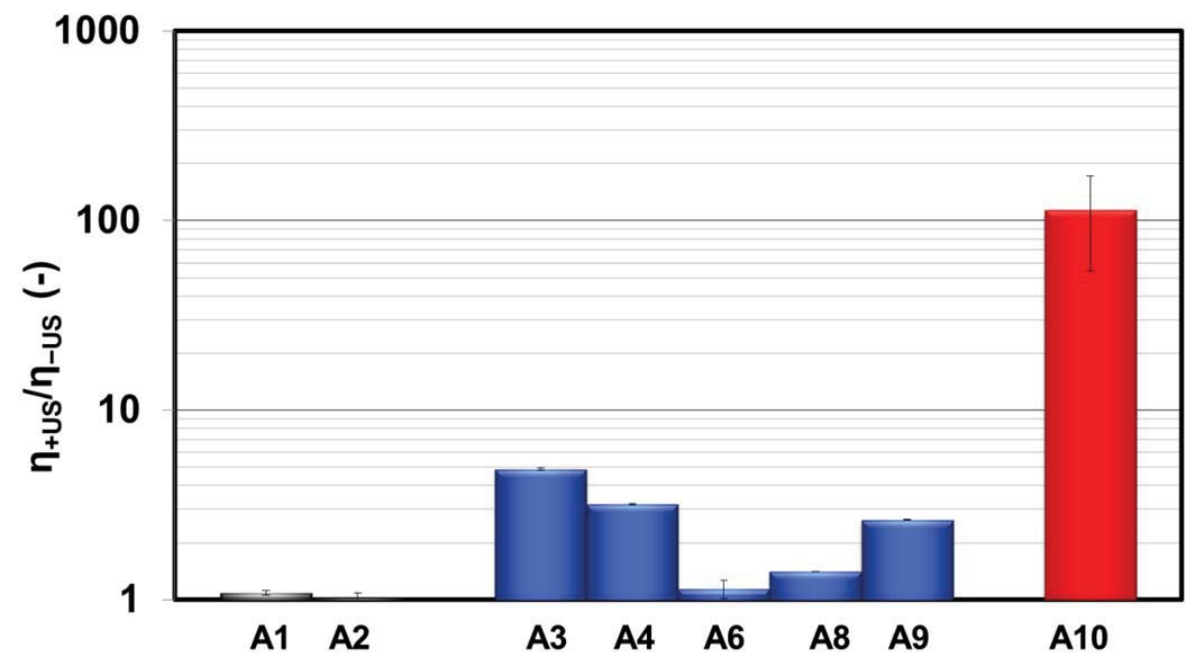

Fig. 69 Acoustic retention factor of AAA tests

\subsubsection{Gas mass flow rate effect}

A global view of the gas mass flow rate effect was already observed in Fig. 65. Moreover, the effect of such an effect has been investigated through experiments performed with constant variables but at different carrier gas mass flow rate. Fig. 70 shows the growth factor of the particles at $12 \mathrm{~kg} / \mathrm{h}, 50 \mathrm{~kg} / \mathrm{h}$ and $100 \mathrm{~kg} / \mathrm{h}$ flow rates (tests number 4,5 and 6 ). 


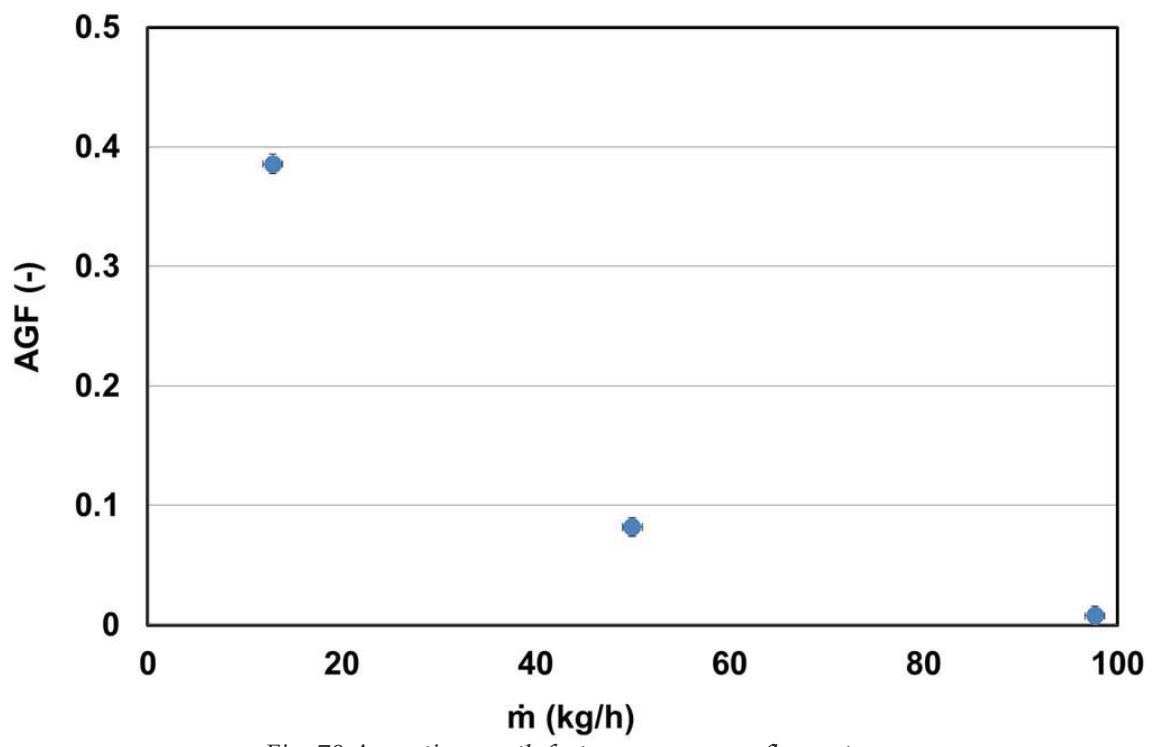

Fig. 70 Acoustic growth factor vs. gas mass flow rate

It is not surprising the increasing trend that can be settled: the lower the gas flow rate, the larger the particles growth. Note that the inverse relation between the gas mass flow rate and the time of residence shows the minimum time that the particles need for being agglomerated. The previous observation indicates that for the current experimental conditions, particles require at least 10 seconds to grow and get retained efficiently. Besides the data points are a few, the relation does not seem to be linear. By decreasing the gas flow in a factor of 2.0 (from $100 \mathrm{~kg} / \mathrm{h}$ to $50 \mathrm{~kg} / \mathrm{h}$ ), particles growth is increased around $8-10 \%$. If the gas flow is drop from $50 \mathrm{~kg} / \mathrm{h}$ to $12 \mathrm{~kg} / \mathrm{h}$ (i.e. factor of 4.0) the particles size increase about $30 \%$.

The large flow rates would induce tangential stresses on particles surface that may weaken particle-particle bounds and eventually, break the agglomerates down. The particles growth trend found is, as far as the acoustic field is applied, the result of the balance between "inhibiting growth mechanisms" induced by high flow rates; and particles coalescence mechanisms as the orthokinetic and hydrodynamic that predominate the interactions and the turbulence ones, which probably play a role. The previous statement mean that the lighter the gas flow the larger the particles chance for a collision, which is additionally increased by the longer residence within the chamber. In this way the exponential trend is explained. 
The particle size distribution is also affected by the gas flow rate. Fig. 71 shows the outgoing distribution with and without ultrasounds for the two tests performed under same experimental conditions except the gas flow rate.

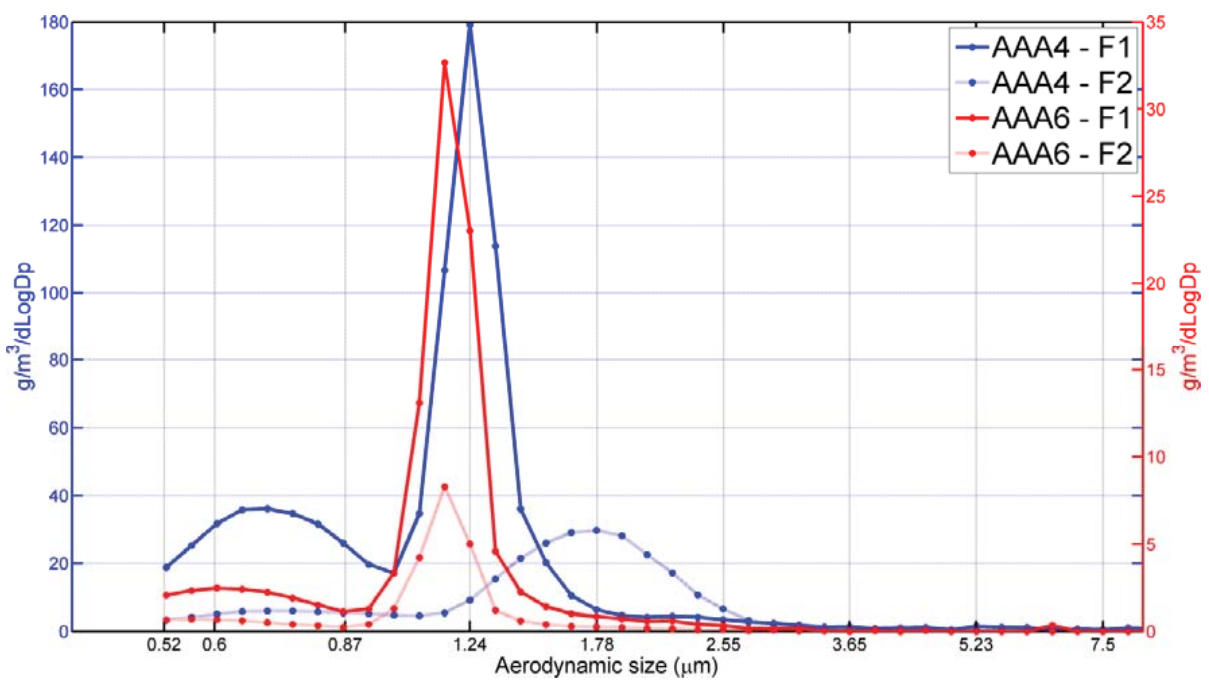

Fig. 71 Particle size distribution at different gas flow rates

No growth can be observed for the gas mass flow of $100 \mathrm{~kg} / \mathrm{h}$. On the other hand, not only a shift in size but a wider size distribution is attained when the mass flow drops to $12 \mathrm{~kg} / \mathrm{h}$. The obtained results validate the previous observations made. The large gas velocities (or short time of residence) do not allow particles to collide and the acoustic growth factor tends to zero. When the velocity decreases (longer time of residence), the agglomeration of different particles sizes is achieved. 


\section{Chapter 6}

\section{Conclusions and future work}

This work presents the experimental database and the insights gained in the behavior of nuclear aerosols in case of a severe accident. Two scenarios have been investigated through three experimental campaigns.

In the first scenario the aerosol behavior and mitigation in the break stage of the secondary side of a steam generator, during a severe accident SGTR sequence has been explored. To do so, two experimental campaigns have been devoted to investigate the breach type (size and shape), particle nature and vibration of tubes influence on the tubes bundle retention. As a result of this work, an experimental database on the aerosols behavior in the break stage of a dry steam generator has been built up. It is available for the development and validation of aerosol retention models to be implemented in severe accident nuclear safety codes.

The second scenario is focused on the assessment of an innovative system to be implemented for the enhancement of the particles source term mitigation during the filtered containment venting process. The innovative system that has been built up is an acoustic chamber where the behavior of aerosols has been characterized under the effect of an ultrasonic field. The experimental campaign studied the influence of variables as the gas mass flow rate and particle nature on the particle growth and as parallel effect, on the particle retention. 


\subsection{Conclusions and final remarks on CAAT2 tests}

The experimental investigation presented and discussed in chapter 4 (CAAT2) has been focused on the aerosol retention in the break stage of a steam generator during SGTR meltdown sequences. By conducting a total of 11 fish-mouth breach experiments in a representative mockup bundle, the effect of variables such as particle nature, gas mass flow rate and breach size on the net retention efficiency was determined. In addition, a comparison to other authors' work has allowed discussing other influences, like the breach shape (fish mouth vs. guillotine breaches).

The most direct outcome of this research is the substantial extension of the existing database. The new data show consistent trends with those from previous campaigns. Both extension and robustness of the present database turns it into a useful tool for modeling development and validation.

Some of the key conclusions drawn from the CAAT2 experiments are:

- Particles entering the secondary side of a steam generator during a SGTR meltdown sequence undergo the effect of inertial and turbulent removal mechanisms that result in a net aerosol retention in the nearby of the tube breach.

- The magnitude of such retention depends heavily on particle nature. The large effect of the aggregation state of particles entering the tube bundle dominates by far any other influence explored. A high retention in the break stage should be expected when single or few-particle agglomerates are carried through the bundle; on the contrary, particle size spectra suggest that low-density agglomerates would get fragmented into sub-micron particles and find their way out of the breach stage.

- Variables other than particle nature (i.e., gas mass flow rate, breach type and size, particle concentration, etc.) have a moderate effect on net retention. Although some trends have been observed, they are very minor when compared to that of particle nature and they even vanish when data uncertainties are taken into account.

- The deposition patterns on the tubes closer to the breach are notably different depending on the breach type. Jet spreading angle, jet momentum loss and effective deposition surface area exposed by tubes, have been postulated as major drivers of the differences observed. Nevertheless, net deposition in the whole break stage is unaffected by deposit distribution in the breach vicinity.

In order to encapsulate the main observations and discussions of the CAAT2 experiments, an empirical correlation has been derived in terms of the ratio between the Stokes and the 
Reynolds number $\left(\mathrm{Stk} / \mathrm{Re}_{\mathrm{p}}\right)$. A sigmoid, easy-to-use equation has been proposed. Despite the fact that presently its nature is fundamentally qualitative and it would benefit from a more extensive database (particularly, in the growing zone of the curve), it allows obtaining an estimate of the aerosol deposition at the break stage.

\subsection{Conclusions and final remarks on SET tests}

The effect of tube vibration on particle retention at the break stage of a steam generator under anticipated conditions of a severe accident SGTR, has been experimentally investigated. It has been done through a matrix of 8 experiments divided into assessment tests (4 tests times 4 flows) and analysis tests (4 tests).

A sensitivity of the integral mass retention due to tube vibration seems to be within the uncertainty band of the measurements. In other words, tubes vibrations do not seem to be a determining factor on the retention. Nevertheless, the observed deposition patterns indicate significant differences in local patterns of the particle deposition found on tubes. An effect of particle filtration would be rather uniform in the absence of vibrations, what contrasts with the deposition gradients observed when tubes vibrate. Despite this difference, the extension of the secondary side causes any effect to vanish in the integral measurement of tube bundle retention. Although mechanical resuspension of aerosols may be the driving mechanism of deposition pattern differences, the number of experiments conducted is too limited to go into further detail in this discussion.

Therefore, the key role played by the particles nature on the breach stage retention has been confirmed by these studies. In addition, these experiments have enlarged the database on the particles retention within the break stage during SGTR sequences.

\subsection{Conclusions and final remarks on AAA tests}

An experimental program has been carried out in order to investigate the aerosols growth capability of the acoustic agglomeration chamber when the particle laden gas expands through it. The aerosol growth has been studied by ten duplicated tests (twenty experiments in total). As a consequence of the particle growth a depletion effect has been found and analyzed too. An influence of variables as the particle nature and the gas mass flow rate has been studied by the particle characterization and the mass measurements of the particles incoming and leaving the acoustic chamber with and without application of a standing ultrasonic field at $21 \mathrm{kHz}$ and 155 $\mathrm{dB}$. 
The principal output of this investigation is evaluating an efficiency of the acoustic chamber in reducing the particle concentration when the directional and powerful acoustic field is applied on the particles flow. Particles retention is mainly achieved due to the agglomeration mechanisms: by means of the hydrodynamic and orthokinetic collisions produced as consequence of the acoustic field.

Additionally, among the final remarks derived from this work, some of the highlighted conclusions drawn are:

- The poly-dispersion of the initial particles mixture dominates the effect of the ultrasonic agglomeration and as a consequence, the particles growth. Monodispersed particles of the same size are lightly sensitive to the acoustic field and so, they are barely agglomerated.

- The acoustic field has an effect on the particle growth when it is applied to polydispersed particle mixtures. It has been observed through the acoustic growth factor. The acoustic field is effective in agglomerating any particle size: on one hand, small particles (under $0.3 \mu \mathrm{m}$, either of $\mathrm{SiO}_{2}$ and $\mathrm{TiO}_{2}$ ). They agglomerate into lower density particles than the former ones, fluffy enough to follow the stream lines and leave the acoustic chamber. On the other hand, on larger particles (over $1 \mu \mathrm{m}$ ), which their collision would generate dense agglomerates prone to get deposited.

- Beyond the objective of the experiments and as a consequence of the particle growth study, it has been found that the acoustic chamber is efficient in the particles depletion regardless the particle type. Under the prevailing conditions investigated, the magnitude of such retention depends on the particles nature and gas mass flow rate. No efficiency of retention is observed for mass flows over 100 $\mathrm{kg} / \mathrm{h}$, below this value, however, the retention ability heavily depends on the particles nature. The retention efficiency is more than two orders of magnitude larger when aerosols are made of agglomerated former particles as $\mathrm{TiO}_{2}$ than if they are compact and dense as $\mathrm{SiO}_{2}$. In any case, the $\mathrm{TiO}_{2}$ results should be validated to extend this conclusion.

\subsection{Future work}

This investigation means a significant contribution to the experimental database on nuclear aerosols. Although from an engineering point of view it seems that the "break stage research" is essentially done, there are still a number of open scientific points that should be addressed for a thorough understanding of the available results. Examples are the exploration of the wake region, aggregate fragmentation and particle resuspension and bouncing. Moreover the CAAT2 and SET results are meant be used in numerical codes as ARI3SG (Herranz and Lopez, 2012; Lopez and Herranz, 2012) for its development and validation. 
The wake region behind the bundle of tubes is an unexplored area where the behavior of the particles is unknown. Experimental and numerical efforts should be focused on the fluid dynamic characterization of this region. Experimental measurements with techniques such as Particle Image Velocimetry (PIV) or Laser Doppler Velocimetry (LDV) can help to understand the particle dynamics and deposition/resuspension mechanisms working behind the tubes. From the numerical point of view, numerical CFD codes as FLUENT could be used to complete the investigation.

The particles nature was demonstrated to be the major variable affecting the aerosol retention. The particle density and the aggregation state are, among others, variables encapsulated within the particle nature and finally are responsible for the results obtained. The clusters density is experimentally unknown but estimated based on theoretical studies. Although some advances have been done, the enlargement of the experimental database on fragmentation of aggregates may help to understand their behavior and, as a consequence their properties as density and shape factor.

The present research dealing with effects of the acoustic agglomeration system on aerosol retention has highlighted open tasks susceptible to being addressed in future research lines. This work is the first step in the application of the ultrasonic chamber as an innovative system for the source term mitigation. The lateral but satisfactory results on particle deposition have confirmed the possibility of using ultrasonic plate transducers as a complementary system to the current FCVS. However this is a first attempt and a global characterization requires a detailed study and analysis of the variables that would have an influence in the process. In short, an assessment of such a technology would definitely need to broaden the experimental database.

Thus, open lines for future work are extent. For instance, the validation of the flow rate effect on the particle growth and the extension of studies focused on the particle nature are required. Moreover, the investigation of these variables as well as other prevailing FCVs boundary conditions as the effect of humidity and temperature on the aerosol depletion is fully open and would be necessary for a thorough understanding. 



\section{Nomenclature}

A

AAA

Ai

a

acfm

ACMD

AGF

$\mathrm{A}_{\mathrm{FT}}$

$\mathrm{A}_{\mathrm{NT}}$

AMMD

APS

ARTIST

ARF

AWE

BEM

$\mathrm{BC}$

C
Breach Area / Peak of acceleration (vibration) / Acoustic agglomeration test Acoustic Aerosol Agglomeration

Acoustic Aerosol Agglomeration test, number i

Instantaneous acceleration (vibration)

Actual cubic feet per minute

Aerodynamic Count Median Diameter

Acoustic Growth Factor

Amplitude of the fixed tube

Amplitude of the normal tube

Aerodynamic Mass Median Diameter

Aerodynamic Particle Sizer

AeRosol Trapping In STeam generator

Acoustic Retention Factor

Acoustic Wake Effect

Boundary Element Method

Boundary Conditions

Particle concentration 
Cc

CAAT

CAAT2

CFD

CSIC

D

$\mathrm{D}_{\mathrm{ae}}$

DF

$\mathrm{d}_{\mathrm{p}}$

$\mathrm{d}_{\mathrm{g}}$

ELPI

FBG

FCV

FCVS

FEI

FEM

FFT

FM

FP

FT

G

GSD

IMP PRIM

IMP SEC

Lbreach

LACE

LASS

LDV

lpm

LWR

MCCI
Slip correction factor

Ciemat Aerosol Artist Tests

Ciemat Aerosol Artist Tests \# 2

Computational Fluid Dynamics

Spanish National Research Council

Breach diameter

Aerodynamic Particle Diameter

Decontamination Factor

Particle diameter

Geometric mean diameter

Electrical Low Pressure Impactor

Fluid Bed Generator

Filtered Containment Venting

Filtered Containment Venting System

Fluid Elastic Instability

Finite Element Method

Fast Fourier Transform

Fish Mouth breach

Flush phase

Fixed tubes

Guillotine breach

Geometric standard deviation

IMPactor PRIIMary side

IMPactor SECondary side

Characteristic length of the breach

Light Water Reactor Aerosol Containment Experiments

Laboratory of Analysis of Safety Systems

Laser Doppler Velocimetry

Liters per minute or $1 / \mathrm{min}$.

Light Water Reactor

Molten Corium Concrete Interactions 


\begin{tabular}{|c|c|}
\hline $\mathrm{m}_{\mathrm{i}}$ & Mass retained by the i device \\
\hline $\mathrm{m}_{\text {in }}$ & Mass of particles entering into the vessel \\
\hline $\mathrm{m}_{\text {out }}$ & Mass of particles outgoing the vessel \\
\hline$m_{\text {ret }}$ & Mass of particle retained \\
\hline $\mathrm{m}_{\text {ret }} \max$ & Maximum of the mass retained \\
\hline $\mathrm{m}_{\text {ret }} \min$ & Minimum of the mass retained \\
\hline $\mathrm{m}_{\mathrm{T}}$ & Mass retained by the $\mathrm{T}$ tube \\
\hline $\mathrm{n}$ & Particle number concentration per bin size (APS) \\
\hline $\mathrm{N}$ & Total number concentration (APS) \\
\hline n.a. & Not available \\
\hline $\mathrm{NC}$ & Nodal circles \\
\hline NT & Normal tubes \\
\hline $\mathrm{p}$ & pitch, distance from the center to center of two neighbour tubes \\
\hline PASSAM & Passive and Active Systems on Severe Accident Source Term Mitigation) \\
\hline PSI & Paul Scherrer Institut \\
\hline PIV & Particle Image Velocimetry \\
\hline PUG & Power Ultrasonics Group \\
\hline PiLi & Membrane filters from the inlet or primary side \\
\hline$-\mathrm{PFi}$ & Filter $i$ at the inlet, without ultrasound field \\
\hline$+\mathrm{PFi}$ & Filter $i$ at the inlet, with ultrasound field \\
\hline $\operatorname{Re}_{\mathrm{D}}$ & Tube Reynolds number \\
\hline RMS & Root Mean Square \\
\hline $\mathrm{RP}$ & Reference phase \\
\hline Sc & Schmidt number \\
\hline$-\mathrm{SFi}$ & Filter i at the outlet, without ultrasound field \\
\hline$+\mathrm{SFi}$ & Filter $i$ at the inlet, with ultrasound field \\
\hline SiLi & Membrane filters from the outlet or secondary side \\
\hline SBWR & Simplified Boiling Water Reactor \\
\hline SEM & Scanning Electron Microscopy \\
\hline SG & Steam Generator \\
\hline SGTR & Steam Generator Tube Rupture \\
\hline SPL & Sound Pressure Level \\
\hline
\end{tabular}




$\begin{array}{ll}\mathrm{S}_{\mathrm{tk}} & \text { Stokes number } \\ \mathrm{V}_{\text {theo }} & \text { Theoretical velocity } \\ \mathrm{v} & \text { Instantaneous velocity } \\ \mathrm{V} & \text { Peak velocity } \\ \mathrm{Vct} & \text { Critical velocity } \\ \mathrm{V}_{\mathrm{g}} & \text { Gas velocity in the acoustic chamber } \\ \mathrm{x} & \text { Displacement } \\ \mathrm{X} & \text { Peak of the displacement } \\ \mathrm{Re}_{\mathrm{D}} & \text { Reynolds number within the broken tube } \\ \mathrm{Re}_{\mathrm{p}} & \text { Particle Reynolds number } \\ t_{s_{i}} & \text { Sampling length of the i device } \\ t_{\text {test }} & \end{array}$

\section{Greek symbols}

$\phi_{\text {test }} \quad$ Average gas flow rate introduced into the bundle during the test length

$\phi_{s_{i}} \quad$ Average mass flow rate passing through the sampling line

$\eta \quad$ Efficiency

$\sigma \quad$ Geometric standard deviation of the size distribution

$\delta \quad$ Uncertainty associated to the variables attached

$\mu \quad$ Mean particle size

$\eta \quad$ Retention efficiency

$\tau \quad$ Residence time 


\section{References}

Aerosol Instrument Manager (Instruction manual, TSI No. APS sensors), 2002.

Albiol, T., Cantrel, L., Herranz, L.E., Riera, E., Guieu, S., Lind, T., Manzini, G., Auvinen, A., Losch, N., 2012. New studies on passive and active systems towards enhanced severe accident source term mitigation - The PASSAM Project. Presented at the EUROSAFE, Brussels (Belgium).

Allelein, H.-J., Auvinen, Ari, Ball, J., Güntay, S., Herranz, L.E., Hidaka, Akihide, Jones, A.V., Kissane, M., Powers, D., Weber, G., 2009. STATE-OF-THE-ART REPORT ON NUCLEAR AEROSOLS (No. NEA/CSNI/R(2009)5).

Ammar, Y., Dehbi, A., Reeks, M.W., 2012. Break-Up of Aerosol Agglomerates in Highly Turbulent Gas Flow. Flow Turbul. Combust. 89, 465-489. doi:10.1007/s10494-0129398-8

Arreghini, F., Jacquemain, D., Garnier, Y., 2000. Summary of Fission Product Behavior and Structure Material Behavior in FPT1.

Auvinen, A., Jokiniemi, J.K., Lähde, A., Routamo, T., Lundström, P., Tuomisto, H., Dienstbier, J., Güntay, S., Suckow, D., Dehbi, A., 2005. Steam generator tube rupture (SGTR) scenarios. Nucl. Eng. Des. 235, 457-472. doi:10.1016/j.nucengdes.2004.08.060

Aylor, D.E., Ferrandino, F.J., 1985. Rebound of pollen and spores during deposition on cylinders by inertial impaction. Atmospheric Environ. 1967 19, 803-806. doi:10.1016/0004-6981(85)90069-1

Bakker, P., 2001. Important Accident Scenarios and Conditions. Presented at the SAM-SGTRD001. 
BIPM, 1993. Guide to the expression of uncertainty in measurement, 1st ed. 1993. ed. International Organization for Standardization, Genève, Switzerland.

Brandt, O., Freund, H., Hiedemann, E., 1936. Zur Theorie der akustischen Koagulation. Kolloid-Z. 77, 103-115. doi:10.1007/BF01422153

Chu, A., 1987. Zeroshift of piezoelectric accelerometers in pyroshock measurements. Presented at the In Shock and Vibration Information Center The Shock and Vibration Bulletin, NASA, San Juan Capistrano, EEUU, pp. 71-80.

Dehbi, A., 2007. How efficient are PWR steam generators as the last barrier during an accident? NES Colloq.

Douglas, P.L., Ilias, S., 1988. On the deposition of aerosol particles on cylinders in turbulent cross flow. Aerosol Sci. 19, 451-462.

ELPI user manual, 2008.

Flow-Induced Vibration of Shell and Tube Heat Exchangers, 2013. , in: Heat Exchanger Design Handbook, Second Edition. CRC Press, pp. 509-562.

Gallego-Juárez, J.A., Riera, E., Rodríguez Corral, G., 1979. Evaluation of an ultrasonic agglomerator as a preconditioner for the removal of fine aerosol particles. Presented at the Ultrasonic International 79, IPC Science Technology Press, Guildford, U.K., pp. 227-232.

Gallego-Juárez, J.A., Riera-Franco De Sarabia, E., Rodríguez-Corral, G., Hoffmann, T.L., Gálvez-Moraleda, J.C., RodrÍguez-Maroto, J.J., Gómez-Moreno, F.J., Bahillo-Ruiz, A., MartÍn-Espigares, M., Acha, M., 1999. Application of Acoustic Agglomeration to Reduce Fine Particle Emissions from Coal Combustion Plants. Environ. Sci. Technol. 33, 3843-3849. doi:10.1021/es990002n

Geldart, D., 1973. Types of gas fluidization. Powder Technol. 7, 285-292. doi:10.1016/00325910(73)80037-3

González, I., Elvira, L., Hoffmann, T.L., Gallego-Juarez, J.A., 2001. Numerical Study of the Hydrodynamic Interaction Between Aerosol Particles Due to the Acoustic Wake Effect. Acustica united with Acustica 87, 454-460.

González, I., Hoffmann, T.L., Gallego, J.A., 2002. Visualization of Hydrodynamic Particle Interactions: Validation of a Numerical Model. Acustica united with Acustica 88, 1926.

Griffin, M.J., 2004. Handbook of human vibration, Reprinted. ed. Elsevier, London.

Guntay, S., 2004. ARTIST: introduction and first results. Nucl. Eng. Des. 231, 109-120. doi:10.1016/j.nucengdes.2004.02.012

Guntay, S., Birchley, J., Suckow, D., Dehbi, A., 2000. Aerosol Trapping in Steam Generator (ARTIST): an investigation of aerosol and iodine behaviour in the secondary side of a steam generator. Presented at the ICONE 8, Baltimore (MD USA). 
Güntay, S., Dehbi, A., Suckow, D., Birchley, J., 2002. ARTIST: an international project investigating aerosol retention in a ruptured steam generator. Presented at the ICAPP, Hollywood, Florida.

Haste, T., Payot, F., Bottomley, P.D.W., 2012. Transport and deposition in the Phébus FP circuit. Ann. Nucl. Energy. doi:10.1016/j.anucene.2012.10.032

Herranz, L.E., Lind, T., Dieschbourg, K., Riera, E., Morandi, S., Rantanen, P., Chebbi, M., Losch, N., 2014. Technical Bases for Experimentation on Source Term Mitigation: The EU-PASSAM Project, in: NUTHOS10-1106. Presented at the The 10th International Topical Meeting on Nuclear Thermal-Hydraulics, Operation and Safety (NUTHOS10), Okinawa, Japan.

Herranz, L.E., Lind, T., Dieschbourg, K., Riera, E., Morandi, S., Rantanen, P., Chebbi, M., Losch, N., 2013. State-Of-The-Art Report Technical Bases for Experimentation on Source Term Mitigation Systems (No. PASSAM - THEOR -T04 [D2.1]).

Herranz, L.E., Lind, T., Mun, C., Riera, E., Morandi, S., Rantanen, P., Azambre, B., Losch, N., 2014. PASSAM Experimental Tests Matrixes (No. PASSAM - THEOR -T04 [D2.2]), Nuclear fission, safety and radiation protection. PASSAM Project.

Herranz, L.E., Lopez, C., 2012. ARI3SG: Aerosol retention in the secondary side of a steam generator. Part I: Model essentials, verification and correlation. Nucl. Eng. Des. doi:10.1016/j.nucengdes.2012.03.032

Herranz, L.E., Prá, C.L. del, Velasco, F.J.S., 2008. Preliminary steps toward assessing aerosol retention in the break stage of a dry steam generator during severe accident SGTR sequences. Nucl. Eng. Des. 238, 1392-1399. doi:10.1016/j.nucengdes.2007.10.007

Herranz, L.E., Tardáguila, R.D., 2014. New data and interpretation on source term attenuation within the break stage during meltdown SGTR sequences. Nucl. Eng. Des. 270, 283-294. doi:10.1016/j.nucengdes.2014.01.010

Herranz, L.E., Velasco, F.J.S., 2013. Characterization of a gas elliptic jet in a nuclear safety $\begin{array}{lllll}\text { scenario. Exp. Therm. Fluid } & \text { 374-384. }\end{array}$ doi:10.1016/j.expthermflusci.2012.07.009

Herranz, L.E., Velasco, F.J.S., Del Prá, C.L., 2006. Aerosol Retention Near the Tube Breach during Steam Generator Tube Rupture Sequences. Nucl. Technol. 154, 85-94.

Hinds, W.C., 1999. Aerosol technology : properties, behavior, and measurement of airborne particles. Wiley, New York [u.a.].

Hoffmann, T.L., 1997. An extended kernel for acoustic agglomeration simulation based on the acoustic wake effect. J. Aerosol Sci. 28, 919-936. doi:10.1016/S00218502(96)00489-2

Hoffmann, T.L., Koopmann, G.H., 1996. Visualization of acoustic particle interaction and agglomeration: Theory and experiments. J. Acoust. Soc. Am. 99, 2130. doi:10.1121/1.415400 
Hwang, S., Namgung, C., Jung, M., Kim, H., Kim, J., 2008. Rupture pressure of wear degraded alloy 600 steam generator tubings. J. Nucl. Mater. 373, 71-74. doi:10.1016/j.jnucmat.2007.05.020

ICP® users manual, 2012.

Ihalainen, M., Lind, T., Arffman, A., Torvela, T., Jokiniemi, J., 2014. Break-Up and Bounce of TiO 2 Agglomerates by Impaction. Aerosol Sci. Technol. 48, 31-41. doi:10.1080/02786826.2013.852155

J A Gallego-Juárez, Luís Herranz, Germán Rodríguez, Víctor M Acosta, Alfonso Blanco, Alberto Pinto, Ignacio Martínez, Roque R Andrés, Enrique Riera, 2014. Aplicación de los transductores ultrasónicos de placa en procesos de aglomeración de partículas en el marco del proyecto europeo PASSAM. doi:10.13140/2.1.1321.1847

Khushnood, S., Khan, Z.M., Malik, M.A., Koreshi, Z.U., Khan, M.A., 2004. A review of heat exchanger tube bundle vibrations in two-phase cross-flow. Nucl. Eng. Des. 230, 233251. doi:10.1016/j.nucengdes.2003.11.024

Kissane, M.P., 2008. On the nature of aerosols produced during a severe accident of a watercooled nuclear reactor. Nucl. Eng. Des. 238, 2792-2800. doi:10.1016/j.nucengdes.2008.06.003

Konstandopoulos, A.G., Labowsky, M.J., Rosner, D.E., 1993. Inertial deposition of particles from potential flows past cylinder arrays. J. Aerosol Sci. 24, 471-483. doi:10.1016/0021-8502(93)90032-5

Leskinen, J., Lyyränen, J., Ruusunen, J., 2010. Comparison of nanoparticle density measurements using APM and impactor-classifier. Presented at the International Aerosol Conference, Helsinki, Finland.

Lind, T., Ammar, Y., Dehbi, A., Güntay, S., 2010a. De-agglomeration mechanisms of TiO2 aerosol agglomerates in PWR steam generator tube rupture conditions. Nucl. Eng. Des. 240, 2046-2053. doi:10.1016/j.nucengdes.2010.03.002

Lind, T., Danner, S., Guentay, S., 2010b. Monodisperse fine aerosol generation using fluidized bed. Powder Technol. 199, 232-237. doi:10.1016/j.powtec.2010.01.011

Lind, T., Dehbi, A., Güntay, S., 2011. Aerosol retention in the flooded steam generator bundle during SGTR. Nucl. Eng. Des. 241, 357-365. doi:10.1016/j.nucengdes.2010.10.025

Lind, T., Güntay, S., Herranz, L.E., Jarayaju, Santhosh, 2012. The results of the ARTIST projects - aerosol retention in a steam generator during SGTR. Presented at the ERMSAR, Cologne (Germany).

Lopez, C., Herranz, L.E., 2012. ARI3SG: Aerosol retention in the secondary side of a steam generator. Part II: Model validation and uncertainty analysis. Nucl. Eng. Des. 248, 282-292. doi:10.1016/j.nucengdes.2012.03.033

López del Prá, C., 2012. A Theoretical Investigation of Aerosol Retention within the Secondary Side of a Steam Generator under a SGTR Severe Accident Sequence in a PWR Nuclear Power Plant. Universidad Politécnica de Valencia. 
López del Prá, C., Sánchez Velasco, F.J., Delgado, R., Herranz, L.E., 2010. Experiments and Modeling of Aerosol Retention in the Break Stage of a Failed Steam Generator during Severe Accident SGTR Sequences (No. DFN/SN-01/OP-10). Ciemat.

López del Prá, C., Sánchez Velasco, F.J., Herranz, L.E., 2007. CFD Modeling of a Gas Jet in the Nearby of a Broken Tube in a Shell-and-tube Heat Exchanger: Application to a Risk-Dominant Scenario in Nuclear Power Plants. Presented at the 5th International Conference on Heat Transfer, Fluid Mechanics and Thermodynamics (HEFAT), Sun City, South Africa.

Magill, J., Caperan, P., Somers, J., Richter, K., Fourcaudot, S., Barraux, P., Lajarge, P., Gallego-Juarez, J.A., Riera-Franco de Sarabia, E., Rodriguez-Corral, G., Seyfert, N., 1992. Characteristics of an electro-acoustic precipitator (EAP). J. Aerosol Sci. 23, 803806. doi:10.1016/0021-8502(92)90533-2

Magill, J., Pickering, S., Fourcaudot, S., Gallego-Juarez, J.A., de Sarabia, E.R.-F., RodriguezCorral, G., 1989. Acoustic aerosol scavenging. J. Nucl. Mater. 166, 208-213. doi:10.1016/0022-3115(89)90191-8

Magill, J., Pickering, S., Fourcaudot, S., Gallego-Juarez, J.A., Riera-Franco De Sarabia, E., Rodriguez-Corral, G., 1988. Ultrasonic aerosol agglomeration at low mass loadings. J. Aerosol Sci. 19, 1377-1380. doi:10.1016/0021-8502(88)90178-4

Mednikov, E.P., 1965. Acoustic coagulation and precipitation of aerosols/ akusticheskaya koagulyatsiya i osazhdenie ... Springer, [Place of publication not identified].

Nippon Shokubai - Seahostar [WWW Document], $2015 . \quad$. https://www.shokubai.co.jp/en/products/functionality/epokara.html.

NUREG-1570, 1998. Risk Assessment of Severe Accident-Induced Steam Generator Tube Rupture, NUREG-1570. USNRC, Sandia National Laboratory.

OECD/NEA/CSNI, 2014. Status Report on Filtered Containment Venting (No. NEA/CSNI/R(2014)7). OECD/NEA/CSNI.

Pagels, J., Gudmundsson, A., Gustavsson, E., Asking, L., Bohgard, M., 2005. Evaluation of Aerodynamic Particle Sizer and Electrical Low-Pressure Impactor for Unimodal and Bimodal Mass-Weighted Size Distributions. Aerosol Sci. Technol. 39, 871-887. doi:10.1080/02786820500295677

Païdoussis, M.P., 1981. Fluidelastic vibration of cylinder arrays in axial and cross flow: State of the art. J. Sound Vib. 76, 329-360. doi:10.1016/0022-460X(81)90516-2

Patterson, H.S., Cawood, W., 1931. Phenomena in a Sounding Tube. Nature 127, 667-667. doi:10.1038/127667a0

Paw U, K.T., 1983. The rebound of particles from natural surfaces. J. Colloid Interface Sci. 93, 442-452. doi:10.1016/0021-9797(83)90428-9

Pettigrew, M.J., 1981. Flow-induced vibration phenomena in nuclear power station components. Power Ind. Res. 1(2), 97-133. 
Pettigrew, M.J., Taylor, C.E., Fisher, N.J., Yetisir, M., Smith, B.A.W., 1998. Flow-induced vibration: recent findings and open questions. Nucl. Eng. Des. 185, 249-276. doi:10.1016/S0029-5493(98)00238-6

Pettigrew, M.J., Taylor, C.E., Jong, J.H., Currie, I.G., 1995. Vibration of a Tube Bundle in Two-Phase Freon Cross-Flow. J. Press. Vessel Technol. 117, 321. doi:10.1115/1.2842130

Pontillon, Y., Ducros, G., 2010. Behaviour of fission products under severe PWR accident conditions. The VERCORS experimental programme-Part 3: Release of low-volatile fission products and actinides. Nucl. Eng. Des. 240, 1867-1881. doi:10.1016/j.nucengdes.2009.06.025

Power ultrasonics: applications of high-intensity ultrasound, 2014. , Woodhead publishing series in electronic and optical materials. Woodhead Pub, Waltham, MA.

Prakash, V., Thirumalai, M., Prabhakar, R., Vaidyanathan, G., 2009. Assessment of flow induced vibration in a sodium-sodium heat exchanger. Nucl. Eng. Des. 239, 169179. doi:10.1016/j.nucengdes.2008.10.007

Price, S.J., 1995. A Review of Theoretical Models for Fluidelastic Instability of Cylinder Arrays in Cross-Flow. J. Fluids Struct. 9, 463-518. doi:10.1006/jfls.1995.1028

Ranz, W.E., Wong, J.B., 1952. Impaction of Dust and Smoke Particles on Surface and Body Collectors. Ind. Eng. Chem. 44, 1371-1381. doi:10.1021/ie50510a050

Riera, E., Gallegojuarez, J., Mason, T., 2005. Airborne ultrasound for the precipitation of smokes and powders and the destruction of foams. Ultrason. Sonochem. doi:10.1016/j.ultsonch.2005.04.001

Riera-Franco de Sarabia, E., Elvira-Segura, L., González-Gómez, I., Rodríguez-Maroto, J.J., Muñoz-Bueno, R., Dorronsoro-Areal, J.L., 2003. Investigation of the influence of humidity on the ultrasonic agglomeration of submicron particles in diesel exhausts. Ultrasonics 41, 277-281. doi:10.1016/S0041-624X(02)00452-3

Riera-Franco de Sarabia, E., Gallego-Juárez, J.A., 1986. Ultrasonic agglomeration of micron aerosols under standing wave conditions. J. Sound Vib. 110, 413-427. doi:10.1016/S0022-460X(86)80144-4

Riera-Franco de Sarabia, E., Gallego-Juárez, J.A., Rodríguez-Corral, G., Elvira-Segura, L., González-Gómez, I., 2000. Application of high-power ultrasound to enhance fluid/solid particle separation processes. Ultrasonics 38, 642-646. doi:10.1016/S0041624X(99)00129-8

Routamo, T., Auvinen, A., Jokiniemi, J., 2005. Aerosol Deposition in a Horizontal VVER-440 Steam Generator. Presented at the International congress on advances in nuclear power plants, Seoul, Korea, pp. 1255-1262.

Rozenberg, L.D. (Ed.), 1973. Physical Principles of Ultrasonic Technology. Springer US, Boston, MA. 
Sánchez Velasco, F.J., 2008. Experimental Characterizatin of Aerosol Retention in the Break Stage of a Dry Steam Generator in SGTR Sequences. Universidad Politécnica de Valencia, Valencia, Spain.

Sánchez-Velasco, F.J., Del Prá, C.L., Herranz, L.E., 2010. Aerosol Retention in the Vicinity of a Breach in a Tube Bundle: An Experimental Investigation. Aerosol Sci. Technol. 44, 349-361. doi:10.1080/02786821003652638

Savkar, S.D., Litzinger, T.A., 1982. Buffeting forces induced by cross-flow through arrays of cylinders. Presented at the Proceedings of the 3rd international conference on vibration in nuclear plant, British Nuclear Energy Society, Keswick (GB).

Scott, D.S., 1975. A new approach to the acoustic conditioning of industrial aerosol emissions. J. Sound Vib. 43, 607-619. doi:10.1016/0022-460X(75)90223-0

Shaw, D.T., Tu, K.W., 1979. Acoustic particle agglomeration due to hydrodynamic interaction between monodisperse aerosols. J. Aerosol Sci. 10, 317-328. doi:10.1016/0021-8502(79)90047-8

Song, L., Koopmann, G.H., Hoffmann, T.L., 1994. An Improved Theoretical Model of Acoustic Agglomeration. J. Vib. Acoust. 116, 208. doi:10.1115/1.2930414

Tardáguila, R.D., Herranz, L.E., 2013. Attenuation of radioactive releases from NPP under accident conditions: An experimental research on risk-dominant scenarios. Chem. Eng. Res. Des. 91, 603-613. doi:10.1016/j.cherd.2013.02.016

Temkin, S., 1994. Gasdynamic agglomeration of aerosols. I. Acoustic waves. Phys. Fluids 6, 2294. doi:10.1063/1.868180

Timoshenko, V., Belen'kii, V., Fedoruk, T., 1976. Kinetics of sonic coagulation and precipatation of high disperse aerosols. Ultrasonics 14, 218-222. doi:10.1016/0041624X(76)90021-4

Torquato, S., Truskett, T., Debenedetti, P., 2000. Is Random Close Packing of Spheres Well Defined? Phys. Rev. Lett. 84, 2064-2067. doi:10.1103/PhysRevLett.84.2064

USNRC, 1996. Steam generator tube failures (NUREG/CR-6365).

USNRC, 1990. Severe Accident Risks: An Assessment for Five U.S. Nuclear Power Plants, NUREG-1150. Sandia National Laboratory.

Wambsganss, M.W., 1987. Tube Vibration and Flow Distribution in Shell-and-Tube Heat Exchangers. Heat Transf. Eng. 8, 62-72. doi:10.1080/01457638708962804

Wang, H.-C., John, W., 1988. Dynamic Adhesion of Particles Impacting a Cylinder, in: Mittal, K.L. (Ed.), Particles on Surfaces 1. Springer US, Boston, MA, pp. 211-224.

Wang, Z., Kwauk, M., Li, H., 1998. Fluidization of fine particles. Chem. Eng. Sci. 53, 377-395. doi:10.1016/S0009-2509(97)00280-7

Weaver, D.S., Ziada, S., Au-Yang, M.K., Chen, S.S., Païdoussis, M.P., Pettigrew, M.J., 2000. Flow-Induced Vibrations in Power and Process Plant Components-Progress and Prospects. J. Press. Vessel Technol. 122, 339. doi:10.1115/1.556190 
Wessel, R.A., Righi, J., 1988. Generalized Correlations for Inertial Impaction of Particles on a Circular Cylinder. Aerosol Sci. Technol. 9, 29-60. doi:10.1080/02786828808959193

Wong, J.B., Johnstone, H.F., n.d. Engineering Experimental Station (No. 11). University of Illinois.

www.panthersnuclearpower7.wikispaces.com, n.d.

Zhu, C., Lin, C.-H., Cheung, C.S., 2000. Inertial impaction-dominated fibrous filtration with rectangular or cylindrical fibers. Powder Technol. 112, 149-162. doi:10.1016/S00325910(99)00315-0 
APPENDIXES 



\section{APPENDIX 1}

\section{State of the Art on Aerosol Acoustic}

\section{Agglomeration Systems: The stepped plate transducers}

In the 70's a new type of piezoelectric air-borne sonic and ultrasonic power generator was designed and developed at CSIC by Gallego-Juárez (Gallego-Juárez et al., 1979). It could achieve a very high efficiency (up to $80 \%$ ) and directivity. The structure of the transducer essentially consists of a vibrating circular plate with a stepped profile driven at its center by a piezoelectrically activated vibrator.

The first acoustic agglomeration system of this kind, was designed, developed and tested at CSIC. It consisted of a stepped plate-transducer with $150 \mathrm{~W}$ power capacity. It operated at 20 $\mathrm{kHz}$ and was coupled to a cylindrical chamber (220 mm diameter and $2 \mathrm{~m}$ in length, approx.) in which a standing wave was generated by placing a reflector opposite to the emitter. It was initially tested as a precipitator. The average sound pressure level (SPL) inside the chamber was $160 \mathrm{~dB}$. Precipitation tests on polydisperse carbon black smoke $(\mathrm{dp}=1 \mu \mathrm{m}, \mathrm{GSD}=2.2)$ were 
carried out with flow rates around $60 \mathrm{~m}^{3} / \mathrm{h}$ and mass loading from $4-14 \mathrm{~g} / \mathrm{m}^{3}$. These experiments gave a mass collection efficiencies in the chamber of about $93 \%$ achieved with an energy consumption of approximately $3 \cdot 10^{-3} \mathrm{kWh} / \mathrm{m}^{3}$.

The ultrasonic chamber was then investigated as a pre-conditioner, i.e., to be placed upstream of a conventional collector system (cyclone, electrostatic filter, scrubber, etc.). The main advantage of this configuration is that for a given agglomeration efficiency, higher flow rates could be used. Dynamic tests were performed to assess the degree of particle agglomeration as a function of acoustic intensity and treatment time. The particle size distribution was measured before and after the ultrasonic treatment with an aerosol flow rate of about $100 \mathrm{~m}^{3} / \mathrm{h}$. An increase of one order of magnitude in the average size of the aerosol at the chamber outlet for a treatment time of $2.5 \mathrm{~s}$ was obtained (initial $\mathrm{dp}=0.6 \mu \mathrm{m}$; final $\mathrm{dp}=9.6 \mu \mathrm{m}$ ) with an energy consumption of approximately $1.5 \cdot 10^{-3} \mathrm{kWh} / \mathrm{m}^{3}$. The results confirmed the improvement of the collector with the pre-conditioning phase.

An important prerequisite was the development of new higher power versions of the steppedplate ultrasonic emitter. So, new transducers operating at $20 \mathrm{kHz}$ and with power capacities up to $0.5 \mathrm{~kW}$ and acoustic conversion efficiency of $75 \%$ were designed and constructed. These transducers were tested under static conditions in parallelepiped chambers of $5 \mathrm{~m}^{3}$ and $15 \mathrm{~m}^{3}$. The time variation of the mass loading of the aerosol in the chamber as a function of the acoustic power and time is given in Fig. 72 for a soot aerosol with initial mass loading of $1 \mathrm{~g} /$ $\mathrm{m}^{3}$. Sound Pressure Levels (SPL) ranging from $160 \mathrm{~dB}$ along the axis of the transducer, to $140 \mathrm{~dB}$ far from the sources measured. Three types of aerosols were tested with mass loading of about 1 $\mathrm{g} / \mathrm{m}^{3}$ and mean particle diameter of around $0.8 \mu \mathrm{m}$ : dense black soot aerosol (solid), artificial fog aerosol (liquid) and a mixture of both aerosols. The observation of a second peak in the particle distribution after acoustic treatment provided clear evidence of the orthokinetic interaction as the dominant mechanism of acoustic agglomeration process.

A new step forward was an experimental installation for dynamic tests to analyse the role of ultrasound in the enhancement of an electrostatic precipitator (ESP) performance in the submicron particle range. The aerosol used in this study was produced by heating glycerol at high temperature and rapidly mixing the hot vapor with cold air. The resulting dense white condensation aerosol has a log-normal particle size distribution, having a geometrical mean diameter of $0.8 \mu \mathrm{m}(\mathrm{GSD}=1.4)$. Standing wave fields at $20 \mathrm{kHz}$ were generated in a rectangular cross-section chamber. Stepped plate transducers with power capacities up to $0.5 \mathrm{~kW}$ were used in an experimental plant. For this purpose, the aerosol flow rate varied from 150 to $1500 \mathrm{~m}^{3} / \mathrm{h}$, resulting flow velocities of 0.17 to $1.7 \mathrm{~m} / \mathrm{s}$ inside the acoustic chamber and $0.33-3.3 \mathrm{~m} / \mathrm{s}$ in the ESP. In the experiments the total particle number concentration was $2 \cdot 10^{6}$ partic/ $\mathrm{cm}^{3}$ and mass loading of about $1.35 \mathrm{~g} / \mathrm{m}^{3}$. The separation efficiency of the ESP was increased from $87 \%$ to $92 \%$ when ultrasonic energy was applied at $20 \mathrm{kHz}$ (transducer operating at $400 \mathrm{~W}$ ). In addition, the combined electro-acoustic precipitator (EAP) reduced the cumulative rest mass below $5 \mu \mathrm{m}$ leaving the ESP from $10^{3} \mathrm{mg} / \mathrm{m}^{3}$ to $74 \mathrm{mg} / \mathrm{m}^{3}$, which confirms the benefits of using acoustic energy to increase the efficiency of conventional separators in the submicron range. 


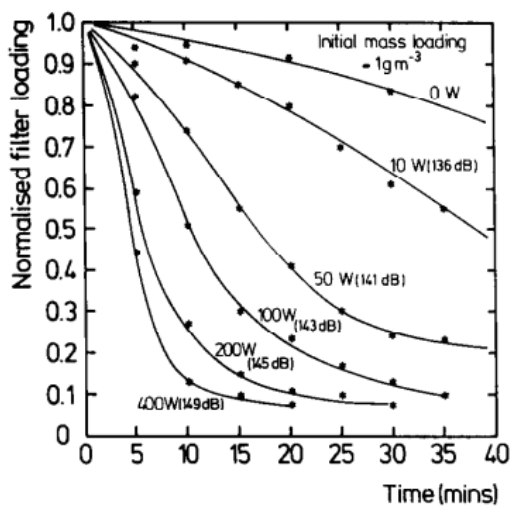

Fig. 72 The normalized mass loading (with respect to the initial mass loading) as a function of time for various transducer power applied within the $5 \mathrm{~m}^{3}$ chamber under static condition (Magill et al., 1989)

Under the frame of a research agreement among CSIC and CIEMAT research institutions and the private company ENDESA, a pilot plant was developed. It had a multifrequency acoustic preconditioning chamber and an electrostatic precipitator (ESP) for the for the exhaust fumes treatment. The pilot plant was tested with fumes from a 0.5 MWt fluidized bed coal combustor.

The objective of these tests was to acoustically agglomerate micron and submicron sized particles to quantify the separation improvement of the EF. The acoustic chamber was $3.6 \mathrm{~m}$ long with a rectangular cross-section of $0.7 \mathrm{~m} \times 0.5 \mathrm{~m}$. The residence time of the aerosol in the acoustic chamber was of about $2 \mathrm{~s}$. Four stepped-plate high-intensity macrosonic transducers of $10 \mathrm{kHz}$ and $20 \mathrm{kHz}$ were used to achieve average sound pressure levels of about $151 \mathrm{~dB}$ in the entire volume of the chamber and peak values of $165 \mathrm{~dB}$. In the experiments the gas entered the chamber at $250{ }^{\circ} \mathrm{C}$, flow rate of $1600 \mathrm{~m}^{3} / \mathrm{h}$ with mass loading of $5 \mathrm{~g} / \mathrm{m}^{3}$ and particle number concentration of $5 \cdot 10^{5}$ partic/ $\mathrm{cm}^{3}$. When ultrasound was applied (four transducers at $400 \mathrm{~W}$ ), the reduction in micron-sized particles reached $76 \%$ with respect to the initial number of particles. Reductions of about $34 \%$ were obtained in the submicron size distribution. This system can be applied to any industrial process where agglomeration and precipitation of airborne particles is required.

CSIC subsequently studied the influence of humidity on the ultrasonic agglomeration and precipitation at $20 \mathrm{kHz}$ of submicron particles $(0.2 \mu \mathrm{m})$ generated by a $97 \mathrm{~kW}$ diesel engine. The pilot plant used for these tests was modified by introducing a dilution system and a nozzle atomizer (Fig. 73) and placing the transducers (four transducers of $20 \mathrm{kHz}$ ) on the lateral side of the chamber. The ESP was not employed in these tests because its retention efficiency was very 
low (of about $40 \%$ ) due to the very small size of the particles and their low resistivity. The ultrasonic chamber alone, with flow rates of $900 \mathrm{Nm}^{3} / \mathrm{h}$, produced a reduction in the number concentration of particles of the order of $25 \%$. Such reduction, which represents a measure of the agglomeration rate, was raised up to $56 \%$ by injecting water droplets in to get a moisture concentration of $6 \%$ (weight).

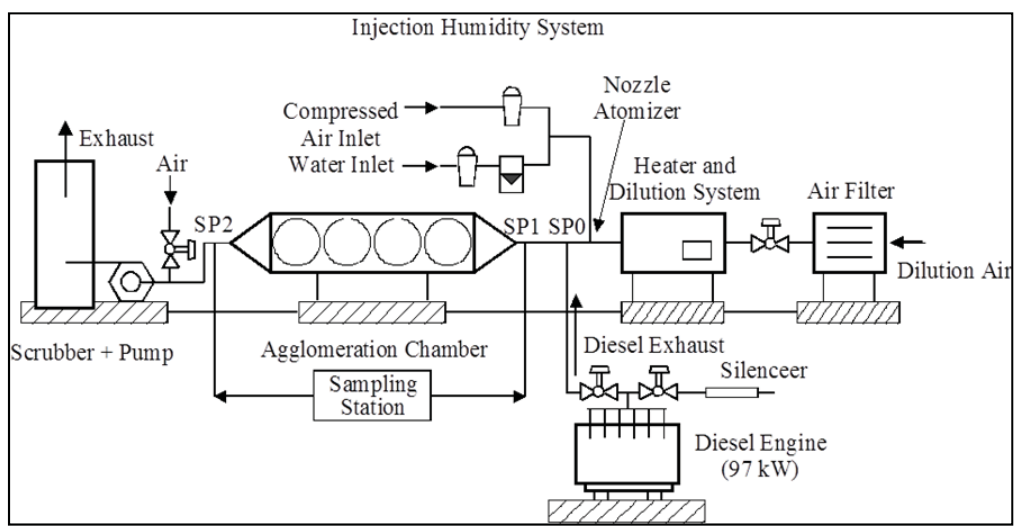

Fig. 73 Scheme of the pilot plant scale ultrasonic installation at $20 \mathrm{kHz}$ for fine particle agglomeration with diesel exhausts under dynamic conditions

The conditions tested during the research projects on AAA performance are summarized in TABLE 20. 


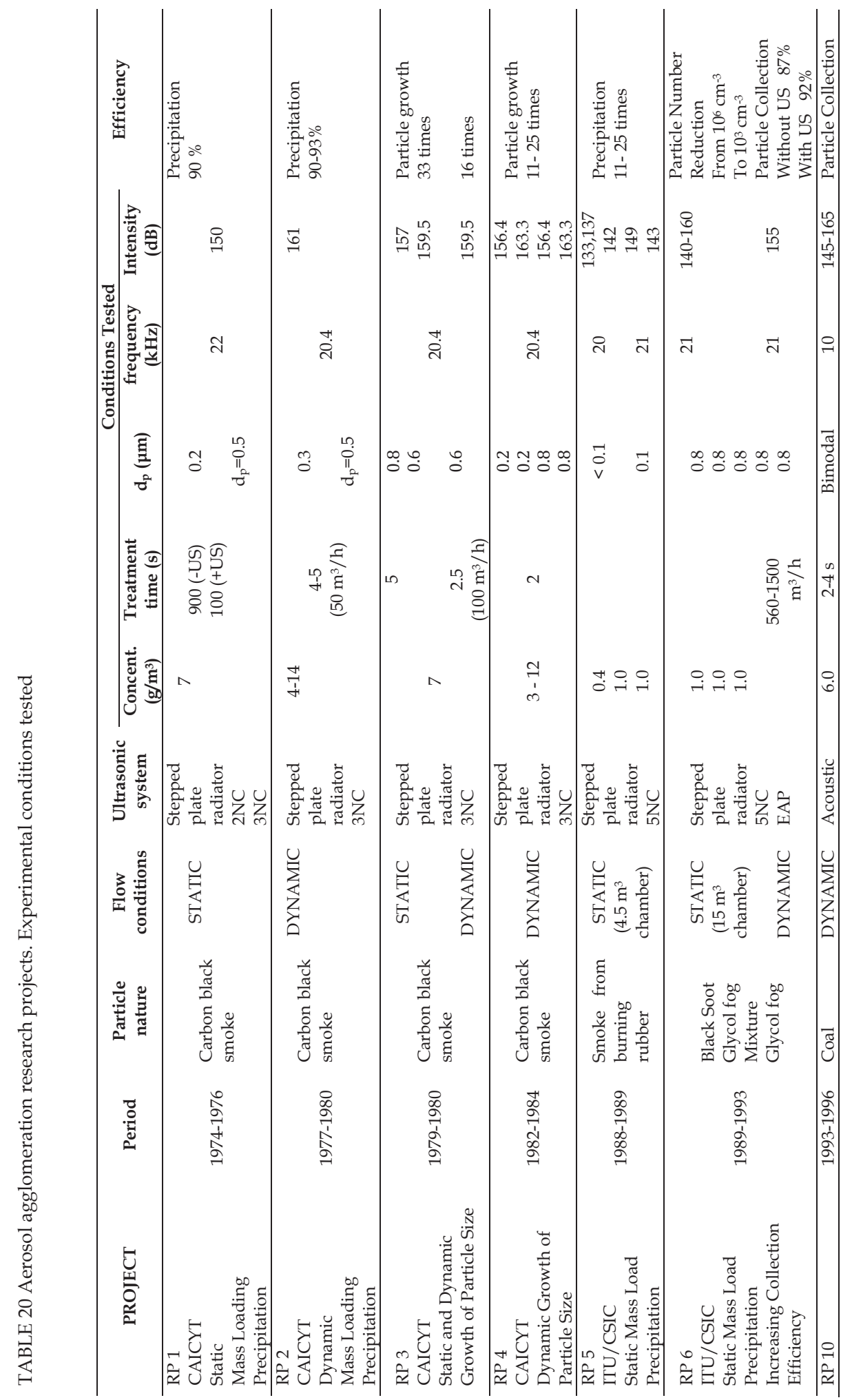




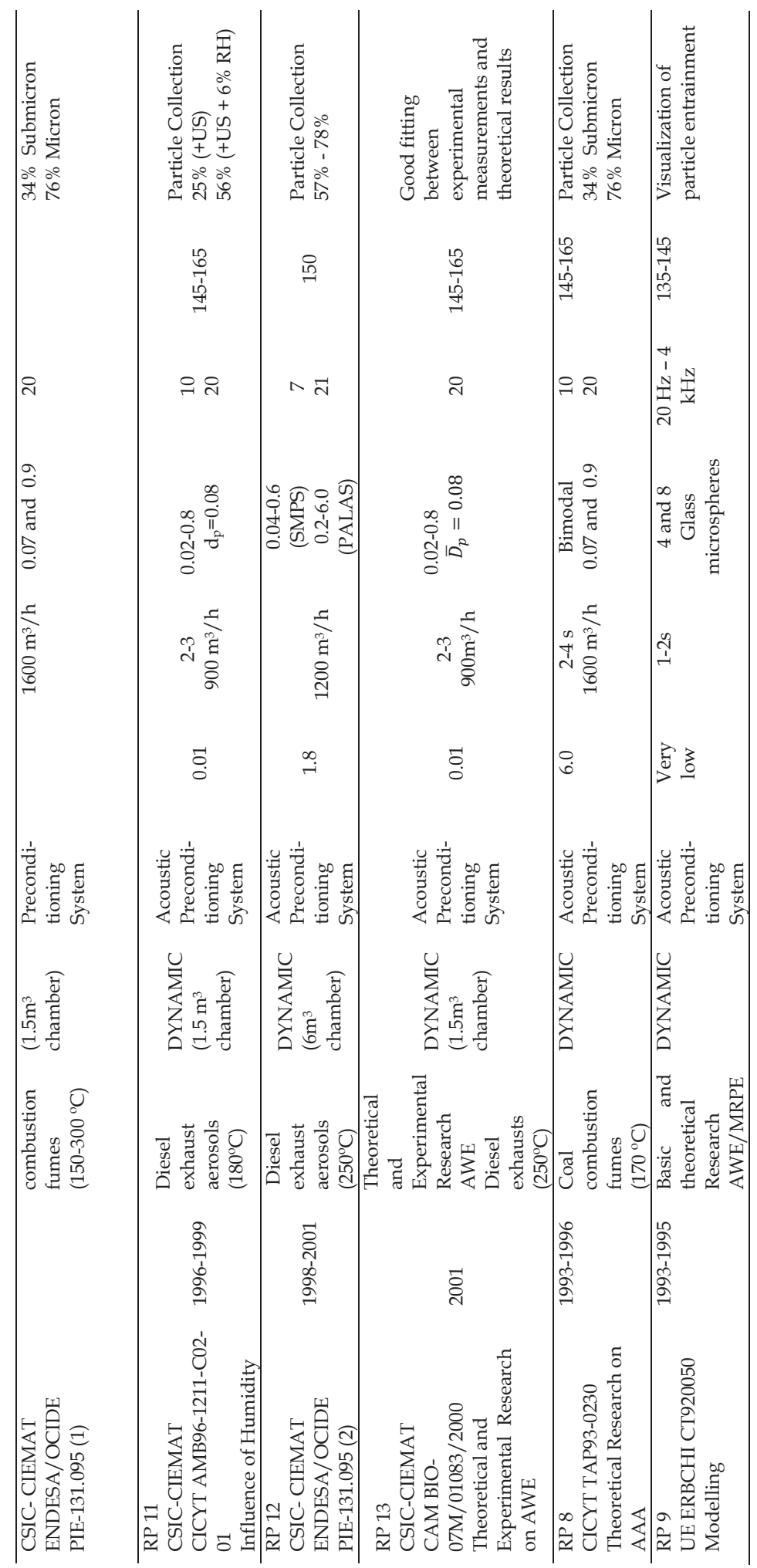




\section{APPENDIX 2}

\section{Uncertainty Analysis}

\subsection{Retention efficiency}

There are two possible equations for determining the retention efficiency (i.e. $\quad \eta=\frac{m_{\text {ret }}}{m_{\text {in }}}$ and $\eta=1-\frac{m_{\text {out }}}{m_{\text {in }}}$

in ). The uncertainty analysis differs from one to the other, but, in both cases the uncertainty of the calculated retention efficiency has been quantified by error propagation calculus from the measured quantities, following the ISO guidelines (BIPM, 1993):

1) $\eta=\frac{m_{r e t}}{m_{i n}} \Rightarrow \delta \eta=\sqrt{\left[\frac{\partial \eta}{\partial m_{r e t}} \cdot \delta m_{r e t}\right]^{2}+\left[\frac{\partial \eta}{\partial m_{i n}} \cdot \delta m_{i n}\right]^{2}}$

Where the uncertainty of each term has been derived from the following measurement chain: 
- $\frac{\partial \eta}{\partial m_{\text {ret }}}=\frac{1}{m_{\text {in }}}$

- $\frac{\partial \eta}{\partial m_{\text {in }}}=-\frac{m_{r e t}}{m_{\text {in }}^{2}}$

- $\delta m_{\text {ret }}$ is determined experimentally from the uncertainty of the mass weight after sweeping the mass collected on the tubes surface. After a systematic study to assess the uncertainty in the gravimetric measurements, $\delta m_{\text {ret }}$ was estimated to be $10 \%$ of the final $m_{\text {ret }}$ measured with a minimum value of $1 \mathrm{~g}$.

- $\mathrm{m}_{\mathrm{in}}$ is the inlet mass which is estimated from the membrane filters measurements at the inlet of the bundle. It is given by:

$m_{\text {in }}=\overline{m_{F}} \cdot \frac{\overline{\phi_{\text {test }}}}{\overline{\phi_{s}}} \cdot \frac{t_{\text {test }}}{t_{s}}$, and its base error :

$\delta m_{i n}=\sqrt{\left[\frac{\partial m_{i n}}{\partial \bar{m}_{F}} \cdot \delta \overline{m_{F}}\right]^{2}+\left[\frac{\partial m_{\text {in }}}{\partial \bar{\phi}_{\text {test }}} \cdot \delta \overline{\phi_{\text {test }}}\right]^{2}+\left[\frac{\partial m_{\text {in }}}{\partial \bar{\phi}_{s}} \cdot \delta \overline{\phi_{s}}\right]^{2}+\left[\frac{\partial m_{\text {in }}}{\partial t_{\text {test }}} \cdot \delta t_{\text {test }}\right]^{2}+\left[\frac{\partial m_{\text {in }}}{\partial t_{s}} \cdot \delta t_{s}\right]^{2}}$

Where

- $\frac{\partial m_{\text {in }}}{\partial \bar{m}_{F}}=\frac{\overline{\phi_{\text {test }}}}{\overline{\phi_{s}}} \cdot \frac{t_{\text {test }}}{t_{s}}$

- $\frac{\partial m_{\text {in }}}{\partial \overline{\phi_{s}}}=-\overline{m_{F}} \cdot \frac{\overline{\phi_{\text {test }}}}{\overline{\phi_{s}{ }^{2}}} \cdot \frac{t_{\text {test }}}{t_{s}}$

- $\frac{\partial m_{\text {in }}}{\partial \overline{\phi_{\text {test }}}}=\frac{\overline{m_{F}}}{\overline{\phi_{s}}} \cdot \frac{t_{\text {test }}}{t_{s}}$

- $\frac{\partial m_{\text {in }}}{\partial t_{\text {test }}}=\frac{\overline{m_{F}}}{t_{s}} \cdot \frac{\overline{\phi_{\text {test }}}}{\overline{\phi_{s}}}$

- $\frac{\partial m_{\text {in }}}{\partial t_{s}}=-\overline{m_{F}} \cdot \frac{\overline{\phi_{\text {test }}}}{\overline{\phi_{s}}} \cdot \frac{t_{\text {test }}}{t_{s}^{2}}$

- $\bar{m}_{F}$ is determined experimentally from the mass retained by several filters. The base error of the average mass is estimated as twice the standard deviation of the independent measurements (assuming the normal distribution or a confidence level of $95 \%$.

- The flow rate, either at the main line ( $\left.\phi_{\text {test }}\right)$ and the sampling one, $\left(\phi_{\mathrm{s}}\right)$ fluctuates around the average flow set. It is recorded each $700 \mathrm{~ms}$ and the error associated can be assumed also as double the standard 
deviation of the data acquired (assuming normal distribution, i.e. $95 \%$ of confidence level)

- $\delta t_{\text {test }}=\delta t_{\mathrm{s}}=1 \mathrm{~s}$.

2) $\eta=\frac{m_{\text {ret }}}{m_{\text {ret }}+m_{\text {out }}} \Rightarrow \delta \eta=\sqrt{\left[\frac{\partial \eta}{\partial m_{\text {ret }}} \cdot \delta m_{\text {ret }}\right]^{2}+\left[\frac{\partial \eta}{\partial m_{\text {out }}} \cdot \delta m_{\text {out }}\right]^{2}}$

The calculus required for the uncertainty of the retention efficiency is parallel to the previous one. As a result, the new expressions are derived here:

- $\frac{\partial \eta}{\partial m_{\text {ret }}}=\frac{m_{\text {out }}}{\left(m_{\text {ret }}+m_{\text {out }}\right)^{2}}$

- $\frac{\partial \eta}{\partial m_{\text {out }}}=-\frac{m_{\text {ret }}}{\left(m_{\text {ret }}+m_{\text {out }}\right)^{2}}$

\subsection{Particle concentration}

The particles concentration entering and leaving the vessel is determined through the sample withdrawn by the filters (section 3.2.7.2.2). It is given by

$$
C\left(\frac{g}{m^{3}}\right)=\frac{\Delta m(g)}{\frac{Q_{s}(\mathrm{Nl} / \mathrm{min})}{10^{3}\left(\frac{\mathrm{l}}{\mathrm{m}^{3}}\right)} \cdot \frac{1 \cdot 29\left(\frac{\mathrm{kg}}{\mathrm{Nm}}\right)}{\rho g\left(\frac{\mathrm{kg}}{\mathrm{m}^{3}}\right)} \cdot \frac{\Delta t(\mathrm{~s})}{60\left(\frac{\mathrm{s}}{\mathrm{min}}\right)}}
$$

The concentration depends on $C=C(\Delta m, Q s, \rho g, \Delta t)$. The concentration associated uncertainty is given by:

$$
\delta C=\sqrt{\left[\frac{\partial C}{\partial \Delta m} \cdot \delta \Delta m\right]^{2}+\left[\frac{\partial C}{\partial Q s} \cdot \delta Q s\right]^{2}+\left[\frac{\partial C}{\partial \rho_{g}} \cdot \delta \rho_{g}\right]^{2}+\left[\frac{\partial C}{\partial \Delta t} \cdot \delta \Delta t\right]^{2}}
$$

Where:

$$
\text { - } \frac{\partial C}{\partial \Delta m}=\frac{1}{\frac{Q_{S}(\mathrm{Nl} / \mathrm{min})}{10^{3}\left(\frac{\mathrm{l}}{\mathrm{m}^{3}}\right)} \cdot \frac{1.29\left(\frac{\mathrm{kg}}{\mathrm{Nm}}\right)}{\rho_{g}\left(\frac{\mathrm{kg}}{\mathrm{m}^{3}}\right)} \cdot \frac{\Delta t(s)}{60\left(\frac{s}{\mathrm{~min}}\right)}}
$$

- $\delta \Delta \mathrm{m}$ : After a systematic study to assess the uncertainty in the gravimetric measurements, $\delta \Delta \mathrm{m}$ was estimated to be $10 \%$ of the final $\Delta \mathrm{m}$ measured. 
- $\frac{\partial C}{\partial Q_{S}}=-\frac{\Delta m(g)}{\frac{\left[Q_{S}(\mathrm{Nl} / \mathrm{min})\right]^{2}}{10^{3}\left(\frac{\mathrm{l}}{\mathrm{m}^{3}}\right)} \cdot \frac{1.29\left(\frac{\mathrm{kg}}{\mathrm{Nm}}\right)}{\rho g\left(\frac{\mathrm{kg}}{\mathrm{m}^{3}}\right)} \cdot \frac{\Delta t(s)}{60\left(\frac{\mathrm{s}}{\mathrm{min}}\right)}}$

- $\partial Q_{S}=2 \sigma_{Q S}$ The particular volumetric flow rate error was estimated as double of a standard deviation of the acquired data (assuming the normal distribution), i.e. with a confidence level of $95 \%$.

- $\frac{\partial C}{\partial \rho_{g}}=\frac{\Delta m(g)}{\frac{Q_{S}(N l / m i n)}{10^{3}\left(\frac{l}{m^{3}}\right)} \cdot 1.29\left(\frac{k g}{N m^{3}}\right) \cdot \frac{\Delta t(s)}{60\left(\frac{s}{\min }\right)}}$

- $\delta \rho_{g}(P, T)=\sqrt{\left(\frac{\partial \rho}{\partial P} \cdot \delta P\right)^{2}+\left(\frac{\partial \rho}{\partial T} \cdot \delta T\right)^{2}}=\sqrt{\left(\frac{1}{R T} \cdot \delta P\right)^{2}+\left(-\frac{P}{R T^{2}} \cdot \delta T\right)^{2}}$

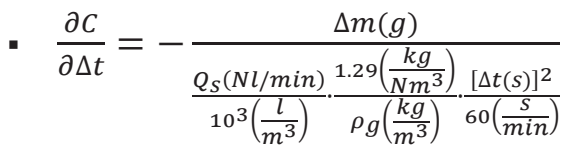

- $\delta \Delta \mathrm{t}=1 \mathrm{~s}$

\subsection{AGF}

The AGF is given the equations 20 and 21 derived in section 5.6.2. For a three particles mixture, the acoustic growth factor is eventually given by:

$$
\begin{aligned}
& A G F=\frac{C_{\text {out } A P}}{C_{\text {outAP }}+C_{\text {outFP }}}\left[\frac{A M M D_{A P 1}-A M M D_{R P 1}}{A M M D_{R P 1}}+\frac{A M M D_{A P 2}-A M M D_{R P 2}}{A M M D_{R P 2}}+\frac{A M M D_{A P 1}-A M M D_{R P 1}}{A M M D_{R P 1}}\right]+ \\
& \frac{C_{\text {outFP }}}{C_{\text {outAP }}+C_{\text {outFP }}}\left[\frac{A M M D_{F P}-A M M D_{R P 2}}{A M M D_{R P 2}}\right]
\end{aligned}
$$

The subscripts FP refer to Flush phase, RP to reference phase of P1, P2 and P3 peak 1, 2 and 3 respectively,. From this relationship the error formula is developed: 


$$
\begin{aligned}
& \delta A G F=\left[\left(\frac{\partial A G F}{\partial C_{\text {out } A P}} \delta C_{\text {outAP }}\right)^{2}+\left(\frac{\partial A G F}{\partial C_{\text {out } F P}} \delta C_{\text {outFP }}\right)^{2}+\left(\frac{\partial A G F}{\partial A M M D_{A P 1}} \delta A M M D_{A P 1}\right)^{2}+\right. \\
& \left(\frac{\partial A G F}{\partial A M M D_{A P 2}} \delta A M M D_{A P 2}\right)^{2}+\left(\frac{\partial A G F}{\partial A M M D_{A P 3}} \delta A M M D_{A P 3}\right)^{2}+ \\
& \left(\frac{\partial A G F}{\partial A M M D_{R P 1}} \delta A M M D_{R P 1}\right)^{2}+\left(\frac{\partial A G F}{\partial A M M D_{R P 2}} \delta A M M D_{R P 2}\right)^{2}+ \\
& \left.\left(\frac{\partial A G F}{\partial A M M D_{R P 3}} \delta A M M D_{R P 3}\right)^{2}+\left(\frac{\partial A G F}{\partial A M M D_{F P}} \delta A M M D_{F P}\right)^{2}\right]^{1 / 2}
\end{aligned}
$$

The sensitivity of the AGF with respect every parameter has been calculated or estimated as follows:

$$
\begin{aligned}
& \text { - } \frac{\partial A G F}{\partial C_{\text {out } A P}}=\frac{C_{\text {outFP }}}{\left(C_{\text {out } A P}+C_{\text {outFP }}\right)^{2}}\left[\frac{A M M D_{A P 1}-A M M D_{R P 1}}{A M M D_{R P 1}}+\frac{A M M D_{A P 2}-A M M D_{R P 2}}{A M M D_{R P 2}}+\right. \\
& \left.\frac{A M M D_{A P 1}-A M M D_{R P 1}}{A M M D_{R P 1}}\right]+\frac{-C_{\text {out } F P}}{\left(C_{\text {out } A P}+C_{\text {outFP }}\right)^{2}}\left[\frac{A M M D_{F P}-A M M D_{R P 2}}{A M M D_{R P 2}}\right]
\end{aligned}
$$

- $\frac{\partial A G F}{\partial C_{\text {outFP }}}=\frac{-C_{\text {outAP }}}{\left(C_{\text {out } A P}+C_{\text {outFP }}\right)^{2}}\left[\frac{A M M D_{A P 1}-A M M D_{R P 1}}{A M M D_{R P 1}}+\frac{A M M D_{A P 2}-A M M D_{R P 2}}{A M M D_{R P 2}}+\right.$ $\left.\frac{A M M D_{A P 1}-A M M D_{R P 1}}{A M M D_{R P 1}}\right]+\frac{C_{\text {out } A P}}{\left(C_{\text {out } A P}+C_{\text {outFP }}\right)^{2}}\left[\frac{A M M D_{F P}-A M M D_{R P 2}}{A M M D_{R P 2}}\right]$

- $\frac{\partial A G F}{\partial A M M D_{A P 1}}=\frac{\partial A G F}{\partial A M M D_{A P 2}}=\frac{\partial A G F}{\partial A M M D_{A P 3}}=\frac{C_{\text {out } A P}}{\left(C_{\text {out } A P}+C_{\text {outFP }}\right)}$

- $\frac{\partial A G F}{\partial A M M D_{F P}}=\frac{C_{\text {outFP }}}{\left(C_{\text {out } A P}+C_{\text {outFP }}\right)}$

- $\frac{\partial A G F}{\partial A M M D_{R P 1}}=-\frac{A M M D_{A P 1}}{A M M D_{R P 1}{ }^{2}} \frac{C_{\text {out } A P}}{\left(C_{\text {outAP }}+C_{\text {outFP }}\right)}$

- $\frac{\partial A G F}{\partial A M M D_{R P 2}}=-\frac{A M M D_{A P 2}}{A M M D_{R P 2}{ }^{2}} \frac{C_{\text {out } A P}}{\left(C_{\text {out } A P}+C_{\text {outFP } P}\right)}-\frac{A M M D_{F P}}{A M M D_{R P 2}{ }^{2}} \frac{C_{\text {out } F P}}{\left(C_{\text {out } A P}+C_{\text {out } F P}\right)}$

- $\frac{\partial A G F}{\partial A M M D_{R P 3}}=-\frac{A M M D_{A P 3}}{A M M D_{R P 3}{ }^{2}} \frac{C_{\text {out } A P}}{\left(C_{\text {out } A P}+C_{\text {outFP }}\right)}$

- $\delta C_{\text {outAp: }}$ the error of the concentration was estimated as the sensitivity of the 
APS that resulted to be $5 \%$ of the concentration measured.

- $\delta A M M D_{\mathrm{AP} 1}=\delta \mathrm{AMMD}_{\mathrm{AP} 2}=\delta \mathrm{AMMD}_{\mathrm{AP} 3}=\delta \mathrm{AMMD}_{\mathrm{RP} 1}=\delta \mathrm{AMMD}_{\mathrm{RP} 2}=\delta \mathrm{AMMD}_{\mathrm{RP} 3}=$ $\delta A M M D_{\mathrm{FP}}$ : The each particular AMMD error was estimated as double of a standard deviation interval of the corresponding aerosol size distribution (assuming the normal distribution), i.e. with a confidence level of $95 \%$.

\subsection{Acoustic chamber retention}

The acoustic retention is a dimensionless quantity to assess the effect of the ultrasonic field on the particle retention. It is defined as the ratio of the retention efficiency of the acoustic chamber with ultrasonic field to the retention efficiency without ultrasonic field. In order to make easier the uncertainty denotation, it has been called ARF.

$$
A R F=\frac{\eta_{+U S}}{\eta_{-U S}}
$$

Where $\eta$ is defined in accordance to eq. (4). At AAA experiments $\eta$ is a derived magnitude from the mass entering $\left(\mathrm{m}_{\mathrm{in}}\right)$ and leaving the acoustic chamber $\left(\mathrm{m}_{\text {out }}\right): \mathrm{m}_{\text {ret }}=\mathrm{m}_{\text {out }}-\mathrm{m}_{\text {in }}$. Then,

$$
\begin{aligned}
& \eta_{+U S}=1-\frac{m_{\text {out } /+U S}}{m_{\text {in }}} \\
& \eta_{-U S}=1-\frac{m_{\text {out } /-U S}}{m_{\text {in }}}
\end{aligned}
$$

$\mathrm{m}_{\text {in }}$ and $\mathrm{m}_{\text {out }}$ are calculated from the membrane filters measurements according to equation (6). They are derived in section 4.5.1.

Its development leads to the following equation and associated uncertainty:

$$
A R F=\frac{\eta_{+U S}}{\eta_{-U S}}=\frac{\frac{m_{\text {in }+U S^{-}} m_{\text {out }+U S}}{m_{\text {in } U S}}}{\frac{m_{\text {in-US }}-m_{\text {out }-U S}}{m_{\text {in }}-U S}}
$$




$$
\begin{aligned}
& \delta A R F=\left[\left(\frac{\partial A R F}{\partial m_{\text {in }+U S}} \delta m_{\text {in }+U S}\right)^{2}+\left(\frac{\partial A R F}{\partial m_{\text {out }+U S}} \delta m_{\text {out }+U S}\right)^{2}+\left(\frac{\partial A R F}{\partial m_{\text {in }-U S}} \delta m_{\text {in }-U S}\right)^{2}+\right. \\
& \left.\left(\frac{\partial A R F}{\partial m_{\text {out }-U S}} \delta m_{\text {out }-U S}\right)^{2}\right]^{1 / 2}
\end{aligned}
$$

The sensitivity of the ARF parameter with respect to each parameter has been calculated or estimated as follows:

$$
\begin{aligned}
& \text { - } \frac{\partial A R F}{\partial m_{\text {in }+U S}}=\frac{\frac{m_{\text {out }+U S}}{\left(m_{\text {in }+U S}\right)^{2}}}{\frac{m_{\text {in }-U S^{-} m_{\text {out }-U S}}}{m_{\text {in }-U S}}} \\
& \text { - } \frac{\partial A R F}{\partial m_{\text {out }+U S}}=-\frac{\frac{m_{\text {in }+U S}}{\left(m_{\text {in }+U S}\right)^{2}}}{\frac{m_{\text {in-US }}-m_{\text {out }-U S}}{m_{\text {in }-U S}}} \\
& \text { - } \frac{\partial A R F}{\partial m_{\text {in-US }}}=-\frac{\frac{m_{\text {in }+U S^{-} m_{\text {out }+U S}}}{m_{\text {in }+U S}}}{\left(\frac{m_{\text {in-US }}-m_{\text {out }-U S}}{m_{\text {in }-U S}}\right)^{2}} \cdot \frac{m_{\text {out }-U S}}{\left(m_{\text {in }-U S}\right)^{2}} \\
& \text { - } \frac{\partial A R F}{\partial m_{\text {out }-U S}}=-\frac{\frac{m_{\text {in }+U S^{-}} m_{\text {out }+U S}}{m_{\text {in }}+U S}}{\left(\frac{m_{\text {in-US }}-m_{\text {out }-U S}}{m_{\text {in }-U S}}\right)^{2}} \cdot \frac{1}{m_{\text {in-US }}}
\end{aligned}
$$

$\mathrm{m}_{\mathrm{intUS}}$ and $\mathrm{m}_{\text {outtUS }}$ are the inlet and outlet mass which are estimated from the membrane filters (eq 6). Their base errors have been estimated according to equations derived in previous section. 



\section{APPENDIX 3}

\section{SET campaign: A dynamic analysis of the tubes vibration results}

\subsection{Background on tube vibration}

Flow induced vibrations are widely recognized as an important concern in the SG design. The problem arises since the SG has become a common reason to shut down the NPP due to SGTR leakages. If at this moment a severe accident happens, source term would escape to the environment.

The tube failures are invariably associated with high velocity cross-flow inducing vibration but no previous experimental studies oriented to assess the effect of the tube vibration on aerosol retention in a bundle of tubes have been found in open literature. However, from the eighties to the very beginning of the new century, considerable progress has been made in the area of flowinduced vibration. Vibration excitation mechanisms in a single-phase (liquid or gas phase) are better understood than in two-phase (liquid-gas) flows, although relevant studies have been performed in the both fields since mid-eighties. 
This study is not intended to be a comprehensive review of earlier work regarding the flowinduced vibration which can be found in several review documents such as Pettigrew et al., 1995; Price, 1995; Weaver et al., 2000, but it is focused on the effect of the aerosol retention on the tube bundle. Nevertheless, aimed to understand the effect of the vibration on the aerosol retention, the dynamic behavior of the anticipated tube bundle has been investigated within the SET campaign too.

\subsubsection{Fundamentals of the vibratory motion}

It is well known that vibration is an oscillatory motion. A body is said to vibrate when it describes an oscillating motion about a reference position. The motion is not constant, but alternately greater and less than some average values. The extent of the oscillation determinates the magnitude of the vibration and the repetition rate of the cycles of oscillation determines the frequency of vibration (Griffin, 2004).

Most vibratory responses of structures can be modelled as single-degree-of-freedom spring mass system. Since vibration is defined as an oscillatory motion, it involves a change of position, or displacement (Fig. 74).

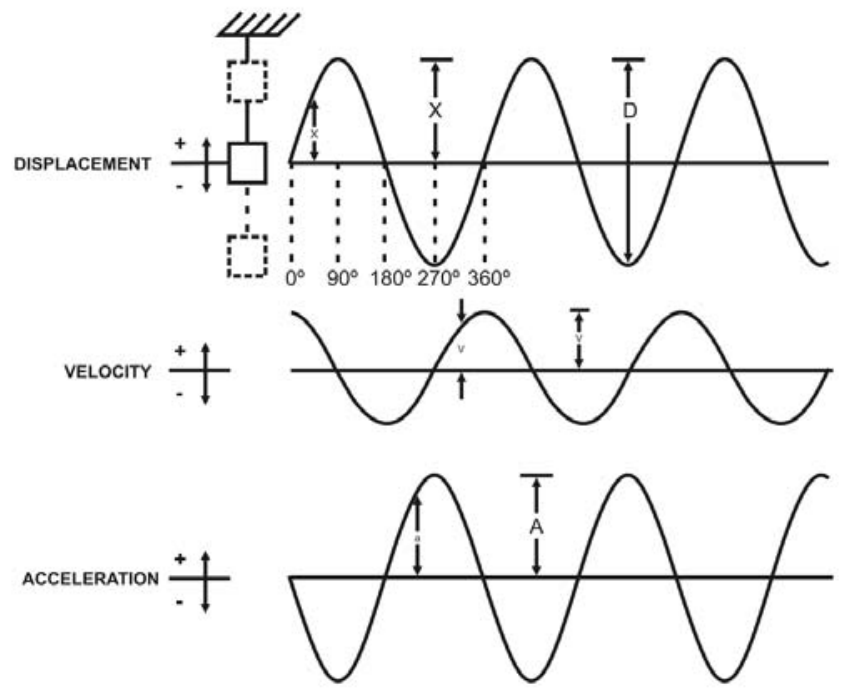

Fig. 74 Phase relationships among displacement, velocity and acceleration

The spring mass system, maintained at a constant displacement amplitude, exhibits simple harmonic motion, or sinusoidal motion. That is, its displacement amplitude vs. time traces out a 
sinusoidal curve. Given a peak displacement of X, frequency $\mathrm{f}$, and instantaneous displacement $\mathrm{x}$, at any time $\mathrm{t}$ :

$$
x=X \sin (2 \pi f t)
$$

Velocity is the time rate of change of displacement, which is the derivate of the time function of displacement. For instantaneous velocity, v:

$$
v=2 \pi f X \cos (2 \pi f t)
$$

Since vibratory displacement is most often measured in terms of peak-to-peak, double amplitude, displacement $\mathrm{D}=2 \mathrm{X}$ :

$$
v=\pi f D \cos (2 \pi f t)
$$

If the interest is focused on the peak amplitudes and time variation and phases relationships are ignored, then the peak velocity is given by:

$$
V=\pi f D
$$

Similarly, acceleration is the time rate of change of velocity, and the acceleration equation is the derivative of the velocity expression:

$$
a=4 \pi^{2} f^{2} X(-\sin (2 \pi f t))
$$

And the peak acceleration:

$$
A=2 \pi^{2} f^{2} D
$$

In summary it can be shown that:

$$
\begin{aligned}
V=\pi f D \text { and thus, } & D=V / \pi f \\
A=2 \pi^{2} f^{2} D \text { and thus, } & D=A / 2 \pi^{2} f^{2}
\end{aligned}
$$


From these equations it can be seen that low-frequency motion is likely to exhibit lowamplitude accelerations even though displacement may be large. It can also be seen that highfrequency motion is likely to exhibit low-amplitude displacements, even though acceleration is large.

\subsubsection{The piezoelectric effect}

The vibration measurements are performed by measuring the acceleration with piezoelectric (PE) transducers as the accelerometers. Piezoelectric sensors use the piezoelectric effect of the sensing elements to produce a charge output. A PE sensor does not require an external power and it is considered self-generating. PE materials have a regular crystalline molecular structure, with a net charge distribution that changes when strained (Chu, 1987). They may also have a dipole when unstressed. When the piezoelectric elements are strained by an external force, displaced electrical charge accumulates on opposing surfaces. Fig. 75 illustrates the displacement of electrical charge due to the deflection of the lattice in a naturally piezoelectric quartz crystal.

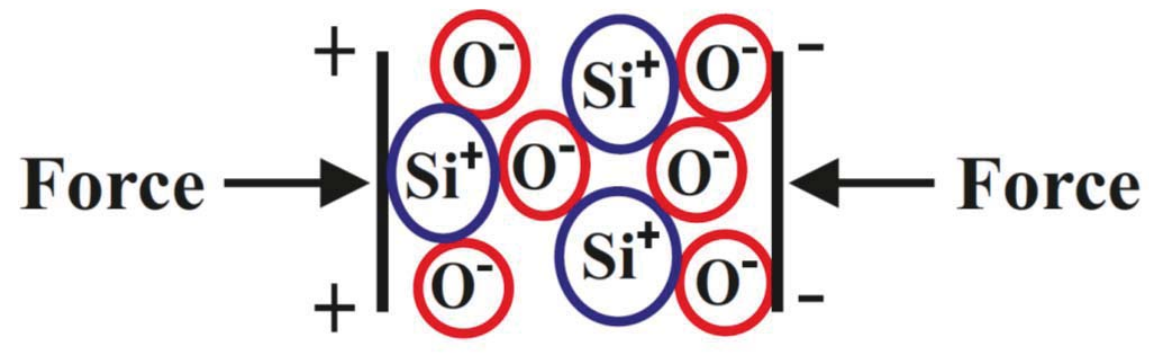

Fig. 75 Atoms displacement by the application of a force

A sketch of an accelerator sensor is shown in Fig. 76. The accelerometers measure motion. The invariant seismic mass (in grey color) is forced to follow the motion of the base and structure to which it is attached that imposes a force on the crystal. Over its specified frequency range, this structure obeys the second Newton's law of motion, i.e. F=ma. Therefore, the total amount of accumulated charge is proportional to the applied force, and the applied force is proportional to an acceleration of mass. Electrodes collect and wires transmit the charge to a signal conditioner. PCB sensors containing integral electronics are known by their trademarked term, Integrated Circuit Piezoelectric, or ICP® ("ICP® users manual," 2012). 


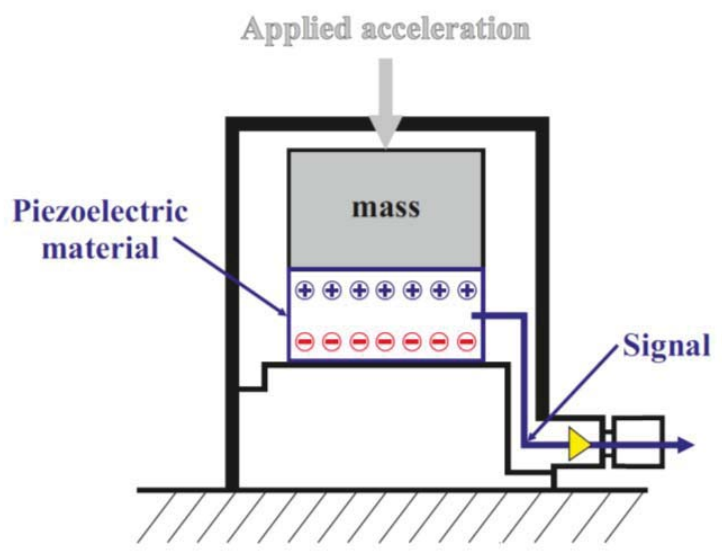

Fig. 76 Sketch of an accelerometer

\subsubsection{Fluid dynamics on the tube bundle}

A flow of fluid over an array of tubes results in hydrodynamic effects or fluid oscillation and fluid-structure coupling (Pettigrew, 1981; Wambsganss, 1987; Weaver et al., 2000). These effects generate hydrodynamic forces and fluid structure coupling forces. The dynamic behavior of a tubes bundle in increasing cross flow velocity might be manifested in three steps as velocity raises (Païdoussis, 1981):

1. At low velocities the tubes respond principally to turbulent buffeting (Savkar and Litzinger, 1982). It refers to a low amplitude before a threshold velocity resulting in the amplitude of tube response large enough to collide with the adjacent tubes (critical velocity, $\mathrm{V}_{\mathrm{ct}}$ Fig. 80) (Prakash et al., 2009).

2. At higher velocities, the excitation may be a consequence of mechanisms such as turbulent buffeting and vortex shedding. The vortex shedding results from the wake formed behind the tube when the fluid flows across the cylinders (Fig. 77). A periodic shedding of vortices from the tube surface results in an oscillating force exerted on the tube (Pettigrew et al., 1998). 


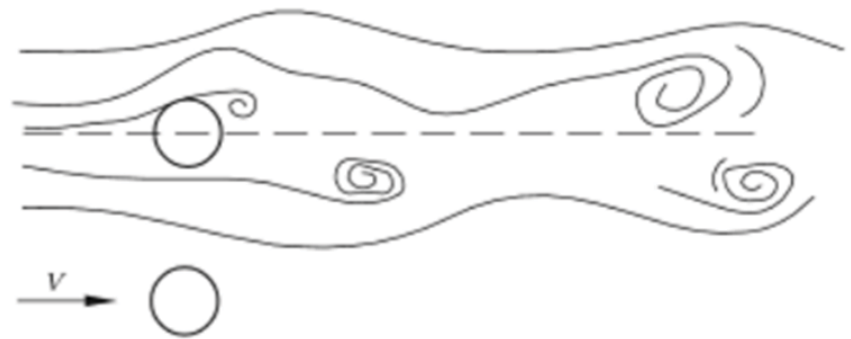

Fig. 77 Vortex shedding (von Karman vortices)

The vibration of the tube bundle seems to be coupled with feedback mechanisms which enhance the initial perturbation (Prakash et al., 2009). Basically, two mechanisms would generate upstream feedback of disturbances: the structural vibration of the tube (Fig. 78) and the flow impingement on a downstream tube (Fig. 79).

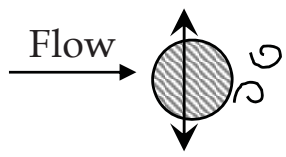

Fig. 78 Structural tube vibration coupled with vortex shedding

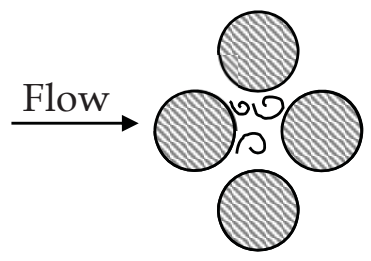

Fig. 79 Turbulent eddies coupled

The periodic shedding of vortices causes a periodic movement of the tube, traduced in a characteristic frequency, i.e., a narrow peak in the FFT-(Fast Fourier Transform) tube response spectrum.

3. At sufficient high flow velocities, the fluid elastic instability will generally develop, 
and the amplitude of vibration increases rapidly with the flow velocity ("FlowInduced Vibration of Shell and Tube Heat Exchangers," 2013). The fluid elastic instability (FEI) arises from the balance of the flow force induced to the tube and the damping effect due to viscous forces of the flow. The fluid is capable of imparting driving forces to the tubes and at the same time damping forces (i.e. viscous) remove a certain amount of energy per cycle. The frequency of the vibration due to FEI is close to the natural frequency of the tube.

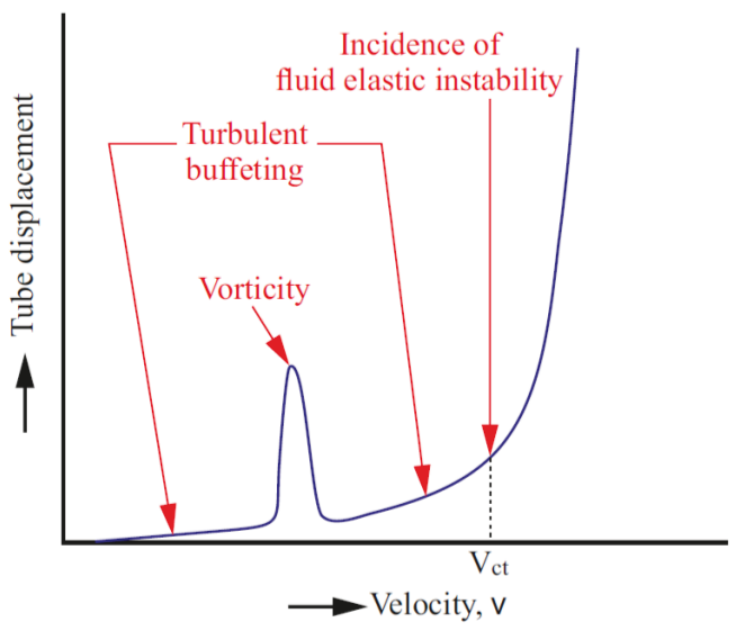

Fig. 80 Tube displacement vs. flow velocity ("Flow-Induced Vibration of Shell and Tube Heat Exchangers," 2013)

\subsection{Dynamic analysis of the SET campaign results}

The dynamic behavior of the tubes is analyzed thanks to the FFT spectra. Fig. 81 shows the spectra response of the T4-y tube within the experiment SET 3. At low velocities (i.e. $40 \mathrm{~m} / \mathrm{s}$ or flow rates of $50 \mathrm{~kg} / \mathrm{h}$ ) the tubes might respond principally to turbulent buffeting which is produced by the flow recirculation that produces low intensity amplitudes in the tubes that cannot be avoided. At higher velocities (over $82 \mathrm{~m} / \mathrm{s}$ i.e., flow rates over $100 \mathrm{~kg} / \mathrm{h}$ ) the excitation produced by turbulent buffeting mechanisms would remain but it is increased by the effect of vortex shedding. It is the consequence of the wake that is formed behind the tube when the fluid flows across the cylinders (Fig. 79). At velocities over $180 \mathrm{~m} / \mathrm{s}$ (i.e., $200 \mathrm{~kg} / \mathrm{h}$ ), frequency increases rapidly as a result of the fluid elastic instability. The fluid elastic instability is the result of the balance of the flow force induced to the tube and the damping effect due to viscous forces of the flow. 
It can be observed that the higher the amplitude the higher the variability of the frequency. At low velocities, the tube responds to one flow mechanism and the low variability of the movement results in low amplitudes. The amplitude of the tubes increases as the dynamics of the flow gets more complex and the frequency of the tube is more variable. Finally, the highest amplitudes are observed for the highest flow rates that produces a chaotic movement of the flow.

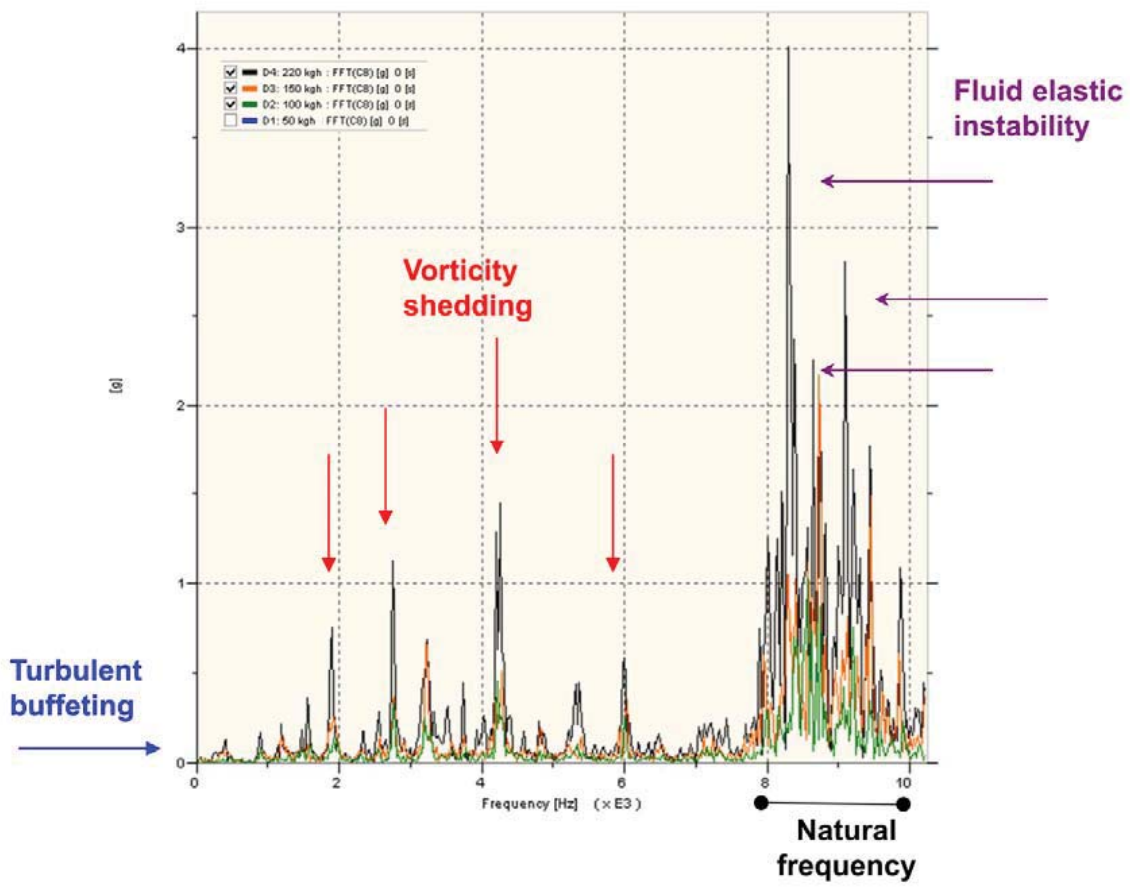

Fig. 81 T4-y FFT spectra

\subsubsection{Conclusions}

The tubes vibrations induced by the flow leaving the breach have been characterized in terms of frequency and amplitude within a bundle of tubes simulating the break stage of the steam generator. The FFT spectra of the signal from accelerometers have been used in order to understand the fluid dynamics transferred into the bundle. The fluid elastic instability mechanisms seem to be responsible for the largest amplitudes as result of flow rates over 180 $\mathrm{kg} / \mathrm{h}$. 


\section{APPENDIX 4}

\section{Separate Effect Test with Expanded Polyethylene}

The Separate Effect Tests (SET) have been performed by fixing the tubes with expanded polyethylene (EPE). This appendix summarizes the results of the SET obtained with this material.

\subsection{Experimental matrix}

TABLE 21 shows the experimental matrix of the Separate Effect Test in which the vibration has been modified with EPE. In total are 9 experiments divided into the Analysis tests (from test No. 1 to test No.5) and the Assessment tests (from test No. 6 to No. 10). 
TABLE 21. Experimental matrix of SET campaign performed with EPE

\begin{tabular}{|c|c|c|c|c|c|c|c|c|c|c|}
\hline & \multirow[t]{2}{*}{ Test } & \multirow{2}{*}{$\begin{array}{l}\text { Particle } \\
\text { nature }\end{array}$} & \multicolumn{2}{|c|}{ Configuration } & \multicolumn{2}{|c|}{$\begin{array}{c}\text { Tube } \\
\text { arrangement }\end{array}$} & \multicolumn{4}{|c|}{ Gas flow rate $(\mathrm{kg} / \mathrm{h})$} \\
\hline & & & Guillotine & Fish-mouth & Fixed & Normal & 50 & 100 & 150 & 200 \\
\hline \multirow{9}{*}{ 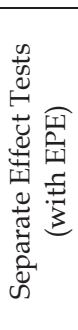 } & 1 & & $\mathrm{X}$ & & & $X$ & & & & $\mathrm{X}$ \\
\hline & 2 & $\mathrm{TiO}_{2}$ & $x$ & & $X$ & & & & & $x$ \\
\hline & 3 & & $X$ & & $X$ & & & $X$ & & \\
\hline & 4 & $\mathrm{SiO}_{2}$ & $x$ & & $X$ & & & & & $X$ \\
\hline & 5 & & & $x$ & $x$ & & & & & $\mathrm{X}$ \\
\hline & 6 & & $\bar{X}$ & & $\bar{X}$ & & $\mathrm{X}$ & $x$ & 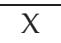 & $\mathrm{X}$ \\
\hline & 7 & & & $x$ & $x$ & & $\mathrm{X}$ & $x$ & $x$ & $x$ \\
\hline & 8 & & & $x$ & & $x$ & $x$ & $x$ & $x$ & $x$ \\
\hline & 9 & & $x$ & & & $x$ & $x$ & $x$ & $x$ & $x$ \\
\hline
\end{tabular}

\subsection{Expanded Polyethylene}

The tubes have been "fixed" with expanded polyethylene (EPE), an impact absorbing foam recommended to avoid vibration (Fig. 82). The properties of the EPE foam are summarized in Fig. 82.

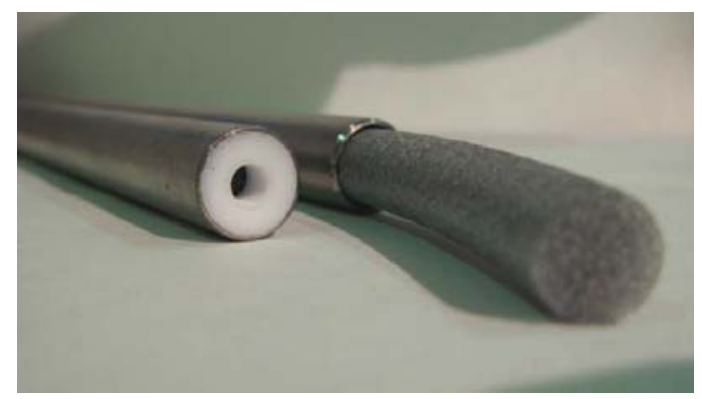

Fig. 82 Tubes filled with EPE

TABLE 22 Expanded Polyethylene properties

\begin{tabular}{lcc}
\hline Variable & Units & \\
\hline Density & $\mathrm{kg} / \mathrm{m}^{3}$ & $25-40$ \\
Thermal Conductivity & $\mathrm{W} / \mathrm{m} \cdot \mathrm{K}$ & 0.032 \\
Operating Temperature & ${ }^{\circ} \mathrm{C}$ & $-60-80$ \\
\hline
\end{tabular}




\subsection{Results}

The Assessment Tests have been rather simpler than the analysis ones since they do not inject aerosols in the bundle. The vibration of "as-fabricated" and fixed tubes has been characterized as a function of the gas flowrate for two breach shapes, guillotine and fish-mouth.

The experiments have been performed under atmospheric conditions. Once the desired flowrate was stable, measurements started. This operation has been repeated for each flow tested. The vibration of the tubes has been characterized with 8 accelerometers (Fig. 83). Two accelerometers in each tube allowed determining the frequency and amplitude of each tube in two directions, parallel and perpendicular to the jet exit. The accelerometers have been placed at the height of the tube at which, theoretically, the maximum vibration occurs, i.e. at the middle point between the plates that hold the tube.

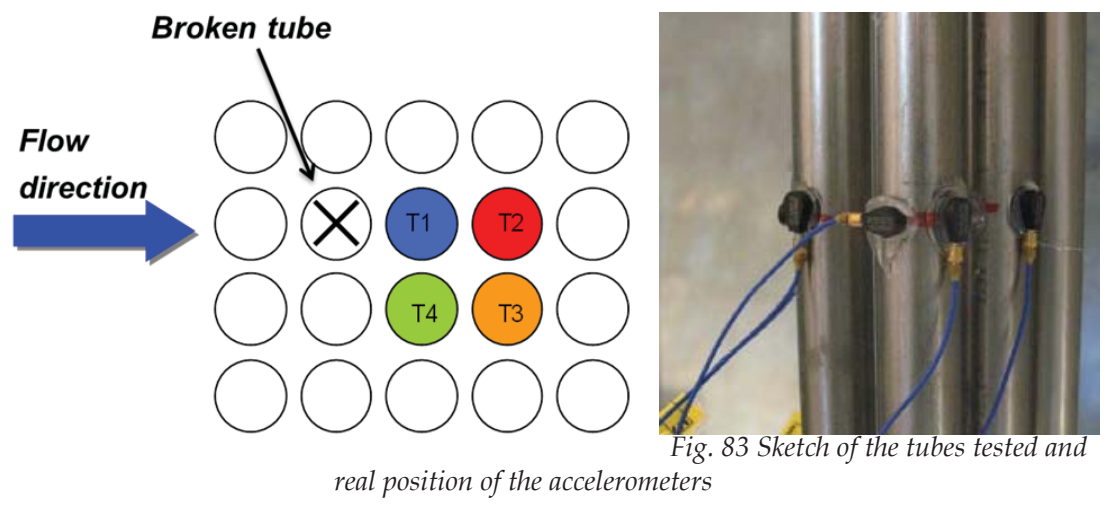

\subsubsection{Major insights}

\subsubsection{Analysis tests}

Fig. 84 shows the results obtained in the analysis experiments. The net retention within the normal and fixed bundle are similar whatever the experimental conditions tested. Some differences (15\% retention more for fixed than normal tubes) have been found in those experiments of $\mathrm{SiO}_{2}$ performed under the highest flow rate (i.e. $230 \mathrm{~kg} / \mathrm{h}$ ). Nevertheless they cannot be attributed to vibration since the results fall within the same range when the uncertainty bars are considered. As result, an experimental campaigned aimed to understand if the fixed and normal tubes vibrate differently has been performed. 


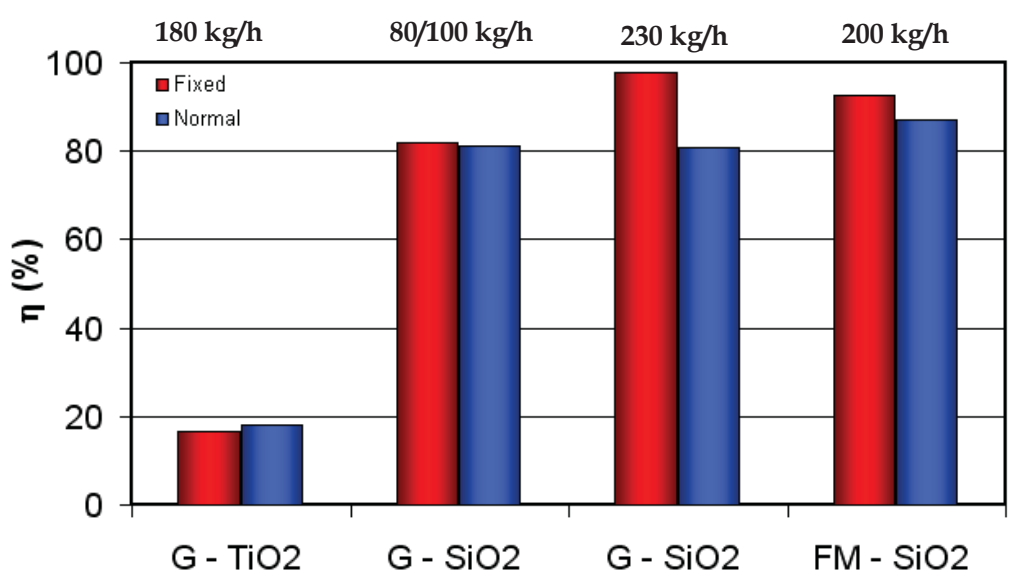

Fig. 84 Collected efficiency in the Analysis Tests under

Guillotine $(G)$ and Fish-mouth (FM) configurations.

\subsubsection{Assessment tests}

The vibration of the tubes has been characterized in terms of their amplitude and characteristic frequency. A study to understand the vibration mode and the driving mechanisms has been done. The amplitude is given in terms of gain which is a measure of the increase of the signal's amplitude when tubes vibrate. Its units are g (i.e. $g=9.81 \mathrm{~m} / \mathrm{s}^{2}$ ). Fig. 85 shows the amplitude at which the tube vibrates at flows around 100, 150 and $220 \mathrm{~kg} / \mathrm{h}$. X-direction refers to the accelerometer placed in the tube $\mathrm{Ti}$ in the same direction as the flow leaving the breach whereas $y$-direction refers to the axial direction of the tube.

Results do not show any sound evidence of attenuation of vibration. At $100 \mathrm{~kg} / \mathrm{h}$, fixed and asfabricated tubes have very similar degree of vibration (gain) in most of the cases. When the flow is increased to $150 \mathrm{~kg} / \mathrm{h}$ and to $220 \mathrm{~kg} / \mathrm{h}$ an apparent attenuation is produced under guillotine configuration. Depending of the tube position it drops up to $67 \%$. However under higher jet momentums (fish mouth configuration) this trend is lost and even reverse. 
GUILLOTINE
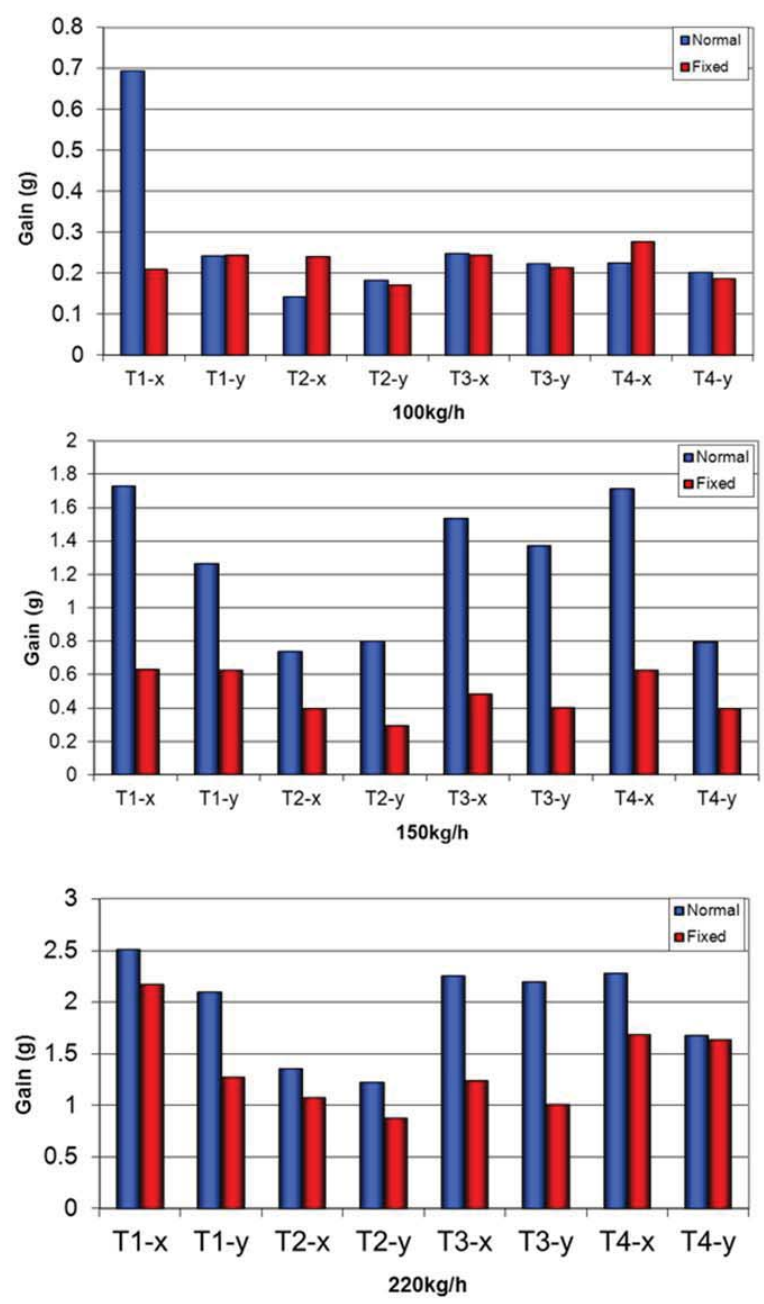

FISH-MOUTH
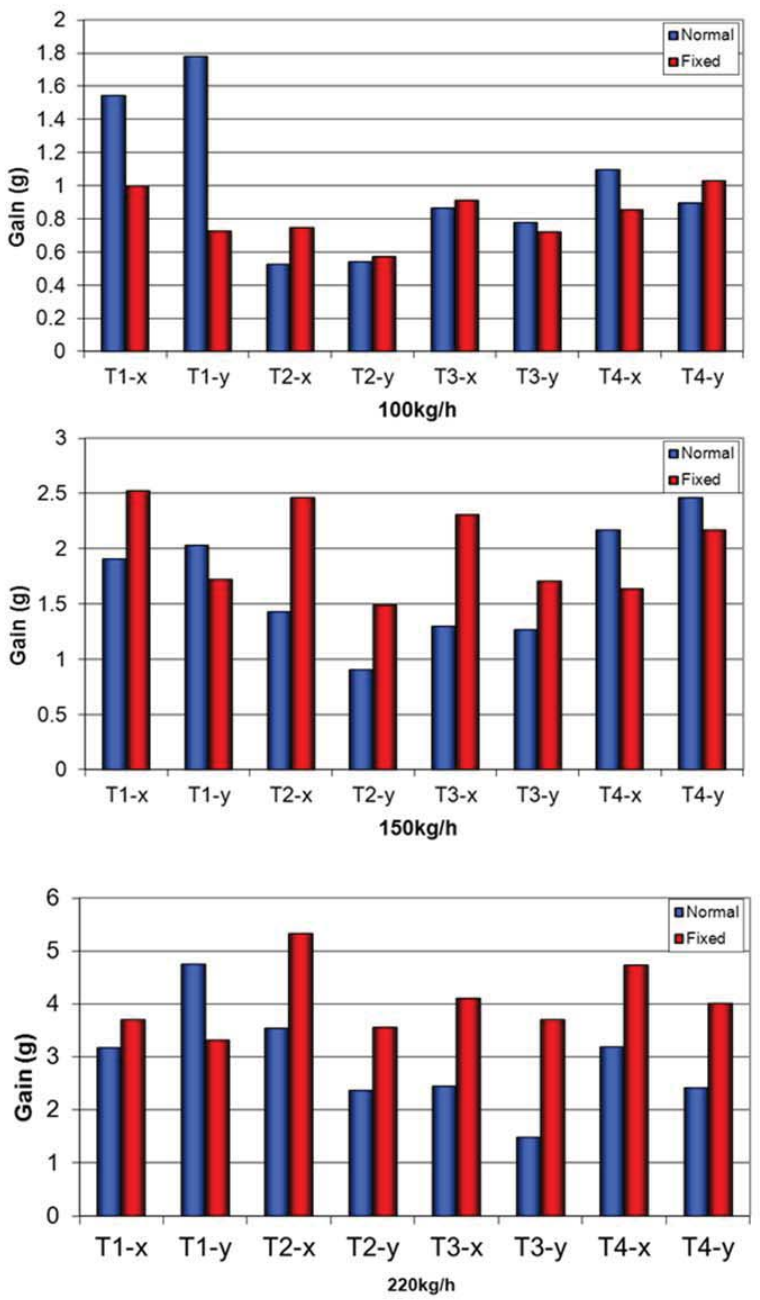

Fig. 85 Amplitude of the tubes under the excitation of $150 \mathrm{~kg} / \mathrm{h}$ flow rate 

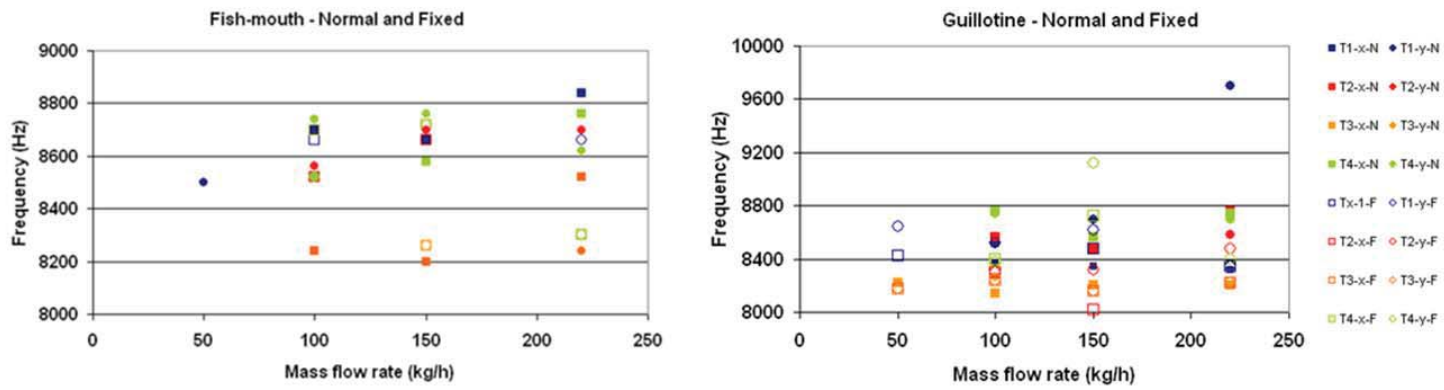

Fig. 86 Frequency of vibration of the tubes at the flow rates tested

Fig. 86 shows the characterization of the tubes vibration mode in terms of their characteristic frequency. The main observation coming out from the plot is the frequency range, 8000 $8800 \mathrm{~Hz}$, for both configurations. Those two points from fish-mouth over $8800 \mathrm{~Hz}$ are not considered to be extremely higher than the working range. The tubes vibrate at the same frequency range with independence of the jet momentum.

\subsection{Conclusions}

The experimental investigation presented and discussed in the sections above (Separate Effect Tests) has been focused on the aerosol retention in the break stage of a steam generator during SGTR meltdown sequences. By conducting a total of 5 analysis experiments and 4 assessment experiments in a representative mock-up bundle the effect of tube vibration and other variables such as particle nature, gas mass flow rate and breach shape on net retention efficiency has been determined.

Some of the key conclusions drawn from the experimental campaign are:

- Under all the conditions explored, a significant fraction of particles entering a "dry" secondary side of a steam generator during a SGTR meltdown sequence got trapped in the nearby of the breach (i.e., break stage).

- The magnitude of such retention depends heavily on particle nature with independence of the tube vibration.

- The modification of the bundle arrangement by fixing the tubes with EPE, has resulted inefficient to attenuate the vibration.

Despite the progress achieved, a new methodology will be follow for studying the flow induced vibration in the bundle and its effect on the aerosol deposition. It is based on a new method for fixing the tubes. The idea is increasing the tube mass and fixing them to the supporting structures (Chapter 4). 


\section{APPENDIX 5}

\section{Description and characterization of the}

\section{Mitigative System Acoustic Agglomerator}

\section{(MSAA)}

\subsection{Introduction}

The wide field of power ultrasonics (PU) is currently considered as a green emerging technology that offers a great potential for a wide range of processes. It implies a great variety of practical processing systems with characteristics which are dependent on the effect to be exploited. Thus, aerosol processes are usually based on the effects of co-vibration, radiation pressure, hydrodynamic interactions and translational motions which are produced on the suspended particles by the action of a high-intensity acoustic field. For this purpose adequate vibration amplitudes and treatment times are required.

In general, an ultrasonic system for aerosol processing is basically constituted of a treatment chamber and a set of power ultrasonic transducers coupled to it. Therefore, the feasibility of the 
application depends on the efficiency of the transducers-chamber system, bearing in mind that the concept of efficiency has to be considered in relation to the useful field. As a consequence, a knowledge of the influence of geometry and dimensions of the processing chamber as well as the effect of the excitation transducers on the acoustic field distribution is essential for the development of practical systems.

As a general rule, the power acoustic systems operate in continuous non-linear waves and the chamber dimensions are large compared with wavelength. The environment is usually a standing-wave field. This field structure inside the chamber is desirable because the pressure or the particle velocity can be amplified at determined areas (nodes or loops) where the treatment should take place. To set up strong standing-wave fields, rigid-walled regular chamber are required. If the two dimensions of the chamber cross-section are smaller than the wavelength, a one-dimensional standing wave can be obtained by placing the transducer face parallel to the opposite surface of the chamber and at a distance adjusted to a resonance length. In the more general case in which the three dimensions of the chamber are higher than the wavelength, the standing-wave pattern becomes much more complicated and it is determined by the normal modes of the chamber and the characteristics of the transducers.

\subsection{Structure of the MSAA}

The experimental MSAA and power stepped-plate traducers are systems developed by CSIC: The facility basically consists of an acoustic agglomeration chamber manufactured in carbon steel to operate in vertical position inside the PECA vessel as described in chapter 5 . A picture of the modular MSAA is shown in Fig. 87. A high-intensity ultrasonic standing-wave field perpendicular to the gas flow was established within the acoustic agglomeration chamber. In the agglomeration experiments the transducers operate with an applied input power of $300 \mathrm{~W}$ per transducer generating inside the chamber a mean sound pressure level (SPL) of about 155 $\mathrm{dB}$. It is important to point out that according to literature to generate an acoustic agglomeration process it is necessary to achieve a SPL higher than $140 \mathrm{~dB}$ (Mednikov, 1965). 


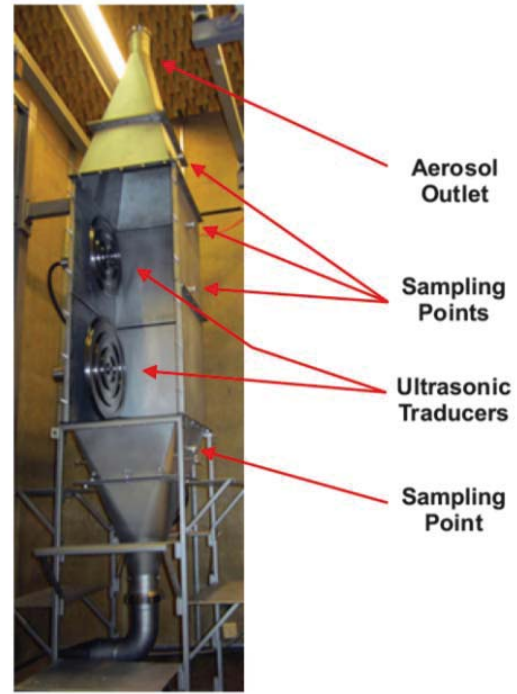

Fig. 87 MSAA (overall height $3444 \mathrm{~mm}$ )

\subsubsection{Power stepped-plate transducers}

For the generation of high-intensity ultrasonic fields special power piezoelectric transducers are needed covering adequate requirements. Particularly, the gas media presents a low specific acoustic impedance and a high acoustic absorption. Therefore, in order to obtain an efficient transmission of energy, it is necessary to achieve good impedance matching between the transducer and the medium and large vibration amplitude. High directional is also required for energy concentration and to stablish a good standing wave pattern. At present, commercial transducers such as sirens and whistles have low efficiency (usually less than 20\%) and poor directivity being the acoustic energy provided by gas jet. That means that these systems have many limitations in covering these requirements.

Piezoelectric ceramics have also found a wide current in ultrasonic technology. The piezoelectric effect (appendix 3, section 3.1.2) lies in the electric polarization of some anisotropic insulators and semiconductors produced by a mechanical stress (it is the so-called direct piezoelectric effect). The reverse piezoelectric consists in a strain imposed on these materials by external electric field. Piezoelectricity involves the interaction between the electrical and mechanical behaviour of the medium. This means, an interaction between Hooke's law (elasticity) and Gauss's theorem (electricity). To a good approximation this interaction can be described by linear relations between two electrical and mechanical variables: 


$$
\begin{aligned}
& S=s^{E} T+d E \\
& D=d T+\varepsilon^{T} E
\end{aligned}
$$

where $S$ is the strain (relative deformation), $s^{E}$ the elastic compliance for a constant electric field, $T$ the mechanical stress, $d$ the piezoelectric chargeconstant, $E$ the electric field, $D$ the dielectric displacement, $\varepsilon^{T}$ the permittivity at constant stress.

To obtain large displacements, the transducer must contain a mechanical amplifier and the different parts of the structure should be carefully designed to obtain a resonant assembly with very high quality factor $(\mathrm{Q})$. In the analysis developed here we use a typical electric equivalent circuit of a piezoelectric transducer shown in Fig. 88. In Fig. 88a, the circuit is formed by a L- C - R series in parallel with a static capacity $C_{0}$ and in Fig. $88 \mathrm{~b}$.

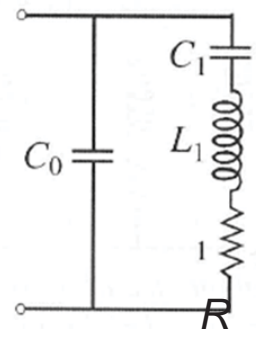

a)

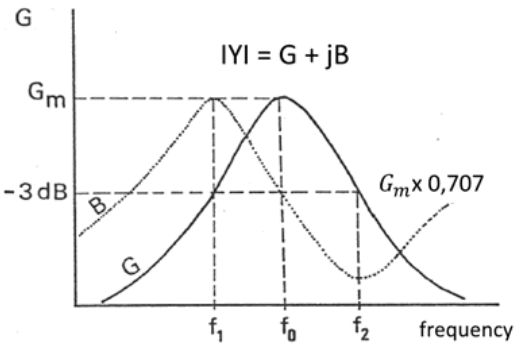

b)

Fig. 88 a) Simple RLC equivalent electrical circuit of a piezoelectric transducer at the resonance; $b$ ) Conductance $(G)$ and Susceptance $(B)$ of a piezoelectric transducer at the resonance versus frequency

\subsubsection{The Impedance, Resonance and $Q$ factor}

The relationships between forces, motions, and losses within a mechanical vibratory system, and transmission of acoustic waves in general, are similar to those that exist between voltages, current, and impedances within electrical circuit. Equivalent circuits and acoustic impedances are very useful and important concepts in analyzing and designing acoustic systems. The equilibrium equation of a simple spring-mass oscillator loses taking into account the mechanisms of friction, internal absorption and air resistance is given by

$$
F_{t}=m \frac{d^{2} x}{d t^{2}}+R_{m} \frac{d x}{d t}+k x
$$


where $\mathrm{m}$ is the mass of the oscillator, $R_{m}$ is the loss factor, $\mathrm{k}$ the elastic constant, and $F_{t}$ is the driving force. Thus the second term of the right side of the equation above represents the sum of all loses in the system. The damped angular frequency is given by

$$
\omega_{d}=\sqrt{\omega_{0}^{2}-\frac{R_{m}^{2}}{4 m^{2}}}=\sqrt{\omega_{0}^{2}-\alpha^{2}}
$$

where $\omega_{0}$ is the undamped angular frequency, and $\alpha=R_{m} / 2 m$ the so-called damping factor.

Note the comparisons between the mathematical relationships describing the motion in the mechanical system and the electrical functions of Fig. 88a, are closed-loop series R - L - C circuit. The equation that relates the loop current, $i$, with the source voltage $V_{t}$ in the case $C_{0}=0$ is

$$
L \frac{d^{2} i}{d t^{2}}+R_{1} \frac{d i}{d t}+\frac{1}{c} \int i d t=V_{t}
$$

Equations (67) and (69) are identical. That means mass (m), mechanical resistance $\left(R_{m}\right)$, particle velocity $\left(\frac{d x}{d x}\right)$, and elastic constant $(k)$ are equivalent to inductance $(\mathrm{L})$, electrical resistance $\left(R_{1}\right)$, current (i) and the inverse of capacitance $(1 / C)$, respectively. This comparison shows the logic behind equivalent circuits for use in designing and analysing acoustic systems.

The characteristic frequency of the radiated power in $R_{1}$ is determined largely by the mechanical Q of the transducer. Let us assume that $C_{0}$ is tuned out by an inductance $L_{0}$, and $R_{1}$ is only dissipative element in the circuit shown in Fig. 88 a). Then the quality factor for the first harmonic mode $\left(\omega_{0}\right)$ is equal to the ratio between the energy stored in $L$ to the energy dissipated in $R_{1}$ per cycle; then, the analytical expression can be expressed as

$$
Q=\frac{\omega_{0} L_{1}}{R_{1}}=\frac{\omega_{0} m}{\rho_{0} c S}
$$

Where, $S$ is the area of the radiator surface and $\rho_{0} c$ is the load of the air.

The electrical quality factor, $Q$, is a measure of the sharpness of resonance of an oscillatory system. In a series resonance circuit (Fig. 88b), it is defined as

$$
Q=\frac{\omega_{r}}{\omega_{2}-\omega_{1}}=\frac{f_{r}}{f_{2}-f_{1}}
$$


where $\omega_{r}=2 \pi f_{r}$ is the angular frequency at resonance, $\omega_{1}=2 \pi f_{1}$ the angular frequency below resonance at which the amplitude of displacement in a driven system is 0.707 times its amplitude at resonance, $\omega_{2}=2 \pi f_{2}$ the angular frequency above resonance at which the amplitude of displacement is 0.707 its amplitude at resonance, and $\omega_{2}-\omega_{1}$ the bandwidth of the system.

In general terms, the power ultrasound implies the development of transducers with very high $Q$ values $(\geq 1000)$ and very low bandwidth $(<5 \mathrm{~Hz})$. The transducers developed for the AAA tests have $Q$ factors of the order or higher than of 4500 . To achieve this $Q$ factors the losses of the ultrasonic plate-transducer together with the electronic driving system have to be minimized.

For high power capacity, the electrical, mechanical and thermal limits have to be considered. From the electrical point of view, increasing the $\mathrm{Q}$ factor yields increased power, and the mechanical limitation for the radiated power is determined by the integral of the elastic strain energy density taken over the volume of the transducer structure. It is limited by factors such as material fatigue and elastic nonlinearities produced at high vibration amplitudes, which should thus be minimized.

This generator is based on the stepped-plate piezoelectric transducer (Fig. 59). It consists of an extensive circular vibrating plate of stepped profile driven at its center by a piezoelectrically activated vibrator. The vibrator has two components, a piezoelectric element of transduction in a sandwich configuration and a mechanical transformer (also known as solid horn) which acts as a vibration amplifier. The sandwich transducer is a half-wave resonant length-expander structure, which consists of paired discs of piezoelectric ceramics sandwiched between two metal blocks. The extensional vibration generated by the transducer element and amplified by the horn drives the radiating plate which vibrates flexurally in one of its modes. It is important to point out that the mechanical amplifier acts as specially shaped transmission line, which produces displacement amplification at the working end. Such a transmission line is formed by a half-wavelength resonant bar of variable cross-section that vibrates extensionally. The horn is designed to resonate at the same frequency as the sandwich transducer that is driving it. The vibration amplitude at the radiating surface of the circular plate depends on the geometry of the mechanical amplifier. In the present case, the mechanical amplifier is a stepped horn made of titanium alloy. The assembly formed by the piezoelectric sandwich and the stepped horn constitutes the ultrasonic vibrator that drives the circular vibrating plate. The main components which constitutes the airborne ultrasonic transduce are listed in TABLE 14. 
The extensive surface of the plate increases the radiation resistance and offers the vibrating system good impedance matching with the gas medium. On the other hand, the special profile of the plate permits the control of the vibration amplitude and the radiation pattern in such a way that high directional radiation can be obtained in order to produce high-intensity acoustic levels. The idea behind the design of the stepped profile is as follows. A flat plate radiator presents in general a poor directivity pattern due to phase cancellation. Nevertheless, if the surface elements vibrating in counterphase on the two sides of the nodal lines are alternatively shifted along the acoustic axis to half of a wavelength of the sound in the propagating medium, the radiation produced will be in phase across the whole beam and a directivity pattern equivalent to that of the theoretical piston will be obtained. The transducers have been designed based on analytical methods and by applying the finite element method (FEM) (Fig. 89). The CFD analysis code ANSYS and the Comsol Multiphysics ${ }^{\circledR}$ software have been used.

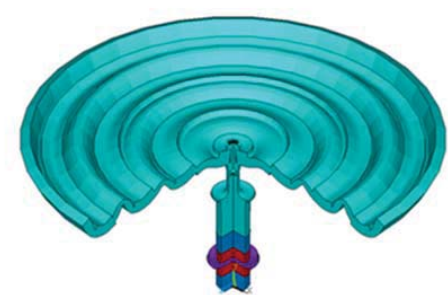

a) Numerical design of the airborne ultrasonic power transducer by FEM. (View of the front face)

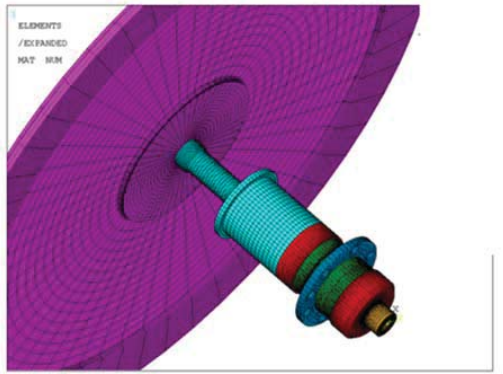

b) 3D meshing modeling of the circular stepped-plate transducer (view of the face)

Fig. 89 Ultrasonic power transducer

Two electronic driving systems have been designed and constructed to operate continuously at the resonant frequency of both transducers. Both systems basically consist of two electronic controllers, two power amplifiers and one double matching impedance circuit to generate and control the driving signal for the transducers (Fig. 90) 


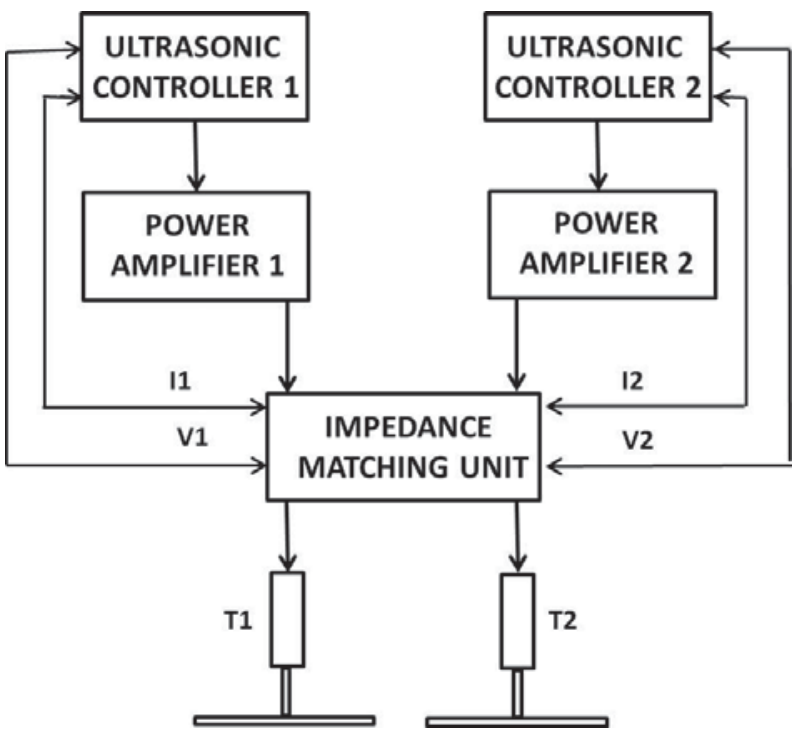

Fig. 90 Scheme of the electronic equipment

The main characteristics of the developed airborne directional circular stepped-plate transducers are summarized in TABLE 23.

TABLE 23 Main characteristics of directional circular stepped-plate transducers at $21 \mathrm{kHz}$

\begin{tabular}{ll} 
Electroacoustic Efficiency & $75-80 \%$ \\
Directivity (-3 dB beam with) & $1.5^{\circ}$ \\
Power Capacity & $300-350 \mathrm{~W}$ \\
Resonant Frequency & $\sim 21 \mathrm{kHz}$ \\
Maximum intensity levels in free field & $170 \mathrm{~dB}$ \\
Bandwidth & $1.5 \mathrm{~Hz}$ \\
Q factor & $>4000$ \\
Impedance (IZI) & $\sim 700 \Omega$ \\
Conductance (G) & $1.444 \mathrm{mS}^{*}$ \\
\hline
\end{tabular}

*S: Siemens

The electrical response ( $\mathrm{G}$, conductance) of the ultrasonic transducers was measured at low power with an Impedance/Gain-Phase Analyzer (HP-4194a) (Fig. 91a). Fig. 91b shows the resonant frequency and the conductance $(\mathrm{G})$ of one of the transducers driven with one volt. It is 
clear from the figure that the transducer has its resonant frequency at $21.6 \mathrm{kHz}$. At this frequency the stepped radiating plate vibrates in a flexural mode with seven nodal circles (measured with laser vibrometer). The electrical response of the transducer in the frequency range from $21.5 \mathrm{kHz}$ to $21.7 \mathrm{kHz}$ presents a maximum peak value of its conductance $\mathrm{G}=1.444$ $\mathrm{mS}$. It means an electrical impedance IZI $=692 \Omega$. Both values are important parameters to take into account for electrical driving.

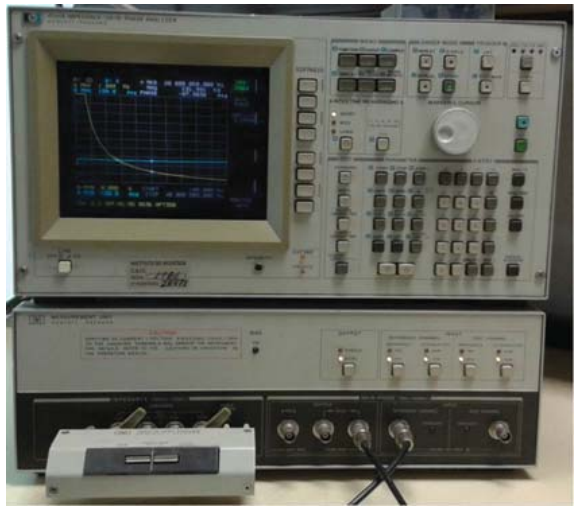

a)Front view of the Impedance Analyzer HP-4194A

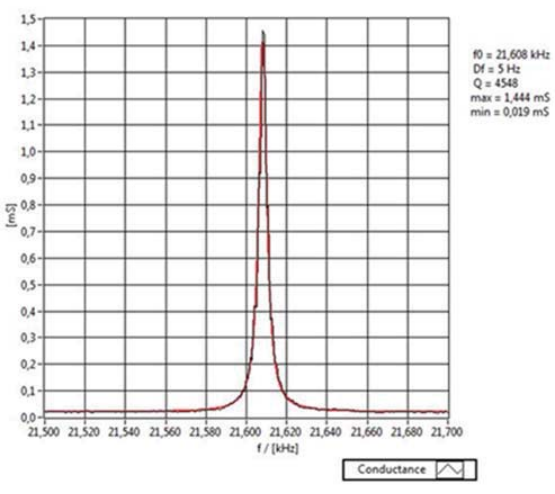

b) Electrical response $(G)$ of one of the power ultrasonic transducers measured with an impedance analyzer at its resonance

Fig. 91 Impedance Analyzer and response

The total energy consumption of each ultrasonic transducer has been measured experimentally as follows: the total energy consume at the inlet of the electronic equipment (described in Fig. 90) has been measured with a Digital Power Meter Yokogawa WT230 (600 W - 700 W), whereas the total energy consume at the outlet of the electronic equipment has been measured taking samples of the voltage and the current on the out-port-side of the "Impedance Matching unit" $(300 \mathrm{~W})$. In this way, the electrical efficiency of the power amplifiers used in this research has been estimated in the range $40 \%-50 \%$.

\subsubsection{Acoustic field measurements inside the MSAA}

The experimental validation of the stepped-plate transducers has been carried out by measuring the acoustic field under free field conditions and inside the acoustic agglomeration chamber. It was measured in a semi-anechoic chamber. A PC-controlled 3D measuring system was used. The $\mathrm{X}, \mathrm{Y}, \mathrm{Z}$ coordinates related to the microphone position are governed by means of numerical control equipment (LabView code, National Instruments, Austin, TX), and they are sent to an 
analogue treatment stage. 2D Raster scans, which measure the SPL (planes of symmetry X-Y), were made with 1/8" Pressure Microphone (Type 40DP, GRAS Sound and Vibration, Holte, Denmark; (http://www.gras.dk/products/preamplifiers-for-microphone-cartridge.html) parallel to the axis of symmetry (X-axis) of the cavity and perpendicular to the radial distance (Y-axis) to the walls. The calibration chart of the microphone user in this research is shown in Fig. 92.

\begin{tabular}{|c|c|c|c|c|c|}
\hline $\begin{array}{l}\text { Calibration Ch } \\
\text { 1/8" Pressure Microp/ } \\
\text { Type 40DP }\end{array}$ & & & & & VIBRATION \\
\hline $\begin{array}{l}\text { Microphone Type 40DP: } \\
\text { Calibration Date: } \\
\text { Operator: } \\
\text { Enviromental Calibration }\end{array}$ & $\begin{array}{l}\text { Serial No. } 56395 \\
\text { 23. May, } 2012 \\
\text { HM }\end{array}$ & \multicolumn{4}{|c|}{$\begin{array}{l}\text { Open Circuit Sensitivity } \\
\text { The calibration is performed by comparison with a Reference } \\
\text { Microphone Cartridge Type } 40 A G \text { and is traceable to the } \\
\text { National Physical Laboratory. UK. } \\
\text { The stated sensitivity for the microphone cartridge is the open } \\
\text { circuit sensitivity. When used with a typical preamplifier, like } \\
\text { the G.R.A.S. Type 26AH, the sensitivity will be } 0.2 \mathrm{~dB} \text { lower. }\end{array}$} \\
\hline \multirow{2}{*}{$\begin{array}{l}\text { Temperature: } \\
\text { Relative humidity: } \\
\text { Barometric pressure: }\end{array}$} & \multirow[t]{2}{*}{$\begin{array}{l}24{ }^{\circ} \mathrm{C} \\
45 \% \\
1017 \mathrm{hPa}\end{array}$} & $\begin{array}{c}\text { Test Frequency } \\
{[\mathrm{Hz}]}\end{array}$ & $\begin{array}{c}\begin{array}{c}\text { Measured Level } \\
{[\mathrm{mV} / \mathrm{Pa}]}\end{array} \\
\end{array}$ & $\begin{array}{c}\text { Measured Level } \\
\text { [dB re. IV/Pa] }\end{array}$ & $\begin{array}{l}\text { Uncertainty } \\
\text { [dB] }\end{array}$ \\
\hline & & 250 & 0.88 & -61.09 & \pm 0.06 \\
\hline
\end{tabular}

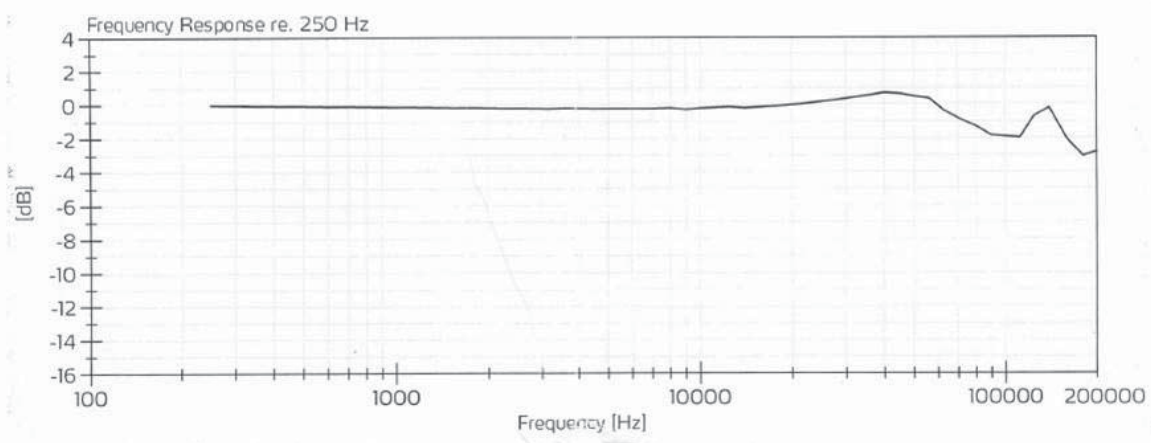

Fig. 92 Calibration Chart of the 1/8" pressure microphone type 40DP, GRAS Sound and Vibration

The microphone was stepped in $0.75 \mathrm{~mm}$ increments in both X- and Y-directions. The electrical output signal of the microphone was captured and stored on a PC. The output voltage level from the microphone was converted to the equivalent acoustic pressure (Pa) using the known sensitivity of the microphone. In this way, both the ultrasonic pressure distribution pattern in free field and inside the acoustic agglomeration chamber were obtained (Fig. 93). From these measurements the average SPL obtained inside the chamber was of about $155 \mathrm{~dB}$ when the electric power applied to the transducer was $300 \mathrm{~W}$. 


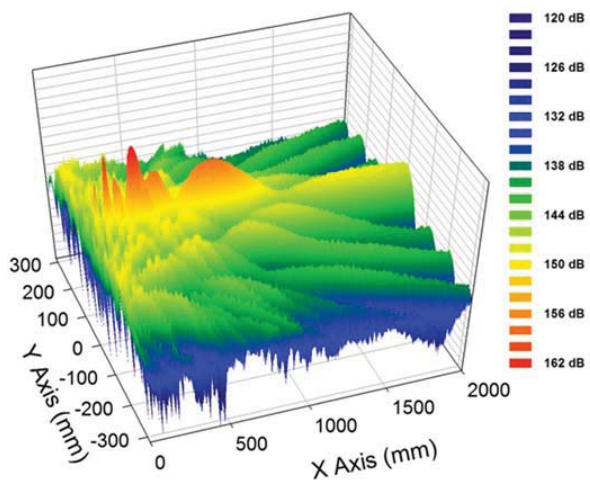

a) $2 \mathrm{D}$ ultrasonic field pattern measured in free field

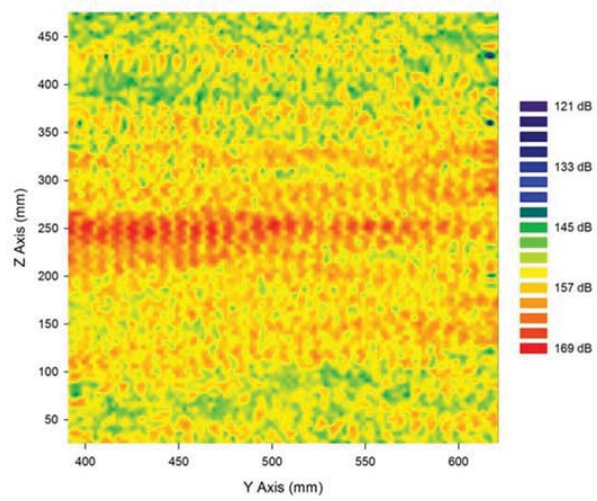

b) 2D ultrasonic field pattern measured inside the agglomeration chamber

Fig. 93 Ultrasound field patterns

In addition, Fig. 94 show two pictures of the acoustic agglomeration chamber positioning inside the semi-anechoic chamber and the $1 / 8^{\prime \prime}$ microphone used for the acoustic field measurements.

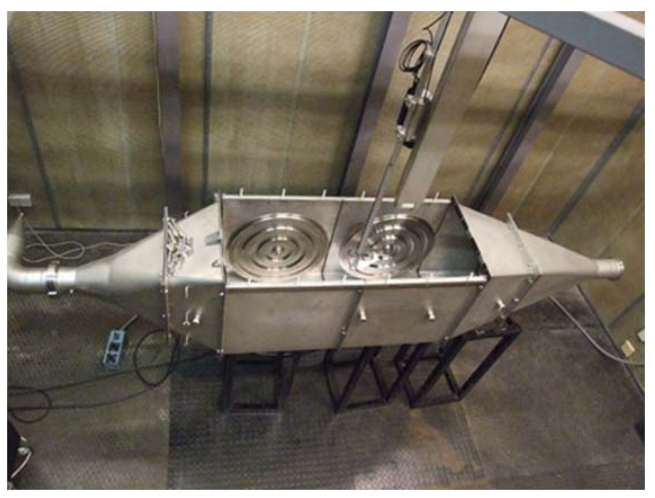

a) Acoustic measurements inside the agglomeration chamber

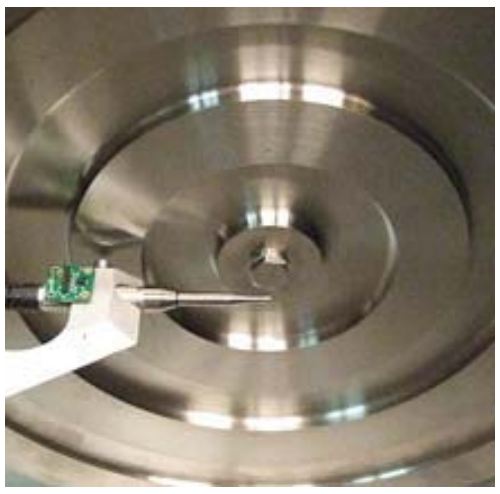

b) View of the microphone positioning inside the chamber facing the transducer

Fig. 94 MSAA Acoustic measurements 
Fig. 95 shows the basic scheme of the experimental set-up developed inside the semi-anechoic chamber for the acoustic field measurements.

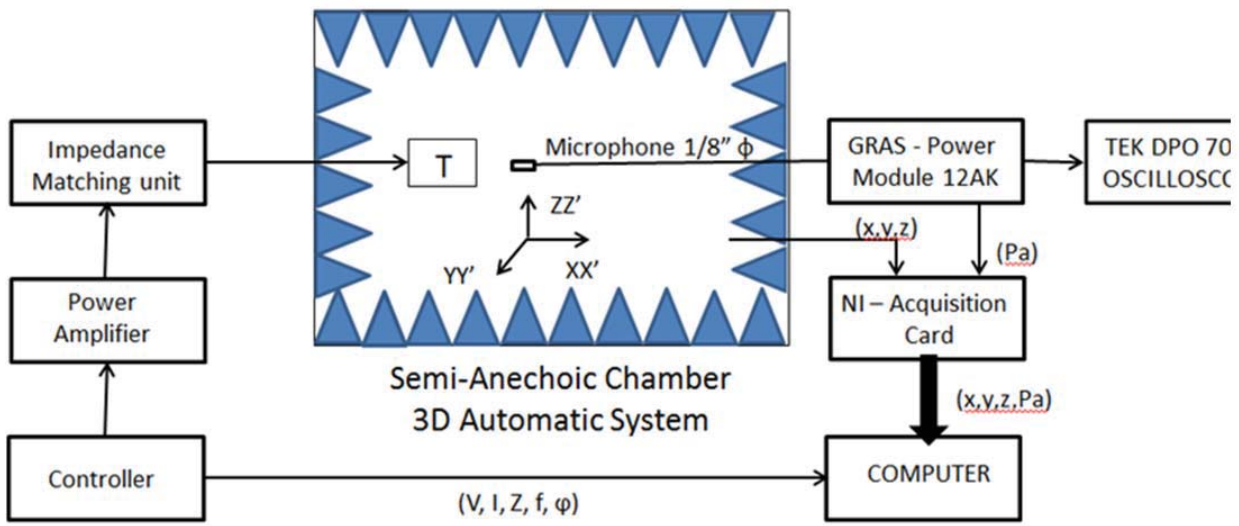

Fig. 95 Sketch of the experimental set-up for acoustic field measurments in the semi-anechoic chamber

The directivity pattern of one of the developed airborne directional stepped-plate transducers is shown in Fig. 96. This measure was carried out in the anechoic chamber located at CSIC (Madrid).

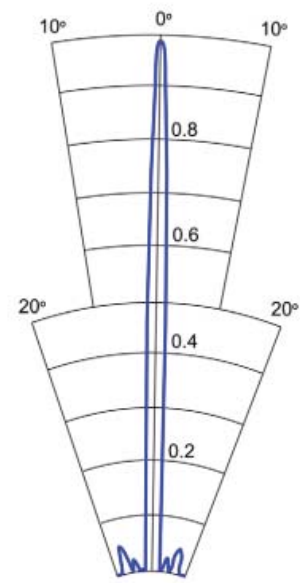

Fig. 96 Directivity pattern of a circular stepped-plate directional transducer of $21 \mathrm{kHz}$ 


\section{APPENDIX 6}

\section{Preliminary Tests}

\subsection{Introduction}

The CAAT2, SET and AAA tests campaigns have been preceded by preliminary tests of different nature depending on the boundary conditions under which the experiments were going to be performed.

The tests are of mainly of two kinds: separate, in which the devices and instrumentation have been tested individually; and integral, in which all the facility under real experimental conditions is tested. These experiments led to the arrangement of the variables and conditions of the final experimental matrix.

\subsection{Aerosol generation and characterization}

Aerosols generation and characterization preliminary tests were aimed to study the concentration of particles able to generate and characterize under the AAA tests conditions. 
Particles were generated with the Solid Particle Disperser RBG-1000 with $\mathrm{N}_{2}$ as a carrier gas. The $\mathrm{N}_{2}$ flows at a constant flow rate equal to $37 \mathrm{lpm}$ (no other gas was injected in the main line). The particles produced were injected into the main line of the PECA-MSAA setup. The main line was blocked upstream from the injection point to avoid particles flowing backwards. Particles have been characterized with the APS and the ELPI devices during 30 min at constant particle generation conditions, with and without dilutor. In both cases the procedure was the particle generation and stabilization, particle measurements with APS and ELPI without dilution and particle measurements with APS and ELPI with dilution. The theoretical dilution used was 100:1 for APS and 60:1 for ELPI.

\section{- APS and ELPI measurements}

The maximum particle concentration was generated with RBG under the prevailing conditions. The particles generated were measured with the APS and the ELPI devices at the same time into the line after the particles stabilization. In both cases it was observed that the signal of APS and ELPI was over the working range of the devices. Thus, the dilution of the sample is compulsory and required for the data acquisition. In order to study the dilution ratio of each device a set of measurements with and without dilution was done.

The maximum dilution ratio possible for each device was used for the tests, i.e. 100:1 and 60:1 for APS and ELPI respectively. Fig. 97 and Fig. 98 show the concentration results with and without dilution for both devices. The final data show that the concentration measured is stable and between $10^{5}$ and $10^{7} \# / \mathrm{cm}^{3}$. Differences of the final values are due to the different particle principles and they need to be correlated as will be done in next section.

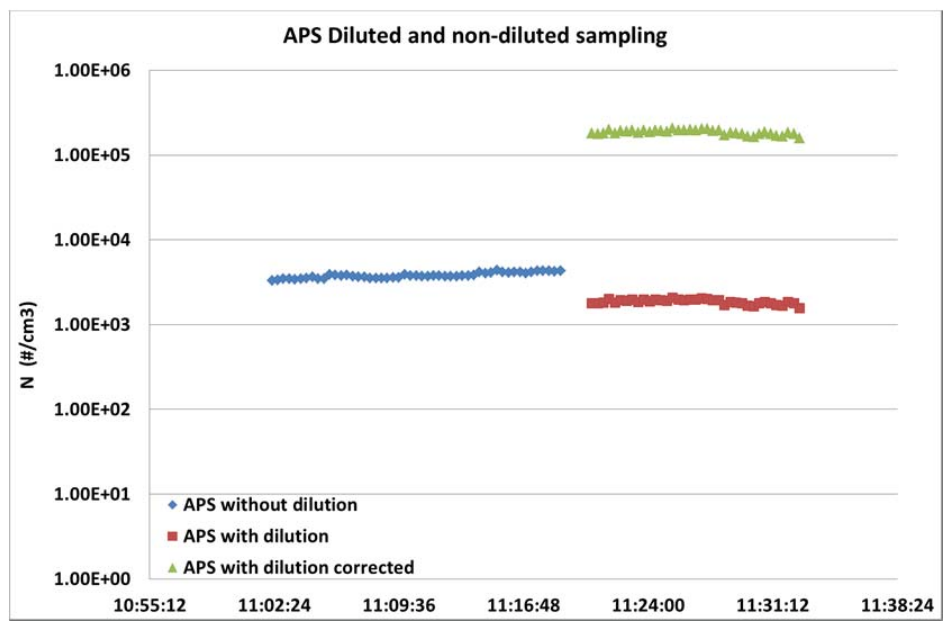

Fig. 97 APS measurements with and without dilution. 


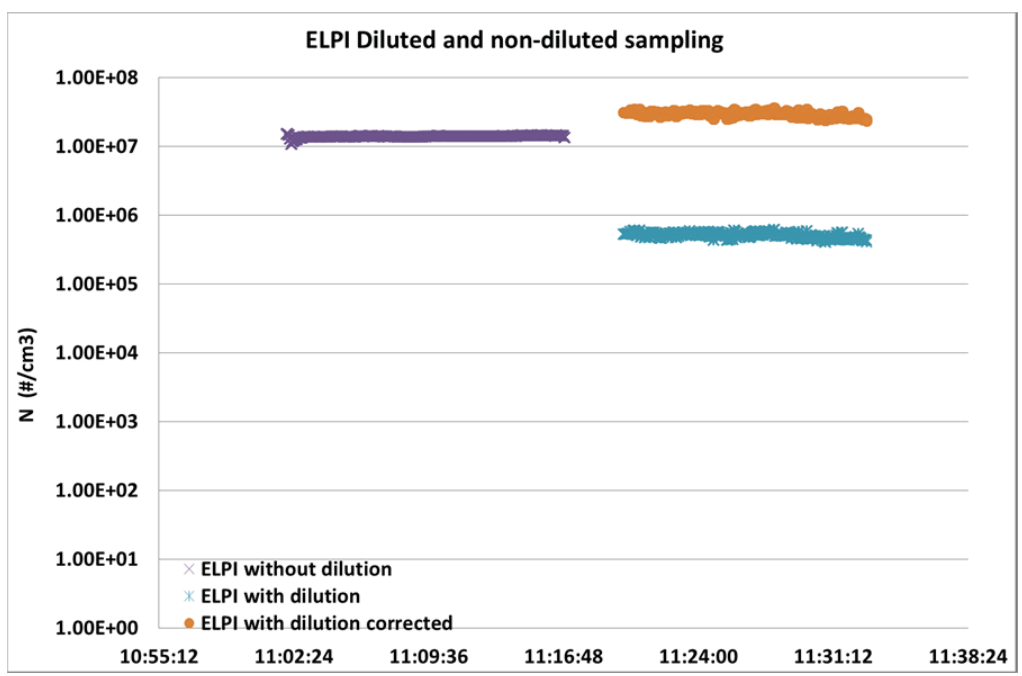

Fig. 98 ELPI measurements with and without dilution

\section{- APS saturation}

As shown above, the APS working range is below the ELPI one. In order to determine the working range precisely it has been particle concentration has been tested under different conditions. The boundary conditions (BC) and results are summarized below.

\section{Boundary conditions:}

- $\quad \dot{\mathrm{m}}_{\mathrm{air}}=100 \mathrm{~kg} / \mathrm{h}$ and $25 \mathrm{~kg} / \mathrm{h}$

- $\quad \mathrm{SiO}_{2} ; 1 \mu \mathrm{m}$

- $\quad$-US

- $\quad$ APS: outlet without dilution

Test phases:

- $\quad \dot{\mathrm{m}}_{\text {air }}=100 \mathrm{~kg} / \mathrm{h}$ stabilization

- $\mathrm{SiO}_{2}$ generation and stabilization

- $10^{\prime}$ APS measurements

- $\quad \dot{\mathrm{m}}_{\text {air }}=25 \mathrm{~kg} / \mathrm{h}$ stabilization

Test Results:

- $10^{\prime}$ APS measurements

- $\quad \dot{\mathrm{m}}_{\text {air }}=99.5 \mathrm{~kg} / \mathrm{h} \rightarrow \mathrm{N}_{\mathrm{APS}}=3.7 \cdot 10^{3} \# / \mathrm{cm}^{3}$

- $\quad \dot{\mathrm{m}}_{\mathrm{air}}=24.6 \mathrm{~kg} / \mathrm{h} \rightarrow \mathrm{N}_{\mathrm{APS}}=4.5 \cdot 10^{3} \# / \mathrm{cm}^{3}$ 


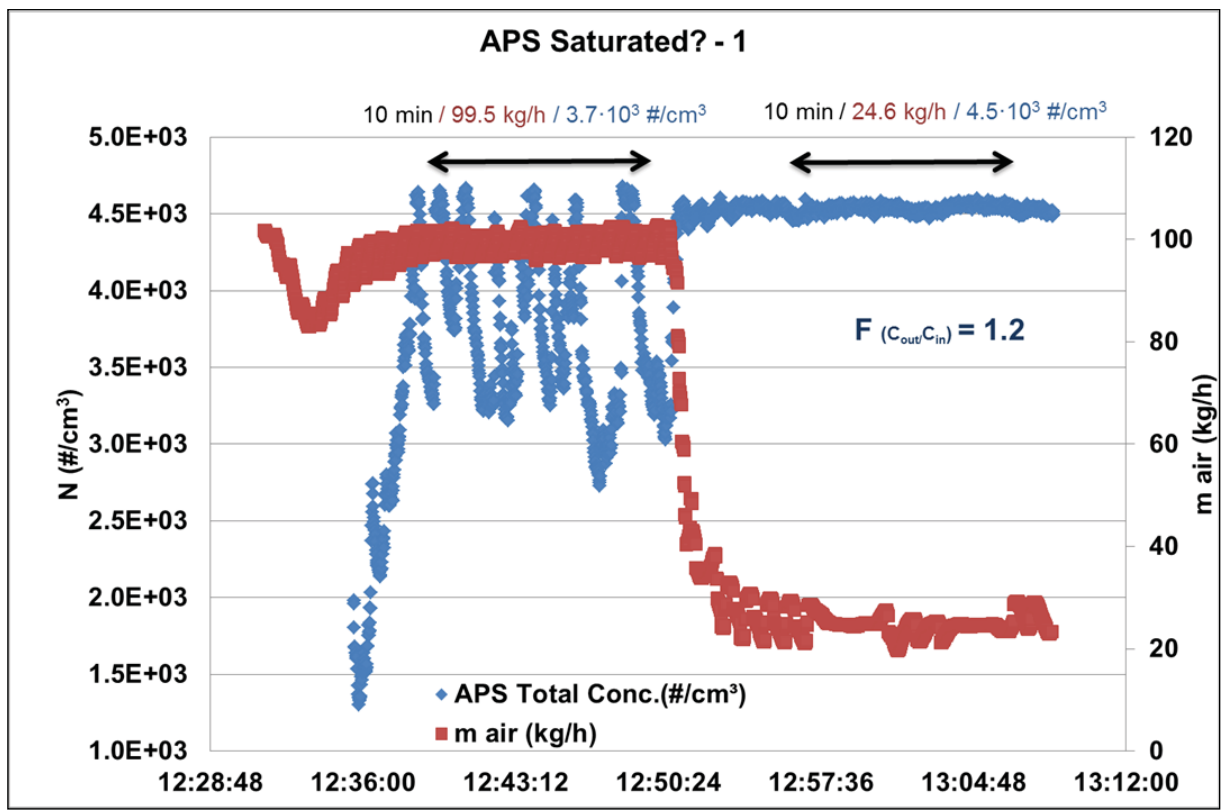

Fig. 99. APS saturation tests

Fig. 99 shows the average concentration of particles with $25 \mathrm{~kg} / \mathrm{h}$ and $100 \mathrm{~kg} / \mathrm{h}$ gas mass flow. The concentration obtained at $100 \mathrm{~kg} / \mathrm{h}$ fluctuates around $3.7 \cdot 10^{3} \# / \mathrm{cm}^{3}$. If credit is given to this result, the concentration expected with a gas mass flow rate of $25 \mathrm{~kg} / \mathrm{h}$ should increase in a factor 4 , in other words, to be around $15 \cdot 10^{3} \# / \mathrm{cm}^{3}$. Results show that at $25 \mathrm{~kg} / \mathrm{h}$ the concentration is almost constant at $4.5 \cdot 10^{3} \mathrm{\#} / \mathrm{cm}^{3}$. The concentration factor resulting evidences the saturation of the APS. Then the maximum concentration to be measured by the APS is $4.5 \cdot 10^{3} \# / \mathrm{cm}^{3}$.

\section{- Particles characterization}

Particles have been characterized in terms of size and concentration. Previous section show the results with respect to the concentration measured with APS and ELPI. The size of particles has been estimated with APS (Fig. 100). Results are consistent with the concentration ones obtained at each bin measured. 


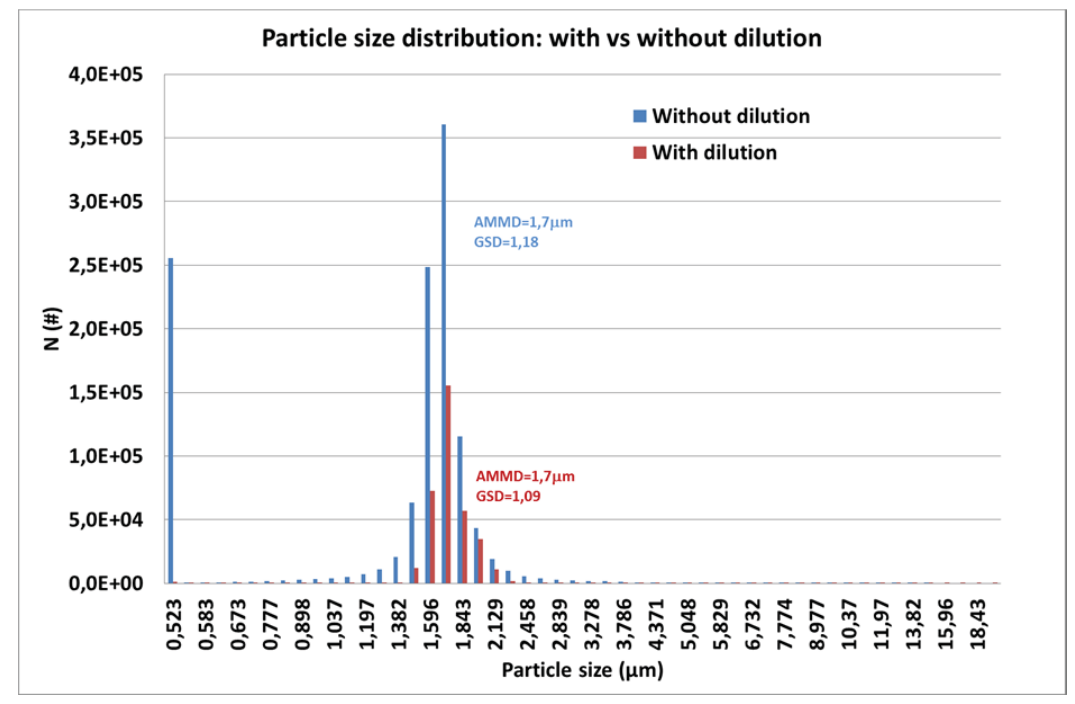

Fig. 100 With a Particle size distributions with and without dilution

\section{- Conclusions}

o Particles are generated with RBG-1000. The concentration measured goes from $10^{5}$ to $10^{7} \# / \mathrm{cm}^{3}$, with a gas mass flow rate of $37 \mathrm{lpm}$. It is worth to point out that for an efficient acoustic chamber, the particle concentration is recommended to be over $10^{5} \# / \mathrm{cm}^{3}$. Then, the total gas mass flow rate should be as low as possible, i.e. $12.5 \mathrm{~kg} / \mathrm{h}$. In order to study the gas mass flow rate effect, two more flow rates were tested $50 \mathrm{~kg} / \mathrm{h}$ and $100 \mathrm{~kg} / \mathrm{h}$.

o RBG-1000 shows concentrations steady in time.

- The capacity of the RBG particles reservoir allows non-stop generation during approximately 30-45 min under the conditions studied. Each test should not be larger than $45 \mathrm{~min}$.

o APS is saturated at $4.5 \cdot 10^{3} \# / \mathrm{cm}^{3}$ and the ELPI at $5 \cdot 10^{5} \# / \mathrm{cm}^{3}$. A dilution of 1:100 and 1:60 is required for the APS and the ELPI respectively to avoid the saturation of devices.

o Particle size and concentration measurements are consistent. 


\subsection{Devices correlation}

The APS and ELPI are devices aimed to estimate the particle size distribution. In both cases, the size distribution is based on particles concentration measurements. They work under different physical principles: APS rely on the time of flight and ELPI on the particle charge. They are usually calibrated against latex particle, which are spherical and very well known characterized particles. Nevertheless these instruments are used to measure aerosol particles of different nature than latex.

ELPI and APS have been correlated by measuring $\mathrm{SiO}_{2}$ particles under the same thermalhydraulic conditions (Fig. 101). The tests have been done by measuring by isokinetic samples at the main line. It is worth to point out that the range differs both in width and bin size. APS measures from $0.5 \mu \mathrm{m}$ to $20 \mu \mathrm{m}$ while ELPI range goes from $0.03 \mu \mathrm{m}$ to $10 \mu \mathrm{m}$. Thus, the estimation of the concentration and the size distribution (ACMD and GSD) will be different.

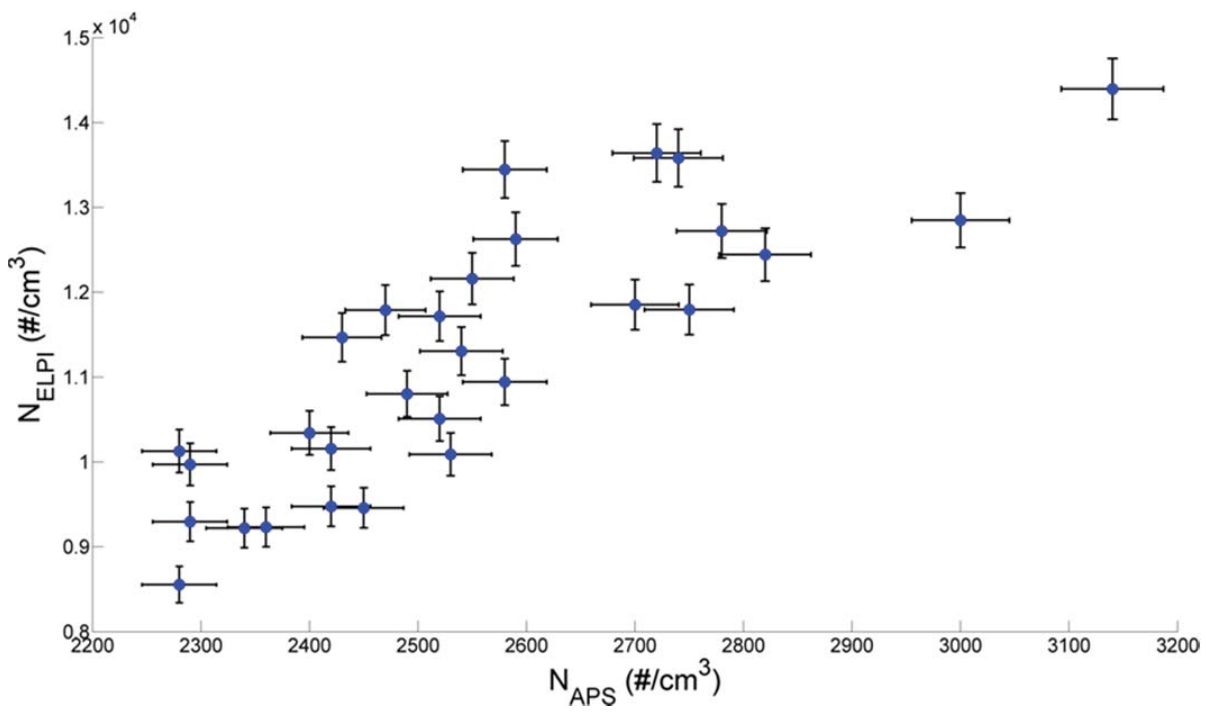

Fig. 101 ELPI vs APS

From Fig. 101 it can be observed that ELPI overestimate the particle concentration with respect to APS. In average it has been estimated to be in a factor between 2 and 3 . The results are in accordance with literature (Pagels et al., 2005). 


\subsection{Integral preliminary tests}

3 integral preliminary tests have been performed before the final AAA campaign. They were aimed to fix the protocol to follow during the tests.

\begin{tabular}{lccccccc}
\hline Test & $\begin{array}{c}\text { Ultrasonic } \\
\text { Frequency } \\
(\mathbf{k H z})\end{array}$ & $\begin{array}{c}\text { Power } \\
\text { Applied } \\
(\mathbf{W})\end{array}$ & $\begin{array}{c}\text { Gas } \\
\text { composition }\end{array}$ & $\begin{array}{c}\text { Gas mass } \\
\text { flow rate } \\
\mathbf{( k g / h )}\end{array}$ & $\begin{array}{c}\mathbf{v}_{\mathbf{g}} \\
(\mathbf{m} / \mathbf{s})\end{array}$ & $\begin{array}{c}\mathrm{C}_{\text {aerosol }} \\
(\mathbf{g} / \mathbf{N m} 3)\end{array}$ & $\begin{array}{c}\mathbf{d p} \\
(\mathbf{\mu m})\end{array}$ \\
\hline 7 & 21 & 300 & Air & 50 & 0.05 & 0.01 & 1 \\
$7^{\prime}$ & 21 & 300 & Air & 50 & 0.05 & 0.01 & 1 \\
8 & 21 & 300 & Air & 25 & 0.025 & 0.02 & 1 \\
\hline
\end{tabular}

Room temperature and atmospheric pressure have been kept in the vessel during the preliminary tests. Once the gas mass flow rate was reached and steady, the aerosols were injected. When the particle injection was stable the acquisition of measurements started. The total duration of a test was about $30 \mathrm{~min}$. ELPI covered the full experiment while APS was measuring when the filter was not withdrawing the sample. After particle stabilization, the sampling was taking with filters at the inlet and at the outlet, first without ultrasound and then with ultrasounds. The procedure of the test can be followed in Fig. 102.

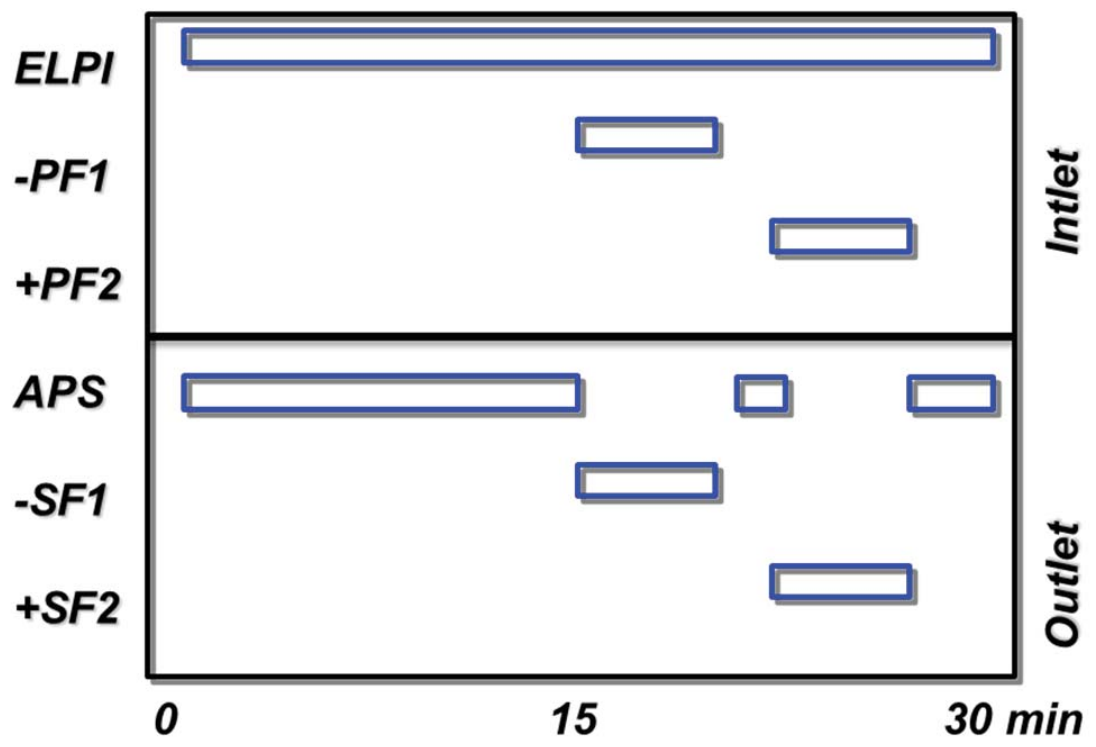

Fig. 102 Integral-preliminary test protocol 
From these tests, it was found out that some particles could get deposited into the chamber. Since they did not reach the outlet they were not characterized. Then, a new test protocol with a phase at the end of each test, called "flush phase" was introduced (Fig. 103). In the flush phased, the gas mass flow rate is increased in a short time. The velocity of the flow is large enough to drag the particles outside.

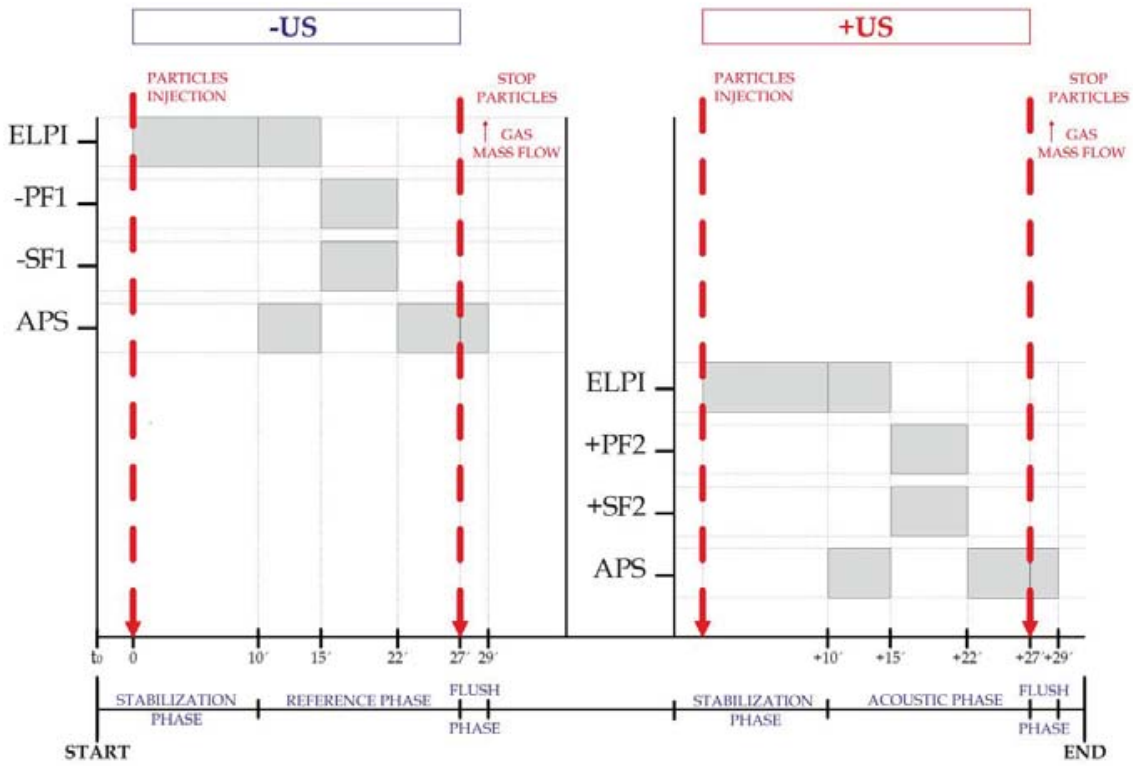

Fig. 103 AAA test protocol 


\section{APPENDIX 7}

\section{Particle size data processing}

\subsection{Introduction}

The APS and ELPI are two devices aimed to estimate the particle size distribution. In both cases, the size distribution is based on number particle counts at each bin size. They work under different physical principles (APS rely on the time of flight and ELPI on the particle charge) and use different range sizes.

APS and ELPI software estimate the particle size distribution and concentration. However, aimed to data processing validation, it has been calculated separately. This appendix presents the data processing to estimate the particle size distribution and particle concentration from the raw data given by the device. 


\subsubsection{APS and ELPI size intervals}

TABLE 24 and TABLE 25 show the bin sizes of each device.

TABLE 24 APS bin sizes

\begin{tabular}{|c|c|c|c|c|}
\hline Channel & Low bound $(\mu \mathrm{m})$ & Upper bound $(\mu \mathrm{m})$ & $\mathrm{d}_{\mathrm{g}}(\mu \mathrm{m})$ & dlogDp \\
\hline 0 & 0.37000 & 0.52300 & 0.43990 & 0.15030 \\
\hline 1 & 0.52300 & 0.56200 & 0.54200 & 0.03123 \\
\hline 2 & 0.56200 & 0.60400 & 0.58300 & 0.03130 \\
\hline 3 & 0.60400 & 0.64900 & 0.62600 & 0.03121 \\
\hline 4 & 0.64900 & 0.69700 & 0.67300 & 0.03099 \\
\hline 5 & 0.69700 & 0.74900 & 0.72300 & 0.03125 \\
\hline 6 & 0.74900 & 0.80500 & 0.77700 & 0.03131 \\
\hline 7 & 0.80500 & 0.86500 & 0.83500 & 0.03122 \\
\hline 8 & 0.86500 & 0.93000 & 0.89800 & 0.03147 \\
\hline 9 & 0.93000 & 0.99900 & 0.96500 & 0.03108 \\
\hline 10 & 0.99900 & 1.07400 & 1.03700 & 0.03144 \\
\hline 11 & 1.07400 & 1.15400 & 1.11400 & 0.03120 \\
\hline 12 & 1.15400 & 1.24000 & 1.19700 & 0.03122 \\
\hline 13 & 1.24000 & 1.33300 & 1.28600 & 0.03141 \\
\hline 14 & 1.33300 & 1.43200 & 1.38200 & 0.03111 \\
\hline 15 & 1.43200 & 1.53900 & 1.48600 & 0.03130 \\
\hline 16 & 1.53900 & 1.65400 & 1.59600 & 0.03130 \\
\hline 17 & 1.65400 & 1.77700 & 1.71500 & 0.03115 \\
\hline 18 & 1.77700 & 1.91000 & 1.84300 & 0.03135 \\
\hline 19 & 1.91000 & 2.05200 & 1.98100 & 0.03114 \\
\hline 20 & 2.05200 & 2.20500 & 2.12900 & 0.03123 \\
\hline 21 & 2.20500 & 2.37000 & 2.28800 & 0.03134 \\
\hline 22 & 2.37000 & 2.54700 & 2.45800 & 0.03128 \\
\hline 23 & 2.54700 & 2.73700 & 2.64200 & 0.03125 \\
\hline 24 & 2.73700 & 2.94100 & 2.83900 & 0.03122 \\
\hline 25 & 2.94100 & 3.16000 & 3.05100 & 0.03119 \\
\hline 26 & 3.16000 & 3.39600 & 3.27800 & 0.03128 \\
\hline 27 & 3.39600 & 3.65000 & 3.52300 & 0.03133 \\
\hline 28 & 3.65000 & 3.92400 & 3.78600 & 0.03144 \\
\hline 29 & 3.92400 & 4.21700 & 4.06800 & 0.03127 \\
\hline 30 & 4.21700 & 4.53200 & 4.37100 & 0.03129 \\
\hline 31 & 4.53200 & 4.87000 & 4.69800 & 0.03124 \\
\hline 32 & 4.87000 & 5.23300 & 5.04800 & 0.03122 \\
\hline 33 & 5.23300 & 5.62300 & 5.42500 & 0.03122 \\
\hline 34 & 5.62300 & 6.04300 & 5.82900 & 0.03128 \\
\hline 35 & 6.04300 & 6.49400 & 6.26400 & 0.03126 \\
\hline 36 & 6.49400 & 6.97800 & 6.73200 & 0.03122 \\
\hline 37 & 6.97800 & 7.49900 & 7.23400 & 0.03127 \\
\hline 38 & 7.49900 & 8.05900 & 7.77400 & 0.03128 \\
\hline 39 & 8.05900 & 8.66000 & 8.35400 & 0.03124 \\
\hline 40 & 8.66000 & 9.30600 & 8.97700 & 0.03125 \\
\hline 41 & 9.30600 & 10.00200 & 9.64700 & 0.03132 \\
\hline 42 & 10.00200 & 10.74800 & 10.37000 & 0.03124 \\
\hline 43 & 10.74800 & 11.54800 & 11.14000 & 0.03118 \\
\hline 44 & 11.54800 & 12.40200 & 11.97000 & 0.03098 \\
\hline 45 & 12.40200 & 13.33800 & 12.86000 & 0.03160 \\
\hline 46 & 13.33800 & 14.33200 & 13.82000 & 0.03122 \\
\hline 47 & 14.33200 & 15.40000 & 14.86000 & 0.03121 \\
\hline 48 & 15.40000 & 16.53900 & 15.96000 & 0.03099 \\
\hline 49 & 16.53900 & 17.77300 & 17.15000 & 0.03125 \\
\hline 50 & 17.77300 & 19.09900 & 18.43000 & 0.03125 \\
\hline 51 & 19.09900 & 20.53530 & 19.81000 & 0.03149 \\
\hline 52 & 20.53530 & & & \\
\hline \multicolumn{5}{|c|}{ TABLE 25 ELPI bin sizes } \\
\hline Channel & Low bound $(\mu \mathrm{m})$ & Upper bound $(\mu \mathrm{m})$ & $d_{g}(\mu \mathrm{m})$ & dlogDp \\
\hline 1 & 0.0280 & 0.0560 & 0.0396 & 0.3010 \\
\hline 2 & 0.0560 & 0.0949 & 0.0729 & 0.2295 \\
\hline 3 & 0.0950 & 0.1559 & 0.1217 & 0.2154 \\
\hline 4 & 0.1560 & 0.2610 & 0.2018 & 0.2235 \\
\hline 5 & 0.2610 & 0.3790 & 0.3145 & 0.1620 \\
\hline 6 & 0.3790 & 0.6089 & 0.4804 & 0.2060 \\
\hline 7 & 0.6090 & 0.9430 & 0.7578 & 0.1899 \\
\hline 8 & 0.9430 & 1.5900 & 1.2245 & 0.2269 \\
\hline 9 & 1.5900 & 2.3800 & 1.9453 & 0.1752 \\
\hline 10 & 2.3800 & 3.9701 & 3.0739 & 0.2222 \\
\hline 11 & 3.9700 & 6.6499 & 5.1381 & 0.2240 \\
\hline 12 & 6.6500 & 9.8601 & 8.0975 & 0.1711 \\
\hline 13 & 9.860 & & & \\
\hline
\end{tabular}


The common range of ELPI and APS is shown in Fig. 104

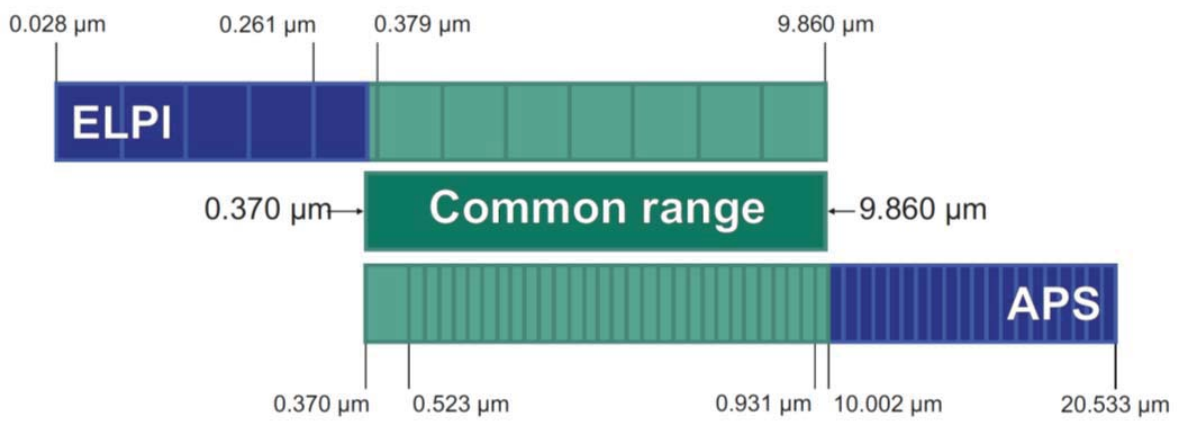

Fig. 104 APS and ELPI common range

\subsubsection{Data processing}

\subsubsection{Number size distribution}

The distribution measured by the APS is converted to number concentration/dlogdp by calculus from the raw counts and the total concentration. Then it is validated by the conversion from the APS software. This calculus is done by the equation 72 where the term $\phi / t Q \eta$ is calculated from equations 73 and 74 , where $\mathrm{n}$ is the channel particle concentration, $\mathrm{c}$ is the particle raw count given by the APS, $\mathrm{t}$ the sample time, $\mathrm{Q}$ Sample flow rate, $\varphi$ sample dilution factor, $\eta$ is the channel sample efficiency factor (taken as constant for all channels), $\mathrm{Np}$ total particle concentration given by the APS software and the summation goes to all the channels:

$$
\begin{array}{r}
n=\frac{c}{t Q} \frac{\phi}{\eta} \\
N_{p}=\sum n \\
\frac{\phi}{t Q \eta}=c t e=\frac{N p}{\sum_{l}^{u} c}
\end{array}
$$

Then the concentrations are adjusted by the dilution factor that is 100 for the APS. 


\subsubsection{Mass size distribution}

The mass distribution is calculated with the equations 75 to 78 from the number concentration and the bin sizes. The equation 75 gives the mass of a particle with a given stokes diameter Dp and density $\rho$. The stokes diameter is calculated according to equation 5 where $\chi$ the form factor (taken as 1 as the particles tested are spherical and dense particles), $\mathrm{Da}$ is the aerodynamic diameter (which is taken as the $d_{g}$ of each bin), $\rho_{0}$ unity density, $\rho$ the particle density and $C_{a}$ and $C_{p}$ the Cunningham slip correction for each diameter (aerodynamic and stokes) which are calculated iterating equation 76 with 77 and 78.

$$
\begin{gathered}
M=\frac{\pi}{6} D_{p}^{3} \rho \\
D_{p}=D_{a} \sqrt{\frac{\rho_{0} C_{a} \chi}{\rho C_{p}}} \\
C=1+K n\left[1.252+0.399 e^{-\frac{1.10}{K n}}\right] \\
K n=\frac{D}{2 l}
\end{gathered}
$$

The mass concentration is validated with the mass concentration calculated by the software.

\subsubsection{Number and mass concentration}

The total number and mass concentration are calculated by simply summing all channels.

\subsubsection{Mean distributions}

The mean distributions are calculated by averaging the distributions during the sampling time. The final distribution has been estimated as the sum of lognormal distributions (79) and adjusted by least squares.

$$
f=\sum \text { A lognormal }(\overline{d p}, \sigma)=\sum \frac{1}{d p \cdot \sigma \sqrt{2 \pi}} e^{-\frac{(\ln d p-\overline{d p})^{2}}{2 \sigma^{2}}}
$$




\section{APPENDIX 8}

\section{AAA Tests Results}

This appendix presents the measurements and integral results obtained in each AAA test.

\subsection{AAA1}

This test was conducted successfully in the MSAA-PECA facility of the Laboratory of Analysis of Safety Systems (LASS). The mixture used for the test and the boundary conditions is summarized in TABLE 26.

TABLE 26 Mixture of particles

\begin{tabular}{lll}
\hline $\mathrm{SiO}_{2}$ mixture & mass $(\mathrm{g})$ & $\mathrm{X}_{\mathrm{m}}(\%)$ \\
\hline $\mathrm{dp}_{1}=0.28 \mu \mathrm{m}$ & 100 & 100 \\
$\mathrm{dp}_{2}=1 \mu \mathrm{m}$ & & \\
$\mathrm{dp}_{3}=2.5 \mu \mathrm{m}$ & 100 & \\
\hline Total & & \\
\hline
\end{tabular}




\subsubsection{Test stages and protocol}

1) Phase 1
a. Reference phase
b. Flashing phase 1

2) Phase 2
a. Acoustic phase

b. Flashing phase 2

\begin{tabular}{|c|c|c|c|c|c|c|}
\hline Phase 1 (-US) & Order & Action & Value & Time length & $t_{\text {in }}$ & $t_{f}$ \\
\hline \multirow[t]{5}{*}{ Reference phase } & $1-$ & $\dot{m}(\mathrm{~kg} / \mathrm{h})$ & 12 & Stability & & \\
\hline & $2-$ & $\mathrm{SiO}_{2}$ injection & & Stability - $15^{\prime}$ & $11: 36: 55$ & $11: 51: 55$ \\
\hline & & ELPI in & & & $11: 36: 55$ & \\
\hline & $3-$ & F 1 (in/out) & & $7^{\prime}$ & $11: 52: 00$ & $11: 59: 00$ \\
\hline & $4-$ & APS out & & $7^{\prime}$ & 11:59:16 & 12:06:16 \\
\hline \multirow[t]{3}{*}{ Flushing phase } & $5-$ & Stop $\mathrm{SiO} 2$ & & & 12:06:16 & \\
\hline & & 个m (kg/h) & 200 & & $12: 06: 50$ & \\
\hline & & APS out & & $7^{\prime}$ & 12:06:50 & 12:13:50 \\
\hline \multicolumn{7}{|l|}{ Phase 2 (+US) } \\
\hline \multirow[t]{5}{*}{ Acoustic phase } & 1 - & $\dot{\mathrm{m}}(\mathrm{kg} / \mathrm{h})$ & 12 & Stability & & \\
\hline & $2-$ & $\mathrm{SiO}_{2}$ injection & & Stability - $15^{\prime}$ & $12: 25: 35$ & $12: 40: 35$ \\
\hline & $3-$ & +US & & & $12: 40: 35$ & \\
\hline & & F 2 (in/out) & & $7^{\prime}$ & $12: 47: 53$ & $12: 54: 50$ \\
\hline & $4-$ & APS out & & $5^{\prime}$ & $12: 55: 30$ & 13:00:30 \\
\hline \multirow[t]{4}{*}{ Flushing phase 1} & $5-$ & Stop $\mathrm{SiO} 2$ & & & $12: 54: 50$ & \\
\hline & & -US & & & $12: 54: 50$ & \\
\hline & & $\uparrow \dot{m}(\mathrm{~kg} / \mathrm{h})$ & 200 & & $12: 55: 30$ & \\
\hline & & APS out & & $5^{\prime}$ & $12: 55: 30$ & 13:00:30 \\
\hline Phase 1' (-US) & Order & Action & & Time & $t_{\text {in }}$ & $t_{f}$ \\
\hline \multirow[t]{4}{*}{ Reference phase } & $1-$ & $\dot{\mathrm{m}}(\mathrm{kg} / \mathrm{h})$ & 12 & Stability & & \\
\hline & $2-$ & $\mathrm{SiO}_{2}$ injection & & Stability - $15^{\prime}$ & 13:12:15 & 13:27:15 \\
\hline & $3-$ & F 3 (in/out) & & $7^{\prime}$ & $13: 27: 30$ & $13: 34: 30$ \\
\hline & $4-$ & APS out & & $7^{\prime}$ & 13:34:40 & $13: 42: 20$ \\
\hline \multirow[t]{3}{*}{ Flushing phase } & $5-$ & Stop $\mathrm{SiO} 2$ & & & 13:43:00 & \\
\hline & & $\uparrow \dot{m}(\mathrm{~kg} / \mathrm{h})$ & 200 & & 13:43:30 & \\
\hline & & APS out & & $5^{\prime}$ & 13:43:30 & $13: 49: 45$ \\
\hline \multicolumn{7}{|l|}{ Phase 2' (+US) } \\
\hline \multirow[t]{5}{*}{ Acoustic phase } & $1-$ & $\dot{m}(\mathrm{~kg} / \mathrm{h})$ & 12 & Stability & & \\
\hline & $2-$ & $\mathrm{SiO}_{2}$ injection & & Stability - $15^{\prime}$ & $14: 01: 20$ & $14: 16: 20$ \\
\hline & $3-$ & +US & & & $14: 16: 20$ & \\
\hline & & F4 (in/out) & & $7^{\prime}$ & $14: 16: 20$ & $14: 23: 20$ \\
\hline & 4- & APS out & & $7^{\prime}$ & $14: 23: 45$ & $14: 30: 45$ \\
\hline \multirow[t]{5}{*}{ Flushing phase } & $5-$ & Stop $\mathrm{SiO}_{2}$ & & & 14:30:45 & \\
\hline & & -US & & & $14: 30: 45$ & \\
\hline & & $\uparrow \dot{m}(\mathrm{~kg} / \mathrm{h})$ & 200 & & $14: 31: 30$ & \\
\hline & & APS out & & $5^{\prime}$ & $14: 31: 30$ & $14: 36: 30$ \\
\hline & & ELPI in & & & & $14: 36: 30$ \\
\hline
\end{tabular}

\subsubsection{Summary of the test evolution}

The evolution of the main hydraulic variables is summarized in Fig. 105. They have been controlled and logged every 700ms through the PLC of the LASS. 


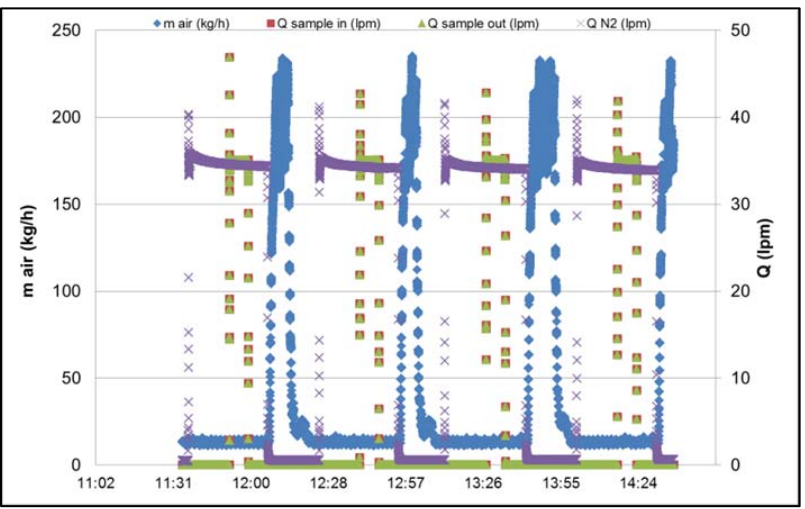

Fig. 105 Hydraulic variables evolution

\subsubsection{Particle concentration}

- Concentration evolution (APS/ELPI): Inlet/outlet: $\mathrm{N}\left(\# / \mathrm{cm}^{3}\right)$ vs time
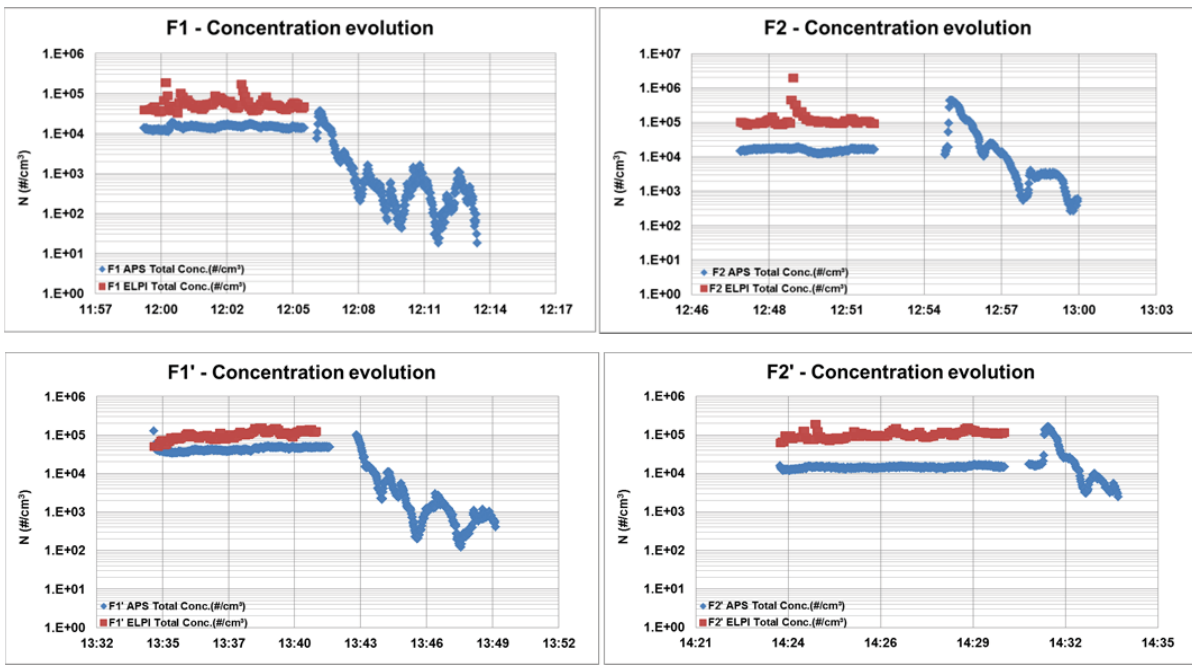
- Concentration comparison (filters)

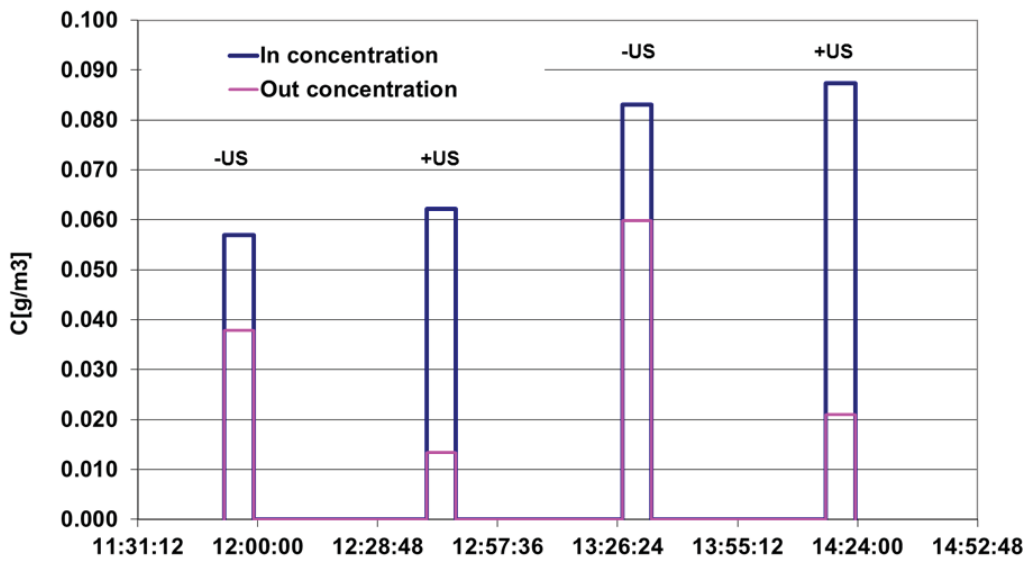

\subsubsection{Particle size}

Particle size distribution: Average size during the -US /+US periods.
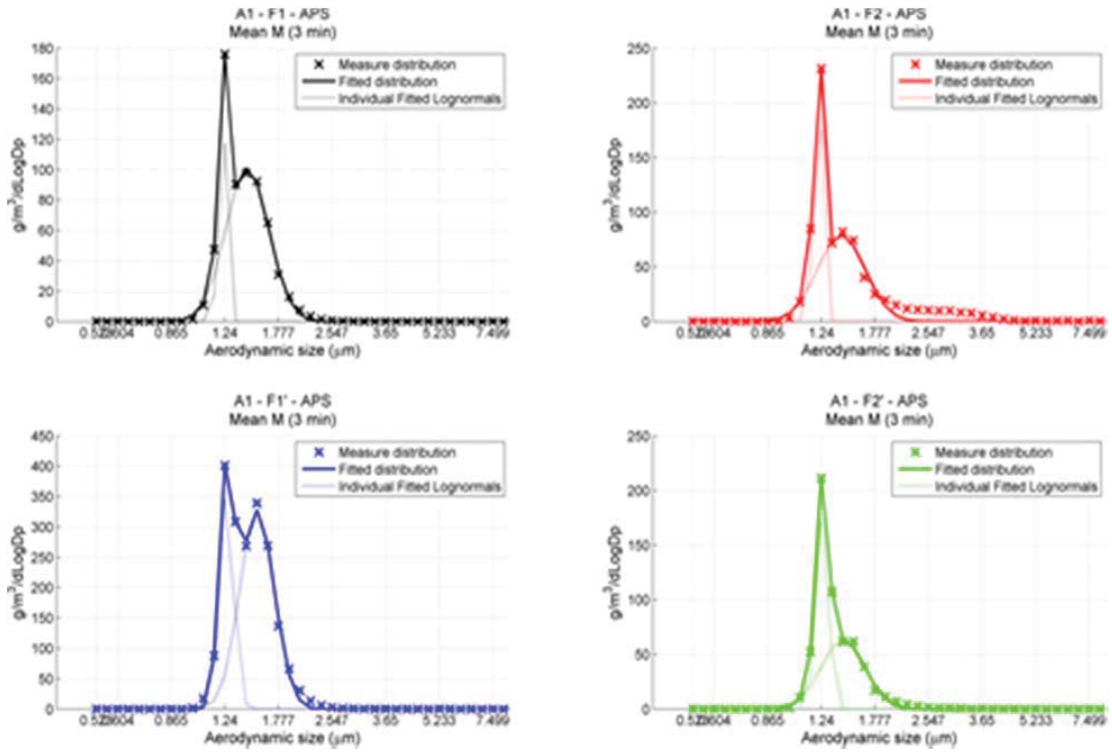
Particle size evolution: ACMD/AMMD and GSD

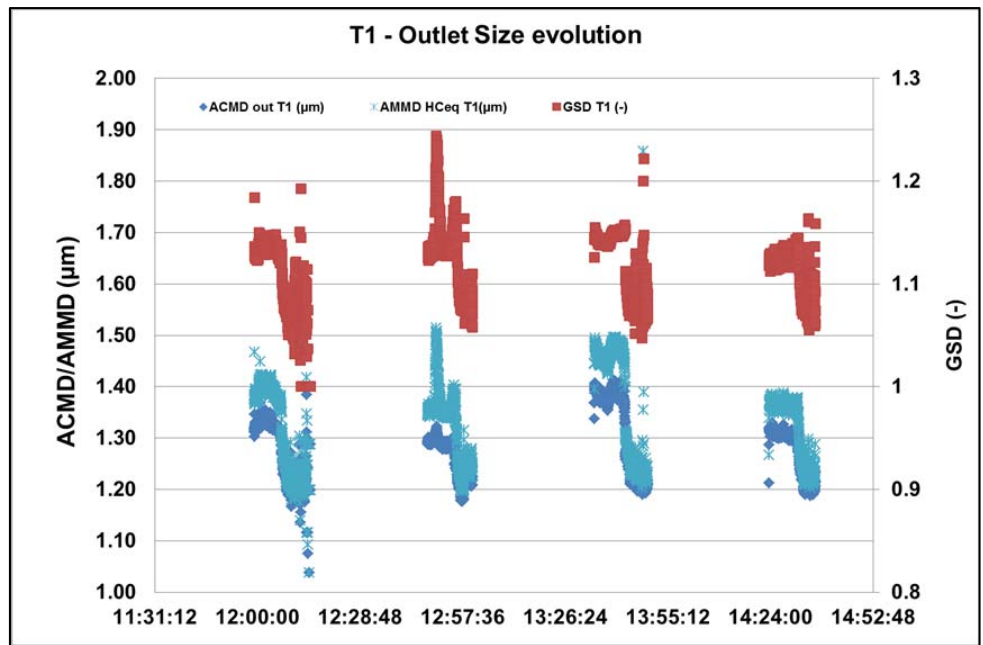




\section{2. $\mathrm{AAA2}$}

This test was conducted successfully on 10.3.2015 in the MSAA-PECA facility of the Laboratory of Analysis of Safety Systems (LASS). The mixture used for the test is summarized in TABLE 27.

TABLE 27 Mixture of particles

\begin{tabular}{lcc}
\hline $\mathrm{SiO}_{2}$ mixture & mass $(\mathrm{g})$ & $\mathrm{X}_{\mathrm{m}}(\%)$ \\
\hline $\mathrm{dp}_{1}=0.28 \mu \mathrm{m}$ & 100 & 100 \\
$\mathrm{dp}_{2}=1 \mu \mathrm{m}$ & & \\
$\mathrm{dp}_{3}=2.5 \mu \mathrm{m}$ & 100 & \\
\hline Total & & \\
\hline
\end{tabular}

\subsubsection{Test stages and protocol}

\begin{tabular}{|c|c|c|c|c|c|c|}
\hline Phase 1(-US) & Order & Action & Value & Time length & $t_{i n}$ & $t_{f}$ \\
\hline \multirow[t]{5}{*}{ Reference phase } & $1-$ & $\dot{\mathrm{m}}(\mathrm{kg} / \mathrm{h})$ & 100 & Stability & & \\
\hline & $2-$ & $\mathrm{SiO}_{2}$ injection & & Stability - $15^{\prime}$ & $11: 27: 25$ & $11: 43: 20$ \\
\hline & & ELPI in & & & $11: 27: 25$ & \\
\hline & $3-$ & F1 (in/out) & & $7^{\prime}$ & $11: 43: 20$ & $11: 50: 20$ \\
\hline & $4-$ & APS out & & $7^{\prime}$ & $11: 50: 40$ & 11:57:40 \\
\hline \multirow[t]{3}{*}{ Flashing phase 1} & $5-$ & Stop SiO2 & & & $11: 57: 40$ & \\
\hline & & $\uparrow \dot{m}(\mathrm{~kg} / \mathrm{h})$ & 200 & & $11: 58: 15$ & \\
\hline & & APS out & & $5^{\prime}$ & 11:58:15 & 12:03:15 \\
\hline \multicolumn{7}{|l|}{ Phase 2 (+US) } \\
\hline \multirow[t]{5}{*}{ Acoustic phase } & 1 - & $\dot{\mathrm{m}}(\mathrm{kg} / \mathrm{h})$ & 100 & Stability & & \\
\hline & $2-$ & $\mathrm{SiO}_{2}$ injection & & Stability - $15^{\prime}$ & 12:13:45 & $12: 28: 48$ \\
\hline & $3-$ & +US & & & $12: 27: 00$ & \\
\hline & & F 2 (in/out) & & $7^{\prime}$ & $12: 28: 48$ & $12: 35: 48$ \\
\hline & 4- & APS out & & $7^{\prime}$ & $12: 36: 00$ & $12: 43: 05$ \\
\hline \multirow[t]{4}{*}{ Flashing phase 1} & $5-$ & -US & & & $12: 44: 20$ & \\
\hline & & Stop $\mathrm{SiO}_{2}$ & & & 12:43:05 & \\
\hline & & $\uparrow \dot{m}(\mathrm{~kg} / \mathrm{h})$ & 200 & & $12: 44: 00$ & \\
\hline & & APS out & & $5^{\prime}$ & $12: 44: 00$ & $12: 49: 00$ \\
\hline Phase 1' (-US) & Order & Action & & Time & $t_{\text {in }}$ & $t_{f}$ \\
\hline \multirow[t]{4}{*}{ Reference phase } & $1-$ & $\dot{\mathrm{m}}(\mathrm{kg} / \mathrm{h})$ & 100 & Stability & & \\
\hline & $2-$ & $\mathrm{SiO}_{2}$ injection & & Stability - $15^{\prime}$ & $12: 55: 55$ & \\
\hline & $3-$ & F 3 (in/out) & & $7^{\prime}$ & 13:11:00 & $13: 18: 00$ \\
\hline & $4-$ & APS out & & $7^{\prime}$ & $13: 18: 10$ & 13:25:00 \\
\hline \multirow[t]{3}{*}{ Flashing phase 1} & $5-$ & Stop $\mathrm{SiO} 2$ & & & $13: 25: 00$ & \\
\hline & & $\uparrow \dot{m}(\mathrm{~kg} / \mathrm{h})$ & 200 & & $13: 25: 50$ & \\
\hline & & APS out & & $5^{\prime}$ & 13:26:00 & 13:31:00 \\
\hline \multicolumn{7}{|l|}{ Phase 2' (+US) } \\
\hline \multirow[t]{5}{*}{ Acoustic phase } & $1-$ & $\dot{\mathrm{m}}(\mathrm{kg} / \mathrm{h})$ & 100 & Stability & & \\
\hline & $2-$ & $\mathrm{SiO}_{2}$ injection & & Stability - $15^{\prime}$ & $13: 40: 30$ & \\
\hline & $3-$ & +US & & & 13:55:00 & \\
\hline & & F 4 (in/out) & & $7^{\prime}$ & $13: 55: 30$ & $14: 02: 30$ \\
\hline & $4-$ & APS out & & $7^{\prime}$ & 14:02:45 & $14: 09: 45$ \\
\hline \multirow[t]{5}{*}{ Flashing phase 1} & $5-$ & -US & & & 14:10:48 & \\
\hline & & Stop $\mathrm{SiO} 2$ & & & 14:09:50 & \\
\hline & & $\uparrow \dot{m}(\mathrm{~kg} / \mathrm{h})$ & 200 & & $14: 10: 26$ & \\
\hline & & APS out & & $5^{\prime}$ & $14: 10: 26$ & $14: 15: 30$ \\
\hline & & ELPI in & & & & $14: 15: 30$ \\
\hline
\end{tabular}




\subsubsection{Summary of the test evolution}

The evolution of the main hydraulic variables is summarized in Fig. 106. They have been controlled and logged every 700ms through the PLC of the LASS.

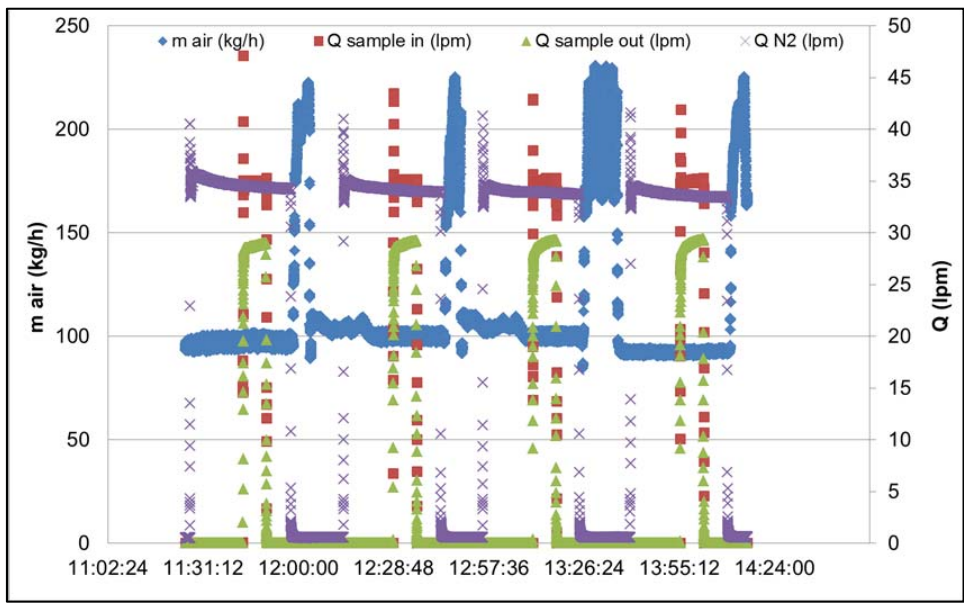

Fig. 106 Hydraulic variables evolution

\subsubsection{Particle concentration}

- Concentration comparison (filters)

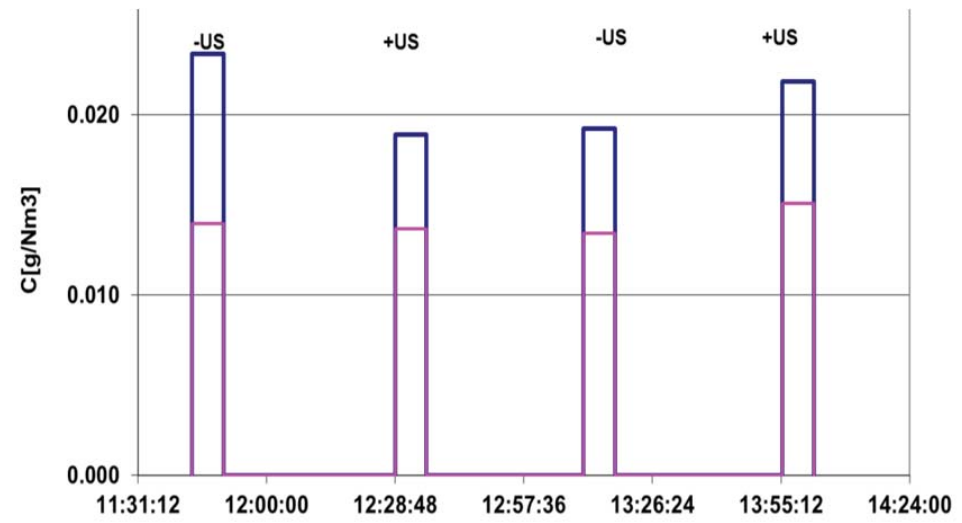




\subsubsection{Particle size}

Particle size evolution: ACMD/AMMD and GSD vs time

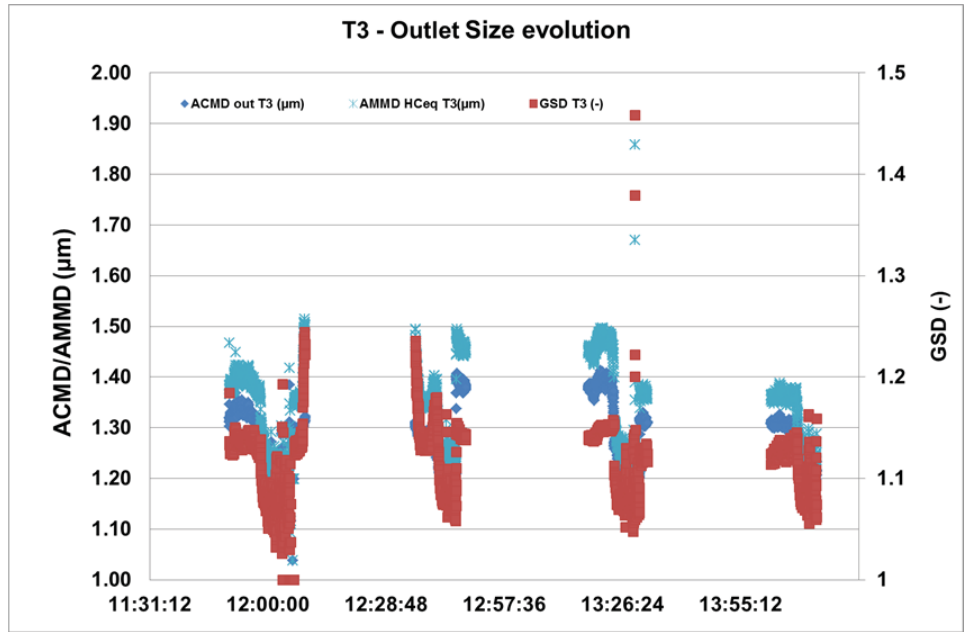

Particle size distribution: Average size during the -US /+US periods.
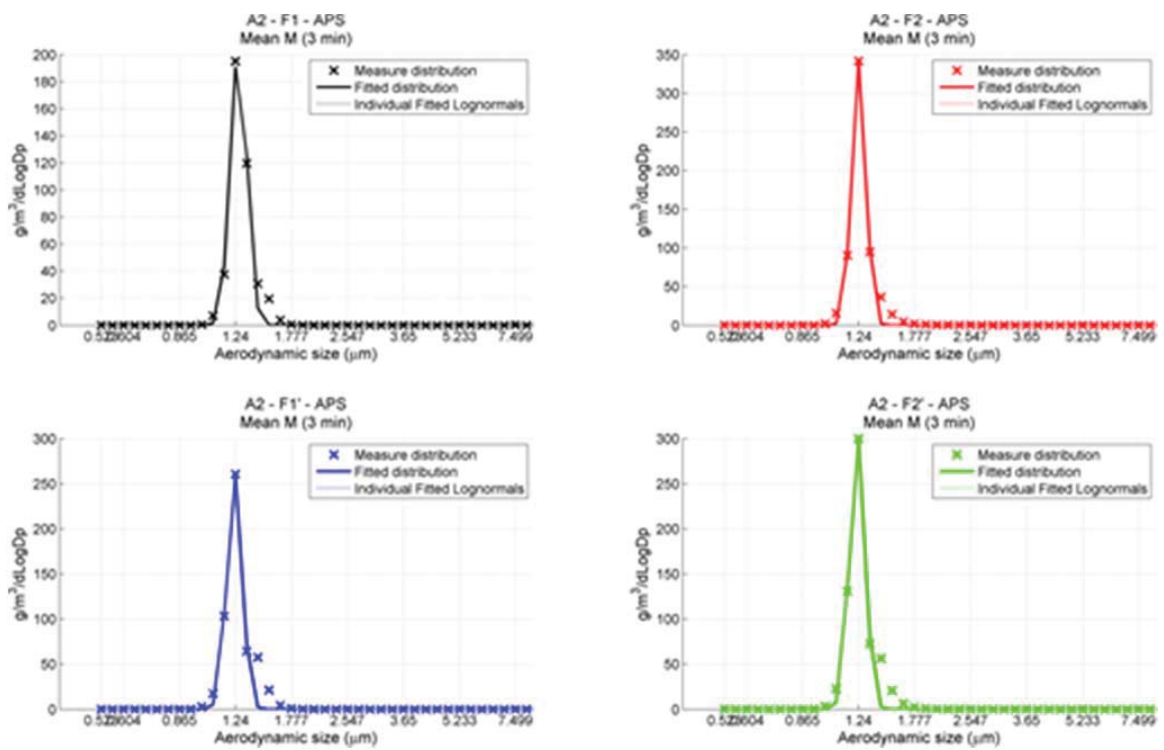


\section{3. $\mathrm{AAA3}$}

This test was conducted successfully in the MSAA-PECA facility of the Laboratory of Analysis of Safety Systems (LASS). The mixture used for the test is summarized in TABLE 28.

TABLE 28 Mixture of particles

\begin{tabular}{lll}
\hline $\mathrm{SiO}_{2}$ mixture & mass $(\mathrm{g})$ & $\mathbf{X}_{\mathrm{m}}(\%)$ \\
\hline $\mathrm{dp}_{1}=\mathbf{0 . 2 8} \boldsymbol{\mu m}$ & 50.02 & 49.97 \\
$\mathrm{dp}_{2}=\mathbf{1} \boldsymbol{\mu \mathrm { m }}$ & 50.08 & 50.03 \\
$\mathrm{dp}_{3}=\mathbf{2 . 5} \boldsymbol{\mu \mathrm { m }}$ & 0 & 0.00 \\
\hline Total & 100.1 & \\
\hline
\end{tabular}

\subsubsection{Test stages and protocol}

\begin{tabular}{|c|c|c|c|c|c|c|}
\hline Phase 1 (-US) & Order & Action & Value & Time length & $t_{\text {in }}$ & $t_{f}$ \\
\hline \multirow[t]{5}{*}{ Reference phase } & $1-$ & $\dot{\mathrm{m}}(\mathrm{kg} / \mathrm{h})$ & 12 & Stability & & \\
\hline & $2-$ & $\mathrm{SiO}_{2}$ injection & & Stability - $10^{\prime}$ & $10: 46: 42$ & $10: 56: 43$ \\
\hline & & ELPI in & & & $10: 56: 00$ & \\
\hline & $3-$ & F 1 (in/out) & & $7^{\prime}$ & 10:56:42 & $11: 03: 43$ \\
\hline & $4-$ & APS out & & $5^{\prime}$ & 11:03:58 & 11:08:58 \\
\hline \multirow[t]{3}{*}{ Flushing phase } & $5-$ & Stop $\mathrm{SiO} 2$ & & & 11:09:42 & \\
\hline & & $\uparrow \dot{m}(\mathrm{~kg} / \mathrm{h})$ & 200 & & 11:10:06 & \\
\hline & & APS out & & $5^{\prime}$ & 11:10:06 & 11:15:06 \\
\hline \multicolumn{7}{|l|}{ Phase 2 (+US) } \\
\hline \multirow[t]{5}{*}{ Acoustic phase } & $1-$ & $\dot{\mathrm{m}}(\mathrm{kg} / \mathrm{h})$ & 12 & Stability & & \\
\hline & $2-$ & $\mathrm{SiO}_{2}$ injection & & Stability - $10^{\prime}$ & $11: 21: 53$ & 11:31:53 \\
\hline & $3-$ & +US & & & 11:22:08 & \\
\hline & & F 2 (in/out) & & $7^{\prime}$ & $11: 32: 00$ & $11: 39: 00$ \\
\hline & $4-$ & APS out & & $7^{\prime}$ & $11: 39: 15$ & $11: 44: 15$ \\
\hline \multirow[t]{4}{*}{ Flushing phase 1} & $5-$ & Stop $\mathrm{SiO} 2$ & & & $11: 45: 15$ & \\
\hline & & -US & & & $11: 45: 45$ & \\
\hline & & $\uparrow \dot{m}(\mathrm{~kg} / \mathrm{h})$ & 200 & & $11: 45: 55$ & \\
\hline & & APS out & & $5^{\prime}$ & $11: 45: 55$ & $11: 55: 55$ \\
\hline Phase 1' (-US) & Order & Action & & Time & $t_{i n}$ & $t_{f}$ \\
\hline \multirow[t]{4}{*}{ Reference phase } & $1-$ & $\dot{\mathrm{m}}(\mathrm{kg} / \mathrm{h})$ & 12 & Stability & & \\
\hline & $2-$ & $\mathrm{SiO}_{2}$ injection & & Stability - $10^{\prime}$ & 11:56:55 & 12:06:55 \\
\hline & $3-$ & F 3 (in/out) & & $7^{\prime}$ & $12: 07: 00$ & $12: 14: 00$ \\
\hline & $4-$ & APS out & & $5^{\prime}$ & $12: 14: 10$ & 12:19:10 \\
\hline \multirow[t]{3}{*}{ Flushing phase } & $5-$ & Stop $\mathrm{SiO} 2$ & & & $12: 19: 40$ & \\
\hline & & $\uparrow \dot{m}(\mathrm{~kg} / \mathrm{h})$ & 200 & & 12:19:55 & \\
\hline & & APS out & & $5^{\prime}$ & 12:19:55 & 12:24:55 \\
\hline \multicolumn{7}{|l|}{ Phase 2' (+US) } \\
\hline \multirow[t]{5}{*}{ Acoustic phase } & $1-$ & $\dot{\mathrm{m}}(\mathrm{kg} / \mathrm{h})$ & 12 & Stability & & \\
\hline & $2-$ & $\mathrm{SiO}_{2}$ injection & & Stability - $10^{\prime}$ & $12: 31: 36$ & 12:41:36 \\
\hline & $3-$ & +US & & & 12:32:10 & \\
\hline & & F 4 (in/out) & & $7^{\prime}$ & $12: 41: 30$ & $12: 48: 30$ \\
\hline & $4-$ & APS out & & $3^{\prime}+$ US_2'-US_2'+US_2' & 12:48:42 & 13:03:42 \\
\hline \multirow[t]{5}{*}{ Flushing phase } & $5-$ & Stop $\mathrm{SiO} 2$ & & & 13:03:45 & \\
\hline & & -US & & & $13: 03: 43$ & \\
\hline & & $\uparrow \dot{m}(\mathrm{~kg} / \mathrm{h})$ & 200 & & $13: 04: 20$ & \\
\hline & & APS out & & & $13: 04: 20$ & 13:07:45 \\
\hline & & ELPI in & & & & 13:08:00 \\
\hline
\end{tabular}




\subsubsection{Summary of the test evolution}

The evolution of the main hydraulic variables is summarized in Fig. 107. They have been controlled and logged every 700ms through the PLC of the LASS.

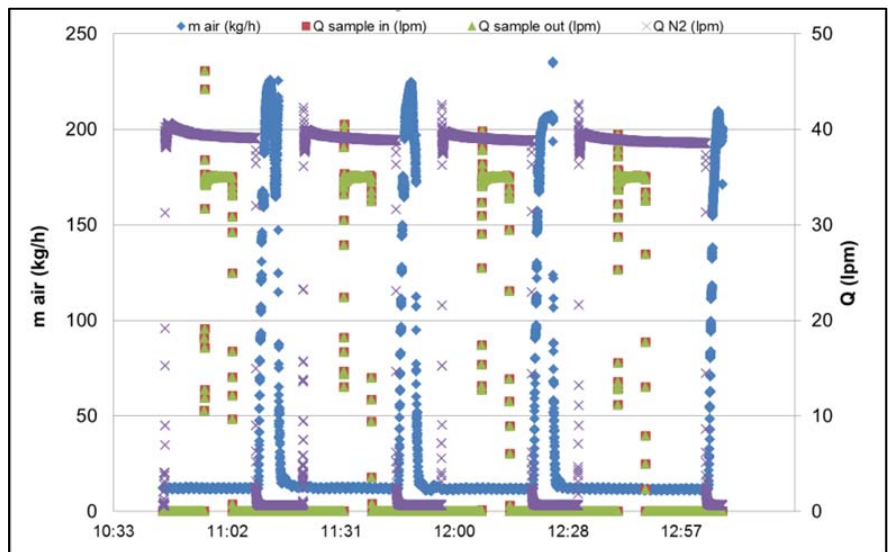

Fig. 107 Hydraulic variables evolution

\subsubsection{Particle concentration}

- Concentration evolution (APS/ELPI): Inlet/outlet: $\mathrm{N}\left(\# / \mathrm{cm}^{3}\right)$
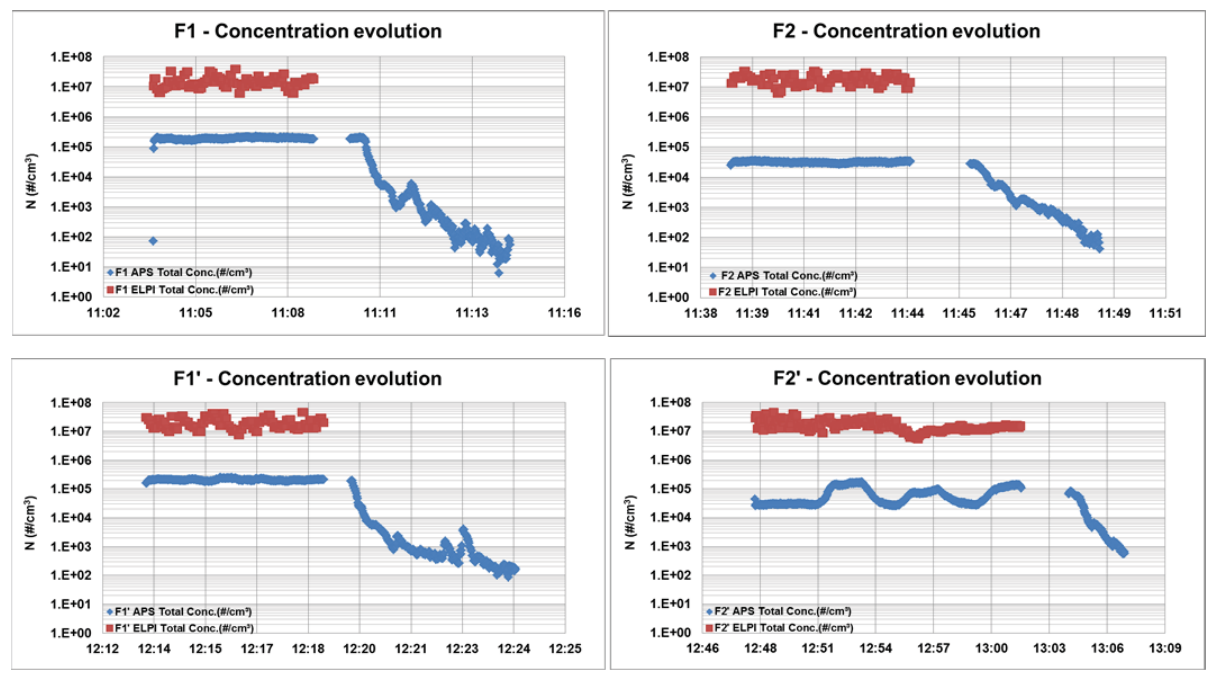
- Concentration comparison (filters)

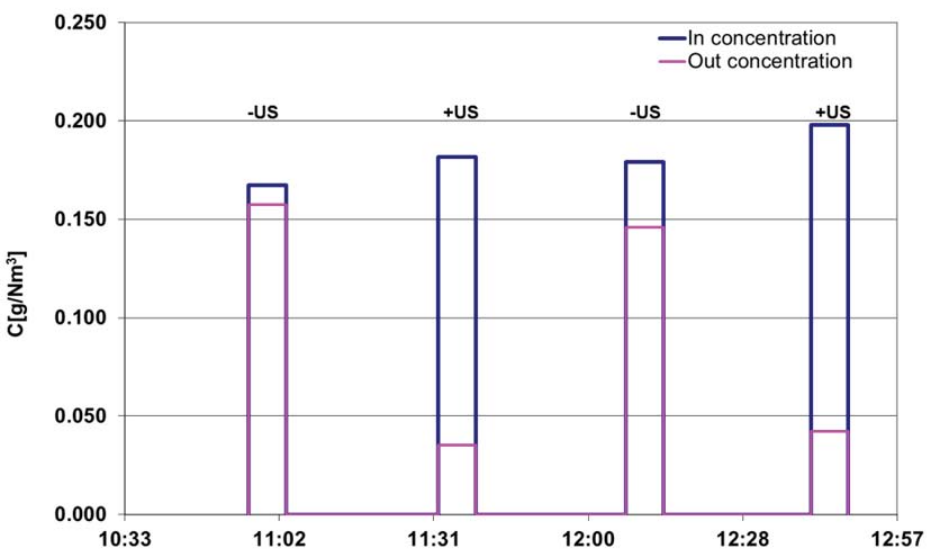

\subsubsection{Particle size}

Particle size evolution: ACMD/AMMD and GSD.

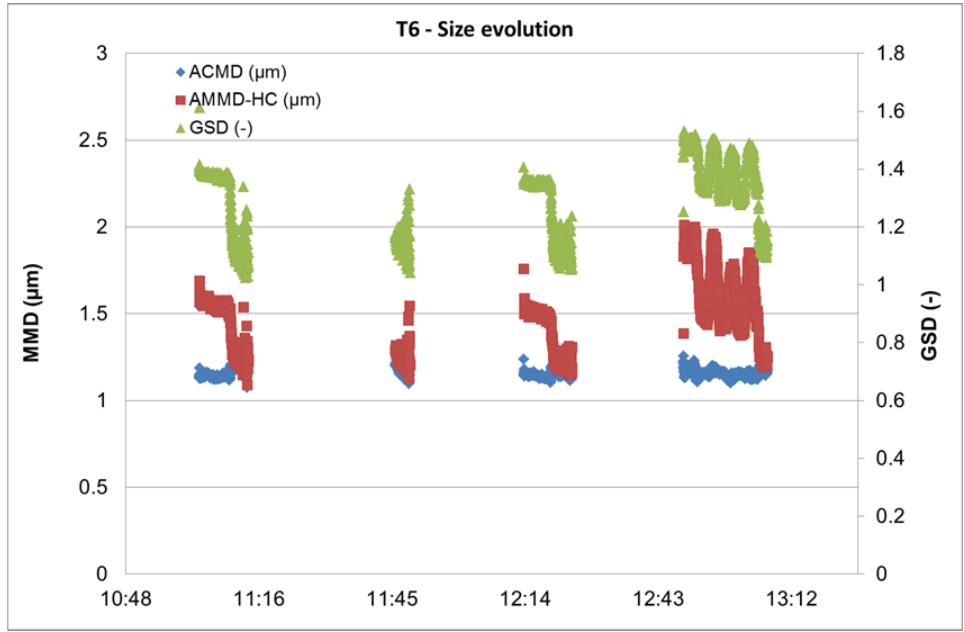


Particle size distribution: Average size during the -US /+US periods.
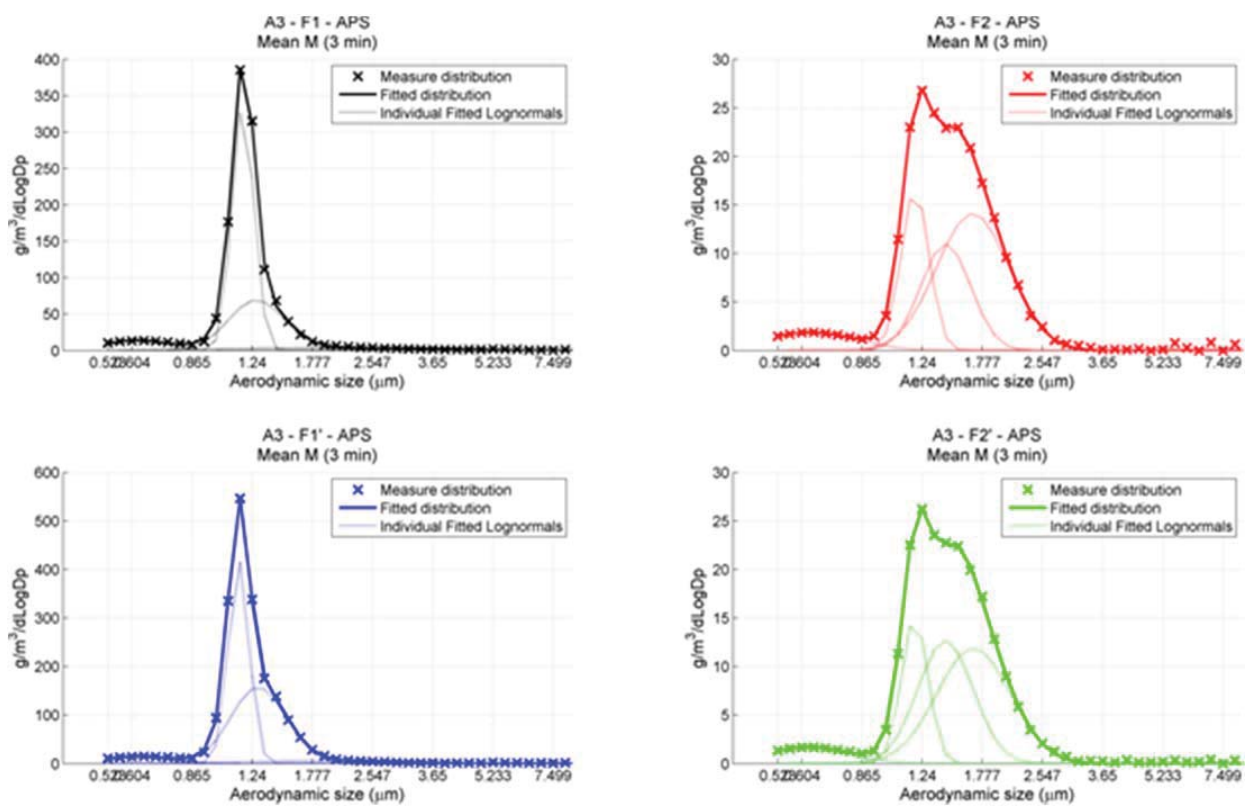


\subsection{AAA4}

This test was conducted successfully in the MSAA-PECA facility of the Laboratory of Analysis of Safety Systems (LASS). The mixture used for the test is summarized in

TABLE 29.

TABLE 29 Mixture of particles

\begin{tabular}{lll}
\hline $\mathrm{SiO}_{2}$ mixture & mass $(\mathrm{g})$ & $\mathbf{X}_{\mathrm{m}}(\mathbf{\%})$ \\
\hline $\mathrm{dp}_{\mathbf{1}}=\mathbf{0 . 2 8} \boldsymbol{\mu \mathrm { m }}$ & 50.02 & 49.97 \\
$\mathrm{dp}_{2}=\mathbf{1} \boldsymbol{\mu \mathrm { m }}$ & 50.08 & 50.03 \\
$\mathrm{dp}_{3}=\mathbf{2 . 5} \boldsymbol{\mu \mathrm { m }}$ & 0 & 0.00 \\
\hline Total & 100.1 & \\
\hline
\end{tabular}

\subsubsection{Test stages and protocol}

\begin{tabular}{|c|c|c|c|c|c|c|}
\hline Phase 1 (-US) & Order & Action & Value & Time length & $t_{i n}$ & $t_{f}$ \\
\hline \multirow[t]{5}{*}{ Reference phase } & $1-$ & $\dot{\mathrm{m}}(\mathrm{kg} / \mathrm{h})$ & 12 & Stability & & \\
\hline & $2-$ & $\mathrm{SiO}_{2}$ injection & & Stability - $15^{\prime}$ & 12:39:00 & $12: 49: 00$ \\
\hline & & ELPI in & & & 12:39:00 & \\
\hline & $3-$ & F 1 (in/out) & & $7^{\prime}$ & 12:49:03 & 12:56:02 \\
\hline & $4-$ & APS out & & $7^{\prime}$ & 12:56:10 & 13:01:10 \\
\hline \multirow[t]{3}{*}{ Flashing phase 1} & $5-$ & Stop $\mathrm{SiO} 2$ & & & 13:01:10 & \\
\hline & & $\uparrow \dot{m}(\mathrm{~kg} / \mathrm{h})$ & 200 & & 13:01:45 & \\
\hline & & APS out & & $5^{\prime}$ & 13:01:45 & 13:06:45 \\
\hline \multicolumn{7}{|l|}{ Phase 2 (+US) } \\
\hline \multirow[t]{5}{*}{ Acoustic phase } & 1 - & $\dot{\mathrm{m}}(\mathrm{kg} / \mathrm{h})$ & 12 & Stability & & \\
\hline & 2 - & $\mathrm{SiO}_{2}$ injection & & Stability - $15^{\prime}$ & 13:13:10 & 13:23:10 \\
\hline & $3-$ & +US & & & $13: 16: 40$ & \\
\hline & & F 2 (in/out) & & $7^{\prime}$ & 13:23:10 & 13:30:12 \\
\hline & $4-$ & APS out & & $7^{\prime}$ & 13:30:25 & $13: 35: 25$ \\
\hline \multirow[t]{4}{*}{ Flashing phase 1} & $5-$ & Stop SiO2 & & & $13: 35: 30$ & \\
\hline & & -US & & & $13: 35: 41$ & \\
\hline & & $\uparrow \dot{m}(\mathrm{~kg} / \mathrm{h})$ & 200 & & $13: 37: 00$ & \\
\hline & & APS out & & $5^{\prime}$ & 13:37:00 & $13: 41: 25$ \\
\hline Phase 1' (-US) & Order & Action & & Time & $t_{i n}$ & $t_{f}$ \\
\hline \multirow[t]{4}{*}{ Reference phase } & $1-$ & $\dot{m}(\mathrm{~kg} / \mathrm{h})$ & 12 & Stability & & \\
\hline & $2-$ & $\mathrm{SiO}_{2}$ injection & & Stability - $15^{\prime}$ & 13:49:43 & 13:59:42 \\
\hline & $3-$ & F 3 (in/out) & & $7^{\prime}$ & 13:59:45 & $14: 06: 45$ \\
\hline & 4- & APS out & & $7^{\prime}$ & 14:07:00 & $14: 12: 00$ \\
\hline \multirow[t]{3}{*}{ Flashing phase 1} & $5-$ & Stop $\mathrm{SiO} 2$ & & & $14: 12: 52$ & \\
\hline & & $\uparrow \dot{m}(\mathrm{~kg} / \mathrm{h})$ & 200 & & $14: 12: 55$ & \\
\hline & & APS out & & $5^{\prime}$ & $14: 12: 55$ & 14:16:17 \\
\hline \multicolumn{7}{|l|}{ Phase 2' (+US) } \\
\hline \multirow[t]{5}{*}{ Acoustic phase } & $1-$ & $\dot{\mathrm{m}}(\mathrm{kg} / \mathrm{h})$ & 12 & Stability & & \\
\hline & $2-$ & $\mathrm{SiO}_{2}$ injection & & Stability - $15^{\prime}$ & 14:27:44 & \\
\hline & $3-$ & +US & & & $14: 28: 20$ & \\
\hline & & F 4 (in/out) & & $7^{\prime}$ & 14:37:00 & $14: 44: 00$ \\
\hline & $4-$ & APS out & & $7^{\prime}$ & $14: 44: 15$ & $14: 48: 00$ \\
\hline \multirow[t]{5}{*}{ Flashing phase 1} & $5-$ & Stop $\mathrm{SiO} 2$ & & & $14: 48: 00$ & \\
\hline & & -US & & & $14: 48: 15$ & \\
\hline & & $\uparrow \dot{m}(\mathrm{~kg} / \mathrm{h})$ & 200 & & 14:48:30 & \\
\hline & & APS out & & $5^{\prime}$ & $14: 48: 30$ & $14: 52: 22$ \\
\hline & & ELPI in & & & & $14: 52: 22$ \\
\hline
\end{tabular}




\subsubsection{Summary of the test evolution}

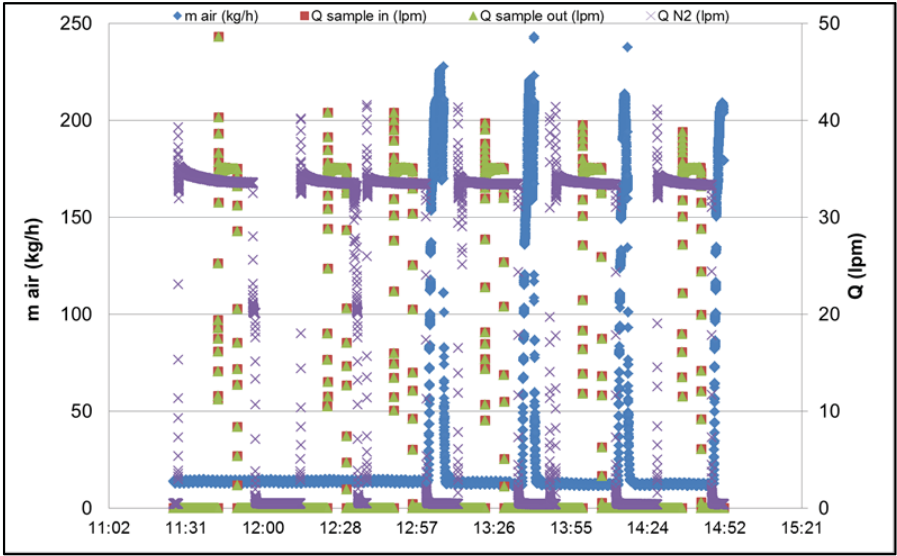

Fig. 108 Hydraulic variables evolution

\subsubsection{Particle concentration}

Concentration evolution (APS/ELPI): Inlet/outlet: $\mathrm{N}\left(\# / \mathrm{cm}^{3}\right)$ vs time
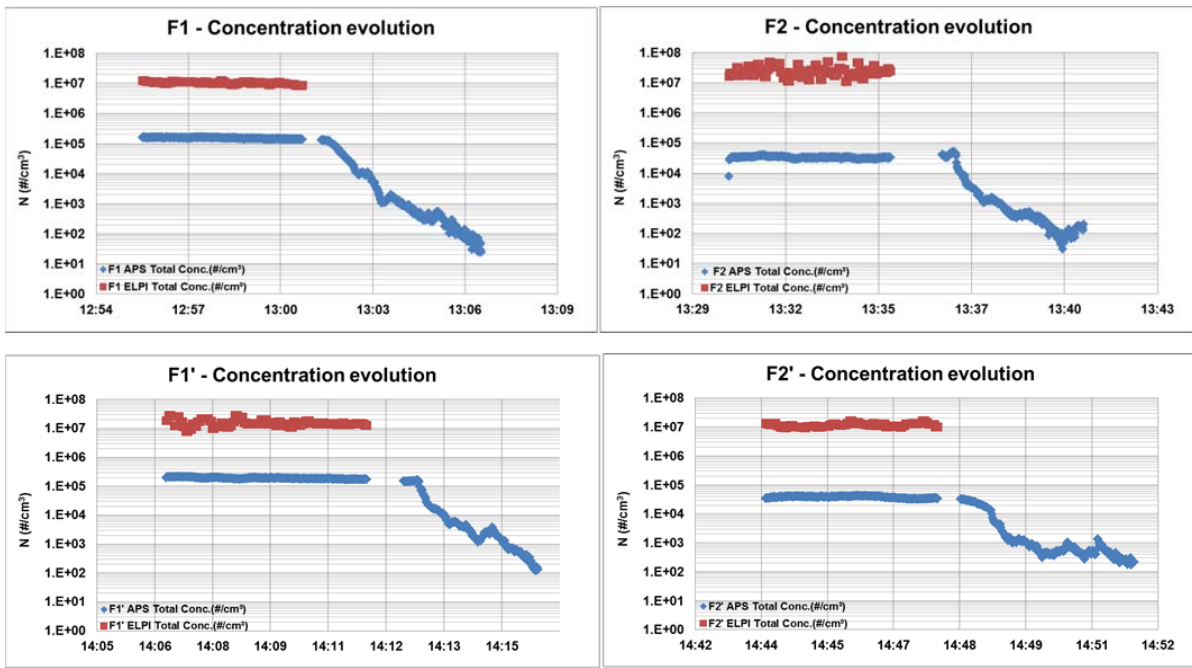
- Concentration comparison (filters)

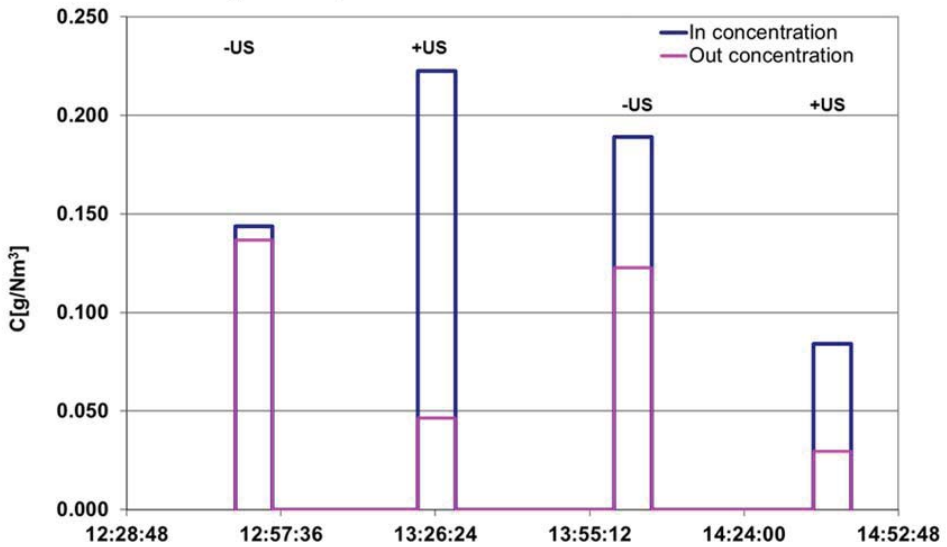

\subsubsection{Particle size}

Particle size evolution ACMD/AMMD and GSD

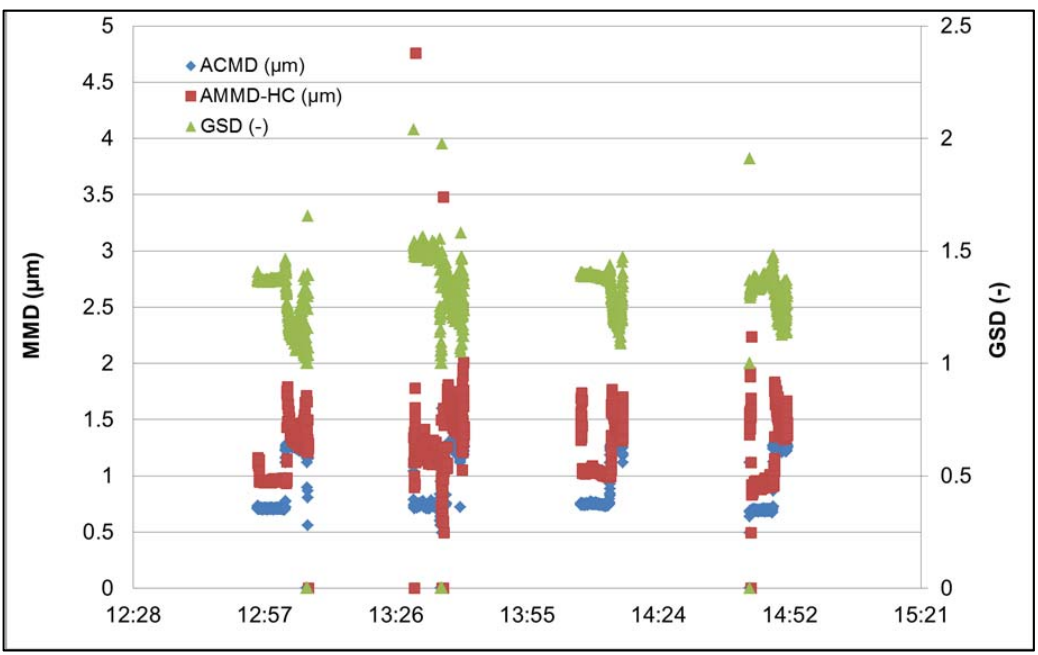


Particle size distribution: Average size during the -US /+US periods.
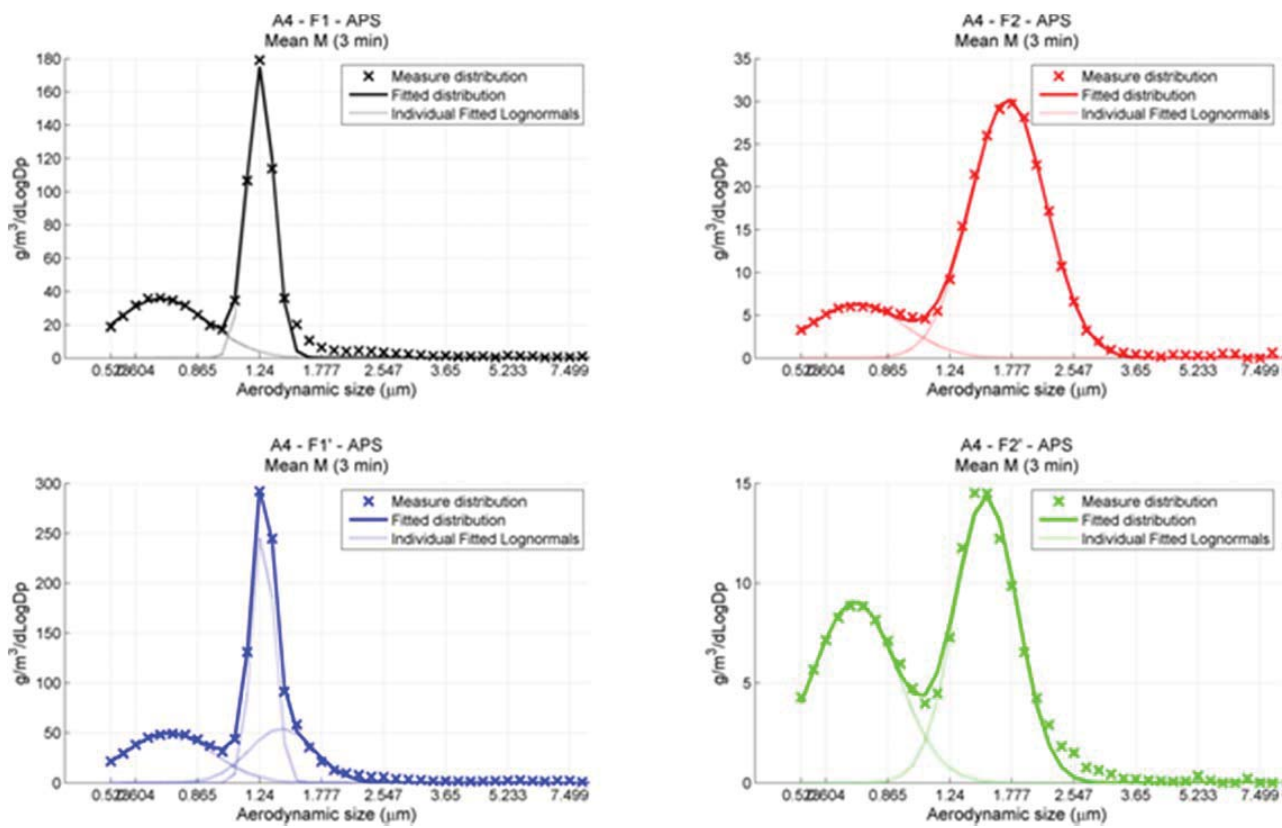


\subsection{AAA5}

This test was conducted successfully in the MSAA-PECA facility of the Laboratory of Analysis of Safety Systems (LASS). The mixture used for the test is summarized in TABLE 30.

TABLE 30 Mixture of particles

\begin{tabular}{lll}
\hline $\mathrm{SiO}_{2}$ mixture & mass $(\mathrm{g})$ & $\mathrm{X}_{\mathrm{m}}(\%)$ \\
\hline $\mathrm{dp}_{1}=\mathbf{0 . 2 8} \boldsymbol{\mu m}$ & 75.09 & 74.99 \\
$\mathrm{dp}_{2}=\mathbf{1} \boldsymbol{\mu m}$ & 25.05 & 25.01 \\
$\mathrm{dp}_{3}=\mathbf{2 . 5} \boldsymbol{\mu m}$ & 0 & 0.00 \\
\hline Total & 100.14 & \\
\hline
\end{tabular}

\subsubsection{Test stages and protocol}

\begin{tabular}{|c|c|c|c|c|c|c|}
\hline Phase 1 (-US) & Order & Action & Value & Time length & $\boldsymbol{t}_{\text {in }}$ & $t_{f}$ \\
\hline \multirow[t]{5}{*}{ Reference phase } & $1-$ & $\dot{\mathrm{m}}(\mathrm{kg} / \mathrm{h})$ & 12 & Stability & & \\
\hline & $2-$ & $\mathrm{SiO}_{2}$ injection & & Stability - $10^{\prime}$ & 11:22:40 & $11: 32: 40$ \\
\hline & & ELPI in & & & $11: 22: 40$ & \\
\hline & $3-$ & F 1 (in/out) & & $7^{\prime}$ & $11: 32: 40$ & $11: 39: 40$ \\
\hline & $4-$ & APS out & & $5^{\prime}$ & $11: 40: 00$ & 11:45:00 \\
\hline \multirow[t]{3}{*}{ Flushing phase } & $5-$ & Stop $\mathrm{SiO}_{2}$ & & & 11:45:00 & \\
\hline & & $\uparrow \dot{m}(\mathrm{~kg} / \mathrm{h})$ & 200 & & $11: 45: 30$ & \\
\hline & & APS out & & $5^{\prime}$ & 11:45:30 & 11:55:11 \\
\hline \multicolumn{7}{|l|}{ Phase 2 (+US) } \\
\hline \multirow[t]{5}{*}{ Acoustic phase } & $1-$ & $\dot{m}(\mathrm{~kg} / \mathrm{h})$ & 12 & Stability & & \\
\hline & $2-$ & $\mathrm{SiO}_{2}$ injection & & Stability - $10^{\prime}$ & 12:12:00 & $12: 20: 00$ \\
\hline & $3-$ & +US & & & 12:09:00 & \\
\hline & & F 2 (in/out) & & $7^{\prime}$ & $12: 20: 00$ & $12: 27: 00$ \\
\hline & $4-$ & APS out & & $7^{\prime}$ & 12:27:12 & 12:32:12 \\
\hline \multirow[t]{4}{*}{ Flushing phase 1} & $5-$ & Stop $\mathrm{SiO} 2$ & & & $12: 32: 12$ & \\
\hline & & -US & & & 12:33:00 & \\
\hline & & $\uparrow \dot{m}(\mathrm{~kg} / \mathrm{h})$ & 200 & & 12:33:00 & \\
\hline & & APS out & & $5^{\prime}$ & $12: 33: 00$ & $12: 38: 00$ \\
\hline Phase 1' (-US) & Order & Action & & Time & $\boldsymbol{t}_{\text {in }}$ & $t_{f}$ \\
\hline \multirow[t]{4}{*}{ Reference phase } & $1-$ & $\dot{\mathrm{m}}(\mathrm{kg} / \mathrm{h})$ & 12 & Stability & & \\
\hline & $2-$ & $\mathrm{SiO}_{2}$ injection & & Stability - $10^{\prime}$ & $12: 45: 00$ & $12: 55: 00$ \\
\hline & $3-$ & F 3 (in/out) & & $7^{\prime}$ & $12: 55: 00$ & $13: 02: 00$ \\
\hline & $4-$ & APS out & & $5^{\prime}$ & 13:02:20 & $13: 07: 20$ \\
\hline \multirow[t]{3}{*}{ Flushing phase } & $5-$ & Stop $\mathrm{SiO}_{2}$ & & & $13: 07: 20$ & \\
\hline & & $\uparrow \dot{m}(\mathrm{~kg} / \mathrm{h})$ & 200 & & 13:07:50 & \\
\hline & & APS out & & $5^{\prime}$ & 13:07:50 & 13:11:35 \\
\hline \multicolumn{7}{|l|}{ Phase 2' (+US) } \\
\hline \multirow[t]{5}{*}{ Acoustic phase } & $1-$ & $\dot{m}(\mathrm{~kg} / \mathrm{h})$ & 12 & Stability & & \\
\hline & $2-$ & $\mathrm{SiO}_{2}$ injection & & Stability - $10^{\prime}$ & 13:18:15 & 13:28:15 \\
\hline & $3-$ & +US & & & 13:18:15 & \\
\hline & & F 4 (in/out) & & $7^{\prime}$ & $13: 28: 00$ & 13:35:00 \\
\hline & $4-$ & APS out & & $3^{\prime}+$ US_2'-US_2'+US_2'-US_2'+US_2'-US & 13:35:30 & 13:48:30 \\
\hline \multirow[t]{5}{*}{ Flushing phase } & $5-$ & Stop $\mathrm{SiO} 2$ & & & $13: 49: 00$ & \\
\hline & & -US & & & 13:49:00 & \\
\hline & & $\uparrow \dot{m}(\mathrm{~kg} / \mathrm{h})$ & 200 & & 13:49:30 & \\
\hline & & APS out & & & 13:49:30 & 13:53:00 \\
\hline & & ELPI in & & & & 13:53:00 \\
\hline
\end{tabular}




\subsubsection{Summary of the test evolution}

The evolution of the main hydraulic variables is summarized in Fig. 109. They have been controlled and logged every 700ms through the PLC of the LASS.

For technical problems with the aerosol generator, all the data acquired between 11:55 and 12:15 hours is not taken into account.

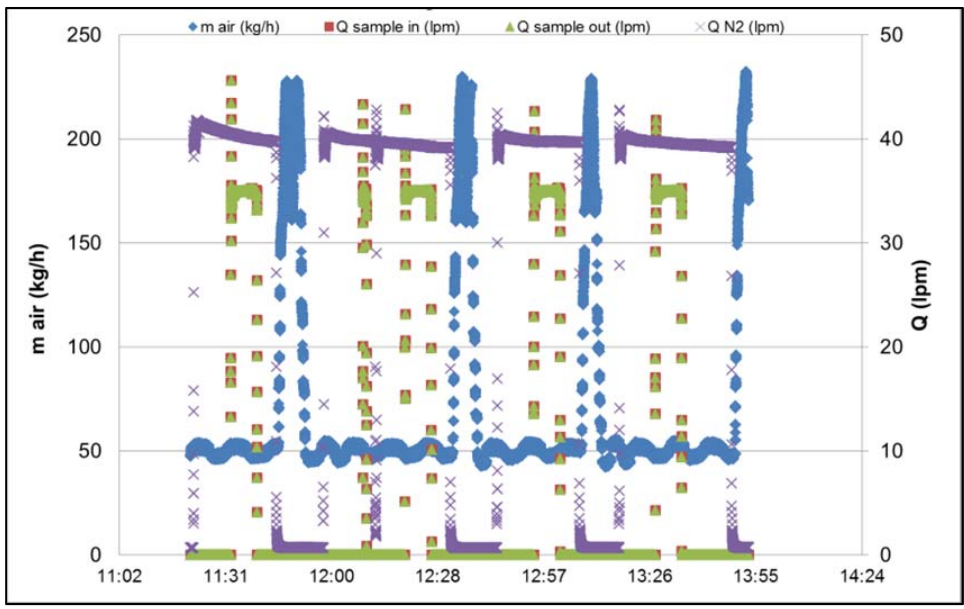

Fig. 109 Hydraulic variables evolution

\subsubsection{Particle concentration}

- Concentration evolution (APS/ELPI): Inlet/outlet: $\mathrm{N}\left(\# / \mathrm{cm}^{3}\right)$ vs time

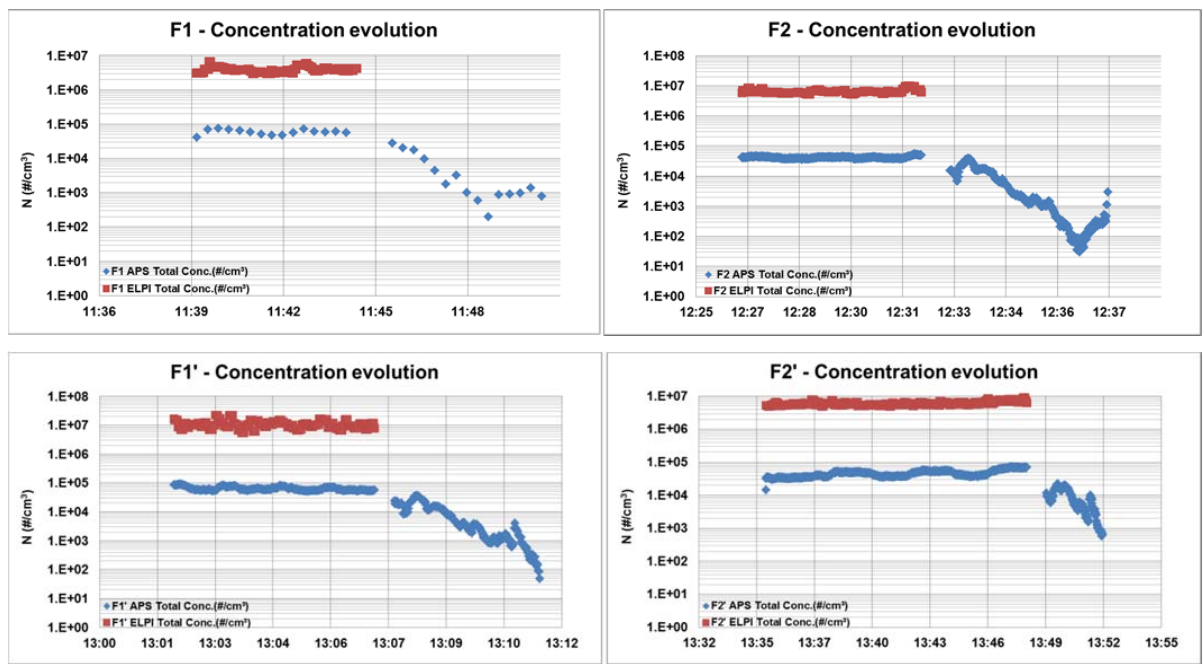


- Concentration comparison (filters)

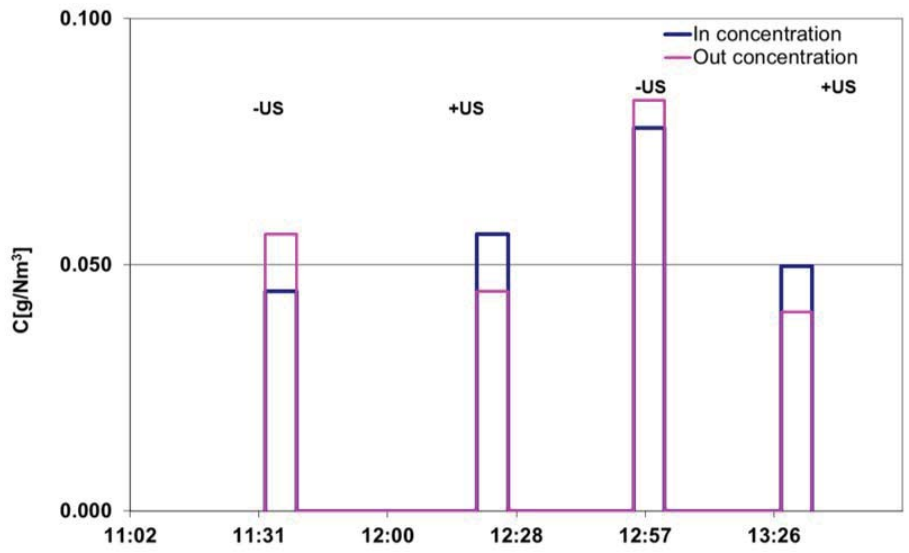

\subsubsection{Particle size}

- Particle size evolution: ACMD/AMMD and GSD.

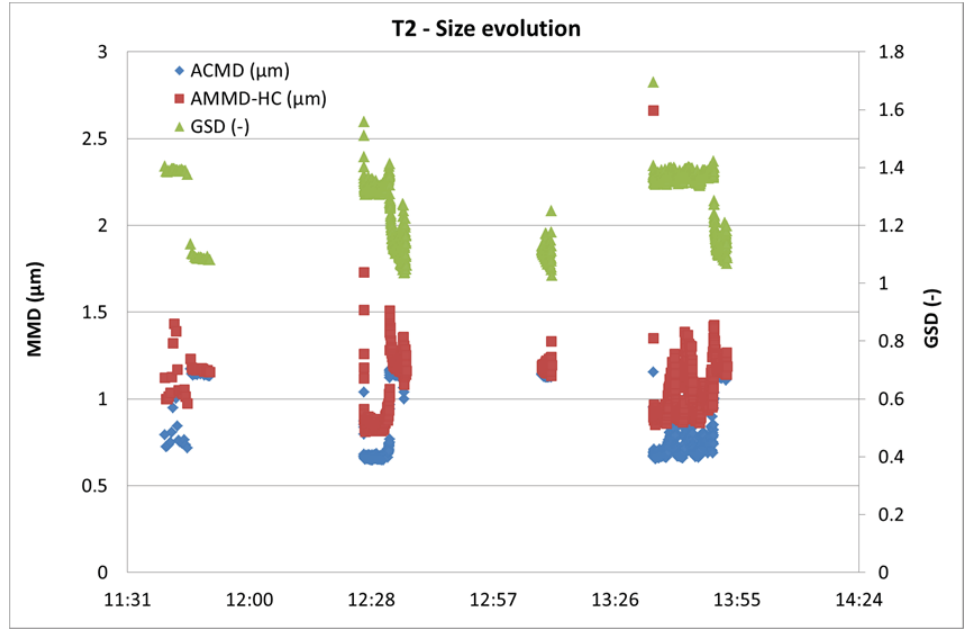


- Particle size distribution (Average size during the -US /+US periods):
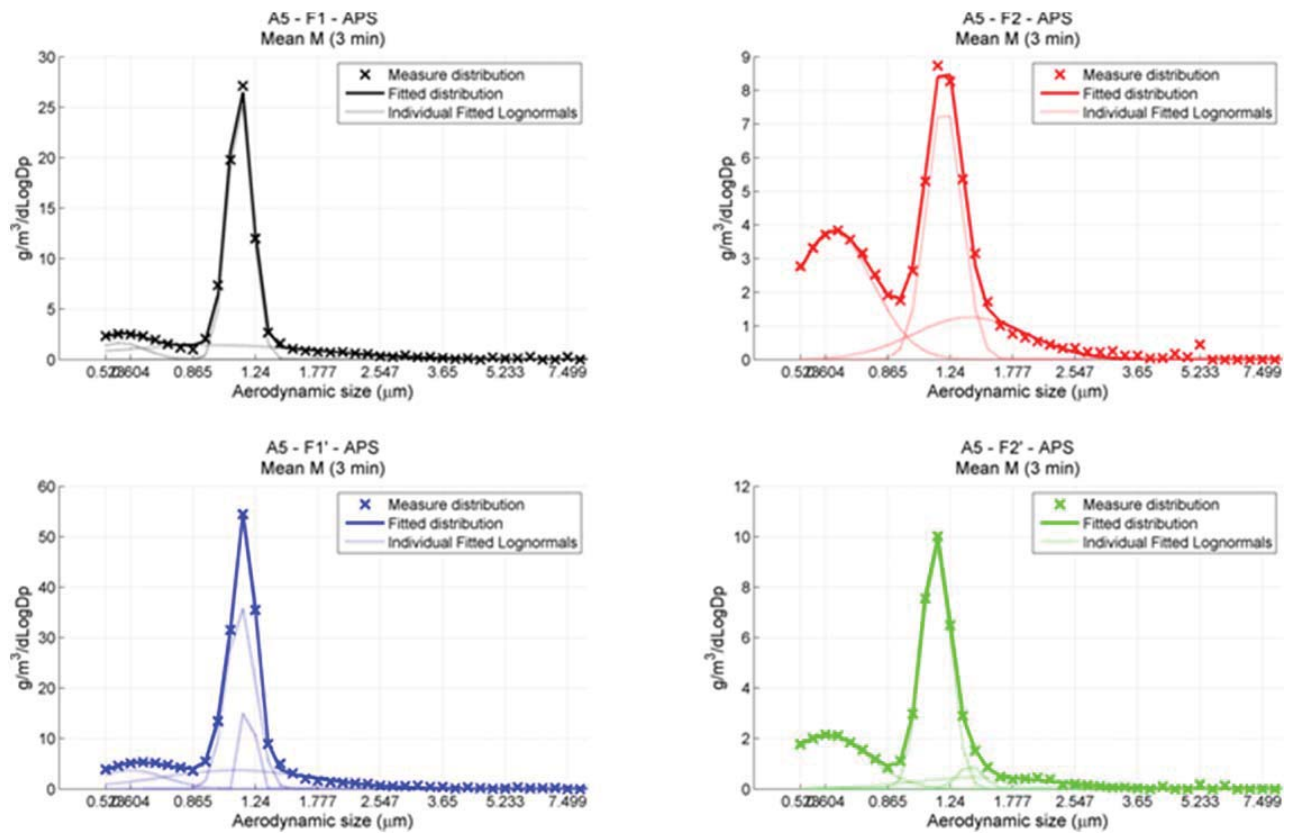


\section{6. $\mathrm{AAA6}$}

This test was conducted successfully in the MSAA-PECA facility of the Laboratory of Analysis of Safety Systems (LASS). The mixture used for the test is summarized in TABLE 31 .

TABLE 31 Mixture of particles

\begin{tabular}{lll}
\hline $\mathrm{SiO}_{2}$ mixture & mass $(\mathrm{g})$ & $\mathbf{X}_{\mathrm{m}}(\%)$ \\
\hline $\mathrm{dp}_{\mathbf{1}}=\mathbf{0 . 2 8} \boldsymbol{\mu \mathrm { m }}$ & 75 & 74.95 \\
$\mathrm{dp}_{2}=\mathbf{1} \boldsymbol{\mu \mathrm { m }}$ & 25.07 & 25.05 \\
$\mathrm{dp}_{3}=\mathbf{2 . 5} \boldsymbol{\mu \mathrm { m }}$ & 0 & 0.00 \\
\hline Total & 100.07 & 100 \\
\hline
\end{tabular}

\subsubsection{Test stages and protocol}

\begin{tabular}{|c|c|c|c|c|c|c|}
\hline Phase 1 (-US) & Order & Action & Value & Time length & $t_{\text {in }}$ & $t_{f}$ \\
\hline \multirow[t]{5}{*}{ Reference phase } & $1-$ & $\dot{\mathrm{m}}(\mathrm{kg} / \mathrm{h})$ & 12 & Stability & & \\
\hline & $2-$ & $\mathrm{SiO}_{2}$ injection & & Stability - $10^{\prime}$ & $12: 34: 35$ & $12: 45: 00$ \\
\hline & & ELPI in & & & $12: 34: 35$ & \\
\hline & $3-$ & F 1 (in/out) & & $7^{\prime}$ & $12: 45: 00$ & $12: 52: 00$ \\
\hline & $4-$ & APS out & & $5^{\prime}$ & 12:52:12 & $12: 57: 00$ \\
\hline \multirow[t]{3}{*}{ Flushing phase } & $5-$ & Stop $\mathrm{SiO} 2$ & & & $12: 57: 00$ & \\
\hline & & $\uparrow \dot{m}(\mathrm{~kg} / \mathrm{h})$ & 200 & & 12:57:40 & \\
\hline & & APS out & & $5^{\prime}$ & 12:57:40 & 13:01:40 \\
\hline \multicolumn{7}{|l|}{ Phase 2 (+US) } \\
\hline \multirow[t]{5}{*}{ Acoustic phase } & $1-$ & $\dot{\mathrm{m}}(\mathrm{kg} / \mathrm{h})$ & 12 & Stability & & \\
\hline & $2-$ & $\mathrm{SiO}_{2}$ injection & & Stability - $10^{\prime}$ & 13:07:50 & 13:23:10 \\
\hline & $3-$ & +US & & & 13:08:30 & \\
\hline & & F 2 (in/out) & & $7^{\prime}$ & $13: 17: 30$ & $13: 24: 30$ \\
\hline & $4-$ & APS out & & $7^{\prime}$ & $13: 24: 40$ & 13:29:00 \\
\hline \multirow[t]{4}{*}{ Flushing phase 1} & $5-$ & Stop $\mathrm{SiO} 2$ & & & 13:29:00 & \\
\hline & & -US & & & $13: 29: 26$ & \\
\hline & & 个mं (kg/h) & 200 & & 13:29:30 & \\
\hline & & APS out & & $5^{\prime}$ & $13: 29: 30$ & 13:33:00 \\
\hline Phase 1' (-US) & Order & Action & & Time & $t_{\text {in }}$ & $t_{f}$ \\
\hline \multirow[t]{4}{*}{ Reference phase } & $1-$ & $\dot{\mathrm{m}}(\mathrm{kg} / \mathrm{h})$ & 12 & Stability & & \\
\hline & $2-$ & $\mathrm{SiO}_{2}$ injection & & Stability - $10^{\prime}$ & 13:38:50 & $13: 48: 00$ \\
\hline & $3-$ & F 3 (in/out) & & $7^{\prime}$ & 13:48:00 & 13:55:00 \\
\hline & $4-$ & APS out & & $5^{\prime}$ & $13: 55: 30$ & $14: 00: 15$ \\
\hline \multirow[t]{3}{*}{ Flushing phase } & $5-$ & Stop $\mathrm{SiO} 2$ & & & $14: 00: 00$ & \\
\hline & & 个m் (kg/h) & 200 & & $14: 00: 20$ & \\
\hline & & APS out & & $5^{\prime}$ & $14: 00: 20$ & 14:03:30 \\
\hline \multicolumn{7}{|l|}{ Phase 2' (+US) } \\
\hline \multirow[t]{5}{*}{ Acoustic phase } & $1-$ & $\dot{\mathrm{m}}(\mathrm{kg} / \mathrm{h})$ & 12 & Stability & & \\
\hline & $2-$ & $\mathrm{SiO}_{2}$ injection & & Stability - $10^{\prime}$ & 14:13:55 & \\
\hline & $3-$ & +US & & & $14: 14: 30$ & \\
\hline & & F 4 (in/out) & & $7^{\prime}$ & $14: 22: 35$ & $14: 29: 30$ \\
\hline & $4-$ & APS out & & $5^{\prime}$ & $14: 29: 45$ & $14: 43: 00$ \\
\hline \multirow[t]{5}{*}{ Flushing phase } & $5-$ & Stop $\mathrm{SiO} 2$ & & & $14: 43: 00$ & \\
\hline & & -US & & & $14: 43: 00$ & \\
\hline & & $\uparrow \dot{m}(\mathrm{~kg} / \mathrm{h})$ & 200 & & $14: 43: 13$ & \\
\hline & & APS out & & $3^{\prime}+$ US_2'-US_2'+ & $14: 43: 13$ & $14: 46: 00$ \\
\hline & & ELPI in & & & & $14: 46: 00$ \\
\hline
\end{tabular}




\subsubsection{Summary of the test evolution}

The evolution of the main hydraulic variables is summarized in Fig. 110. They have been controlled and logged every 700ms through the PLC (Programmable Logic Controller) of the LASS.

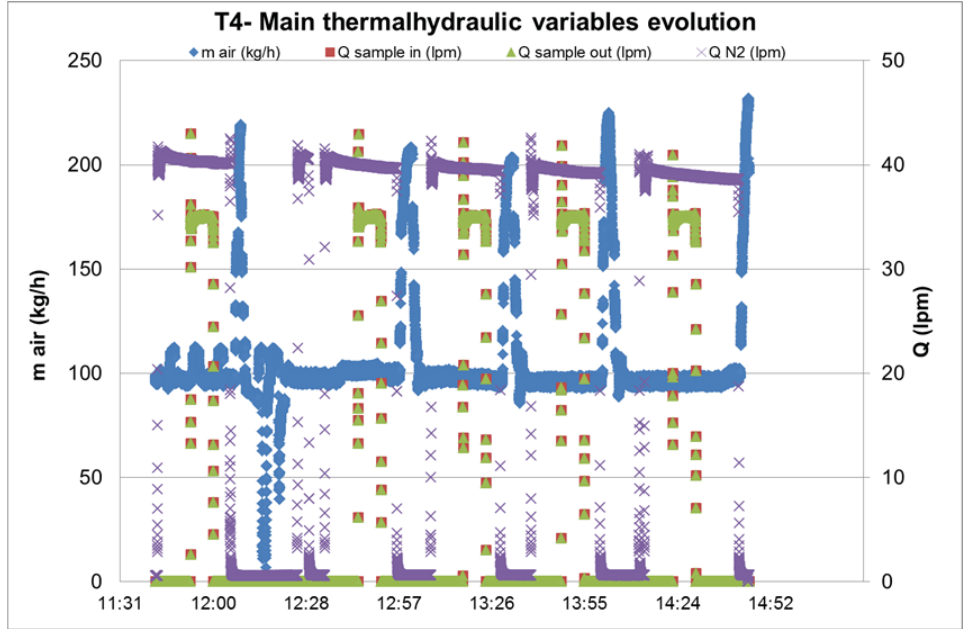

Fig. 110 Hydraulic variables evolution

\subsubsection{Particle concentration}

- Concentration evolution (APS/ELPI): Inlet/outlet: $\mathrm{N}\left(\# / \mathrm{cm}^{3}\right)$.
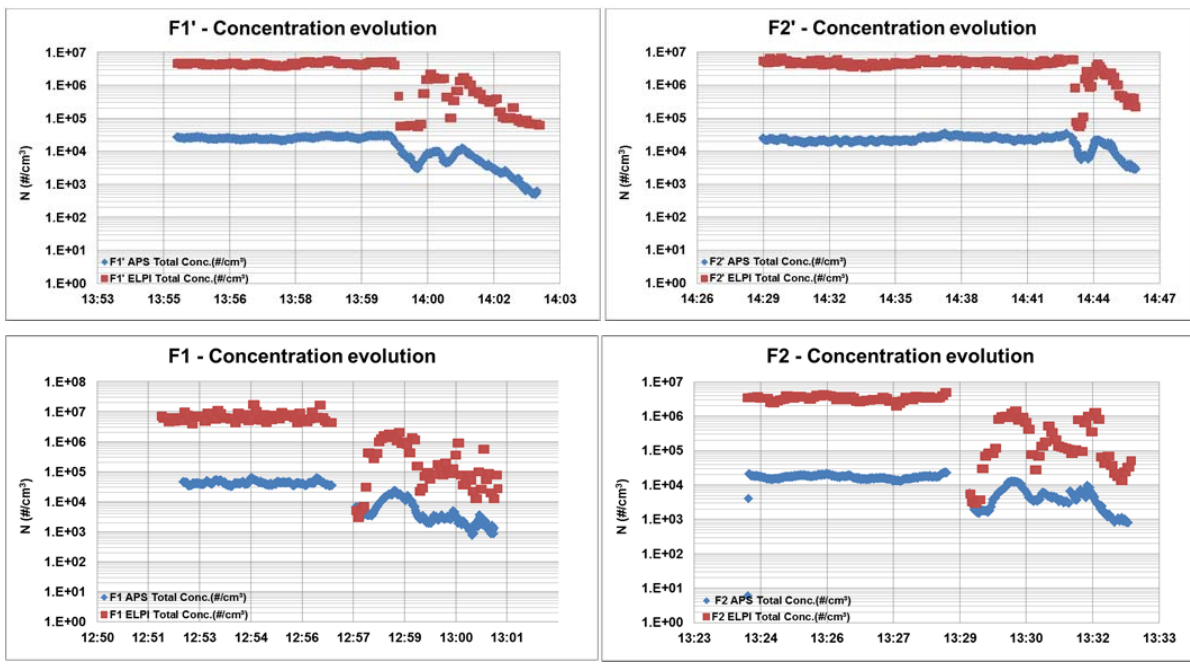
- Concentration comparison (filters)

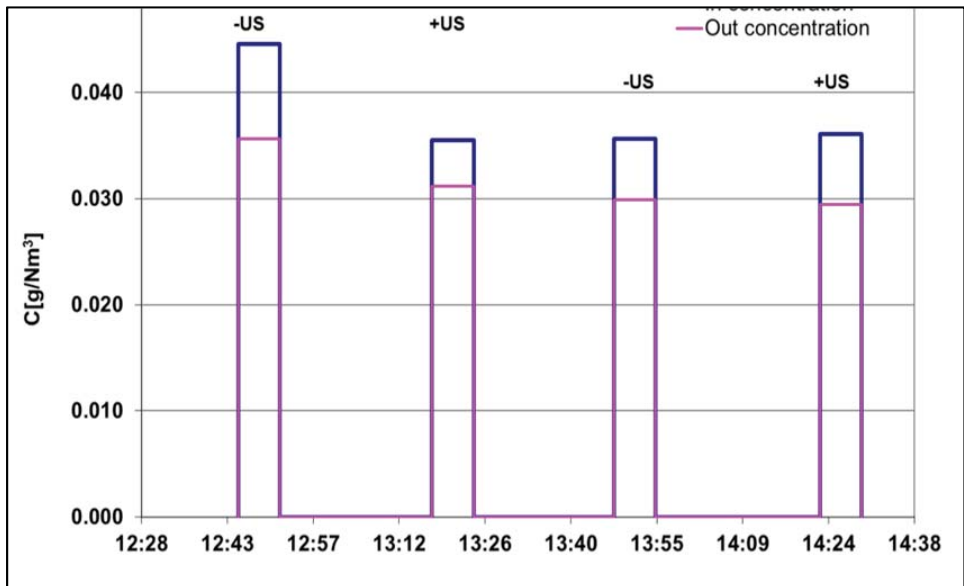

8.6.4. Particle size

- Particle size evolution: ACMD/AMMD and GSD vs time

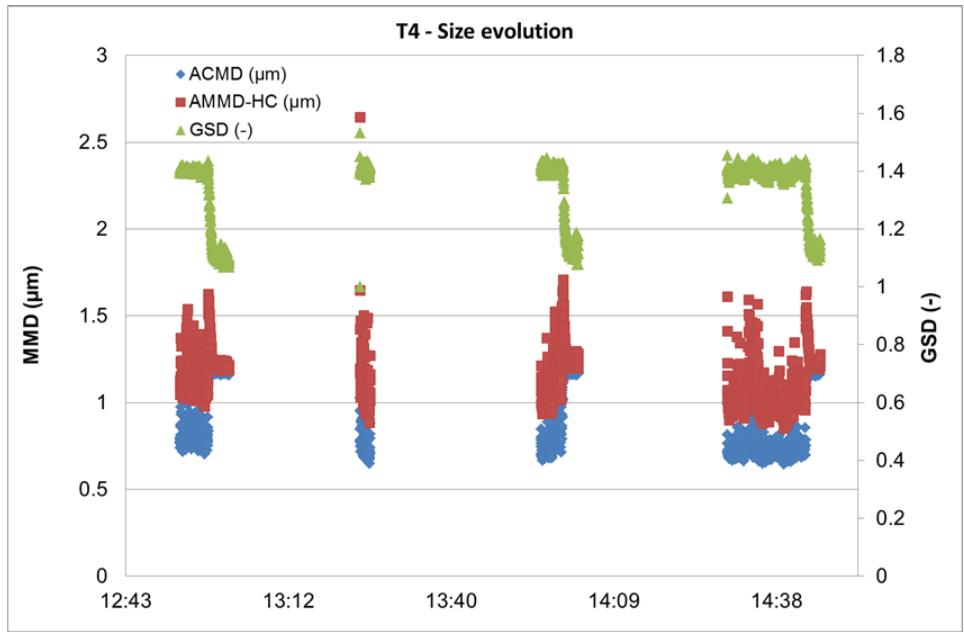


- Particle size distribution (Average size during the -US /+US periods):
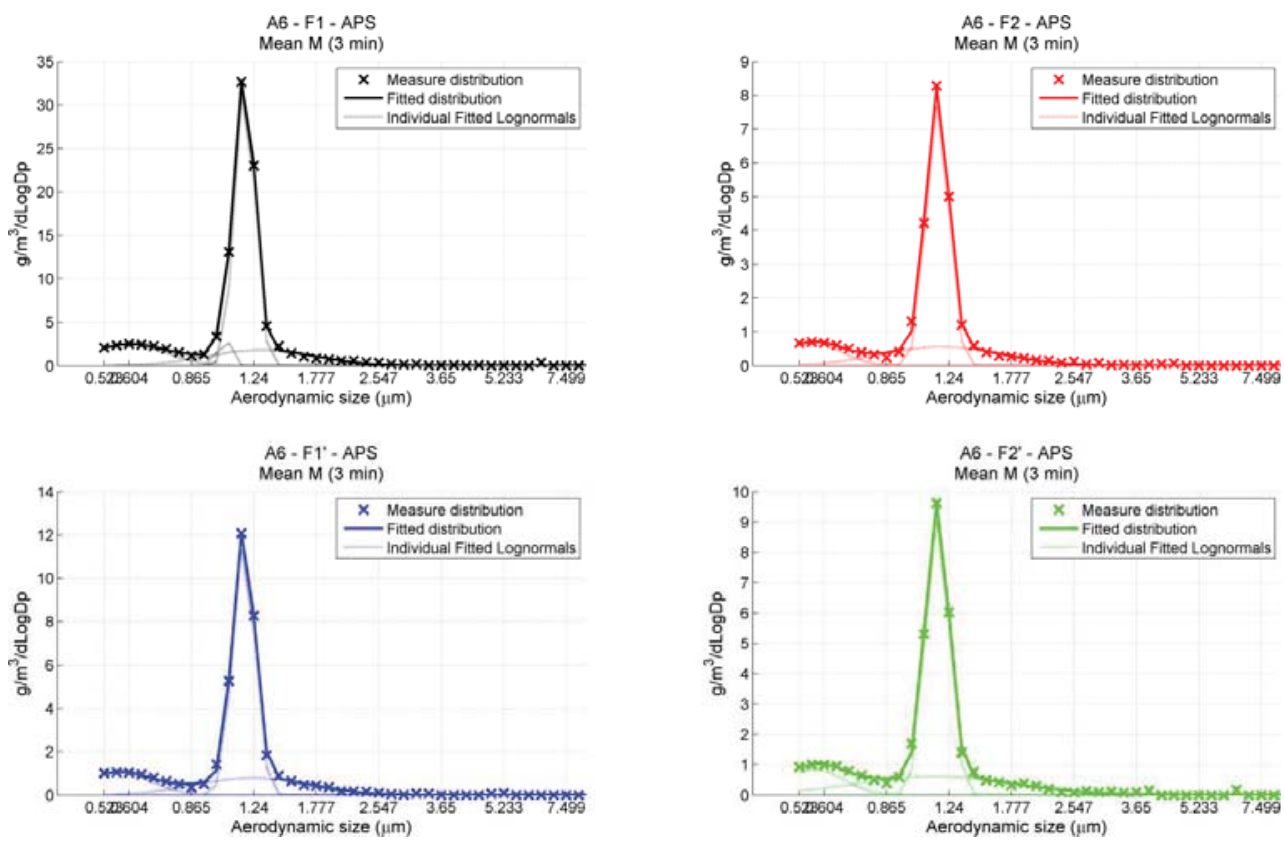


\subsection{AAA7}

This test was conducted successfully in the MSAA-PECA facility of the Laboratory of Analysis of Safety Systems (LASS). The mixture used for the test is summarized in TABLE 32.

TABLE 32 Mixture of particles

\begin{tabular}{lll}
\hline $\mathrm{SiO}_{2}$ mixture & mass $(\mathrm{g})$ & $\mathbf{X}_{\mathrm{m}}(\%)$ \\
\hline $\mathrm{dp}_{1}=\mathbf{0 . 2 8} \boldsymbol{\mu \mathrm { m }}$ & 180.15 & 90.01 \\
$\mathrm{dp}_{2}=\mathbf{1} \boldsymbol{\mu \mathrm { m }}$ & 20 & 9.99 \\
$\mathrm{dp}_{3}=\mathbf{2 . 5} \boldsymbol{\mu \mathrm { m }}$ & 0 & 0.00 \\
\hline Total & 200.15 & \\
\hline
\end{tabular}

\subsubsection{Test stages and protocol}

\begin{tabular}{|c|c|c|c|c|c|c|}
\hline Phase 1 (-US) & Order & Action & Value & Time length & $t_{\text {in }}$ & $t_{f}$ \\
\hline \multirow[t]{5}{*}{ Reference phase } & 1 - & $\dot{\mathrm{m}}(\mathrm{kg} / \mathrm{h})$ & 12 & Stability & & \\
\hline & $2-$ & $\mathrm{SiO}_{2}$ injection & & Stability - $15^{\prime}$ & 11:55:20 & 12:05:35 \\
\hline & & ELPI in & & & $12: 05: 35$ & \\
\hline & $3-$ & F 1 (in/out) & & $7^{\prime}$ & 12:05:35 & 12:12:35 \\
\hline & $4-$ & APS out & & $7^{\prime}$ & 12:13:39 & 12:18:35 \\
\hline \multirow[t]{3}{*}{ Flashing phase 1} & $5-$ & Stop SiO2 & & & 12:18:15 & \\
\hline & & $\uparrow \dot{m}(\mathrm{~kg} / \mathrm{h})$ & 200 & & $12: 19: 00$ & \\
\hline & & APS out & & $5^{\prime}$ & 12:19:00 & $12: 24: 00$ \\
\hline \multicolumn{7}{|l|}{ Phase 2 (+US) } \\
\hline \multirow[t]{5}{*}{ Acoustic phase } & $1-$ & $\dot{\mathrm{m}}(\mathrm{kg} / \mathrm{h})$ & 12 & Stability & & \\
\hline & $2-$ & $\mathrm{SiO}_{2}$ injection & & Stability - $15^{\prime}$ & 13:31:00 & 13:41:00 \\
\hline & $3-$ & +US & & & 13:32:18 & \\
\hline & & F 2 (in/out) & & $7^{\prime}$ & $13: 41: 00$ & $13: 48: 00$ \\
\hline & $4-$ & APS out & & $7^{\prime}$ & 13:48:12 & $13: 53: 00$ \\
\hline \multirow[t]{4}{*}{ Flashing phase 1} & $5-$ & Stop $\mathrm{SiO} 2$ & & & 13:53:00 & \\
\hline & & -US & & & 13:53:00 & \\
\hline & & $\uparrow \dot{m}(\mathrm{~kg} / \mathrm{h})$ & 200 & & $13: 53: 45$ & \\
\hline & & APS out & & $5^{\prime}$ & 13:53:45 & $13: 56: 30$ \\
\hline Phase 1' (-US) & Order & Action & & Time & $t_{\text {in }}$ & $t_{f}$ \\
\hline \multirow[t]{4}{*}{ Reference phase } & 1 - & $\dot{m}(\mathrm{~kg} / \mathrm{h})$ & 12 & Stability & & \\
\hline & $2-$ & $\mathrm{SiO}_{2}$ injection & & Stability - $15^{\prime}$ & 14:03:05 & 14:13:05 \\
\hline & 3- & F 3 (in/out) & & $7^{\prime}$ & $14: 13: 21$ & 14:20:05 \\
\hline & 4- & APS out & & $7^{\prime}$ & $14: 20: 27$ & $14: 26: 20$ \\
\hline \multirow[t]{3}{*}{ Flashing phase 1} & $5-$ & Stop $\mathrm{SiO} 2$ & & & $14: 26: 20$ & \\
\hline & & $\uparrow \dot{m}(\mathrm{~kg} / \mathrm{h})$ & 200 & & $14: 26: 45$ & \\
\hline & & APS out & & $5^{\prime}$ & $14: 26: 45$ & $14: 28: 40$ \\
\hline \multicolumn{7}{|l|}{ Phase 2' (+US) } \\
\hline \multirow[t]{5}{*}{ Acoustic phase } & $1-$ & $\dot{\mathrm{m}}(\mathrm{kg} / \mathrm{h})$ & 12 & Stability & & \\
\hline & $2-$ & $\mathrm{SiO}_{2}$ injection & & Stability - $15^{\prime}$ & $14: 42: 30$ & $14: 52: 30$ \\
\hline & $3-$ & +US & & & $14: 44: 13$ & \\
\hline & & F 4 (in/out) & & $7^{\prime}$ & $14: 52: 30$ & $14: 59: 30$ \\
\hline & $4-$ & APS out & & 7 & $15: 00: 00$ & $15: 12: 00$ \\
\hline \multirow[t]{5}{*}{ Flashing phase 1} & $5-$ & Stop SiO2 & & & $15: 12: 00$ & \\
\hline & & -US & & & $15: 12: 00$ & \\
\hline & & $\uparrow \dot{m}(\mathrm{~kg} / \mathrm{h})$ & 200 & & $15: 12: 50$ & \\
\hline & & APS out & & $5^{\prime}$ & $15: 12: 00$ & $15: 14: 00$ \\
\hline & & ELPI in & & & & $15: 14: 00$ \\
\hline
\end{tabular}




\subsubsection{Summary of the test evolution}

The evolution of the main hydraulic variables is summarized in Fig. 111. They have been controlled and logged every 700ms through the PLC of the LASS.

The first time that was reproduced "Phase 2" the current of the generator was lost. This phase was repeated, and as consequence all the data acquired between 12:30 and 13:00 hours is not taken into account.

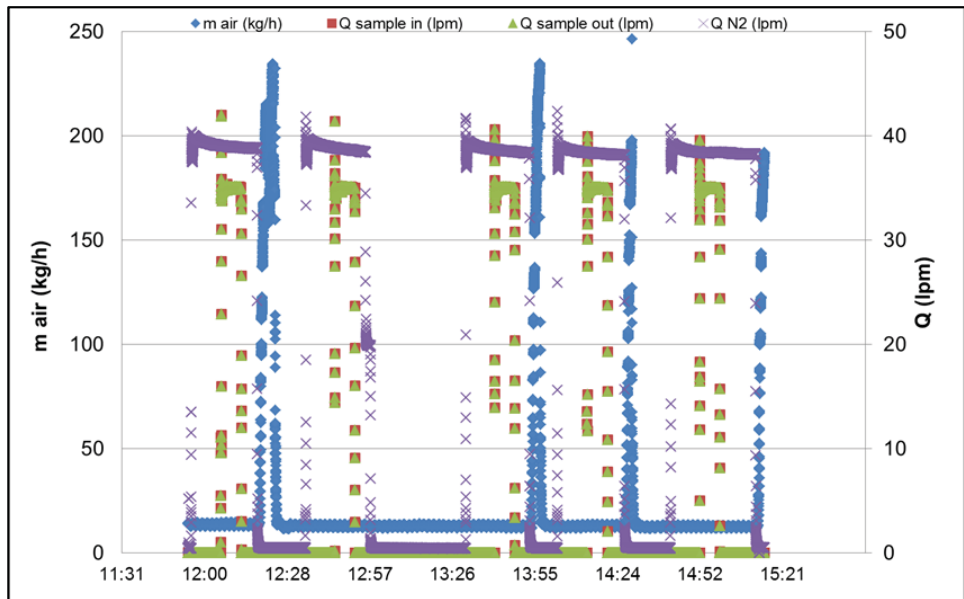

Fig. 111 Hydraulic variables evolution

\subsubsection{Particle concentration}

- Concentration evolution (APS/ELPI): Inlet/outlet: $\mathrm{N}\left(\# / \mathrm{cm}^{3}\right)$ vs time
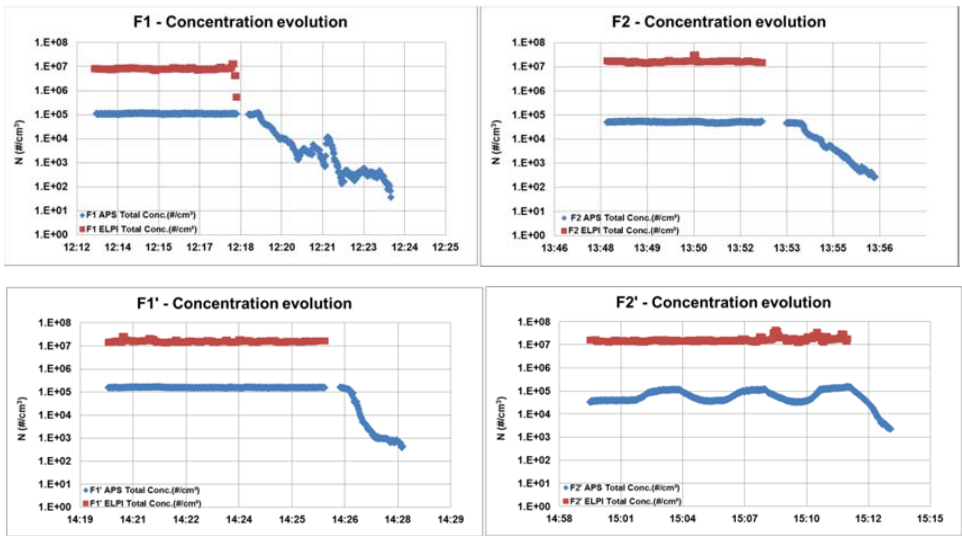
- Concentration comparison (filters)

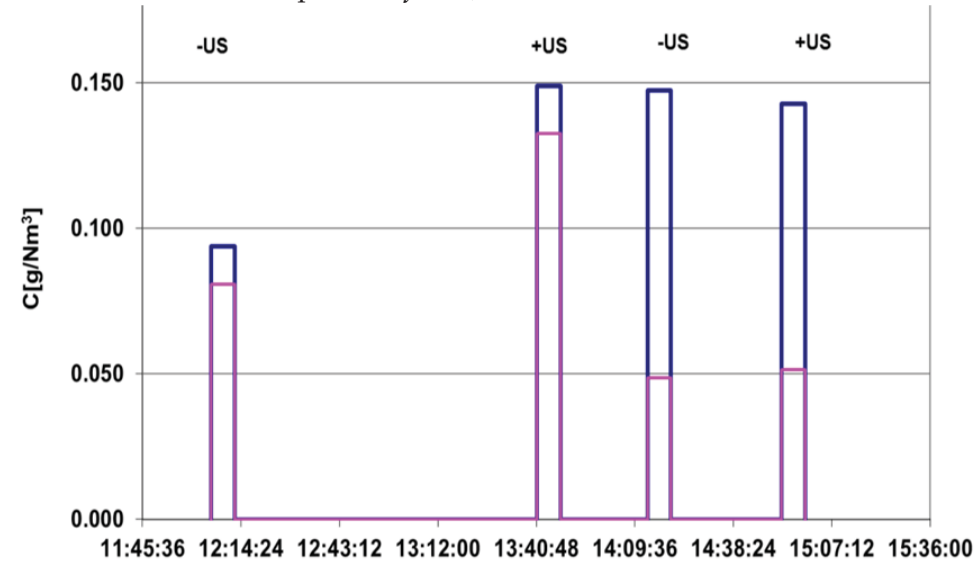

\subsubsection{Particle size}

- Particle size evolution: ACMD/AMMD and GSD vs time

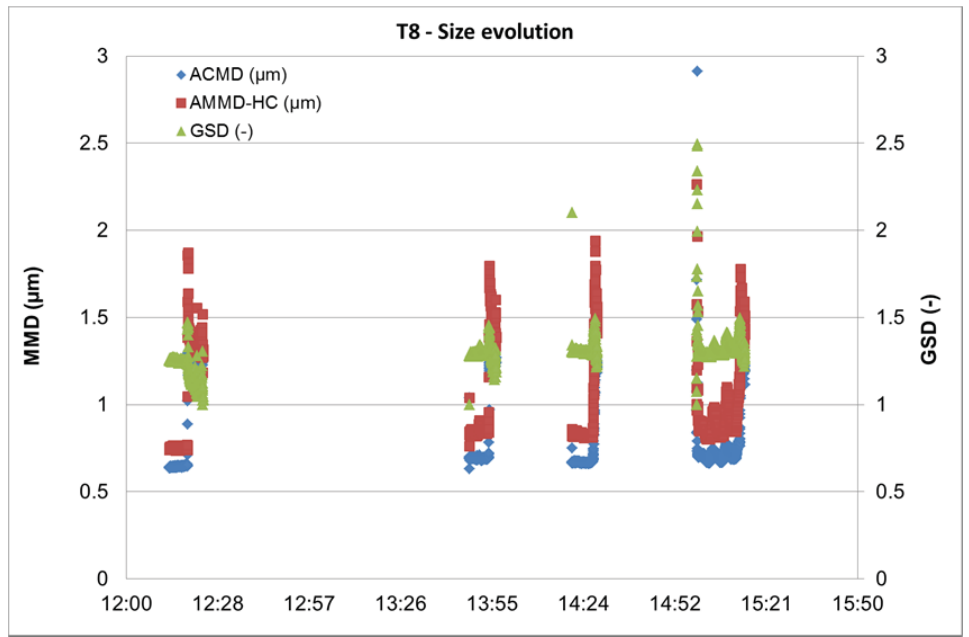


Appendix 8

238

- $\quad$ Particle size distribution (Average size during the -US / +US periods):
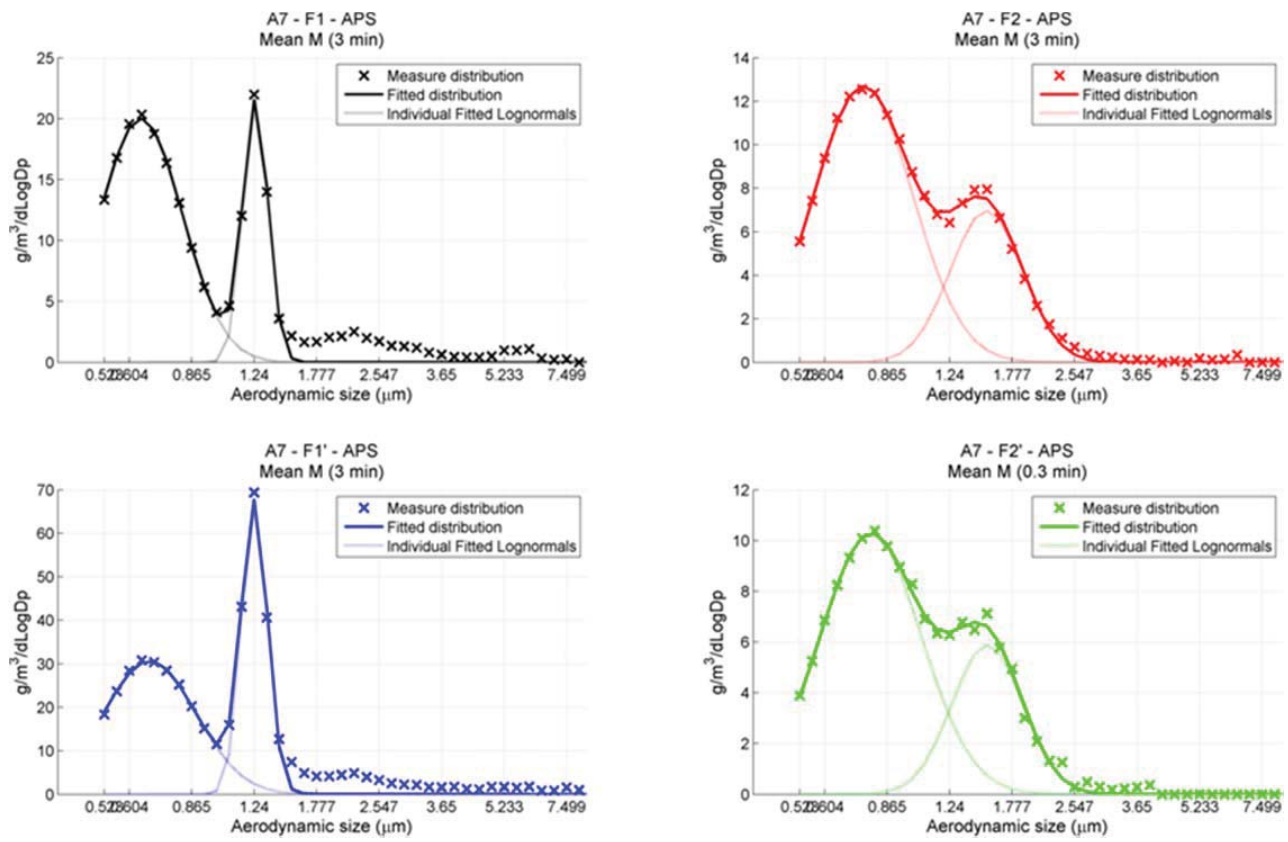


\section{8. $\mathrm{AAA} 8$}

This test was conducted successfully in the MSAA-PECA facility of the Laboratory of Analysis of Safety Systems (LASS). The mixture used for the test and the boundary conditions are summarized in TABLE 33.

TABLE 33 Mixture of particles

\begin{tabular}{lll}
\hline $\mathrm{SiO}_{2}$ mixture & mass $(\mathrm{g})$ & $\mathbf{X}_{\mathrm{m}}(\%)$ \\
\hline $\mathrm{dp}_{\mathbf{1}}=\mathbf{0 . 2 8} \boldsymbol{\mu m}$ & 0 & 0.00 \\
$\mathrm{dp}_{2}=\mathbf{1} \boldsymbol{\mu \mathrm { m }}$ & 75.25 & 74.99 \\
$\mathrm{dp}_{3}=\mathbf{2 . 5} \boldsymbol{\mu m}$ & 25.1 & 25.01 \\
\hline Total & 100.35 & \\
\hline
\end{tabular}

\subsubsection{Test stages and protocol}

\begin{tabular}{|c|c|c|c|c|c|c|}
\hline Phase 1 (-US) & Order & Action & Value & Time length & $t_{\text {in }}$ & $\boldsymbol{t}_{f}$ \\
\hline \multirow[t]{5}{*}{ Reference phase } & $1-$ & $\dot{\mathrm{m}}(\mathrm{kg} / \mathrm{h})$ & 12 & Stability & & \\
\hline & $2-$ & $\mathrm{SiO}_{2}$ injection & & Stability - $10^{\prime}$ & 11:15:20 & $11: 25: 20$ \\
\hline & & ELPI in & & & $11: 15: 20$ & \\
\hline & $3-$ & F 1 (in/out) & & $7^{\prime}$ & $11: 25: 20$ & $11: 32: 20$ \\
\hline & $4-$ & APS out & & $5^{\prime}$ & 11:32:30 & $11: 37: 30$ \\
\hline \multirow[t]{3}{*}{ Flushing phase } & $5-$ & Stop $\mathrm{SiO} 2$ & & & $11: 37: 30$ & \\
\hline & & $\uparrow \dot{m}(\mathrm{~kg} / \mathrm{h})$ & 200 & & 11:17:55 & \\
\hline & & APS out & & $5^{\prime}$ & 11:38:00 & $11: 42: 00$ \\
\hline \multicolumn{7}{|l|}{ Phase 2 (+US) } \\
\hline \multirow[t]{5}{*}{ Acoustic phase } & $1-$ & $\dot{m}(\mathrm{~kg} / \mathrm{h})$ & 12 & Stability & & \\
\hline & $2-$ & $\mathrm{SiO}_{2}$ injection & & Stability - $10^{\prime}$ & $11: 48: 40$ & $11: 58: 40$ \\
\hline & $3-$ & +US & & & $11: 48: 55$ & \\
\hline & & F 2 (in/out) & & $7^{\prime}$ & $11: 58: 45$ & $12: 05: 45$ \\
\hline & $4-$ & APS out & & $7^{\prime}$ & 12:05:55 & 12:11:00 \\
\hline \multirow[t]{4}{*}{ Flushing phase 1} & $5-$ & Stop $\mathrm{SiO} 2$ & & & 12:11:00 & \\
\hline & & -US & & & $12: 11: 25$ & \\
\hline & & $\uparrow \dot{m}(\mathrm{~kg} / \mathrm{h})$ & 200 & & 12:11:40 & \\
\hline & & APS out & & $5^{\prime}$ & 12:11:40 & 12: $15: 00$ \\
\hline Phase 1' (-US) & Order & Action & & Time & $t_{i n}$ & $t_{f}$ \\
\hline \multirow[t]{4}{*}{ Reference phase } & $1-$ & $\dot{\mathrm{m}}(\mathrm{kg} / \mathrm{h})$ & 12 & Stability & & \\
\hline & $2-$ & $\mathrm{SiO}_{2}$ injection & & Stability - $10^{\prime}$ & 12:22:15 & $12: 32: 00$ \\
\hline & $3-$ & F 3 (in/out) & & $7^{\prime}$ & $12: 32: 00$ & 12:39:00 \\
\hline & $4-$ & APS out & & $5^{\prime}$ & 12:39:10 & $12: 44: 30$ \\
\hline \multirow[t]{3}{*}{ Flushing phase } & $5-$ & Stop $\mathrm{SiO} 2$ & & & $12: 44: 30$ & \\
\hline & & $\uparrow \dot{m}(\mathrm{~kg} / \mathrm{h})$ & 200 & & $12: 44: 55$ & \\
\hline & & APS out & & $5^{\prime}$ & $12: 45: 00$ & 12:50:15 \\
\hline \multicolumn{7}{|l|}{ Phase 2' (+US) } \\
\hline \multirow[t]{5}{*}{ Acoustic phase } & $1-$ & $\dot{\mathrm{m}}(\mathrm{kg} / \mathrm{h})$ & 12 & Stability & & \\
\hline & $2-$ & $\mathrm{SiO}_{2}$ injection & & Stability - $10^{\prime}$ & 12:56:20 & 13:05:00 \\
\hline & $3-$ & +US & & & $12: 56: 45$ & \\
\hline & & F 4 (in/out) & & $7^{\prime}$ & 13:05:00 & 13:12:00 \\
\hline & 4- & APS out & & 3'+US_2'-US_2'+US_2'-US_2'+US_2'-US & 13:12:10 & $13: 25: 00$ \\
\hline \multirow[t]{5}{*}{ Flushing phase } & $5-$ & Stop $\mathrm{SiO} 2$ & & & $13: 25: 00$ & \\
\hline & & -US & & & 13:23:00 & \\
\hline & & $\uparrow \dot{m}(\mathrm{~kg} / \mathrm{h})$ & 200 & & $13: 25: 30$ & \\
\hline & & APS out & & & $13: 25: 30$ & $13: 29: 00$ \\
\hline & & ELPI in & & & & 13:29:30 \\
\hline
\end{tabular}




\subsubsection{Summary of the test evolution}

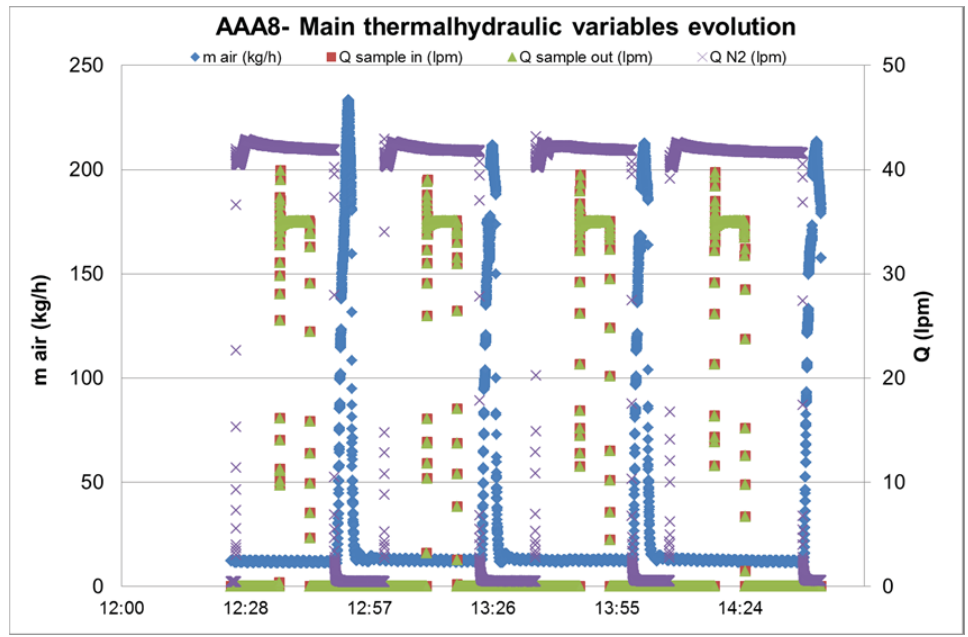

\subsubsection{Particle concentration}

- Concentration evolution (APS/ELPI): Inlet/outlet: $\mathrm{N}\left(\# / \mathrm{cm}^{3}\right)$

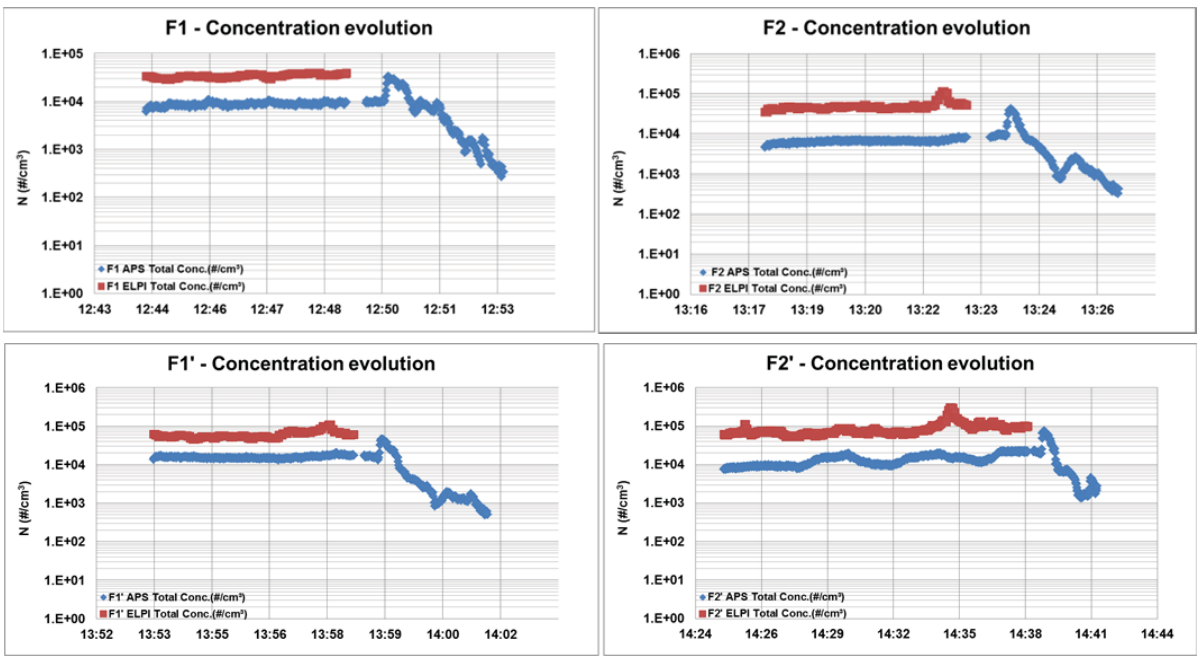


- Concentration comparison (filters)

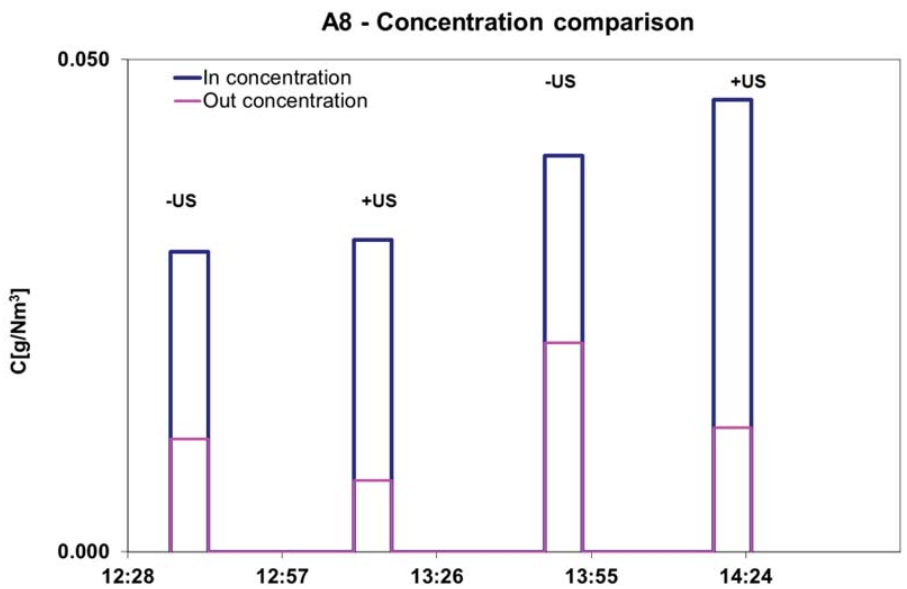

8.8.4. Particle size

- Particle size evolution: ACMD/AMMD and GSD

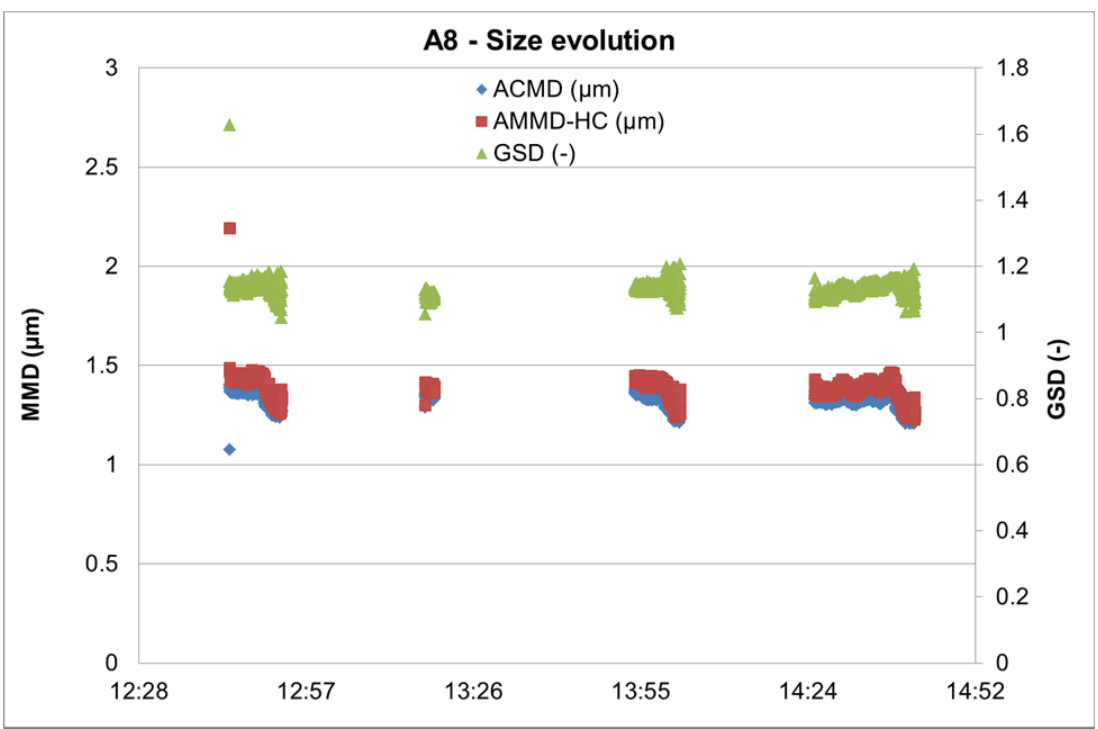


- $\quad$ Particle size distribution (Average size during the -US /+US periods):
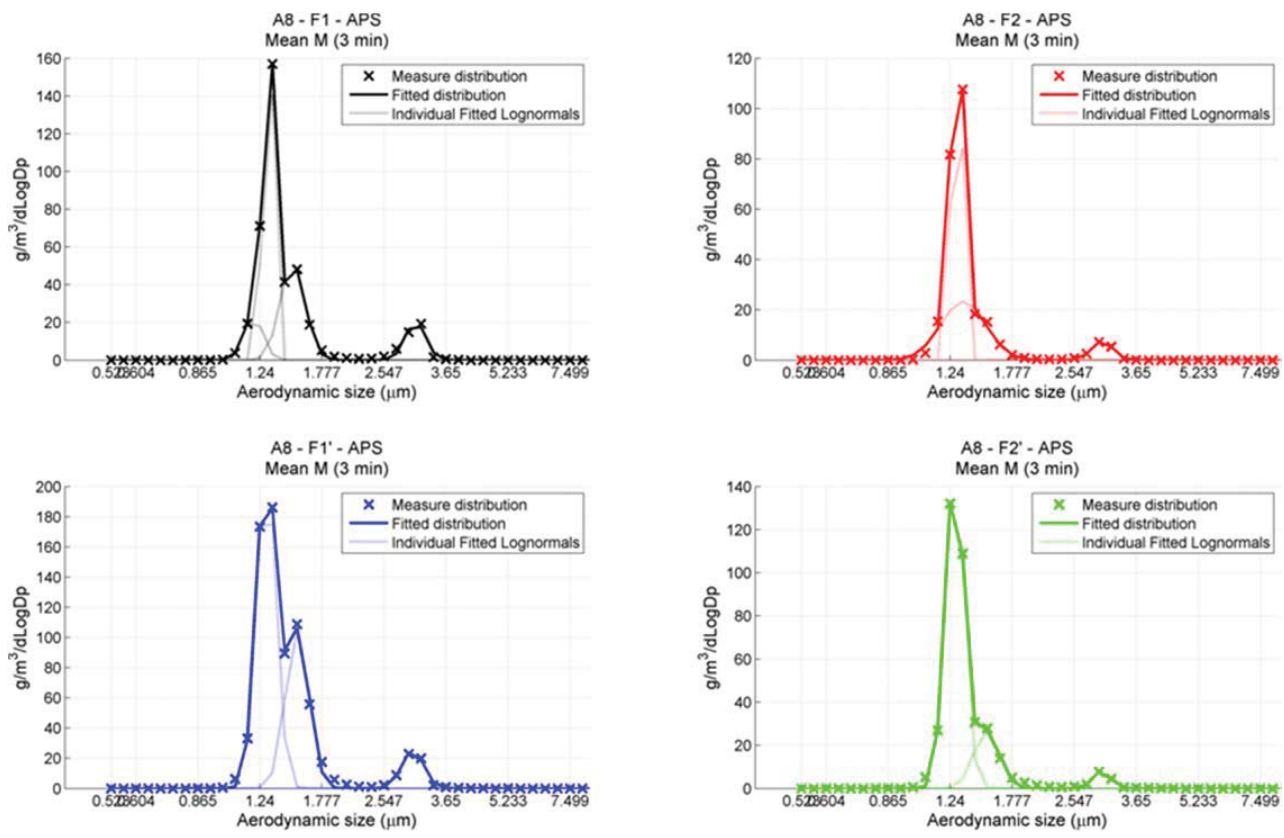


\subsection{AAA9}

This test was conducted successfully in the MSAA-PECA facility of the Laboratory of Analysis of Safety Systems (LASS). The mixture used for the test is summarized in TABLE 34.

TABLE 34 Mixture of particles

\begin{tabular}{lll}
\hline $\mathrm{SiO}_{2}$ mixture & mass $(\mathrm{g})$ & $\mathbf{X}_{\mathrm{m}}(\%)$ \\
\hline $\mathrm{dp}_{\mathbf{1}}=\mathbf{0 . 2 8} \boldsymbol{\mu \mathrm { m }}$ & 50.03 & 49.96 \\
$\mathrm{dp}_{2}=\mathbf{1} \boldsymbol{\mu \mathrm { m }}$ & 30.04 & 30.00 \\
$\mathrm{dp}_{3}=\mathbf{2 . 5} \boldsymbol{\mu m}$ & 20.08 & 20.05 \\
\hline Total & 100.1 & \\
\hline
\end{tabular}

\subsubsection{Test stages and protocol}

\begin{tabular}{|c|c|c|c|c|c|c|}
\hline Phase 1 (-US) & Order & Action & Value & Time length & $t_{\text {in }}$ & $t_{f}$ \\
\hline \multirow[t]{5}{*}{ Reference phase } & $1-$ & $\dot{\mathrm{m}}(\mathrm{kg} / \mathrm{h})$ & 12 & Stability & & \\
\hline & $2-$ & $\mathrm{SiO}_{2}$ injection & & Stability - 10' & 11:51:30 & 12:01:30 \\
\hline & & ELPI in & & & $11: 51: 30$ & \\
\hline & $3-$ & F 1 (in/out) & & $7^{\prime}$ & $12: 01: 33$ & $12: 08: 33$ \\
\hline & $4-$ & APS out & & $5^{\prime}$ & 12:08:40 & 12:14:30 \\
\hline \multirow[t]{3}{*}{ Flushing phase } & $5-$ & Stop SiO2 & & & $12: 14: 30$ & \\
\hline & & $\uparrow \dot{m}(\mathrm{~kg} / \mathrm{h})$ & 200 & & $12: 15: 20$ & \\
\hline & & APS out & & $5^{\prime}$ & $12: 15: 20$ & 12: $18: 40$ \\
\hline \multicolumn{7}{|l|}{ Phase 2 (+US) } \\
\hline \multirow[t]{5}{*}{ Acoustic phase } & $1-$ & $\dot{\mathrm{m}}(\mathrm{kg} / \mathrm{h})$ & 12 & Stability & & \\
\hline & $2-$ & $\mathrm{SiO}_{2}$ injection & & Stability - 10' & $12: 24: 05$ & 12:34:05 \\
\hline & $3-$ & +US & & & $12: 24: 20$ & \\
\hline & & F 2 (in/out) & & $7^{\prime}$ & 12:34:05 & 12:41:05 \\
\hline & $4-$ & APS out & & $7^{\prime}$ & 12:41:15 & 12:46:15 \\
\hline \multirow[t]{4}{*}{ Flushing phase 1} & $5-$ & Stop $\mathrm{SiO} 2$ & & & $12: 46: 15$ & \\
\hline & & -US & & & $12: 46: 19$ & \\
\hline & & $\uparrow \dot{m}(\mathrm{~kg} / \mathrm{h})$ & 200 & & $12: 46: 50$ & \\
\hline & & APS out & & $5^{\prime}$ & $12: 46: 50$ & 12:50:13 \\
\hline Phase 1' (-US) & Order & Action & & Time & $t_{\text {in }}$ & $t_{f}$ \\
\hline \multirow[t]{4}{*}{ Reference phase } & $1-$ & $\dot{\mathrm{m}}(\mathrm{kg} / \mathrm{h})$ & 12 & Stability & & \\
\hline & $2-$ & $\mathrm{SiO}_{2}$ injection & & Stability - $10^{\prime}$ & $12: 55: 55$ & 13:06:05 \\
\hline & $3-$ & F 3 (in/out) & & $7^{\prime}$ & 13:06:05 & 13:13:05 \\
\hline & $4-$ & APS out & & $5^{\prime}$ & 13:13:15 & 13:18:15 \\
\hline \multirow[t]{3}{*}{ Flushing phase } & $5-$ & Stop SiO2 & & & 13:18:15 & \\
\hline & & $\uparrow \dot{m}(\mathrm{~kg} / \mathrm{h})$ & 200 & & 13:19:00 & \\
\hline & & APS out & & $5^{\prime}$ & 13:19:00 & 13:22:10 \\
\hline \multicolumn{7}{|l|}{ Phase 2' (+US) } \\
\hline \multirow[t]{5}{*}{ Acoustic phase } & $1-$ & $\dot{\mathrm{m}}(\mathrm{kg} / \mathrm{h})$ & 12 & Stability & & \\
\hline & $2-$ & $\mathrm{SiO}_{2}$ injection & & Stability - 10' & $13: 27: 50$ & 13:38:15 \\
\hline & $3-$ & +US & & & 13:38:15 & \\
\hline & & F 4 (in/out) & & $7^{\prime}$ & 13:38:15 & 13:45:15 \\
\hline & $4-$ & APS out & & $3^{\prime}+$ US_2'-US_2'+US_2'-US_2'+US_2'-US & 13:48:30 & $14: 00: 30$ \\
\hline \multirow[t]{5}{*}{ Flushing phase } & $5-$ & Stop $\mathrm{SiO} 2$ & & & 14:00:30 & \\
\hline & & -US & & & 13:59:30 & \\
\hline & & $\uparrow \dot{m}(\mathrm{~kg} / \mathrm{h})$ & 200 & & $14: 01: 00$ & \\
\hline & & APS out & & & 14:01:00 & 14:06:00 \\
\hline & & ELPI in & & & & 14:06:00 \\
\hline
\end{tabular}




\subsubsection{Summary of the test evolution}

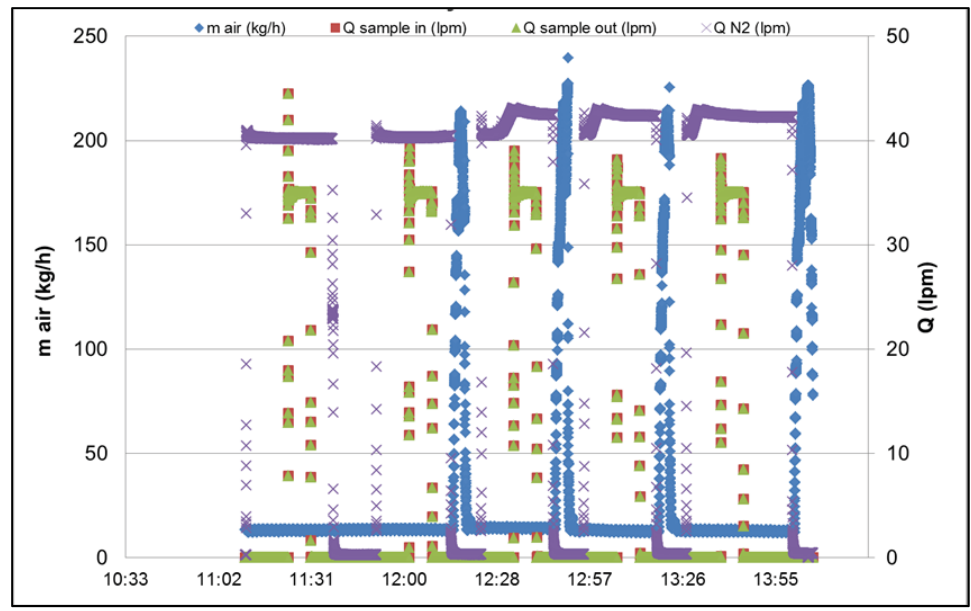

\subsubsection{Particle concentration}

- Concentration evolution (APS/ELPI): Inlet/outlet: $\mathrm{N}\left(\# / \mathrm{cm}^{3}\right)$
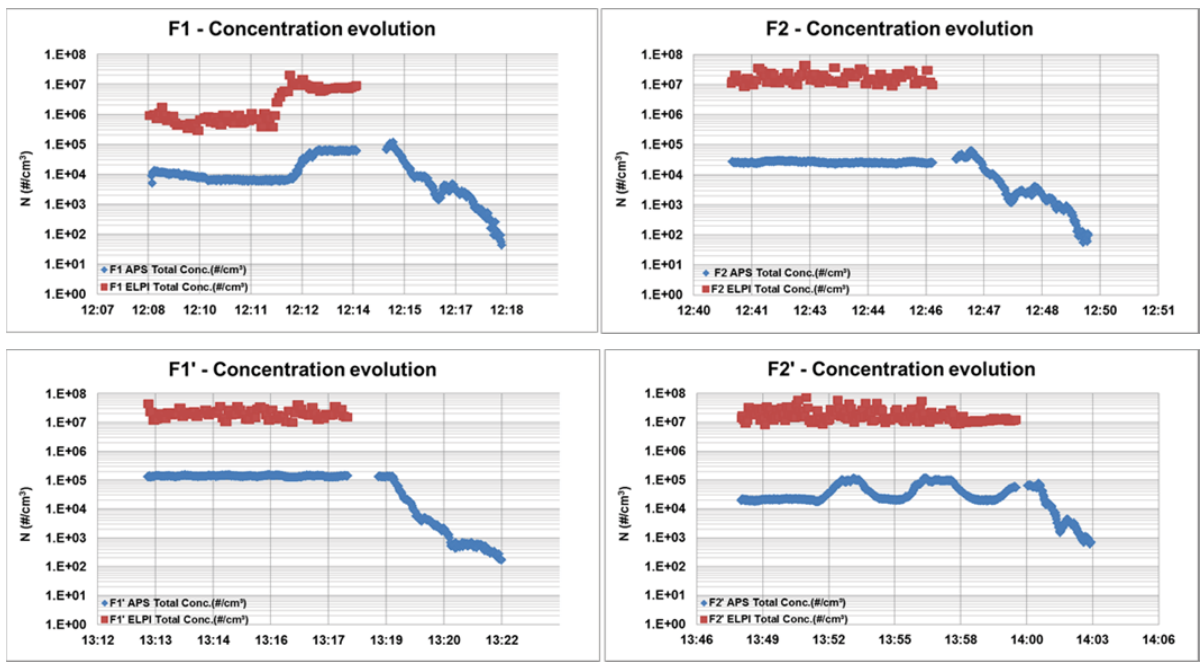
- Concentration comparison (filters)

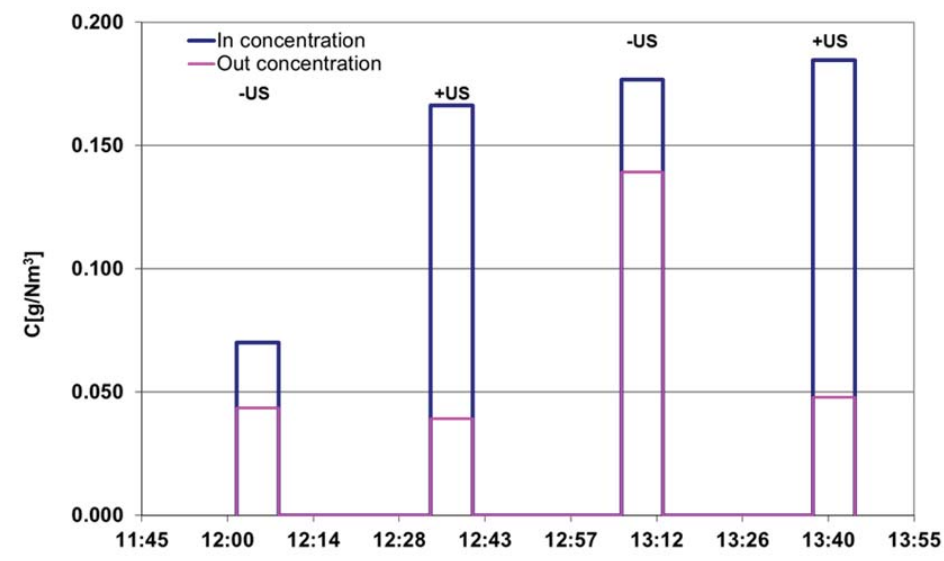

\subsubsection{Particle size}

- Particle size evolution: ACMD/AMMD and GSD

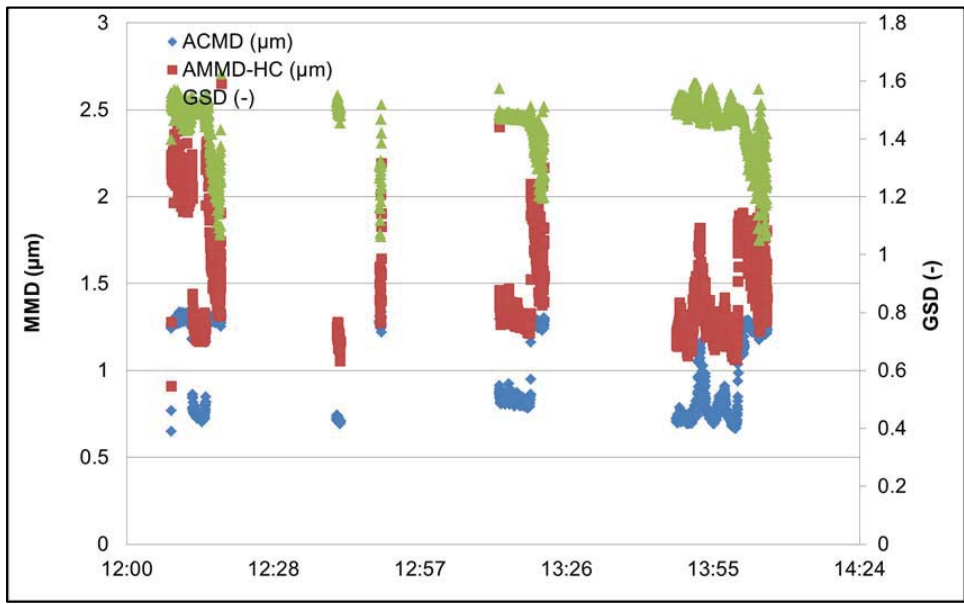


- $\quad$ Particle size distribution (Average size during the -US /+US periods):
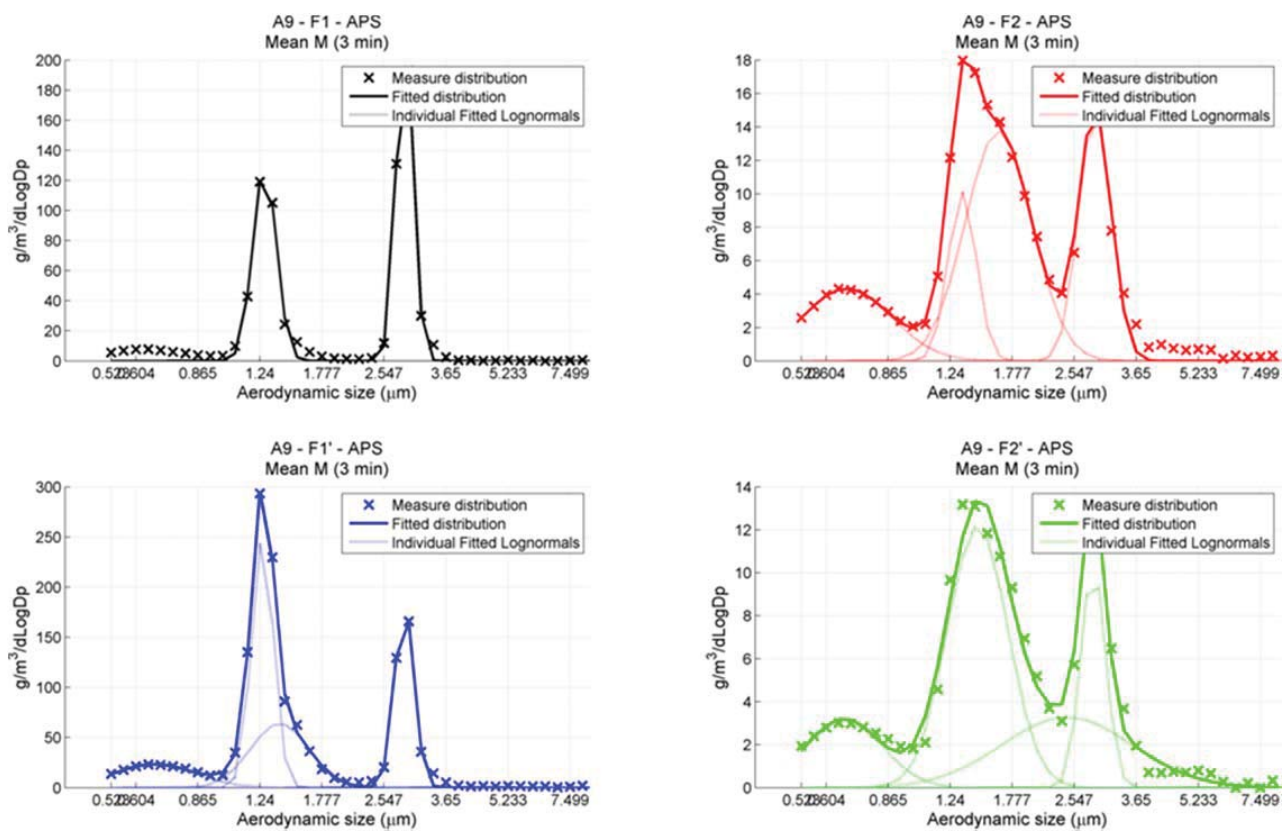


\subsection{AAA10}

This test was conducted successfully in the MSAA-PECA facility of the Laboratory of Analysis of Safety Systems (LASS). The mixture used for the test is summarized in TABLE 35.

It is worth to note that this experiment has been done instead with $\mathrm{SiO} 2$ particles of $2.5 \mu \mathrm{m}$, with particles that are supposed to beTiO2.

TABLE 35 Mixture of particles

\begin{tabular}{lll}
\hline $\mathrm{SiO}_{2}+\mathrm{TiO}_{2}$ mixture & mass $(\mathrm{g})$ & $\mathbf{X}_{\mathrm{m}}(\%)$ \\
\hline $\mathrm{dp}_{1}=\mathbf{0 . 2 8} \boldsymbol{\mu m}$ & 50.11 & 50.00 \\
$\mathrm{dp}_{2}=\mathbf{1} \boldsymbol{\mu \mathrm { m }}$ & 30.11 & 30.04 \\
$\mathrm{dp}_{3}=\mathbf{2 . 5} \boldsymbol{\mu m}$ & 20.00 & 19.96 \\
\hline Total & 100.22 & \\
\hline
\end{tabular}

\subsubsection{Test stages and protocol}

\begin{tabular}{|c|c|c|c|c|c|c|}
\hline Phase 1 (-US) & Order & Action & Value & Time length & $t_{i n}$ & $t_{f}$ \\
\hline \multirow[t]{5}{*}{ Reference phase } & $1-$ & $\dot{m}(\mathrm{~kg} / \mathrm{h})$ & 12 & Stability & & \\
\hline & 2- & $\mathrm{SiO}_{2}$ injection & & Stability - $10^{\prime}$ & $11: 15: 20$ & $11: 25: 20$ \\
\hline & & ELPI in & & & 11:15:20 & \\
\hline & $3-$ & F1 (in/out) & & $7^{\prime}$ & $11: 25: 20$ & $11: 32: 20$ \\
\hline & 4- & APS out & & $5^{\prime}$ & $11: 32: 30$ & $11: 37: 30$ \\
\hline \multirow[t]{3}{*}{ Flushing phase } & $5-$ & Stop $\mathrm{SiO} 2$ & & & $11: 37: 30$ & \\
\hline & & $\uparrow \dot{m}(\mathrm{~kg} / \mathrm{h})$ & 200 & & $11: 17: 55$ & \\
\hline & & APS out & & $5^{\prime}$ & 11:38:00 & $11: 42: 00$ \\
\hline \multicolumn{7}{|l|}{ Phase 2 (+US) } \\
\hline \multirow[t]{5}{*}{ Acoustic phase } & $1-$ & $\dot{m}(\mathrm{~kg} / \mathrm{h})$ & 12 & Stability & & \\
\hline & $2-$ & $\mathrm{SiO}_{2}$ injection & & Stability - 10' & 11:48:40 & $11: 58: 40$ \\
\hline & $3-$ & +US & & & 11:48:55 & \\
\hline & & F 2 (in/out) & & $7^{\prime}$ & $11: 58: 45$ & 12:05:45 \\
\hline & 4- & APS out & & $7^{\prime}$ & 12:05:55 & 12:11:00 \\
\hline \multirow[t]{4}{*}{ Flushing phase 1} & $5-$ & Stop $\mathrm{SiO} 2$ & & & 12:11:00 & \\
\hline & & -US & & & $12: 11: 25$ & \\
\hline & & $\uparrow \dot{m}(\mathrm{~kg} / \mathrm{h})$ & 200 & & $12: 11: 40$ & \\
\hline & & APS out & & $5^{\prime}$ & $12: 11: 40$ & $12: 15: 00$ \\
\hline Phase 1' (-US) & Order & Action & & Time & $t_{\text {in }}$ & $t_{f}$ \\
\hline \multirow[t]{4}{*}{ Reference phase } & $1-$ & $\dot{\mathrm{m}}(\mathrm{kg} / \mathrm{h})$ & 12 & Stability & & \\
\hline & $2-$ & $\mathrm{SiO}_{2}$ injection & & Stability - 10' & 12:22: 15 & $12: 32: 00$ \\
\hline & $3-$ & F 3 (in/out) & & $7^{\prime}$ & $12: 32: 00$ & $12: 39: 00$ \\
\hline & 4- & APS out & & $5^{\prime}$ & 12:39:10 & $12: 44: 30$ \\
\hline \multirow[t]{3}{*}{ Flushing phase } & $5-$ & Stop $\mathrm{SiO} 2$ & & & $12: 44: 30$ & \\
\hline & & $\uparrow \dot{m}(\mathrm{~kg} / \mathrm{h})$ & 200 & & $12: 44: 55$ & \\
\hline & & APS out & & $5^{\prime}$ & $12: 45: 00$ & 12:50:15 \\
\hline \multicolumn{7}{|l|}{ Phase 2' (+US) } \\
\hline \multirow[t]{5}{*}{ Acoustic phase } & $1-$ & $\dot{\mathrm{m}}(\mathrm{kg} / \mathrm{h})$ & 12 & Stability & & \\
\hline & $2-$ & $\mathrm{SiO}_{2}$ injection & & Stability - $10^{\prime}$ & $12: 56: 20$ & $13: 05: 00$ \\
\hline & $3-$ & +US & & & $12: 56: 45$ & \\
\hline & & F 4 (in/out) & & $7^{\prime}$ & 13:05:00 & 13:12:00 \\
\hline & 4- & APS out & & 3'+US_2'-US_2'+US_2'-US_2'+US_2'-US & 13:12:10 & 13:25:00 \\
\hline \multirow[t]{5}{*}{ Flushing phase } & $5-$ & Stop $\mathrm{SiO} 2$ & & & $13: 25: 00$ & \\
\hline & & -US & & & $13: 23: 00$ & \\
\hline & & $\uparrow \dot{m}(\mathrm{~kg} / \mathrm{h})$ & 200 & & $13: 25: 30$ & \\
\hline & & APS out & & & $13: 25: 30$ & 13:29:00 \\
\hline & & ELPI in & & & & 13:29:30 \\
\hline
\end{tabular}




\subsubsection{Summary of the test evolution}

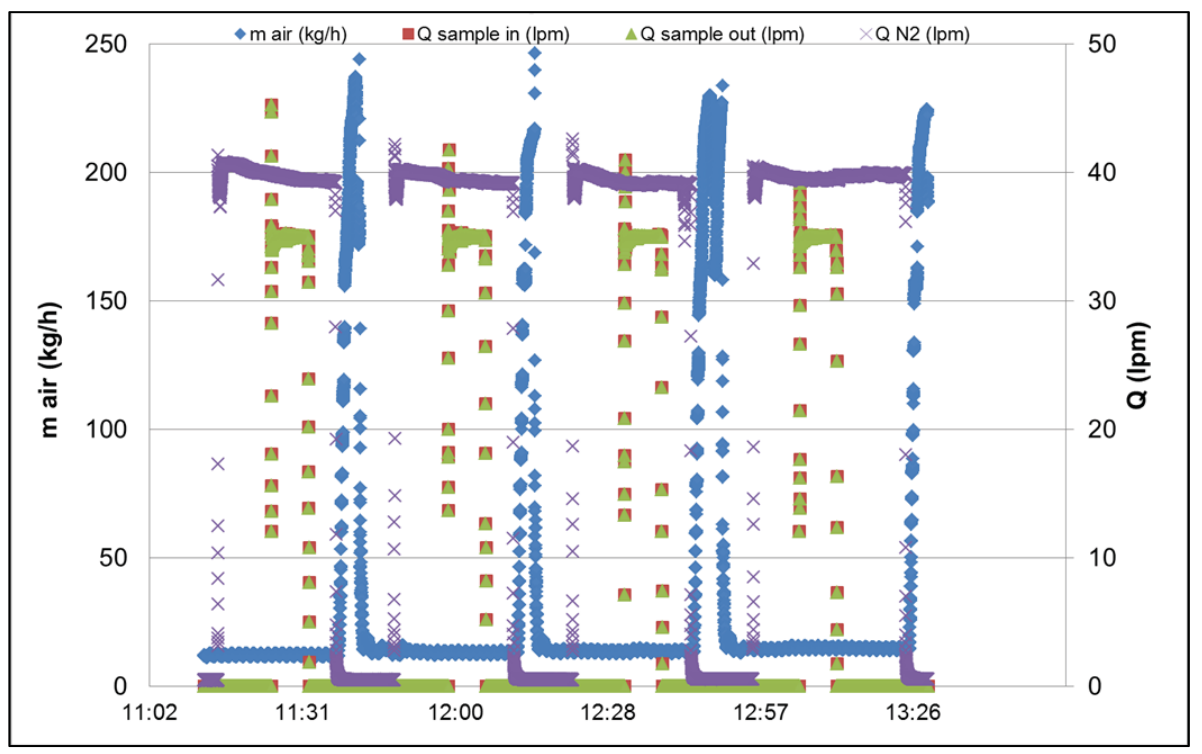

\subsubsection{Particle concentration}

- Concentration evolution (APS/ELPI): Inlet/outlet: $\mathrm{N}\left(\# / \mathrm{cm}^{3}\right)$

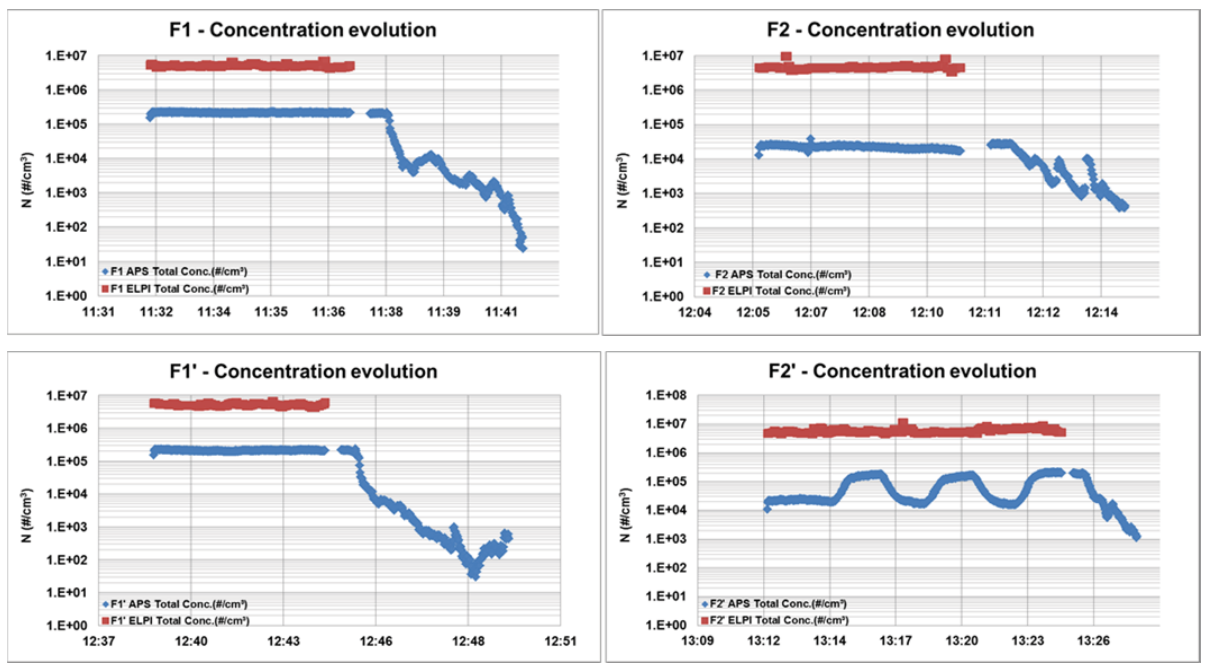


- Concentration comparison (filters)

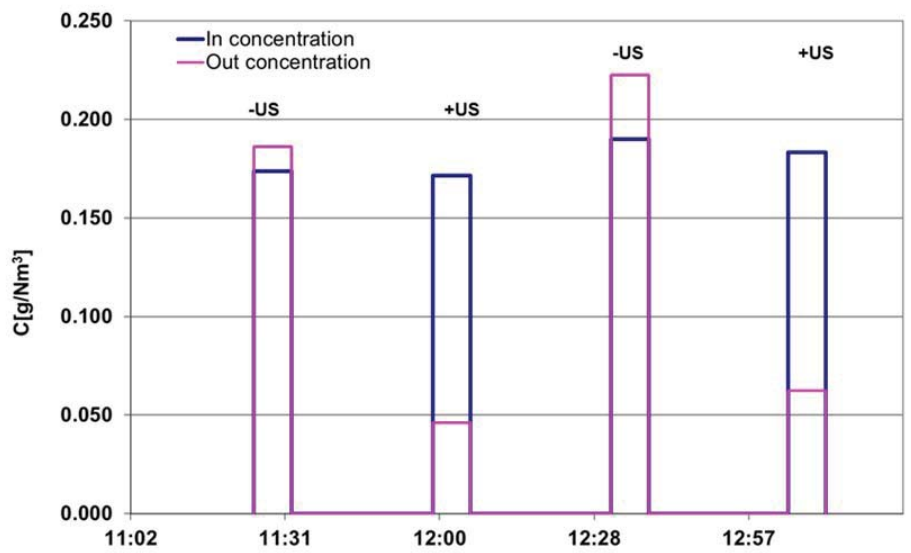

\subsubsection{Particle size}

- Particle size evolution: ACMD/AMMD and GSD

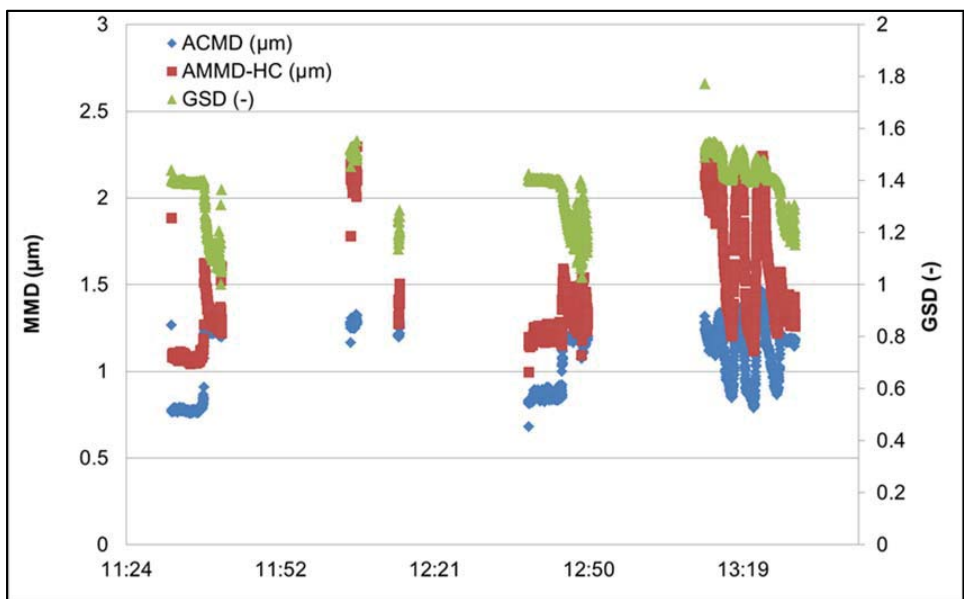


- $\quad$ Particle size distribution (Average size during the -US /+US periods):
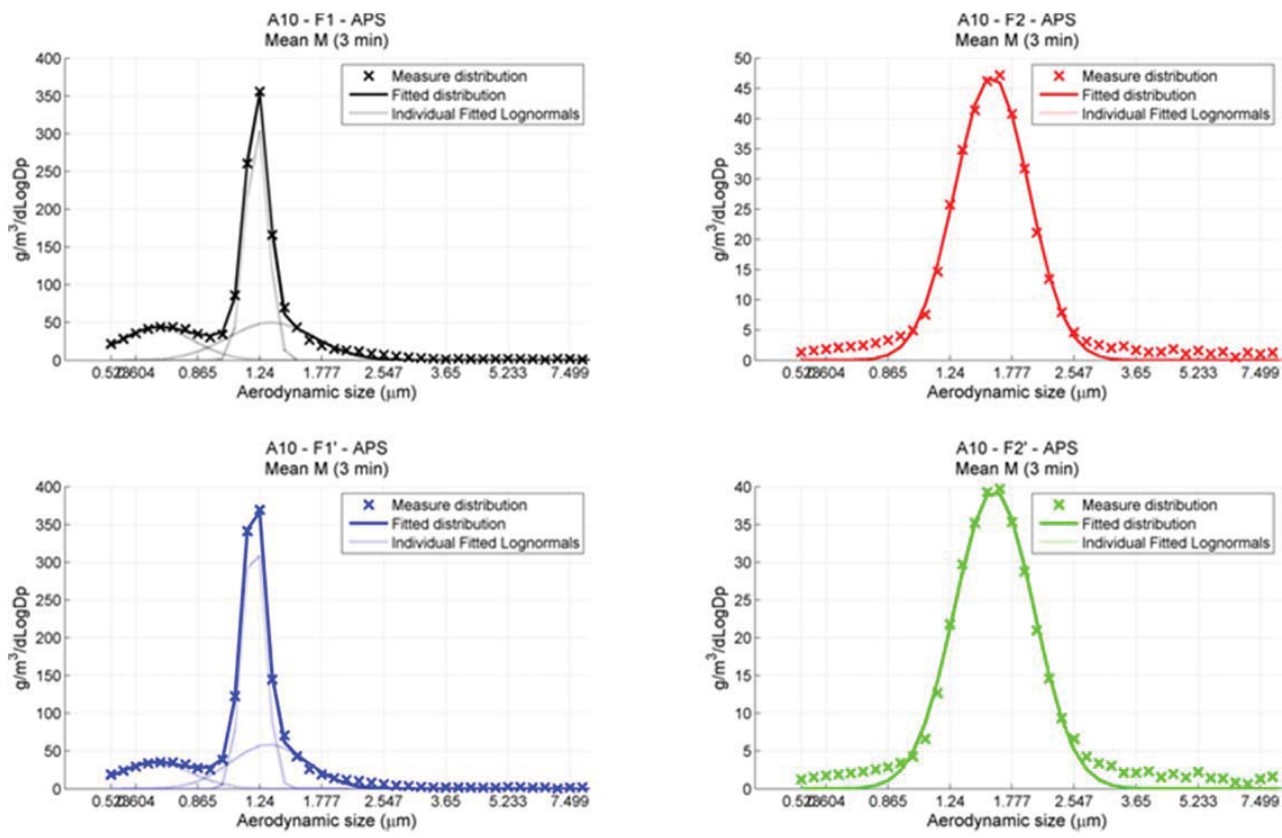


I do not know where I am going from here but I promise it will not be boring

David Bowie 




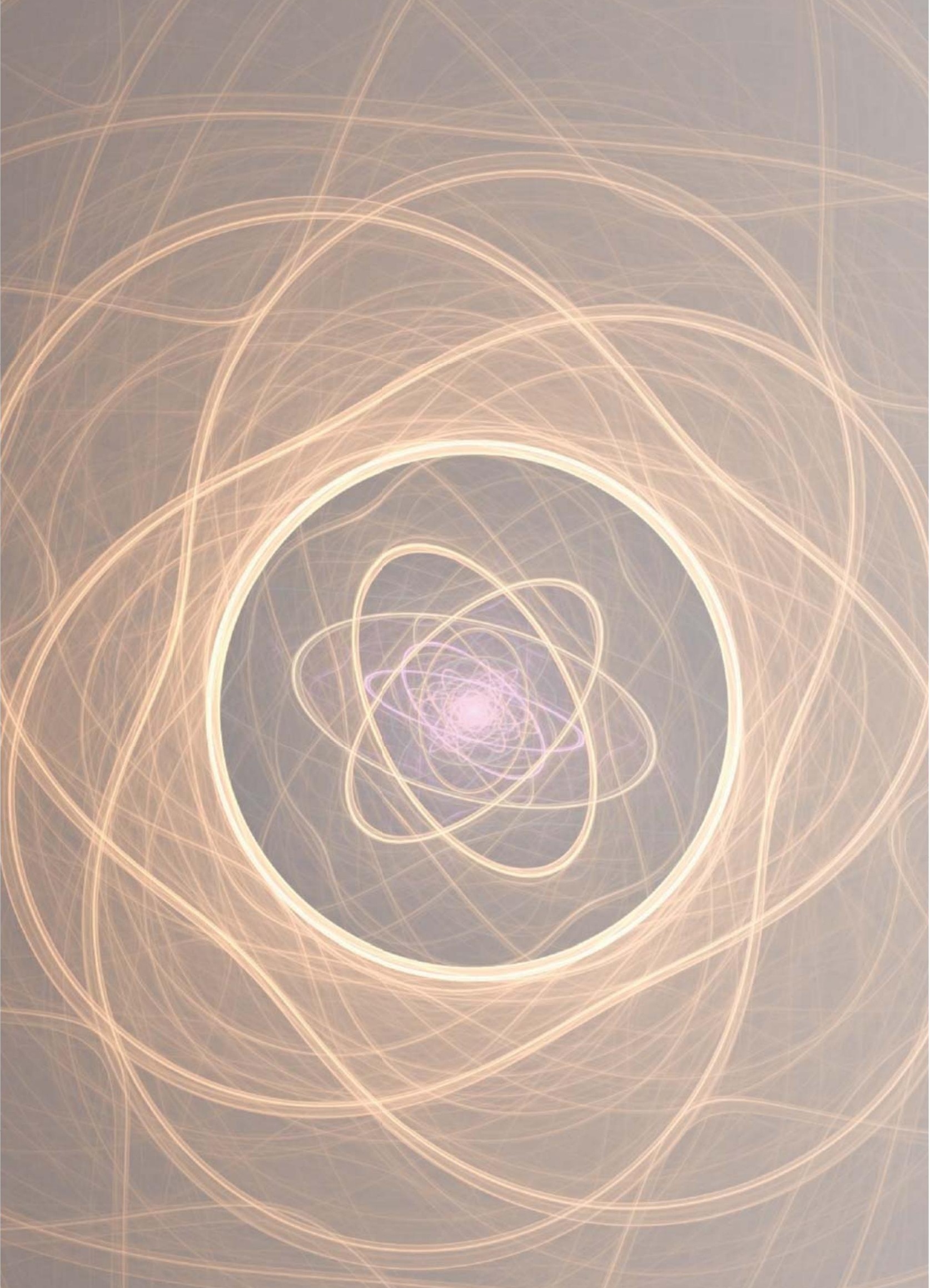

